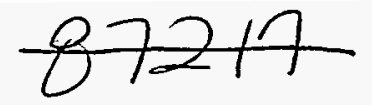

\title{
EPICS
}

\section{Input Output Controller (IOC) Record Reference Manual}

Janet B. Anderson and

RECEVED

Martin R. Kraimer

FEB 141996

Argonne National Laboratory

Advanced Photon Source

December 1,1994 - DRAFT

APS Release 3.12 


\section{Table of Contents}

Chapter 1: Introduction ............................1

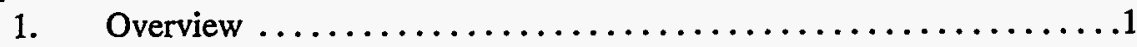

2. Field Summary Table $\ldots \ldots \ldots \ldots \ldots \ldots \ldots \ldots \ldots \ldots \ldots$

Chapter 2: Fields Common to All Record Types ............. 3

1. Introduction $\ldots \ldots \ldots \ldots \ldots \ldots \ldots \ldots \ldots \ldots \ldots \ldots \ldots \ldots \ldots$

2. Database Common: Field Summary .................

3. Database Common: Field Descriptions................. 5

Chapter 3: Fields Common to Many Record Types...........9

1. Introduction $\ldots \ldots \ldots \ldots \ldots \ldots \ldots \ldots \ldots \ldots \ldots \ldots \ldots \ldots$

2. Input Records $\ldots \ldots \ldots \ldots \ldots \ldots \ldots \ldots \ldots \ldots \ldots \ldots$

3. Output Records..............................

Chapter 4: ai - Analog Input........................ 15

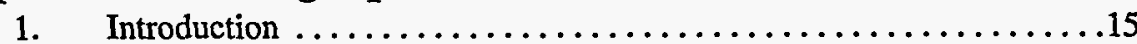

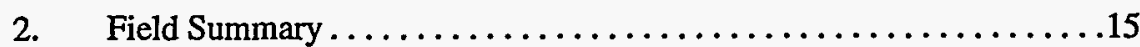

3. Field Descriptions. . . . . . . . . . . . . . . . . . . 17

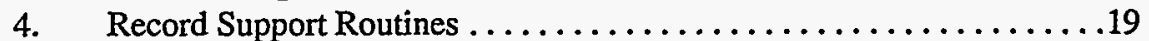

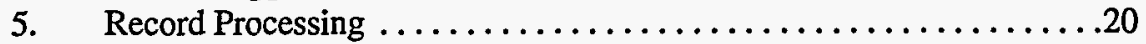

6. Device Support. . . . . . . . . . . . . . . . . . . . 21

7. Device Support For Soft Records. . . . . . . . . . . . . 22

Chapter 5: ao - Analog Output.....................25

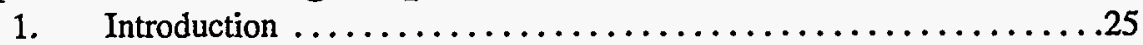

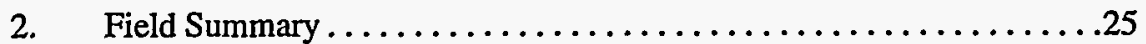

3. Field Descriptions. . . . . . . . . . . . . . . . . . . 27

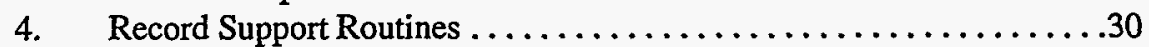

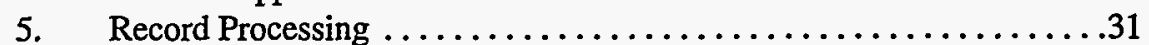

6. Device Support. . . . . . . . . . . . . . . . . . . . . 32 
7. Device Support For Soft Records $\ldots \ldots \ldots \ldots \ldots \ldots \ldots \ldots \ldots \ldots \ldots$

Chapter 6: bi - Binary Input. .......................35

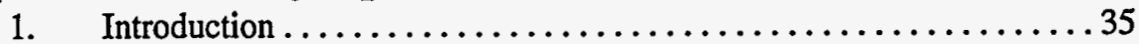

2. Field Summary..................................... 35

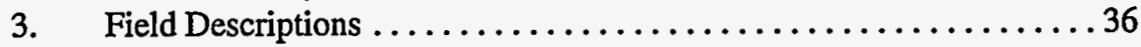

4. Record Support Routines......................... 37

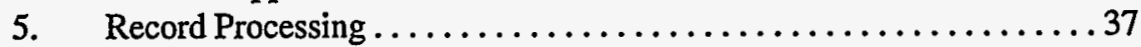

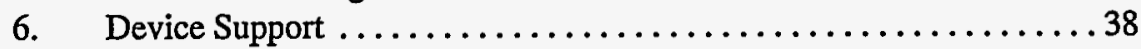

7. Device Support For Soft Records ........................ 39

Chapter 7: bo - Binary Output.....................41

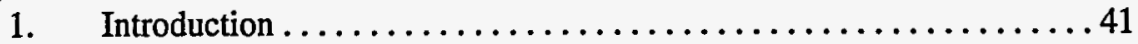

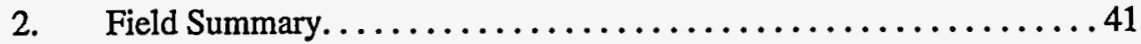

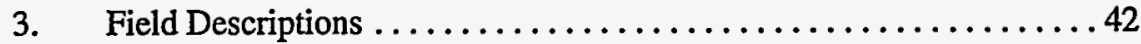

4. Record Support Routines........................43

5. Record Processing .............................. 44

6. Device Support ........................... 45

7. Device Support For Soft Records ................... 46

Chapter 8: calc - Calculation .....................47

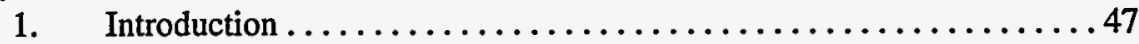

2. Field Summary.............................. 47

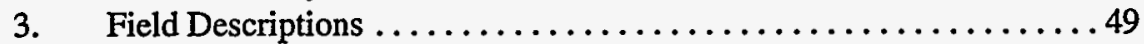

4. Record Support Routines........................ 50

5. Record Processing .................................... 51

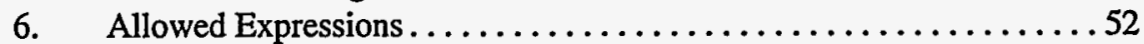

7. Example Expressions........................... 54

Chapter 9: compress - Compression .................. 55

1. Introduction ................................... 55

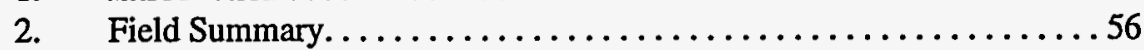

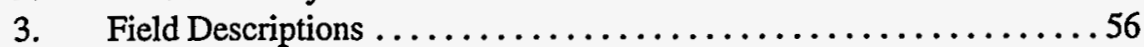

4. Record Support Routines....................... 57

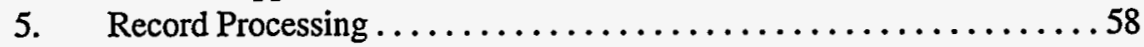

Chapter 10: dfanout...........................61

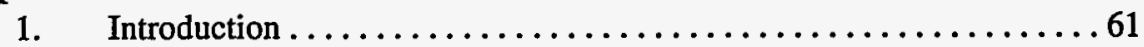

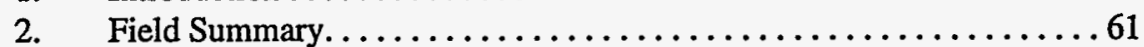

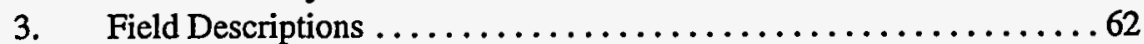

4. Record Support Routines.........................6 64

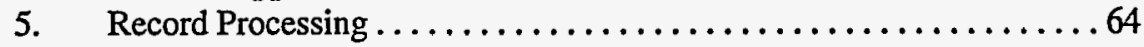

Chapter 11: eg - Event Generator ...................65

1. Introduction...................................65

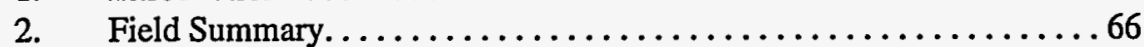

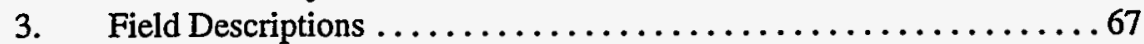

4. Record Processing ...............................69

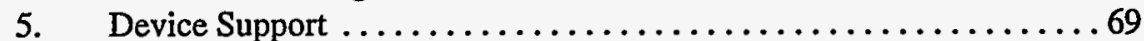

6. Event Records . ..............................69

7. Event System Observations....................... 70

8. Example Database for Global Time Synchronization............ 71

9. Event System Observations...................... 75 
Chapter 12: egevent - Event Generator Event . . . . . . . . 77

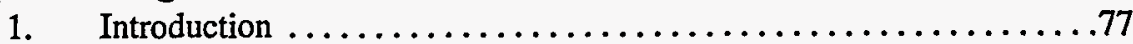

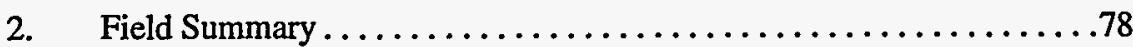

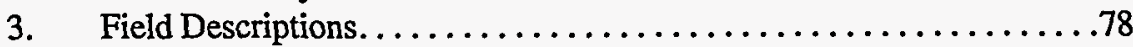

4. Record Processing .................................

5. Device Support. ............................

Chapter 13: er - Event Receiver . . . . . . . . . . . . . . 81

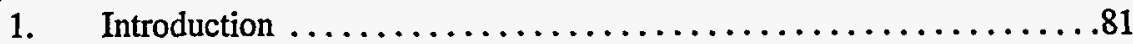

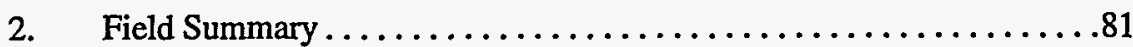

3. Field Descriptions. . . . . . . . . . . . . . . . . . . . . . . 83

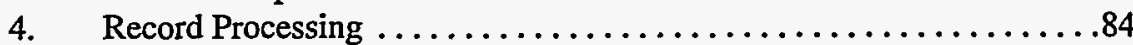

5. Device Support............................. 84

Chapter 14: erevent - Event Receiver Event.............85

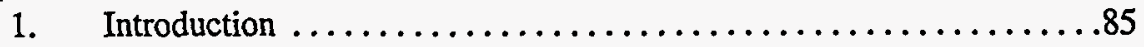

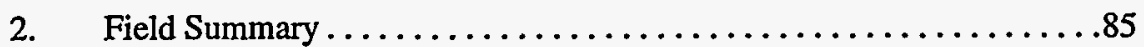

3. Field Descriptions. . . . . . . . . . . . . . . . . . . . . . . . . 86

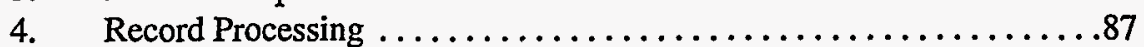

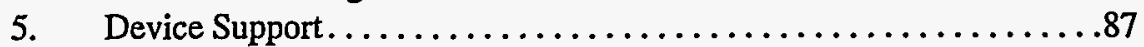

Chapter 15: Event ...........................89

1. Introduction $\ldots \ldots \ldots \ldots \ldots \ldots \ldots \ldots \ldots \ldots \ldots \ldots \ldots \ldots \ldots \ldots . . .69$

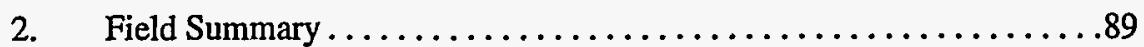

3. Field Descriptions. ........................... 90

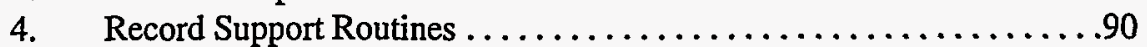

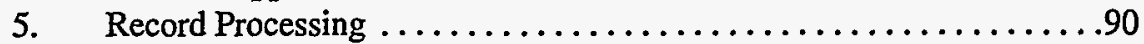

6. Device Support............................. 91

7. Device Support For Soft Records....................92

Chapter 16: Fanout $\ldots \ldots \ldots \ldots \ldots \ldots \ldots \ldots \ldots \ldots \ldots \ldots \ldots \ldots$

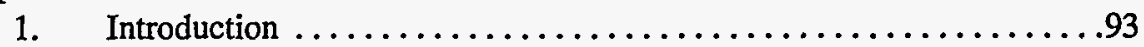

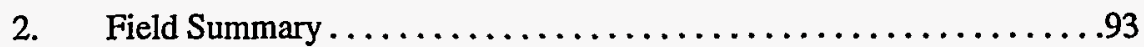

3. Field Descriptions. ............................ 94

4. Record Support Routines ........................94

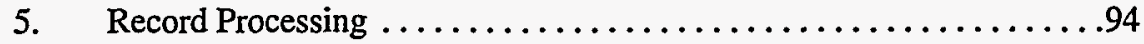

Chapter 17: Histogram $\ldots \ldots \ldots \ldots \ldots \ldots \ldots \ldots \ldots \ldots \ldots \ldots \ldots$

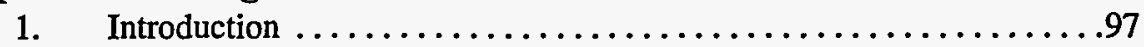

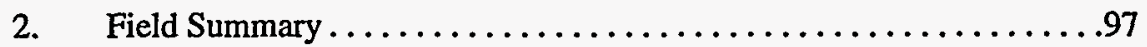

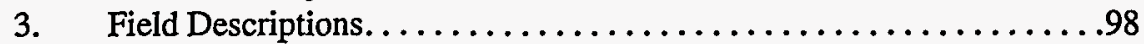

4. Record Support Routines ..........................99

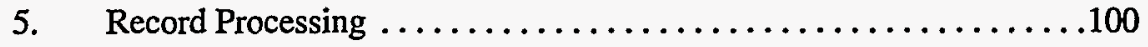

Chapter 18: longin - Long Input $\ldots \ldots \ldots \ldots \ldots \ldots \ldots \ldots \ldots \ldots 1$

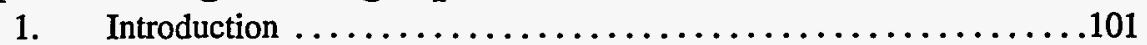

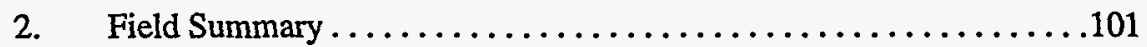

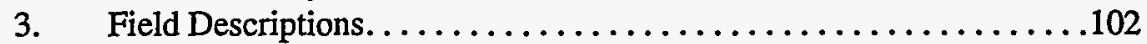

4. Record Support Routines .........................103

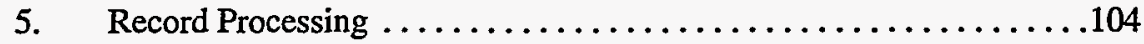

6. Device Support..............................105

7. Device Support For Soft Records...................

Chapter 19: longout - Long Output ................ 107 


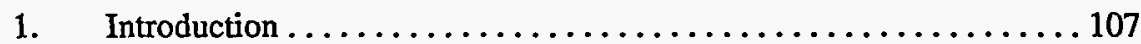

2. Field Summary............................. 107

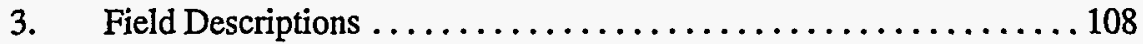

4. Record Support Routines......................... 110

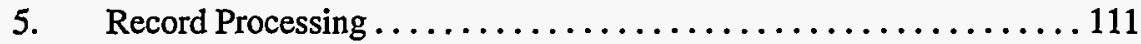

6. Device Support ............................. 112

7. Device Support For Soft Records . . . . . . . . . . . . . . 112

Chapter 20: mbbi - MultiBit Binary Input . . . . . . . . . . 115

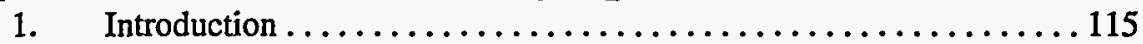

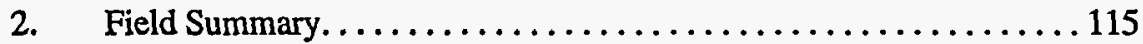

3. Field Descriptions . ............................... 118

4. Record Support Routines......................... 119

5. Record Processing ............................. 120

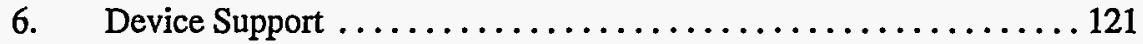

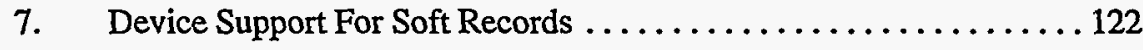

Chapter 21: mbbo - MultiBit Binary Output ............. 123

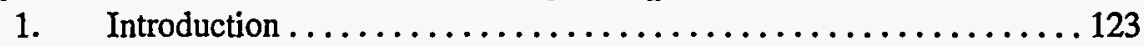

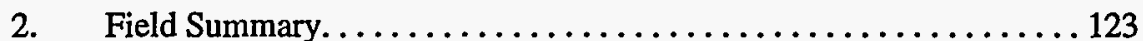

3. Field Descriptions ............................. 126

4. Record Support Routines........................ 127

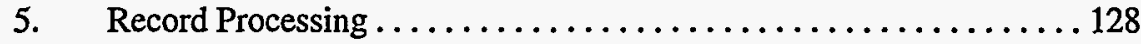

6. Device Support ............................. 129

7. Device Support For Soft Records . . . . . . . . . . . . . 130

Chapter 22: mbbiDirect - MultiBit Binary Input Direct ........ 131

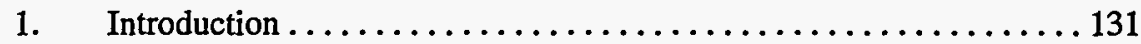

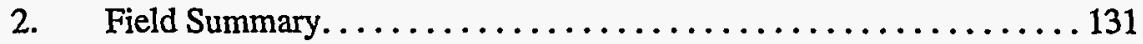

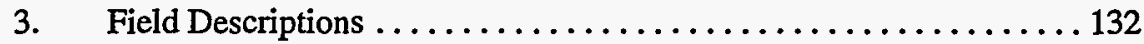

4. Record Support Routines........................ 133

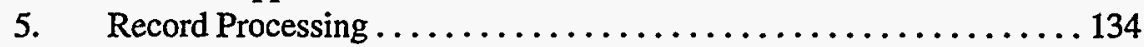

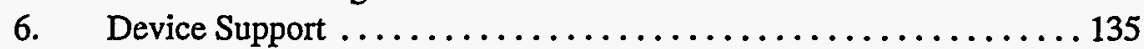

7. Device Support For Soft Records ..................... 136

Chapter 23: mbboDirect - MultiBit Binary Output Direct ...... 137

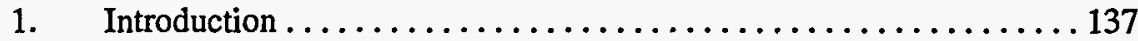

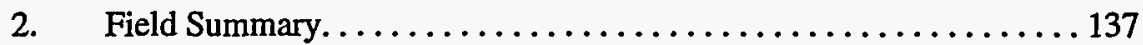

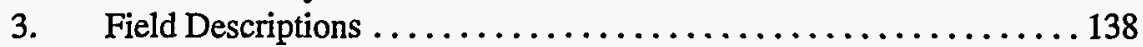

4. Record Support Routines.............................. 140

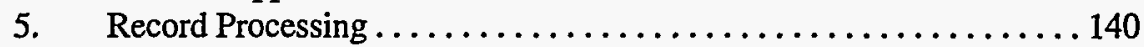

6. Device Support .............................. 141

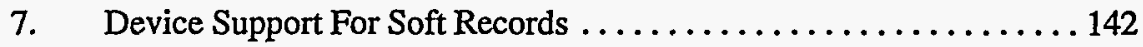

Chapter 24: Permissive .......................... 143

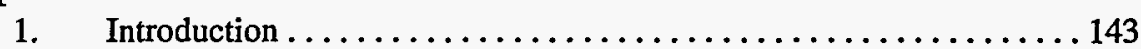

2. Field Summary................................... 143

3. Field Descriptions ............................. 144

4. Record Support Routines....................... 144

Chapter 25: pid - PID Control ..................... 145

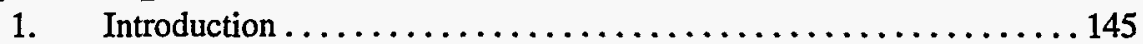

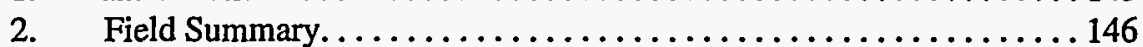

3. Field Descriptions .............................. 147 
4. Record Support Routines .......................149

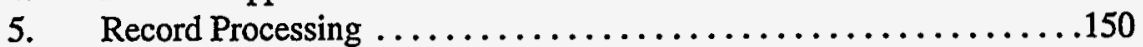

Chapter 26: pulseCounter. . . . . . . . . . . . . . . . 151

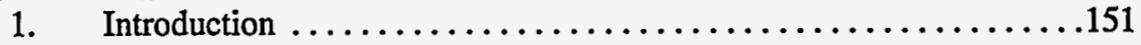

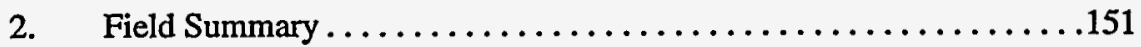

3. Field Descriptions. ............................... 152

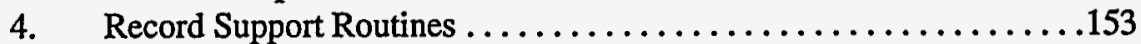

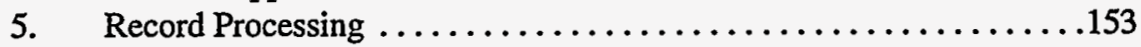

6. Device Support.............................. 154

Chapter 27: pulseDelay $\ldots \ldots \ldots \ldots \ldots \ldots \ldots \ldots \ldots \ldots \ldots \ldots \ldots$

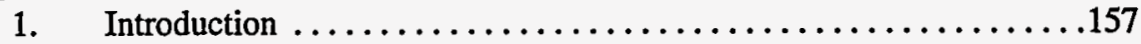

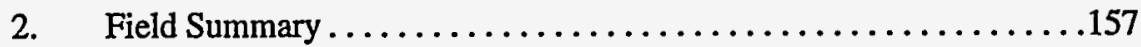

3. Field Descriptions. ..............................

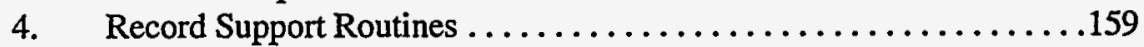

5. Record Processing ................................. 160

6. Device Support.............................161

Chapter 28: pulseTrain ...................... 163

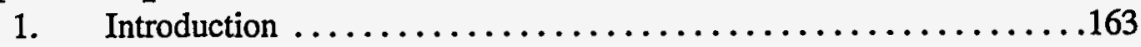

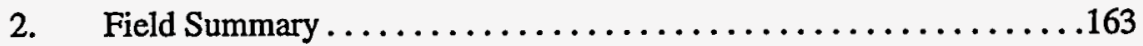

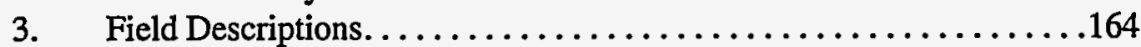

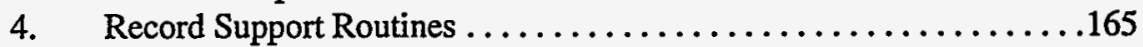

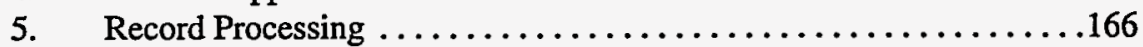

6. Device Support...............................

Chapter 29: scan $\ldots \ldots \ldots \ldots \ldots \ldots \ldots \ldots \ldots \ldots \ldots \ldots \ldots \ldots \ldots \ldots$

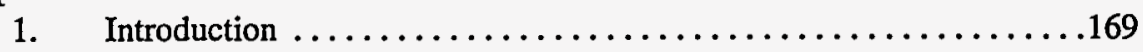

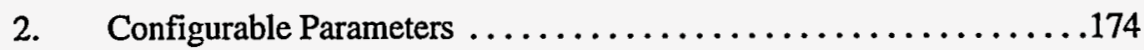

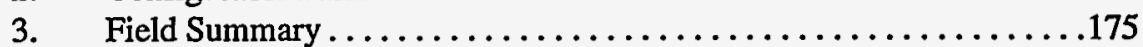

4. Field Descriptions. ............................. 180

5. Record Support Routines .......................... 184

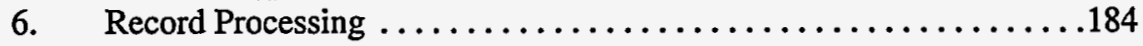

7. Device Support............................... 184

8. Device Support For Soft Records.................... 184

Chapter 30: sel - Select ........................ 185

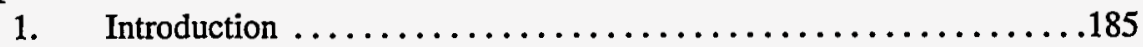

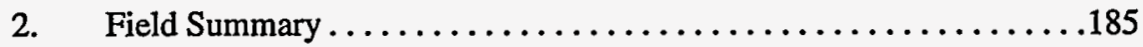

3. Field Descriptions.............................. 187

4. Record Support Routines .........................189

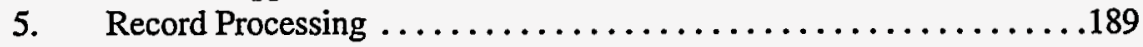

Chapter 31: seq - Sequence....................... 191

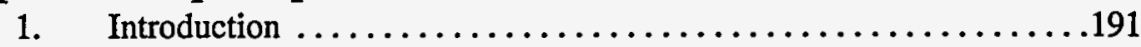

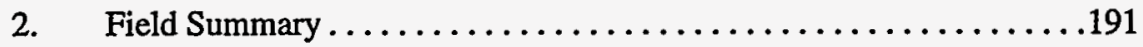

3. Field Descriptions................................

4. Record Support Routines .........................194

Chapter 32: State............................. 195

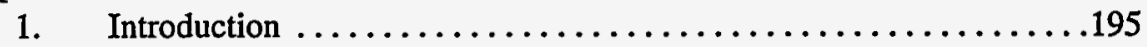

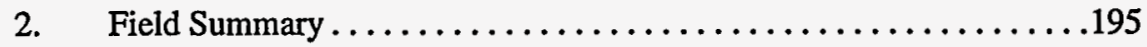

3. Field Descriptions. ................................... 
4. Record Support Routines.................... 196

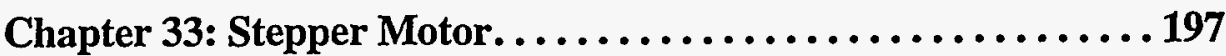

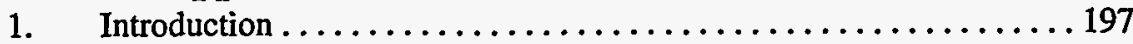

2. Field Summary. . . . . . . . . . . . . . . . . . . . . 197

3. Field Descriptions . . . . . . . . . . . . . . . . . . . . . 199

4. Record Support Routines. ...................... 202

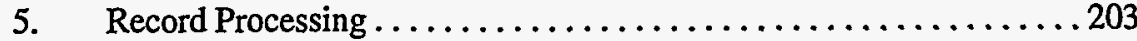

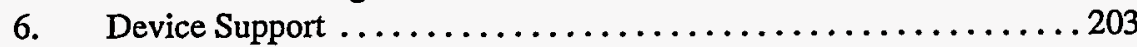

Chapter 34: stringin - String Input ................ 205

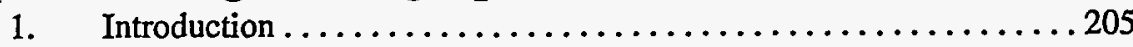

2. Field Summary.............................. 205

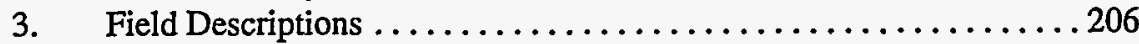

4. Record Support Routines. ..................... 206

5. Record Processing ........................... 207

6. Device Support ........................... 207

7. Device Support For Soft Records . . . . . . . . . . . . . . 208

Chapter 35: stringout - String Output. . . . . . . . . . . . 209

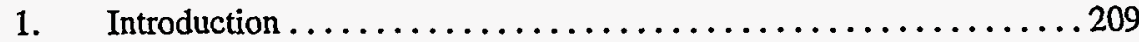

2. Field Summary. . . . . . . . . . . . . . . . . . . . 209

3. Field Descriptions . . . . . . . . . . . . . . . . . . 210

4. Record Support Routines....................... 210

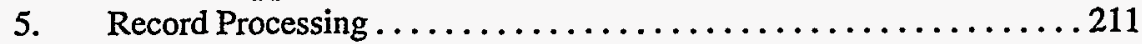

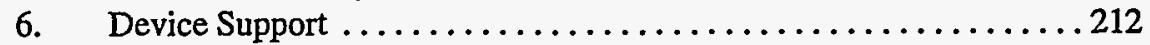

7. Device Support For Soft Records . . . . . . . . . . . . . 213

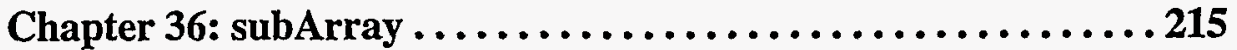

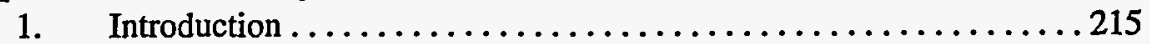

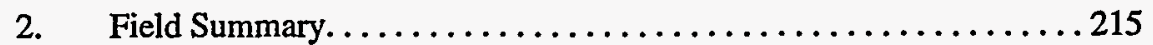

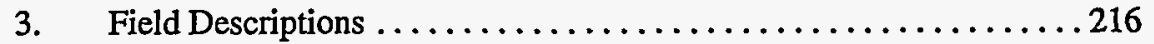

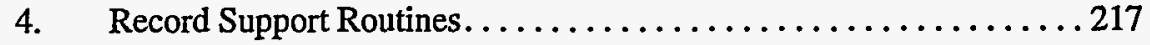

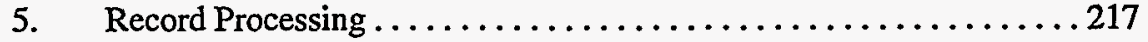

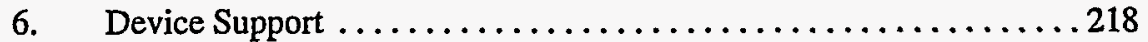

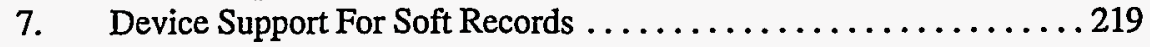

Chapter 37: sub - Subroutine .................... 221

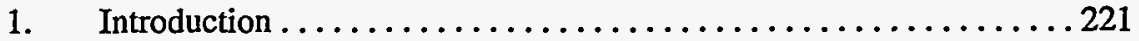

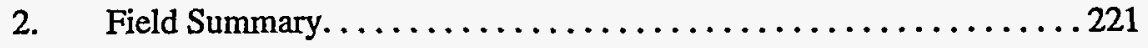

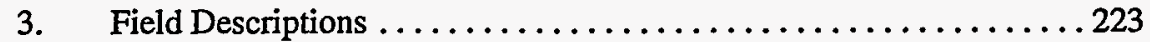

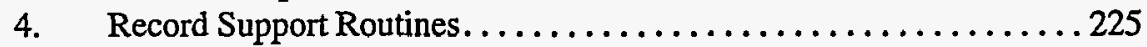

5. Record Processing .......................... 225

6. Example Synchronous Subroutine. . . . . . . . . . . . . . . 226

7. Example Asynchronous Subroutine ................. 226

Chapter 38: Timer...........................229

1. Introduction . . . . . . . . . . . . . . . . . . . . . . . 229

2. Field Summary. .............................. 229

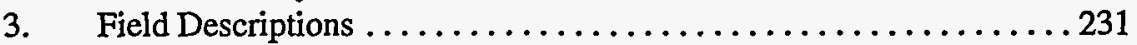

4. Record Support Routines. . . . . . . . . . . . . . . 232

5. Record Processing ......................... 232

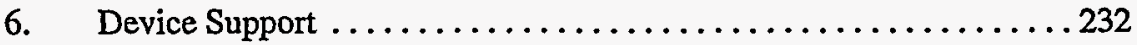


Chapter 39: Wait

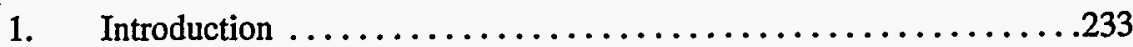

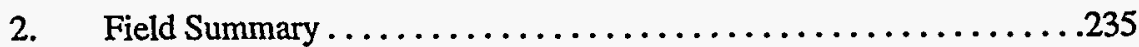

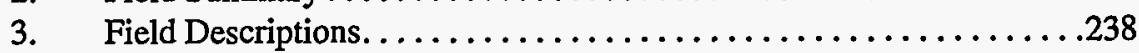

4. Record Support Routines . . . . . . . . . . . . . . . . . . 239

5. Record Processing ............................239

6. Device Support. ............................240

7. Device Support For Soft Records. . . . . . . . . . . . . . 240

Chapter 40: Waveform .........................241

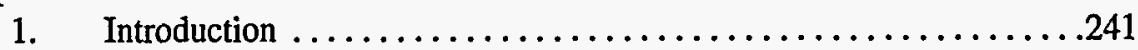

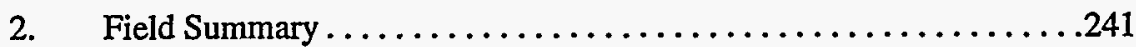

3. Field Descriptions. . . . . . . . . . . . . . . . . . . . . . 242

4. Record Support Routines . . . . . . . . . . . . . . . . 243

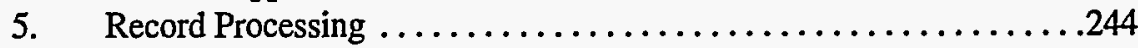

6. Device Support. . . . . . . . . . . . . . . . . . . . . . . . . 245

7. Device Support For Soft Records......................... 


\section{Chapter 1: Introduction}

\section{Overview}

This manual describes all supported EPICS record types. The first chapter gives the introduction and describes the field summary table. The second chapter describes the fields in database common, i.e. the fields that are present in every record type. The third chapter describes the input and output field that are common to many record types and have the same usage wherever they are used. Following the third chapter is a separate chapter for each record type containing a description of all the fields for that record type except those in database common.

\section{Field Summary Table}

Each chapter contains a field summary table of the form:

\begin{tabular}{|c|c|c|c|c|c|c|c|}
\hline Field & Type & DCT & Initial & Access & Modify & $\begin{array}{c}\text { Rec Proc } \\
\text { Monitor }\end{array}$ & PP \\
\hline \hline & & & & & & & \\
\hline & & & & & & & \\
\hline
\end{tabular}

The meaning of each component of the summary table is as follows:

- Field: The field name

- Type: The database field type, i.e. DBE_<type>

- DCT: Is this field definable via the database configuration tool?

- Initial: Initial value when record is created

- Access: Is this field accessible via database access? 
- Modify: Can this field be modified via database access?

- Rec Proc Monitor: Does the record processing routine trigger monitors by a call to db_post_event when this field changes value?

- PP: Process passive? Will dbPutField call dbProcesspassive when this field is processed? 


\section{Chapter 2: Fields Common to All Record Types}

\section{Introduction}

This chapter contains a description of fields that are common to all records. These fields are defined in abcommon.ascii.

2. Database Common: Field Summary

\begin{tabular}{|l|l|l|l|l|l|l|l|}
\hline \multicolumn{1}{|c|}{ Field } & \multicolumn{1}{|c|}{ Type } & DCT & \multicolumn{1}{c|}{ Initial } & Access & Modify & $\begin{array}{l}\text { Rec Proc } \\
\text { Monitor }\end{array}$ & \multicolumn{1}{c|}{ PP } \\
\hline \hline NAME & STRING & Yes & 0 & Yes & No & & No \\
\hline DESC & STRING & Yes & Null & Yes & Yes & No & No \\
\hline ASG & STRING & Yes & Null & Yes & Yes & & No \\
\hline SCAN & GBLCHOICE & Yes & 0 & Yes & Yes & No & No \\
\hline PINI & GBLCHOICE & Yes & 0 & Yes & Yes & No & No \\
\hline PHAS & SHORT & Yes & 0 & Yes & Yes & No & No \\
\hline EVNT & SHORT & Yes & 0 & Yes & Yes & No & No \\
\hline TSE & SHORT & No & 0 & Yes & Yes & & No \\
\hline TSEL & INLINK & Yes & Null & No & No & N/A & No \\
\hline DTYP & DEVCHOICE & Yes & 0 & Yes & No & & No \\
\hline DISV & SHORT & Yes & 1 & Yes & Yes & No & No \\
\hline
\end{tabular}




\begin{tabular}{|c|c|c|c|c|c|c|c|}
\hline Field & Type & DCT & Initial & Access & Modify & $\begin{array}{l}\text { Rec Proc } \\
\text { Monitor } \\
\end{array}$ & PP \\
\hline DISA & SHORT & No & 0 & Yes & Yes & No & No \\
\hline SDIS & INLINK & Yes & 0 & No & No & N/A & No \\
\hline MLOK & NOACCESS & No & 8 & No & No & & No \\
\hline MLIS & NOACCESS & No & 12 & No & No & & No \\
\hline DISP & UCHAR & No & 0 & Yes & Yes & Yes & No \\
\hline PROC & UCHAR & No & 0 & Yes & Yes & No & Yes \\
\hline STAT & GBLCHOICE & No & UDF_ALARM & Yes & No & Yes & No \\
\hline SEVR & GBLCHOICE & No & INVALID_ALARM & Yes & No & Yes & No \\
\hline NSTA & GBLCHOICE & No & 0 & Yes & No & No & No \\
\hline NSEV & GBLCHOICE & No & 0 & Yes & No & No & No \\
\hline ACKS & GBLCHOICE & No & 0 & Yes & No & & No \\
\hline ACKT & GBLCHOICE & No & 11 & Yes & No & & No \\
\hline DISS & GBLCHOICE & Yes & 0 & Yes & Yes & No & No \\
\hline LSET & SHORT & No & 0 & Yes & No & & No \\
\hline LCNT & UCHAR & No & 0 & Yes & No & & No \\
\hline PACT & UCHAR & No & 0 & Yes & No & & No \\
\hline PUTF & UCHAR & No & 0 & Yes & No & & No \\
\hline RPRO & UCHAR & No & 0 & Yes & No & & No \\
\hline ASP & NOACCESS & No & 4 & No & No & & No \\
\hline PPN & NOACCESS & No & 4 & No & No & & No \\
\hline PPNN & NOACCESS & No & 4 & No & No & & No \\
\hline SPVT & NOACCESS & No & 4 & No & No & & No \\
\hline RSET & NOACCESS & No & 4 & No & No & & No \\
\hline DSET & NOACCESS & No & 4 & No & No & & No \\
\hline DPVT & NOACCESS & No & 4 & No & No & & No \\
\hline PRIO & GBLCHOICE & Yes & 0 & Yes & Yes & No & No \\
\hline TPRO & UCHAR & No & 0 & Yes & Yes & No & No \\
\hline BKPT & NOACCESS & No & 1 & No & No & & No \\
\hline UDF & UCHAR & No & 1 & Yes & Yes & No & Yes \\
\hline TIME & NOACCESS & No & 8 & Option & No & No & No \\
\hline FLNK & FWDLINK & Yes & Null & No & No & N/A & No \\
\hline
\end{tabular}




\section{Database Common: Field Descriptions}

\begin{tabular}{|c|c|c|}
\hline Name & Summary & Description \\
\hline NAME & Record Name & $\begin{array}{l}\text { An arbitrary } 28 \text { character record name supplied by the } \\
\text { application developer. This name is the means of } \\
\text { identifying a specific record. It must have a unique value } \\
\text { across all IOCs attached to the same local area subnet. }\end{array}$ \\
\hline DESC & Description & $\begin{array}{l}\text { An arbitrary } 28 \text { character record description supplied by } \\
\text { the application developer. }\end{array}$ \\
\hline ASG & $\begin{array}{l}\text { Access Security } \\
\text { Group }\end{array}$ & $\begin{array}{l}\text { A character string value defining the access security group } \\
\text { for this record. If left NULL, the record is placed in group } \\
\text { DEFAULT. }\end{array}$ \\
\hline SCAN & $\begin{array}{l}\text { Scanning } \\
\text { Algorithm }\end{array}$ & $\begin{array}{l}\text { This can be one of the periodic intervals, } \mathrm{V} / \mathrm{O} \text { event, event, } \\
\text { or passive. }\end{array}$ \\
\hline PINI & $\begin{array}{l}\text { Process at } \\
\text { Initialization }\end{array}$ & $\begin{array}{l}\text { If this field is set to TRUE during database configuration, } \\
\text { then the record is processed once at IOC initialization } \\
\text { (before the normal scan tasks are started). }\end{array}$ \\
\hline PHAS & Scan Phase Number & $\begin{array}{l}\text { This field orders the records within a specific SCAN } \\
\text { group. This is not meaningful for passive records. All } \\
\text { records of a specified phase are processed before those } \\
\text { with higher phase number. Whenever possible it is better } \\
\text { to use linked passive records to enforce the order of } \\
\text { processing rather than phase number. }\end{array}$ \\
\hline EVNT & Event Number & $\begin{array}{l}\text { Event number for scan type SCAN_EVENT. All records } \\
\text { with scan type event and the same EVNT value will be } \\
\text { processed when a call to post_event for EVNT is made. } \\
\text { The call to post_event is: } \\
\text { post_event (short event_number) }\end{array}$ \\
\hline TSE & Time Stamp Event & $\begin{array}{l}\text { The event number for time stamp. This is only } \\
\text { meaningful if the IOC has an associated hardware event } \\
\text { receiver. See 'er' record for details. }\end{array}$ \\
\hline TSEL & $\begin{array}{l}\text { Time Stamp Event } \\
\text { Link }\end{array}$ & An input link for obtaining the time stamp event number. \\
\hline DTYP & Device Type & $\begin{array}{l}\text { This field specifies the device type for the record. Each } \\
\text { record type has its own set of device support routines } \\
\text { which are specified in devSup. ASCII. If a record type } \\
\text { does not have any associated device support, DTYP and } \\
\text { DSET are meaningless. }\end{array}$ \\
\hline DISV & Disable Value & $\begin{array}{l}\text { If } D I S V=D I S A \text {, then the record will be disabled, i.e. } \\
\text { dbProcess will not process the record. }\end{array}$ \\
\hline DISA & $\begin{array}{l}\text { Scan Disable Input } \\
\text { Link Value }\end{array}$ & $\begin{array}{l}\text { This is the value that is compared with DISV to determine } \\
\text { if the record is disabled. Its value is obtained via SDIS if } \\
\text { SDIS is a database or channel access link. If SDIS is not } \\
\text { a database or channel access link, then DISA can be set } \\
\text { via dbPutField or dbPutLink. }\end{array}$ \\
\hline
\end{tabular}




\begin{tabular}{|c|c|c|}
\hline Name & Summary & Description \\
\hline SDIS & $\begin{array}{l}\text { Scan Disable Input } \\
\text { Link }\end{array}$ & $\begin{array}{l}\text { An input link from which to obtain a value for DISA. } \\
\text { This field is ignored unless it is a database link or a } \\
\text { channel access link. If it is a database or a channel access } \\
\text { link, dbProcess calls dbGetLink to obtain a value for } \\
\text { DISA before deciding to call the processing routine. }\end{array}$ \\
\hline MLOK & Monitor Lock & $\begin{array}{l}\text { The lock used by the monitor routines when the monitor } \\
\text { list is being used. The list is locked whenever monitors are } \\
\text { being scheduled, invoked, or when monitors are being } \\
\text { added to or removed from the list. This field is accessed } \\
\text { only by the dbEvent routines. }\end{array}$ \\
\hline MLIS & Monitor List & $\begin{array}{l}\text { This is the head of the list of monitors connected to this } \\
\text { record. Each record support module is responsible for } \\
\text { triggering monitors for any fields that change as a result of } \\
\text { record processing. Monitors are present if mlis.count is } \\
\text { greater than zero. The call to trigger monitors is: } \\
\text { db_post_event (precord, \&data, mask) } \\
\text { Where "mask" is some combination of DBE_ALARM, } \\
\text { DBE_VALUE, and DBE_LOG. }\end{array}$ \\
\hline DISP & Disable putFields & $\begin{array}{l}\text { If this field is set to TRUE, then all dbPutFields } \\
\text { (normally issued by channel access) directed to this } \\
\text { record are ignored except to the field DISP itself. }\end{array}$ \\
\hline PROC & Process Record & $\begin{array}{l}\text { A record will be processed whenever a dbPutField is } \\
\text { directed to this field. }\end{array}$ \\
\hline STAT & $\begin{array}{l}\text { Current Alarm } \\
\text { Status }\end{array}$ & \multirow{4}{*}{$\begin{array}{l}\text { These four fields are the alarm status and severity fields. } \\
\text { STAT and SEVR are the values seen outside database } \\
\text { access. NSTA and NSEV are the fields the database access, } \\
\text { record support, and device support use to set new alarm } \\
\text { status and severity values. Whenever any software } \\
\text { component discovers an alarm condition, it uses the } \\
\text { following macro function: } \\
\text { recGb1setSevx (precord, new_status, new_severity) } \\
\text { This ensures that the current alarm severity is set equal to } \\
\text { the highest outstanding alarm. The file alarm.h defines } \\
\text { all allowed alarm status and severity values. }\end{array}$} \\
\hline SEVR & $\begin{array}{l}\text { Current Alarm } \\
\text { Severity }\end{array}$ & \\
\hline NSTA & New Alarm Status & \\
\hline NSEV & $\begin{array}{l}\text { New Alarm } \\
\text { Severity }\end{array}$ & \\
\hline ACKS & $\begin{array}{l}\text { Alarm Acknowledge } \\
\text { Severity }\end{array}$ & Highest severity unacknowledged alarm \\
\hline $\mathrm{ACKT}$ & $\begin{array}{l}\text { Alarm Acknowledge } \\
\text { Transient }\end{array}$ & Is it necessary to acknowledge transient alarms? \\
\hline DISS & $\begin{array}{l}\text { Disable Alarm } \\
\text { Severity }\end{array}$ & $\begin{array}{l}\text { When this record is disabled, it will be put into alarm with } \\
\text { this severity and a status of DISABLE_ALARM. }\end{array}$ \\
\hline LSET & Lock Set & $\begin{array}{l}\text { The lock set to which this record belongs. All records } \\
\text { linked in any way via input, output, or forward database } \\
\text { links belong to the same lock set. The only exception is } \\
\text { that non-process passive input links do not force the } \\
\text { linked record to be in the same lock set. The lock sets are } \\
\text { determined at IOC initialization time. }\end{array}$ \\
\hline
\end{tabular}




\begin{tabular}{|c|c|c|}
\hline Name & Summary & Description \\
\hline LCNT & Lock Count & $\begin{array}{l}\text { The number of times in succession dbProcess finds the } \\
\text { record active, i.e. PACT is TRUE. If dbProcess finds the } \\
\text { record active MAX_LOCK (currently set to 10) times in } \\
\text { succession, it raises a SCAN_AI.ARM. }\end{array}$ \\
\hline PACT & Processing Active & $\begin{array}{l}\text { See Application Developers Guide for details on usage. } \\
\text { PACT is TRUE while the record is being processed. For } \\
\text { asynchronous records PACT can be TRUE from the time } \\
\text { record processing is started until the asynchronous } \\
\text { completion occurs. As long as PACT is TRUE, } \\
\text { dbProcess will not call the record processing routine. }\end{array}$ \\
\hline PUTF & dbPutField Process & Did abPutField cause the current record processing? \\
\hline RPRO & Reprocess & Reprocess record when current processing completes. \\
\hline ASP & $\begin{array}{l}\text { Access Security } \\
\text { Private }\end{array}$ & \\
\hline PPN & $\begin{array}{l}\text { Address of } \\
\text { putNotify }\end{array}$ & Address of putNotify callback. \\
\hline PPNN & $\begin{array}{l}\text { Next Record for } \\
\text { putNotify }\end{array}$ & Next record for PutNotify. \\
\hline SPVT & Scan Private & This field is for private use of the scanning system. \\
\hline RSET & $\begin{array}{l}\text { Address of Record } \\
\text { Support Entry Table }\end{array}$ & See Application Developers Guide for details on usage. \\
\hline DSET & $\begin{array}{l}\text { Address of Device } \\
\text { Support Entry Table }\end{array}$ & $\begin{array}{l}\text { This address of the device support entry table for this } \\
\text { record. The value of this field is determined at IOC } \\
\text { initialization time. Record support routines use this field } \\
\text { to locate their device support routines. }\end{array}$ \\
\hline DPVT & Device Private & This field is for private use of the device support modules. \\
\hline PRIO & Priority & $\begin{array}{l}\text { Scheduling priority for processing I/O Event scanned } \\
\text { records and asynchronous record completion tasks. }\end{array}$ \\
\hline TPRO & Trace Processing & $\begin{array}{l}\text { If this field is set TRUE, a message is printed each time } \\
\text { this record is processed and a message is printed for each } \\
\text { record processed as a result of this record being processed }\end{array}$ \\
\hline BKPT & BreakPoint & \\
\hline UDF & VAL Undefined & $\begin{array}{l}\text { UDF is initialized to TRUE at IOC initialization. Record } \\
\text { and device support routines which write to the VAI field } \\
\text { are responsible for setting UDF to FALSE. }\end{array}$ \\
\hline TIME & Time & $\begin{array}{l}\text { The time when this record was last processed, in standard } \\
\text { format. }\end{array}$ \\
\hline FLNK & Forward Link & $\begin{array}{l}\text { This field is a database link. If FLNK is specified, } \\
\text { processing this record will force a processing of the scan } \\
\text { passive forward link record. }\end{array}$ \\
\hline
\end{tabular}




\section{Chapter 3: Fields Common to Many Record Types}

\section{Introduction}

This chapter describes input and output fields that are common to multiple record types. These fields have the same meaning whenever they are used.

\section{Input Records}

\section{Common Fields}

\begin{tabular}{|l|l|l|}
\hline \multicolumn{1}{|c|}{ Name } & \multicolumn{1}{|c|}{ Summary } & \multicolumn{1}{c|}{ Description } \\
\hline \hline INP & Input Link & $\begin{array}{l}\text { This field is used by the device support routines to obtain } \\
\text { input. For soft analog records it can be a constant, a } \\
\text { database link, or a channel access link. }\end{array}$ \\
\hline DTYP & Device Type & $\begin{array}{l}\text { DTYP specifies the name of the device support module } \\
\text { that will input values. Each record type has its own set of } \\
\text { device support routines which are specified in } \\
\text { devSup. ascii. If a record type does not have any } \\
\text { associated device support, DTYP is meaningless. }\end{array}$ \\
\hline RVAL & Raw Value & $\begin{array}{l}\text { Whenever possible this field contains the raw data value } \\
\text { exactly as it is obtained from the hardware or from the } \\
\text { associated device driver. }\end{array}$ \\
\hline VAL & Value & $\begin{array}{l}\text { This is the record's final value, after any needed } \\
\text { conversions have been performed. }\end{array}$ \\
\hline
\end{tabular}


- If the INP link type is CA_LINK, then dbCaGetLink is called to obtain a new input value. If $d b C a G e t I i n k$ returns an error, a LINK alarm with a severity of INVALID is raised. RecGblGetLinkValue returns the status of abcaGetLink.

If the return status of recGblGetLinkValue is zero and the INP link type is not CONSTANT, then UDF is set to FALSE. The device support read routine normally returns the status of recGblGetLinkValue.

Simulation Mode

A record can be switched into simulation mode of operation by setting the value of SIMM to YES. During simulation, the record will be put into alarm with a severity of SIMS and a status of SIMM_ALARM. While in simulation mode, input values, in engineering units, will be obtained from SIOL instead of INP. Also, while the record is in simulation mode, there will be no raw value conversion and no calls to device support during record processing.

Normally input records contain a private readvalue routine which performs the following steps:

- If PACT is TRUE, the device support read routine is called, status is set to its return code, and readvalue returns.

- Call recGblGetLinkValue to get a new value for SIMM if SIML is a DB_LINK or a CA_LINK.

- Check value of SIMM

- If SIMM is No, then call the device support read routine, set status to its return code, and return.

- If SIMM is YES, then call recGblGetLinkValue to read the input value from SIOL into SVAL. If success, then set VAL to SVAL and UDF to FALSE and set status to 2 (don't convert) if input record supports conversion. If SIMS is greater than zero, set alarm status to SIMM and severity to SIMS. Set status to the return code from recGblGetLinkValue and return.

- IF SIMM is not YES or NO, a SOFT alarm with a severity of INVALID is raised, and return status is set to -1 .

\section{Output Records}

\section{Common Fields}

\begin{tabular}{|l|l|l|}
\hline \multicolumn{1}{|c|}{ Name } & \multicolumn{1}{|c|}{ Summary } & \multicolumn{1}{c|}{ Description } \\
\hline \hline OUT & Output Link & $\begin{array}{l}\text { This field is used by the device support routines to decide } \\
\text { where to send output. For soft records, it can be a } \\
\text { constant, a database link, or a channel access link. If the } \\
\text { link is a constant, the result is no output. }\end{array}$ \\
\hline DTYP & Device Type & $\begin{array}{l}\text { DTYP specifies the device support module that will } \\
\text { receive values. }\end{array}$ \\
\hline VAL & Value & $\begin{array}{l}\text { This is the desired value before any conversions to raw } \\
\text { output have been performed. }\end{array}$ \\
\hline
\end{tabular}




\begin{tabular}{|c|c|c|}
\hline Name & Summary & Description \\
\hline OVAL & Output Value & $\begin{array}{l}\text { OVAL is used to decide when to invoke monitors. Archive } \\
\text { and value change monitors are invoked if OVAL is not } \\
\text { equal to VAL. If a record type needs to make } \\
\text { adjustments, OVAL is used to enforce the maximum rate } \\
\text { of change limit before converting the desired value to a } \\
\text { raw value. }\end{array}$ \\
\hline RVAL & Raw Value & $\begin{array}{l}\text { Whenever possible this is the actual value sent to the } \\
\text { hardware itself or to the associated device driver. }\end{array}$ \\
\hline RBV & Read Back Value & $\begin{array}{l}\text { Whenever possible this is the actual read back value } \\
\text { obtained from the hardware itself or from the associated } \\
\text { device driver. }\end{array}$ \\
\hline DOL & $\begin{array}{l}\text { Desired Output } \\
\text { Location (an Input } \\
\text { Link) }\end{array}$ & $\begin{array}{l}\text { DOL can be a constant, a database link, or a channel access } \\
\text { link. There is no device support associated with DOL. If } \\
\text { DOL is a database or channel access link and OMSL is } \\
\text { CLOSED_LOOP, then VAL is obtained from DOL. }\end{array}$ \\
\hline OMSL & Output Mode Select & $\begin{array}{l}\text { This field has either the value SUPERVISORY or } \\
\text { CLOSED_IOOP. DOL is used to determine VAL only if } \\
\text { OMSL has the value CLOSED_LOOP. By setting this field } \\
\text { the record can be switched between supervisory and } \\
\text { closed loop mode of operation. While in closed loop } \\
\text { mode, the VAL field cannot be set via dbPuts. }\end{array}$ \\
\hline OIF & $\begin{array}{l}\text { Output Full or } \\
\text { Incremental (ao } \\
\text { record only) }\end{array}$ & $\begin{array}{l}\text { This field, which is only used when input is obtained from } \\
\text { DOL, determines if the value obtained from DOL is an } \\
\text { increment to add to the current VAL or is the actual VAL } \\
\text { desired. }\end{array}$ \\
\hline SIMM & Simulation Mode & $\begin{array}{l}\text { This field has either the value YES or NO. By setting this } \\
\text { field to YES, the record can be switched into simulation } \\
\text { mode of operation. While in simulation mode, output will } \\
\text { be written to SIOL instead of OUT. }\end{array}$ \\
\hline SIML & $\begin{array}{l}\text { Simulation Mode } \\
\text { Location }\end{array}$ & $\begin{array}{l}\text { This field can be a constant, a database link, or a channel } \\
\text { access link. If SIML is a database or channel access link, } \\
\text { then SIMM is read from SIML. If SIML is a constant link } \\
\text { then SIMM is initialized with the constant value but can be } \\
\text { changed via dbPuts. }\end{array}$ \\
\hline SIOL & $\begin{array}{l}\text { Simulation Value } \\
\text { Location }\end{array}$ & $\begin{array}{l}\text { This field can be a constant, a database link, or a channel } \\
\text { access link. If SIOL is a database or channel access link, } \\
\text { then the output value is written to SIOL. If this link is a } \\
\text { constant, the result is no output. }\end{array}$ \\
\hline SIMS & $\begin{array}{l}\text { Simulation Mode } \\
\text { Alarm Severity }\end{array}$ & $\begin{array}{l}\text { When this record is in simulation mode, it will be put into } \\
\text { alarm with this severity and a status of SIMM_AIAARM. }\end{array}$ \\
\hline IVOA & $\begin{array}{l}\text { Invalid Alarm } \\
\text { Output Action }\end{array}$ & $\begin{array}{l}\text { Whenever the record is put into INVALID alarm severity } \\
\text { IVOA specifies an action. IVOA can be one of the } \\
\text { following actions. } \\
\text { - Continue normally } \\
\text { - Don't drive outputs } \\
\text { - Set output equal to IVOV }\end{array}$ \\
\hline
\end{tabular}




\begin{tabular}{|l|l|l|}
\hline \multicolumn{1}{|c|}{ Name } & \multicolumn{1}{|c|}{ Summary } & \multicolumn{1}{c|}{ Description } \\
\hline \hline IVOV & $\begin{array}{l}\text { Invalid Alarm } \\
\text { Output Value, In } \\
\text { Engineering Units }\end{array}$ & $\begin{array}{l}\text { When new severity has been set to INVALID alarm and } \\
\text { IVOA is "Set output equal to IVOV", then, VAL is set to } \\
\text { IVOV and converted to RVAL before device support is } \\
\text { called. }\end{array}$ \\
\hline
\end{tabular}

\section{Soft Output}

\section{Output Mode Select}

Simulation Mode
Normally two soft output device support modules are provided Soft and Raw Soft. Both allow the output link OUT to be a constant, a database link, or a channel access link. It is normally meaningless to use constant output links. The Soft support module writes output from the value associated with OVAL or VAL (if OVAL does not exist). The Raw Soft support module writes the value associated with the RVAI field after conversion has been performed.

The device support write routine normally calls recGblPutLinkValue which performs the following steps:

- If the OUT link type is CONSTANT recGblPutLinkValue does nothing and returns with a status of zero.

- If the OUT link type is DB_LINK, then dbPutLink is called to write the current value. If dbPutLink returns an error, a LINK_AT_ARM with a severity of INVALID_AL_ARM is raised. RecGblPutLinkValue returns the status of dbPutLink.

- If the OUT link type is CA_LINK, then dbCaPutLink is called to write the current value. If dbCaPutLink returns an error, a LINK_ALARM with a severity of INVALID_ALARM is raised. RecGblPutLinkValue returns the status of dbCaPuttink.

The device support write routine normally returns the status of recGblPutLinkValue.

The fields DOL and OMSL are used to allow the output record to be part of a closed loop control algorithm. OMSL is meaningful only if DOL refers to a database or channel access link. It can have the values SUPERVISORY or CLOSED_LOOP. If the mode is SUPERVISORY, then nothing is done to VAL. If the mode is CLOSED_LOOP and the record type does not contain an OIF field, then each time the record is processed, VAL is set equal to the value obtained from the location referenced by DOL. If the mode is CLOSED_LOOP in record types with an OIF field and OIF is Full, VAL is set equal to the value obtained from the location referenced by DOL; if OIF is Incremental VAL is incremented by the value obtained from DOL.

An output record can be switched into simulation mode of operation by setting the value of SIMM to YES. During simulation, the record will be put into alarm with a severity of SIMS and a status of SIMM_ALARM. While in simulation mode, output values, in engineering units, will be written to SIOL instead of OUT. Also, while the record is in simulation mode, there will be no calls to device support during record processing.

Normally output records contain a private writevalue routine which performs the following steps:

- If PACT is TRUE, the device support write routine is called, status is set to its return code, and readvalue returns.

- Call recGblGetLinkValue to get a new value for SIMM if SIML is a DB_LINK or a CA_LINK.

- Check value of SIMM. 
- If SIMM is No, then call the device support write routine, set status to its return code, and return.

- If SIMM is YES, then call recGblPutLinkValue to write the output value from VAL or OVAL to SIOL. Set alarm status to SIMM and severity to SIMS, if SIMS is greater than zero. Set status to the return code from recGblPutLinkValue and return.

- If SIMM not one of the above, a SOFT alarm with a severity of INVALID is raised, and return status is set to -1 .

Invalid Alarm Output Action
Whenever an output record is put into INVALID alarm severity, IVOA specifies an action to take. The record support process routine for each output record contains code which performs the following steps.

- If new severity is less than INVALID, then call writevalue:

- Else do the following:

- If IVOA is CONTINUE, then call writeValue.

- If IVOA is NO_OUTPUT, then do not write output.

- If IVOA is OUTPUT_IVOV, then set VAL to IVOV, call convert if necessary, and then call writevalue.

- If IVOA not one of the above, an error message is generated. 


\section{Chapter 4: ai - Analog Input}

\section{Introduction}

The normal use for this record type is to obtain an analog value converted to engineering units. Most device support modules obtain values from hardware. Soft device modules are provided to obtain input via database or channel access links or via dbPutField or abPutLink requests. The record supports alarm limits, conversion to engineering units, smoothing, and graphics and control limits.

Two soft device support modules are provided. One reads values directly into VAL. The other reads values into RVAI, which is then converted just like raw values obtained from hardware device support modules. If soft device support with a constant INP link is chosen, then the VAI field can be modified via dbPuts.

\section{Field Summary}

\begin{tabular}{|l|l|l|l|l|l|l|l|}
\hline \multicolumn{1}{|c|}{ Field } & \multicolumn{1}{|c|}{ Type } & \multicolumn{1}{c|}{ DCT } & Initial & Access & Modify & $\begin{array}{l}\text { Rec Proc } \\
\text { Monitor }\end{array}$ & \multicolumn{1}{c|}{ PP } \\
\hline \hline VAL & DOUBLE & No & 0 & Yes & Yes & Yes & Yes \\
\hline INP & INLINK & Yes & 0 & No & No & N/A & No \\
\hline PREC & SHORT & Yes & 0 & Yes & Yes & No & No \\
\hline LINR & CVTCHOICE & Yes & 0 & Yes & Yes & No & Yes \\
\hline EGUF & FLOAT & Yes & 0 & Yes & Yes & No & Yes \\
\hline EGUL & FLOAT & Yes & 0 & Yes & Yes & No & Yes \\
\hline
\end{tabular}




\begin{tabular}{|c|c|c|c|c|c|c|c|}
\hline Field & Type & DCT & Initial & Access & Modify & \begin{tabular}{|l|} 
Rec Proc \\
Monitor \\
\end{tabular} & $\mathbf{P P}$ \\
\hline EGU & STRING & Yes & null & Yes & Yes & No & No \\
\hline HOPR & FLOAT & Yes & 0 & Yes & Yes & No & No \\
\hline LOPR & FLOAT & Yes & 0 & Yes & Yes & No & No \\
\hline AOFF & FLOAT & Yes & 0 & Yes & Yes & No & Yes \\
\hline ASLO & FLOAT & Yes & 1 & Yes & Yes & No & Yes \\
\hline SMOO & FLOAT & Yes & 0 & Yes & Yes & No & No \\
\hline HIHI & FLOAT & Yes & 0 & Yes & Yes & No & Yes \\
\hline LOLO & FLOAT & Yes & 0 & Yes & Yes & No & Yes \\
\hline HIGH & FLOAT & Yes & 0 & Yes & Yes & No & Yes \\
\hline LOW & FLOAT & Yes & 0 & Yes & Yes & No & Yes \\
\hline HHSV & GBLCHOICE & Yes & 0 & Yes & Yes & No & Yes \\
\hline LLSV & GBLCHOICE & Yes & 0 & Yes & Yes & No & Yes \\
\hline HSV & GBLCHOICE & Yes & 0 & Yes & Yes & No & Yes \\
\hline LSV & GBLCHOICE & Yes & 0 & Yes & Yes & No & Yes \\
\hline HYST & DOUBLE & Yes & 0 & Yes & Yes & No & No \\
\hline ADEL & DOUBLE & Yes & 0 & Yes & Yes & No & No \\
\hline MDEL & DOUBLE & Yes & 0 & Yes & Yes & No & No \\
\hline ROFF & LONG & No & 0 & Yes & Yes & No & Yes \\
\hline ESLO & DOUBLE & No & 1 & Yes & No & No & No \\
\hline LALM & DOUBLE & No & 0 & Yes & No & No & No \\
\hline ALST & DOUBLE & No & 0 & Yes & No & No & No \\
\hline MLST & DOUBLE & No & 0 & Yes & No & No & No \\
\hline PBRK & NOACCESS & No & 4 & No & No & & No \\
\hline INIT & SHORT & No & 0 & Yes & No & No & No \\
\hline LBRK & SHORT & No & 0 & Yes & No & No & No \\
\hline RVAL & LONG & No & 0 & Yes & Yes & Yes & Yes \\
\hline ORAW & LONG & No & 0 & Yes & No & No & No \\
\hline SIOL & INLINK & Yes & 0 & No & No & N/A & No \\
\hline SVAL & DOUBLE & No & 0 & Yes & Yes & No & No \\
\hline SIML & INLINK & Yes & 0 & No & No & N/A & No \\
\hline SIMM & GBLCHOICE & No & 0 & Yes & Yes & No & No \\
\hline SIMS & GBLCHOICE & Yes & 0 & Yes & Yes & No & No \\
\hline
\end{tabular}




\section{Field Descriptions}

\begin{tabular}{|c|c|c|}
\hline Name & Summary & Description \\
\hline VAL & Value Field & $\begin{array}{l}\text { Unless INP is a constant link and the device support } \\
\text { module specifies no conversion, this is the value resulting } \\
\text { from the record being processed. If INP is a constant, then } \\
\text { VAL is initialized to the INP value but can be changed } \\
\text { dynamically via dbPutField or dbPutLink. }\end{array}$ \\
\hline INP & Input Link & $\begin{array}{l}\text { This field is used by the device support routines to obtain } \\
\text { input. For soft analog records it can be a constant, a } \\
\text { database link, or a channel access link. }\end{array}$ \\
\hline PREC & Display Precision & $\begin{array}{l}\text { Precision with which to display VAL and OVAL. This field } \\
\text { is used by record support to supply a value when } \\
\text { get_precision is called. }\end{array}$ \\
\hline LINR & Conversion Type & $\begin{array}{l}\text { No conversion, linear and breakpoint table conversion are } \\
\text { supported. }\end{array}$ \\
\hline EGUF & $\begin{array}{l}\text { Engineering Units } \\
\text { Full }\end{array}$ & \multirow{4}{*}{ 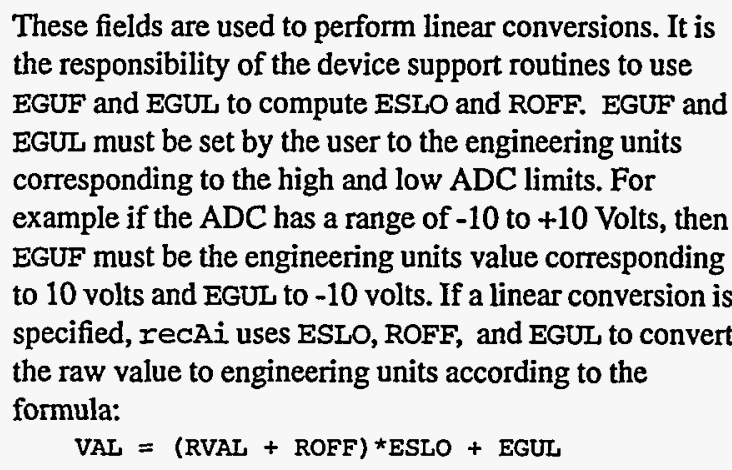 } \\
\hline EGUL & $\begin{array}{l}\text { Engineering Units } \\
\text { Low }\end{array}$ & \\
\hline ROFF & Raw Value Offset & \\
\hline ESLO & $\begin{array}{l}\text { Slope for Linear } \\
\text { Conversions }\end{array}$ & \\
\hline EGU & Engineering Units & $\begin{array}{l}\text { An ASCII string of up to } 16 \text { characters describing the } \\
\text { engineering units. This field is used by record support to } \\
\text { supply a units description string when get_units is } \\
\text { called. }\end{array}$ \\
\hline HOPR & $\begin{array}{l}\text { High Operating } \\
\text { Range }\end{array}$ & \multirow{2}{*}{$\begin{array}{l}\text { These fields determine the upper and lower display limits } \\
\text { for graphics displays and the upper and lower control } \\
\text { limits for control displays. The fields are used by record } \\
\text { support to honor calls to get_graphic_double or } \\
\text { get_control_double. }\end{array}$} \\
\hline LOPR & $\begin{array}{l}\text { Low Operating } \\
\text { Range }\end{array}$ & \\
\hline AOFF & Adjustment Offset & \multirow{2}{*}{$\begin{array}{l}\text { These fields are adjustment parameters for the raw input } \\
\text { values. They are applied to the raw data value returned by } \\
\text { the device support routine before any other conversions } \\
\text { are performed. }\end{array}$} \\
\hline ASLO & Adjustment Slope & \\
\hline SMOO & Smoothing Factor & $\begin{array}{l}\text { The converted data value is subjected to the following } \\
\text { algorithm: } \\
\text { val }=\text { newvalue * }(1-\text { smoo) }+ \text { oldvalue * smoo } \\
\text { SMOO should have a value between } 0 \text { and } 1 \text {, with } 0 \\
\text { meaning no smoothing and } 1 \text { meaning ultimate smoothing } \\
\text { (in fact, the data value will never change). }\end{array}$ \\
\hline
\end{tabular}




\begin{tabular}{|c|c|c|}
\hline Name & Summary & Description \\
\hline $\mathrm{HIHI}$ & Hihi Alarm Limit & \multirow[t]{8}{*}{ These fields specify the alarm limits and severities. } \\
\hline HIGH & High Alarm Limit & \\
\hline LOW & Low Alarm Limit & \\
\hline LOLO & Lolo Alarm Limit & \\
\hline HHSV & Hihi Alarm Severity & \\
\hline HSV & High Alarm Severity & \\
\hline LSV & Low Alarm Severity & \\
\hline LLSV & Lolo Alarm Severity & \\
\hline HYST & Alarm Deadband & \multirow{3}{*}{$\begin{array}{l}\text { These parameters specify hysteresis factors for triggering } \\
\text { monitors by a call to db_post_event or monitor } \\
\text { callbacks, i.e. callbacks specified by calls to } \\
\text { caAddEvent or dbAddEvent. A monitor will not be } \\
\text { triggered until VAI changes by more than the specified } \\
\text { amount. }\end{array}$} \\
\hline ADEL & Archive Deadband & \\
\hline MDEL & $\begin{array}{l}\text { Monitor, i.e. value } \\
\text { change, Deadband }\end{array}$ & \\
\hline LALM & $\begin{array}{l}\text { Last Alarm Monitor } \\
\text { Trigger Value }\end{array}$ & \multirow[t]{3}{*}{$\begin{array}{l}\text { These fields are used to implement the hysteresis factors } \\
\text { for monitor callbacks. }\end{array}$} \\
\hline ALST & $\begin{array}{l}\text { Last Archiver } \\
\text { Monitor Trigger } \\
\text { Value }\end{array}$ & \\
\hline MLST & $\begin{array}{l}\text { Last Value Change } \\
\text { Monitor Trigger } \\
\text { Value }\end{array}$ & \\
\hline INIT & Initialize & $\begin{array}{l}\text { This field is used by record support to perform } \\
\text { initialization for LBRK and for smoothing. }\end{array}$ \\
\hline LBRK & Last Breakpoint & $\begin{array}{l}\text { Index of last breakpoint interval. LBRK is used to perform } \\
\text { conversions via breakpoint tables. }\end{array}$ \\
\hline PBRK & $\begin{array}{l}\text { Address of } \\
\text { Breakpoint Table }\end{array}$ & $\begin{array}{l}\text { PBRK is used to perform conversions via breakpoint } \\
\text { tables. }\end{array}$ \\
\hline RVAL & Raw Value & $\begin{array}{l}\text { RVAL is the raw data value obtained by the device support } \\
\text { routine. Unless the device support routine returns value } \\
\text { requests that no conversion should be performed, the } \\
\text { record support routine converts this value to engineering } \\
\text { units. }\end{array}$ \\
\hline ORAW & Old Raw Value & $\begin{array}{l}\text { ORAW is used to decide if monitors should be triggered for } \\
\text { RVAL at the same time monitors are triggered for changes } \\
\text { in VAL. }\end{array}$ \\
\hline
\end{tabular}




\begin{tabular}{|l|l|l|}
\hline \multicolumn{1}{|c|}{ Name } & \multicolumn{1}{|c|}{ Summary } & \multicolumn{1}{c|}{ Description } \\
\hline \hline SIMM & Simulation Mode & $\begin{array}{l}\text { Simulation mode process variables. Refer to Chapter 3 } \\
\text { Section "Simulation Mode" on page 11 for more } \\
\text { information. }\end{array}$ \\
\hline SIML & $\begin{array}{l}\text { Simulation Mode } \\
\text { Location }\end{array}$ & \\
\cline { 1 - 2 } SVAL & Simulation Value & \\
\hline SIOL & $\begin{array}{l}\text { Simulation Value } \\
\text { Location }\end{array}$ & \\
\hline SIMS & $\begin{array}{l}\text { Simulation Mode } \\
\text { Alarm Severity }\end{array}$ & \\
\hline
\end{tabular}

\section{Record Support Routines}

init_record

process

special

get_value

get_units

get_precision
This routine initializes SIMM with the value of SIML if SIML type is CONSTANT link or creates a channel access link if SIML type is PV_LINK. SVAL is likewise initialized if SIOL is CONSTANT or PV_LINK.

This routine next checks to see that device support is available and a device support read_ai routine is defined. If either does not exist, an error message is issued and processing is terminated.

INIT is then set to TRUE.

If device support includes init_record, it is called.

See next section.

The only special processing for analog input records is SPC_LINCONV. which is invoked whenever any of the fields LINR, EGUF, EGUL or ROFF is changed.

If the device support routine special_linconv exists, it is called.

INIT is set TRUE. This causes PBRK, LBRK, and smoothing to be reinitialized.

Fills in the values of the structure valueDes so that they refer to VAL.

Retrieves EGU.

Retrieves PREC. 
get_graphic_double

get_control_double

get_alarm_double Sets the following values: used.

Sets the upper display and lower display limits for a field. If the field is VAL, HIHI, HIGH, LOW, or LOLO, the limits are set to HOPR and LOPR, else if the field has upper and lower limits defined they will be used, else the upper and lower maximum values for the field type will be used.

Sets the upper control and the lower control limits for a field. If the field is VAI, HIHI, HIGH, LOW, or LOLO, the limits are set to HOPR and LOPR, else if the field has upper and lower limits defined they will be used, else the upper and lower maximum values for the field type will be

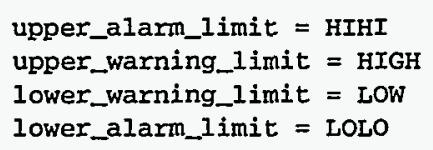

\section{Record Processing}

Routine process implements the following algorithm:

1. Check to see that the appropriate device support module exists. If it doesn't, an error message is issued and processing is terminated with the PACT field set to TRUE. This ensures that processes will no longer be called for this record. Thus error storms will not occur.

2. readValue is called. See Chapter 3 Section "Simulation Mode" on page 11 for details.

3. If PACT has been changed to TRUE, the device support read routine has started but has not completed writing the new value. In this case, the processing routine merely returns, leaving PACT TRUE.

4. PACT is then set to TRUE, TIME is set to tslocaltime and the return status value of readvalue is checked. convert is called only if status is 0 . If status is 2 , then convert is not called, but status is reset to 0 .

5. convert (if necessary): The new raw data value is expected to be in field RVAL. The first step is to set val equal to RVAI + ROFF. The next step is to adjust the raw value via the equation: val $=$ val $*$ ASLO + AOFF

If the conversion algorithm is linear, the raw value is converted via the equation: val $=$ val * ESLO + EGUL

If the conversion is via a breakpoint table, the new value is obtained.

The next step is to apply the following smoothing algorithm: if SMOO equal to 0 . Or INIT is True, VAL = val else VAL = val * $(1-$ SMOO $)+$ Previous_value * SMOO

Since VAL is now defined, the last step is to set UDF to FALSE.

6. Check alarms: This routine checks to see if the new VAL causes the alarm status and severity to change. If So, NSEV, NSTA and LAIM are set. It also honors the alarm hysteresis factor (HYST). Thus the value must change by more than HYST before the alarm status and severity is lowered.

7. Check to see if monitors should be invoked:

- Alarm monitors are invoked if the alarm status or severity has changed. 
- Archive and value change monitors are invoked if ADEL and MDEL conditions are met.

- Monitors for RVAL are checked whenever other monitors are invoked.

- NSEV and NSTA are reset to 0 .

8. Scan forward link if necessary, set PACT and INIT to FALSE, and return.

\section{Device Support}

Fields Of Interest To Device Support

Device Support Routines
Each analog input record must have an associated set of device support routines. The primary responsibility of the device support routines is to obtain a new raw analog input value whenever read_ai is called. The device support routines are primarily interested in the following fields:

\begin{tabular}{|c|c|c|}
\hline Name & Summary & Description \\
\hline $\mathrm{PACT}$ & Processing Active & \multirow{5}{*}{$\begin{array}{l}\text { See Chapter } 2 \text { Section "Database Common: Field } \\
\text { Descriptions" on page } 5 \text { for descriptions. }\end{array}$} \\
\hline DPVT & Device Private & \\
\hline UDF & VAL Undefined & \\
\hline NSEV & New Alarm Severity & \\
\hline NSTA & New Alarm Status & \\
\hline VAL & Value & $\begin{array}{l}\text { This field is used by device support only if it obtains a } \\
\text { value already converted to engineering units. See RVAL } \\
\text { below. }\end{array}$ \\
\hline INP & Input Link & $\begin{array}{l}\text { This field is used by the device support routines to locate } \\
\text { its input. }\end{array}$ \\
\hline EGUF & Engineering Units Full & \multirow{2}{*}{$\begin{array}{l}\text { These fields are used to calculate ESLO. Note that these } \\
\text { fields correspond to the high and low hardware limits. }\end{array}$} \\
\hline EGUL & Engineering Unit Low & \\
\hline ESLO & Slope & \multirow{2}{*}{$\begin{array}{l}\text { These fields are used for linear conversions from raw to } \\
\text { engineering units. The device support routines must } \\
\text { calculate these fields unless they obtain values already in } \\
\text { engineering units. }\end{array}$} \\
\hline ROFF & Raw Offset & \\
\hline RVAL & Raw Value & $\begin{array}{l}\text { It is the responsibility of the device support routine to give } \\
\text { this field a value. If the device support routine obtains a } \\
\text { value already in engineering units, it should place the } \\
\text { value in VAL and return a value of } 2 \text {. }\end{array}$ \\
\hline
\end{tabular}

Device support consists of the following routines:

report (FILE fp, paddr) 
Not currently used.

init

init_record

get_ioint_info

read_ai

special_linconv

\section{Device Support For Soft Records}

Two soft device support modules Soft Channel and Raw Soft Channel are provided for input records not related to actual hardware devices. The INP link type must be either CONSTANT, DB_LINK or CA_LINK.

\section{Soft Channel}

This routine is called once during IOC initialization.

$$
\text { init_record (precord) }
$$

This routine is optional. If provided, it is called by the record support init_record routine.

get_ioint_info (int cmd, struct dbComnon *precord, IOSCANPVT *ppvt)

This routine is called by the ioEventScan system each time the record is added or deleted from an $\mathrm{I} / \mathrm{O}$ event scan list. $\mathrm{cmd}$ has the value $(0,1)$ if the record is being (added to, deleted from) an V/O event list. It must be provided for any device type that can use the ioEvent scanner.

This routine must provide a new input value. Asynchronous device support routines will return with PACT set to TRUE. If PACT is TRUE, the process routine will just return and not continue processing. When the asynchronous routine completes, it can call process which will again call read_ai. Because PACT is still TRUE read_ai knows that this is a request to retrieve the data obtained by the previous call. When finished, read_ai should set PACT to FALSE and return one the following values:

- 0: Success. A new raw value is placed in RVAL. convert will be called.

- 2: Success, but don't call convert. This is useful if read_ai obtains a value already converted to engineering units or in the event a hardware failure is detected.

- Other: Error.

special_linconv (precord, after)

This routine is called whenever any of the fields LINR, EGUF, EGUL or ROFF is modified.
This module places a value directly in VAI. read_ai always returns a value of 2 , which means that no conversion will ever be attempted.

If the INP link type is constant, then the constant value is stored into VAL by init_record, and UDF is set to FALSE. If the INP link type is PV_LINK, then dbCaAddInlink is called by init_record.

read_ai calls recGblGetLinkValue to read the current value of VAL. See Chapter 3 Section "Soft Input" on page 10 for details. 
If the return status of recGblGetLinkValue is zero, then read_ai sets UDF to FALSE. The status of recGblGetLinkValue is returned.

If soft support is chosen, the following fields become meaningless: LINR, EGUF, EGUL, ESLO, ROFF, AOFF, ASLO, and SMOO. The read_ai routine always returns a value of 2 which means don't convert.

Raw Soft

Channel
This module is like the previous except that it places its value in RVAL and read_ai returns a value of 0 . Thus the record processing routine will convert the raw value in the normal way.

If raw soft support is chosen, the fields EGUF and EGUL become meaningless. ESLO and ROFF always have their default values of 1 and 0 . 
Chapter 4: ai - Analog Input

Device Support For Soft Records 


\section{Chapter 5: ao - Analog Output}

\section{Introduction}

The normal use for this record type is to store values to be sent to Digital to Analog Converters. It can also be used to write values to other records via database or channel access links. The oUT field determines how the record is used. The record supports alarm limits, conversion from/to engineering units, and graphics and control limits.

2. Field Summary

\begin{tabular}{|l|l|l|l|l|l|l|l|}
\hline \multicolumn{1}{|c|}{ Field } & \multicolumn{1}{|c|}{ Type } & DCT & Initial & Access & Modify & $\begin{array}{l}\text { Rec Proc } \\
\text { Monitor }\end{array}$ & \multicolumn{1}{c|}{ PP } \\
\hline \hline VAL & DOUBLE & No & 0 & Yes & Yes & Yes & Yes \\
\hline OVAL & DOUBLE & No & 0 & Yes & Yes & Yes & No \\
\hline OUT & OUTLINK & Yes & 0 & No & No & N/A & No \\
\hline OROC & FLOAT & Yes & 0 & Yes & Yes & No & No \\
\hline DOL & INLINK & Yes & 0 & No & No & N/A & No \\
\hline OMSL & GBLCHOICE & Yes & 0 & Yes & Yes & No & No \\
\hline OIF & RECCHOICE & Yes & 0 & Yes & Yes & No & No \\
\hline PREC & SHORT & Yes & 0 & Yes & Yes & No & No \\
\hline LINR & CVTCHOICE & Yes & 0 & Yes & Yes & No & Yes \\
\hline EGUF & FLOAT & Yes & 0 & Yes & Yes & No & Yes \\
\hline
\end{tabular}




\begin{tabular}{|c|c|c|c|c|c|c|c|}
\hline Field & Type & DCT & Initial & Access & Modify & $\begin{array}{l}\text { Rec Proc } \\
\text { Monitor }\end{array}$ & PP \\
\hline EGUL & FLOAT & Yes & 0 & Yes & Yes & No & Yes \\
\hline EGU & STRING & Yes & null & Yes & Yes & No & No \\
\hline ESLO & DOUBLE & No & 1 & Yes & No & No & No \\
\hline ROFF & LONG & No & 0 & Yes & Yes & No & Yes \\
\hline DRVH & FLOAT & Yes & 0 & Yes & Yes & No & Yes \\
\hline DRVL & FLOAT & Yes & 0 & Yes & Yes & No & Yes \\
\hline HOPR & FLOAT & Yes & 0 & Yes & Yes & No & No \\
\hline LOPR & FLOAT & Yes & 0 & Yes & Yes & No & No \\
\hline AOFF & FLOAT & Yes & 0 & Yes & Yes & No & Yes \\
\hline ASLO & FLOAT & Yes & 0 & Yes & Yes & No & Yes \\
\hline HIHI & FLOAT & Yes & 0 & Yes & Yes & No & Yes \\
\hline LOLO & FLOAT & Yes & 0 & Yes & Yes & No & Yes \\
\hline $\mathrm{HIGH}$ & FLOAT & Yes & 0 & Yes & Yes & No & Yes \\
\hline LOW & FLOAT & Yes & 0 & Yes & Yes & No & Yes \\
\hline HHSV & GBLCHOICE & Yes & 0 & Yes & Yes & No & Yes \\
\hline LLSV & GBLCHOICE & Yes & 0 & Yes & Yes & No & Yes \\
\hline HSV & GBLCHOICE & Yes & 0 & Yes & Yes & No & Yes \\
\hline LSV & GBLCHOICE & Yes & 0 & Yes & Yes & No & Yes \\
\hline HYST & DOUBLE & Yes & 0 & Yes & Yes & No & No \\
\hline ADEL & DOUBLE & Yes & 0 & Yes & Yes & No & No \\
\hline MDEL & DOUBLE & Yes & 0 & Yes & Yes & No & No \\
\hline RVAL & LONG & No & 0 & Yes & Yes & Yes & Yes \\
\hline ORAW & LONG & No & $\mathbf{0}$ & Yes & No & No & No \\
\hline RBV & LONG & No & 0 & Yes & No & Yes & No \\
\hline ORBV & LONG & No & 0 & Yes & No & No & No \\
\hline PVAL & DOUBLE & No & $\mathbf{0}$ & Yes & No & No & No \\
\hline LALM & DOUBLE & No & 0 & Yes & No & No & No \\
\hline ALST & DOUBLE & No & 0 & Yes & No & No & No \\
\hline MLST & DOUBLE & No & 0 & Yes & No & No & No \\
\hline PBRK & NOACCESS & No & 4 & No & No & & No \\
\hline INIT & SHORT & No & 0 & Yes & No & No & No \\
\hline LBRK & SHORT & No & 0 & Yes & No & No & No \\
\hline
\end{tabular}




\begin{tabular}{|l|l|l|l|l|l|l|l|}
\hline \multicolumn{1}{|c|}{ Field } & \multicolumn{1}{|c|}{ Type } & DCT & Initial & Access & Modify & $\begin{array}{l}\text { Rec Proc } \\
\text { Monitor }\end{array}$ & \multicolumn{1}{|c|}{ PP } \\
\hline \hline SIOL & INLINK & Yes & 0 & No & No & N/A & No \\
\hline SIML & INLINK & Yes & 0 & No & No & N/A & No \\
\hline SIMM & GBLCHOICE & No & 0 & Yes & Yes & No & No \\
\hline SIMS & GBLCHOICE & Yes & 0 & Yes & Yes & No & No \\
\hline IVOA & GBLCHOICE & Yes & 0 & Yes & Yes & No & No \\
\hline IVOV & DOUBLE & Yes & 0 & Yes & Yes & No & No \\
\hline
\end{tabular}

\section{Field Descriptions}

\begin{tabular}{|c|c|c|}
\hline Name & Summary & Description \\
\hline VAL & Value & $\begin{array}{l}\text { This is the desired output value, in engineering units. If } \\
\text { DRVH and DRVL are defined, VAL is forced to be within } \\
\text { the drive limits. VAL is either obtained from DOL or set } \\
\text { via dbPuts. }\end{array}$ \\
\hline OVAL & Output Value & $\begin{array}{l}\text { This is the desired output value, after adjustments, in } \\
\text { engineering units. It is just VAI possibly adjusted by } \\
\text { OROC. This is the value used to compute RVAL. OVAL is } \\
\text { used to enforce a maximum rate of change limit before } \\
\text { converting the desired value to a raw value. If soft device } \\
\text { support is selected and OUT is a database or channel } \\
\text { access link, this is the value written to the link. }\end{array}$ \\
\hline OUT & Output Link & $\begin{array}{l}\text { This field is used by the device support routines to decide } \\
\text { where to send output. For soft records, it can be a } \\
\text { constant, a database link, or a channel access link. If the } \\
\text { link is a constant, the result is no output. }\end{array}$ \\
\hline OROC & $\begin{array}{l}\text { Maximum Output } \\
\text { Rate of Change }\end{array}$ & $\begin{array}{l}\text { If this is not zero, it specifies the maximum change in } \\
\text { value (engineering units) to be sent to OUT each time the } \\
\text { record is processed. It is this field that can cause VAL and } \\
\text { OVAL to differ. }\end{array}$ \\
\hline DOL & $\begin{array}{l}\text { Desired Output } \\
\text { Location (an Input } \\
\text { Link) }\end{array}$ & $\begin{array}{l}\text { If DOL is a database or channel access link and OMSL is } \\
\text { CLOSED_LOOP, then VAL is read from DOL. After the } \\
\text { check for drive limits, VAL will be set to the value } \\
\text { determined by DOL. }\end{array}$ \\
\hline OMSL & Output Mode Select & $\begin{array}{l}\text { This field has either the value SUPERVISORY or } \\
\text { CLOSED_LOOP. DOL is used to determine VAL only if } \\
\text { OMSL has the value CLOSED_LOOP. By setting this field } \\
\text { the record can be switched between supervisory and } \\
\text { closed loop mode of operation. While in closed loop } \\
\text { mode, the VAL field cannot be set via dbPuts. }\end{array}$ \\
\hline OIF & $\begin{array}{l}\text { Out Full or } \\
\text { Incremental }\end{array}$ & $\begin{array}{l}\text { This field is used when input is obtained from DOL, and } \\
\text { determines if the value obtained from DOL is an increment } \\
\text { to add to the current VAL or is the actual VAL desired. }\end{array}$ \\
\hline
\end{tabular}




\begin{tabular}{|c|c|c|}
\hline Name & Summary & Description \\
\hline PREC & Display Precision & $\begin{array}{l}\text { Precision with which to display VAL. This field is used by } \\
\text { record support to supply a value when get_precision } \\
\text { is called. }\end{array}$ \\
\hline LINR & Conversion Type & $\begin{array}{l}\text { No conversion, linear and breakpoint table conversion are } \\
\text { supported. }\end{array}$ \\
\hline EGUF & $\begin{array}{l}\text { Engineering Units } \\
\text { Full }\end{array}$ & \multirow{4}{*}{$\begin{array}{l}\text { These fields are used to perform linear conversions. It is } \\
\text { the responsibility of the device support routines to use } \\
\text { EGUF and EGUL to compute ESLO and ROFF. EGUF and } \\
\text { EGUL must be set by the user to the engineering units } \\
\text { corresponding to the high and low ADC limits. For } \\
\text { example if the DAC has a range of - } 10 \text { to }+10 \text { Volts, then } \\
\text { EGUF must be the engineering units value corresponding } \\
\text { to } 10 \text { volts and EGUL to - } 10 \text { volts. If a linear conversion is } \\
\text { specified ESLO, ROFF, and EGUL are used to convert the } \\
\text { value from/to engineering units using the following } \\
\text { formula: } \\
\text { RVAL = (OVAL - EGUL) /ESLO - ROFF }\end{array}$} \\
\hline EGUL & $\begin{array}{l}\text { Engineering Units } \\
\text { Low }\end{array}$ & \\
\hline ESLO & $\begin{array}{l}\text { Slope For Linear } \\
\text { Conversions }\end{array}$ & \\
\hline ROFF & Raw Value Offset & \\
\hline EGU & Engineering Units & $\begin{array}{l}\text { ASCII string describing Engineering units. This field is } \\
\text { used by record support to supply a units description string } \\
\text { when get_units is called. }\end{array}$ \\
\hline DRVH & Drive High & \multirow{2}{*}{$\begin{array}{l}\text { If these values are defined then VAL will forced to be in } \\
\text { the range: } \\
\text { DRVL }<=V A L<=D R V H\end{array}$} \\
\hline DRVL & Drive Low & \\
\hline HOPR & $\begin{array}{l}\text { High Operating } \\
\text { Range }\end{array}$ & \multirow{2}{*}{$\begin{array}{l}\text { These fields determine the upper and lower display limits } \\
\text { for graphics displays and the upper and lower control } \\
\text { limits for control displays. The fields are used by record } \\
\text { support to honor calls to get_graphic_double or } \\
\text { get_control_double. If these values are defined, } \\
\text { they must be in the range: } \\
\text { DRVL<=LOPR<=HOPR<=DRVH. }\end{array}$} \\
\hline LOPR & $\begin{array}{l}\text { Low Operating } \\
\text { Range }\end{array}$ & \\
\hline AOFF & Adjustment Offset & \multirow{2}{*}{$\begin{array}{l}\text { These fields are adjustment parameters for the raw output } \\
\text { values. They are applied to the raw output value after } \\
\text { conversion from engineering units. }\end{array}$} \\
\hline ASLO & Adjustment Slope & \\
\hline HIHI & Hihi Alarm Limit & \multirow[t]{8}{*}{ These fields specify the alarm limits and severities. } \\
\hline HIGH & High Alarm Limit & \\
\hline LOW & Low Alarm Limit & \\
\hline LOLO & Lolo Alarm Limit & \\
\hline HHSV & Hihi Alarm Severity & \\
\hline HSV & High Alarm Severity & \\
\hline LSV & Low Alarm Severity & \\
\hline LLSV & Lolo Alarm Severity & \\
\hline
\end{tabular}




\begin{tabular}{|c|c|c|}
\hline Name & Summary & Description \\
\hline HYST & Alarm Deadband & \multirow{3}{*}{$\begin{array}{l}\text { These parameters specify hysteresis factors for triggering } \\
\text { monitor callbacks, i.e. callbacks specified by calls to } \\
\text { caAddEvent or dbAddEvent. A monitor will not be } \\
\text { triggered until VAL changes by more than the specified } \\
\text { amount. }\end{array}$} \\
\hline ADEL & Archive Deadband & \\
\hline MDEL & $\begin{array}{l}\text { Monitor, i.e. value } \\
\text { change, Deadband }\end{array}$ & \\
\hline RVAL & Raw Data Value & RVAL is the value actually sent to the device. \\
\hline ORAW & Old raw data value & $\begin{array}{l}\text { ORAW is used to decide if monitors should be triggered for } \\
\text { RVAL. }\end{array}$ \\
\hline RBV & Read Back Value & $\begin{array}{l}\text { This is the actual read back value obtained from the } \\
\text { hardware itself or from the associated device driver. It is } \\
\text { the responsibility of the device support routine to give this } \\
\text { field a value. }\end{array}$ \\
\hline ORBV & Old read back value & $\begin{array}{l}\text { ORBV is used to decide if monitors should be triggered for } \\
\text { RBV at the same time monitors are triggered for changes } \\
\text { in VAL. }\end{array}$ \\
\hline PVAL & $\begin{array}{l}\text { Previous Data } \\
\text { Value }\end{array}$ & \\
\hline LALM & $\begin{array}{l}\text { Last Alarm Monitor } \\
\text { Trigger Value }\end{array}$ & \multirow[t]{3}{*}{$\begin{array}{l}\text { These fields are used to implement the hysteresis factors } \\
\text { for monitors. }\end{array}$} \\
\hline ALST & $\begin{array}{l}\text { Last Archiver } \\
\text { Monitor Trigger } \\
\text { Value }\end{array}$ & \\
\hline MLST & $\begin{array}{l}\text { Last Value Change } \\
\text { Monitor Trigger } \\
\text { Value }\end{array}$ & \\
\hline INIT & Initialize & $\begin{array}{l}\text { This field is used by record support to perform } \\
\text { initialization for IBRK and for smoothing. }\end{array}$ \\
\hline LBRK & Last Breakpoint & Index of last breakpoint interval \\
\hline PBRK & Breakpoint Pointer & Address of breakpoint table \\
\hline SIMM & Simulation Mode & \multirow{4}{*}{$\begin{array}{l}\text { Simulation mode process variables. Refer to Chapter } 3 \text {, } \\
\text { Section "Simulation Mode" on page } 13 \text { for more } \\
\text { information. }\end{array}$} \\
\hline SIML & $\begin{array}{l}\text { Simulation Mode } \\
\text { Location }\end{array}$ & \\
\hline SIOL & $\begin{array}{l}\text { Simulation Value } \\
\text { Location }\end{array}$ & \\
\hline SIMS & $\begin{array}{l}\text { Simulation Mode } \\
\text { Alarm Severity }\end{array}$ & \\
\hline IVOA & $\begin{array}{l}\text { Invalid Alarm } \\
\text { Output Action }\end{array}$ & \multirow{2}{*}{$\begin{array}{l}\text { Whenever the record is put into INVALID alarm severity } \\
\text { IVOA specifies an action. See Chapter } 3 \text {, Section "Invalid } \\
\text { Alarm Output Action" on page } 14 \text { for more information. }\end{array}$} \\
\hline IVOV & $\begin{array}{l}\text { Invalid Alarm } \\
\text { Output Value }\end{array}$ & \\
\hline
\end{tabular}




\section{Record Support Routines}

\section{init_record}

process

special

get_value

get_units

get_precision

get_graphic_double
This routine initializes SIMM if SIMU is a constant or creates a channel access link if SIML is PV_LINK. If SIOL is PV_LINK a channel access link is created.

This routine next checks to see that device support is available. If DOL is a constant, then VAL is initialized with its value and UDF is set to FALSE.

The routine next checks to see if the device support write routine is defined. If either device support or the device support write routine does not exist, an error message is issued and processing is terminated.

If device support includes init_record, it is called.

INIT is set TRUE. This causes PBRK, LBRK, and smoothing to be reinitialized

If linear conversion is requested, then VAL is computed from RVAL using the algorithm:

VAL $=($ RVAL + ROFF $) / E S L O+E G U L$

and UDF is set to FALSE.

For breakpoint conversion, a call is made to cvtEngToRawBpt and UDF is then set to FALSE. PVAL is set to VAL.

See next section.

The only special processing for analog output records is SPC_LINCONV which is invoked whenever either of the fields LINR, EGUF, EGUL or ROFF is changed

If the device support routine special_linconv exists it is called.

INIT is set TRUE. This causes PBRK, LBRK, and smoothing to be reinitialized.

Fills in the values of struct valueDes so that they refer to VAL.

Retrieves EGU.

Retrieves PREC.

Sets the upper display and lower display limits for the field. If the field is VAL, HIHI, HIGH, LOW, or LOLO, the limits are set to HOPR and LOPR, else if the field has upper and lower limits defined they will be used, else the upper and lower maximum values for the field type will be used. 
get_control_double

get_alarm_double
Sets the upper display and lower control limits for the field. If the field is VAL, HIHI, HIGH, LOW, or LOLO, the limits are set to HOPR and LOPR, else if the field has upper and lower limits defined they will be used, else the upper and lower maximum values for the field type will be used.

Sets the following values:

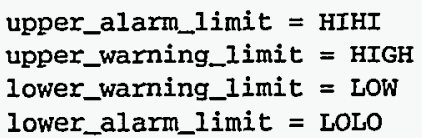

\section{Record Processing}

Routine process implements the following algorithm:

1. Check to see that the appropriate device support module exists. If it doesn't, an error message is issued and processing is terminated with the PACT field set to TRUE. This ensures that processes will no longer be called for this record. Thus error storms will not occur.

2. Check PACT: If PACT is FALSE call fetch_values and convert which perform the following steps:

- fetch_values:

if DOL is DB_LINK and OMSL is CLOSED_LOOP get value from DOL

if OIF is INCREMENTAL then set value = value + VAL

else value $=$ VAL

- convert:

If Drive limits are defined force value to be within limits

Set VAL equal to value

Set UDF to FALSE.

If OVAL is undefined set it equal to value

If OROC is defined and not 0 make lvalue-OVALI $<=O R O C$

Set OVAL equal to value

Compute RVAL from OVAL. using linear or break point table conversion. For linear conversions the algorithm is:

RVAL = (OVAL-EGUL) /ESLO -ROFF

- For break point table conversion a call is made to cvtEngToRawBpt.

3. Check alarms: This routine checks to see if the new val causes the alarm status and severity to change. If so, NSEV, NSTA and $y$ are set. It also honors the alarm hysteresis factor (HYST). Thus the value must change by at least HYST before the alarm status and severity is reduced.

4. Check severity and write the new value. See Chapter 3, Section "Invalid Alarm Output Action" on page 14 for details.

5. If PACT has been changed to TRUE, the device support write output routine has started but has not completed writing the new value. In this case, the processing routine merely returns, leaving PACT TRUE.

6. Check to see if monitors should be invoked:

- Alarm monitors are invoked if the alarm status or severity has changed.

- Archive and value change monitors are invoked if ADEL and MDEL conditions are met. 
- Monitors for RVAL and for RBV are checked whenever other monitors are invoked.

- NSEV and NSTA are reset to 0 .

7. Scan forward link if necessary, set PACT and INIT FALSE, and return.

\section{Device Support}

Fields Of Interest To Device Support

\section{Device Support routines}

init

init_record

get_ioint_info
Each analog output record must have an associated set of device support routines. The primary responsibility of the device support routines is to output a new value whenever write_ao is called. The device support routines are primarily interested in the following fields:

\begin{tabular}{|c|c|c|}
\hline Name & Summary & Description \\
\hline PACT & Processing Active & \multirow{4}{*}{$\begin{array}{l}\text { See Chapter 2, Section "Database Common: Field } \\
\text { Descriptions" on page } 5 \text { for descriptions. }\end{array}$} \\
\hline DPVT & Device Private & \\
\hline NSEV & New Alarm Severity & \\
\hline NSTA & New Alarm Status & \\
\hline OUT & Output Link & $\begin{array}{l}\text { This field is used by the device support routines to locate } \\
\text { its output. }\end{array}$ \\
\hline EGUF & Engineering Units Full & \multirow{2}{*}{$\begin{array}{l}\text { These fields are used to calculate ESLO. Note that these } \\
\text { fields correspond to the high and low hardware limits. }\end{array}$} \\
\hline EGUL & Engineering Unit Low & \\
\hline ESLO & Slope & \multirow{2}{*}{$\begin{array}{l}\text { These fields are used for linear conversions from raw to } \\
\text { engineering units. The device support routines must } \\
\text { calculate these fields unless they obtain values already in } \\
\text { engineering units. }\end{array}$} \\
\hline ROFF & Raw Offset & \\
\hline RVAL & Raw Value & This is the value to write OUT. \\
\hline
\end{tabular}

Device support consists of the following routines:

$$
\text { init() }
$$

This routine is called once during IOC initialization.

$$
\text { init_record (precord) }
$$

This routine is optional. If provided, it is called by the record support init_record routine. It returns a zero for success or a 2 for success, don't convert.

get_ioint_info(int cmd, struct dbcommon *precord,IOSCANPVT *ppvt) 
This routine is called by the ioEventScan system each time the record is added or deleted from an I/O event scan list. cmd has the value $(0,1)$ if the record is being (added to, deleted from) an I/O event list. It must be provided for any device type that can use the ioEvent scanner.

write_ao

special_linconv

write_ao (precord)

This routine must output a new value. Asynchronous device support routines will return with PACT set to TRUE. If PACT is TRUE, the process routine will just return and not continue processing. When the asynchronous routine completes, it can call process which will again call write_ao. When finished, write_ao should set PACT to FALSE and return one the following values:

- 0: Success.

- other: Error.

special_linconv(precord, after)

This routine is called whenever either of the fields LINR, EGUF, EGUL or ROFF is modified.

\section{Device Support For Soft Records}

Two soft device support modules Soft Channel and Raw Soft Channel are provided for output records not related to actual hardware devices. The OUT link type must be either a cONSTANT, DB_LINK, or CA_LINK.

Soft Channel

This module writes the current value of OVAL.

If the OUT link type is PV_LINK, then dbCaAddInlink is called by init_record. init_record always returns a value of 2 , which means that no conversion will ever be attempted.

write_ao calls recGblPutLinkValue to write the current value of VAL. See Chapter 3, Section "Soft Output" on page 13 for details.

Raw Soft

This module is like the previous except that it writes the current value of RVAL.

Channel 


\section{Chapter 6: bi - Binary Input}

\section{Introduction}

The normal use for this record type is to obtain a binary value, i.e. a value that is 0 or 1 . Most device support modules obtain values from hardware and place the value in RVAL. For these devices record processing sets VAL $=(0,1)$ if RVAL is $(0$, not 0$)$. Devices may optionally read a value directly into VAL. Soft device modules are provided to obtain input via database or channel access links or via dbPutField or dbPutLink requests. Two soft device support modules are provided. One allows VAL to be an arbitrary unsigned short integer. The other reads the value into RVAL just like normal hardware modules.

\section{Field Summary}

\begin{tabular}{|l|l|l|l|l|l|l|l|}
\hline \multicolumn{1}{|c|}{ Field } & \multicolumn{1}{|c|}{ Type } & DCT & \multicolumn{1}{c|}{ Initial } & Access & Modify & $\begin{array}{l}\text { Rec Proc } \\
\text { Monitor }\end{array}$ & PP \\
\hline \hline VAL & ENUM & No & 0 & Yes & Yes & Yes & Yes \\
\hline INP & INLINK & Yes & 0 & No & No & N/A & No \\
\hline ZSV & GBLCHOICE & Yes & 0 & Yes & Yes & No & Yes \\
\hline OSV & GBLCHOICE & Yes & 0 & Yes & Yes & No & Yes \\
\hline COSV & GBLCHOICE & Yes & 0 & Yes & Yes & No & Yes \\
\hline ZNAM & STRING & Yes & Null & Yes & Yes & No & Yes \\
\hline ONAM & STRING & Yes & Null & Yes & Yes & No & Yes \\
\hline RVAL & ULONG & No & 0 & Yes & Yes & Yes & Yes \\
\hline
\end{tabular}




\begin{tabular}{|l|l|l|l|l|l|l|l|}
\hline \multicolumn{1}{|c|}{ Field } & \multicolumn{1}{|c|}{ Type } & \multicolumn{1}{c|}{ DCT } & \multicolumn{1}{c|}{ Initial } & Access & Modify & $\begin{array}{l}\text { Rec Proc } \\
\text { Monitor }\end{array}$ & \multicolumn{1}{c|}{ PP } \\
\hline \hline ORAW & ULONG & No & 0 & Yes & No & No & No \\
\hline MASK & ULONG & No & compute & Yes & No & No & No \\
\hline LALM & USHORT & No & 0 & Yes & No & No & No \\
\hline MLST & USHORT & No & 0 & Yes & No & No & No \\
\hline SIOL & INLINK & Yes & 0 & No & No & N/A & No \\
\hline SVAL & USHORT & No & 0 & Yes & Yes & No & No \\
\hline SIML & INLINK & Yes & 0 & No & No & N/A & No \\
\hline SIMM & GBLCHOICE & No & 0 & Yes & Yes & No & No \\
\hline SIMS & GBLCHOICE & Yes & 0 & Yes & Yes & No & No \\
\hline
\end{tabular}

\section{Field Descriptions}

\begin{tabular}{|c|c|c|}
\hline Name & Summary & Description \\
\hline VAL & Value Field & $\begin{array}{l}\text { This is the value resulting from record processing unless } \\
\text { soft device support with a constant INP is chosen. If the } \\
\text { later is chosen, VAL, which is an unsigned short, is given } \\
\text { values via dbPuts. }\end{array}$ \\
\hline INP & Input Link & $\begin{array}{l}\text { This field is used by the device support routines to obtain } \\
\text { input. For soft records, it can be a constant, a database } \\
\text { link, or a channel access link. }\end{array}$ \\
\hline ZSV & Zero Severity & Alarm Severity for state zero. \\
\hline OSV & One Severity & Alarm Severity for state one. \\
\hline cosv & $\begin{array}{l}\text { Change of State } \\
\text { Severity }\end{array}$ & Alarm Severity for change of state. \\
\hline ZNAM & Zero Name & ASCII string defining state zero. \\
\hline ONAM & One Name & ASCII string defining state one. \\
\hline RVAL & Raw Value & RVAL is the value obtained by the device support routine. \\
\hline ORAW & Old Raw Value & $\begin{array}{l}\text { ORAW is used to decide if monitors should be triggered for } \\
\text { RVAL at the same time monitors are triggered for changes } \\
\text { in VAL. }\end{array}$ \\
\hline MASK & Hardware mask & \\
\hline LALM & Last Alarmed Value & Value when last change of state alarm was issued. \\
\hline MLST & $\begin{array}{l}\text { Last Monitored } \\
\text { Value }\end{array}$ & Value when last monitor for value changes was triggered. \\
\hline
\end{tabular}




\begin{tabular}{|l|l|l|}
\hline \multicolumn{1}{|c|}{ Name } & \multicolumn{1}{|c|}{ Summary } & \multicolumn{1}{c|}{ Description } \\
\hline \hline SIMM & Simulation Mode & $\begin{array}{l}\text { Simulation mode process variables. Refer to Chapter 3, } \\
\text { Section "Simulation Mode" on page 11 for more } \\
\text { information. }\end{array}$ \\
\hline SIML & $\begin{array}{l}\text { Simulation Mode } \\
\text { Location }\end{array}$ & \\
\cline { 1 - 2 } SVAL & Simulation Value & \\
\cline { 1 - 2 } SIOL & $\begin{array}{l}\text { Simulation Value } \\
\text { Location }\end{array}$ & \\
\hline SIMS & $\begin{array}{l}\text { Simulation Mode } \\
\text { Alarm Severity }\end{array}$ & \\
\hline
\end{tabular}

\section{Record Support Routines}

\section{init_record}

process

get_value

get_enum_str

get_enum_strs

put_enum_str
This routine initializes SIMM with the value of SIML if SIML type is CONSTANT link or creates a channel access link if SIML type is PV_LINK. SVAL is likewise initialized if SIOL is CONSTANT or PV_LINK.

This routine next checks to see that device support is available and a device support read routine is defined. If either does not exist, an error message is issued and processing is terminated.

If device support includes init_record, it is called.

See next section.

Fills in the values of struct valueDes so that they refer to VAL.

Retrieves ASCII string corresponding to VAL.

Retrieves ASCII strings for ZNAM and ONAM.

Checks if string matches ZNAM or ONAM, and if it does, sets VAL.

\section{Record Processing}

Routine process implements the following algorithm: 
1. Check to see that the appropriate device support module exists. If it doesn't, an error message is issued and processing is terminated with the PACT field still set to TRUE. This ensures that processes will no longer be called for this record. Thus error storms will not occur.

2. readValue is called. See Chapter 3, Section "Simulation Mode" on page 11 for details.

3. If PACT has been changed to TRUE, the device support read routine has started but has not completed reading a new input value. In this case, the processing routine merely returns, leaving PACT TRUE.

4. Convert

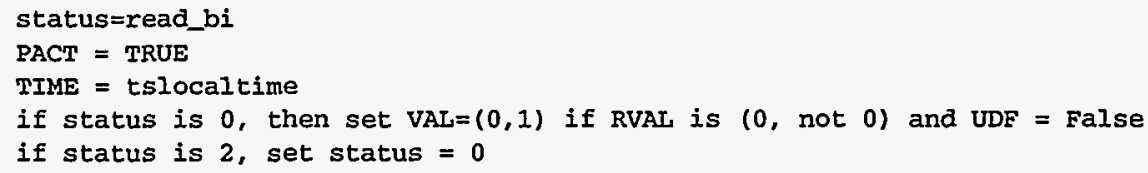

5. Check alarms: This routine checks to see if the new VAL causes the alarm status and severity to change. If So, NSEV and NSTA and LAIM are set. Note that if VAL is greater than 1 , no checking is performed.

6. Check to see if monitors should be invoked:

- Alarm monitors are invoked if the alarm status or severity has changed.

- Archive and value change monitors are invoked if MLST is not equal to VAL.

- Monitors for RVAL are checked whenever other monitors are invoked.

- NSEV and NSTA are reset to 0 .

7. Scan forward link if necessary, set PACT FALSE, and return.

\section{Device Support}

Fields Of Interest To Device Support
Each input record must have an associated set of device support routines. The primary responsibility of the device support routines is to obtain a new raw input value whenever read_bi is called. The device support routines are primarily interested in the following fields:

\begin{tabular}{|l|l|l|}
\hline \multicolumn{1}{|c|}{ Name } & \multicolumn{1}{|c|}{ Summary } & \multicolumn{1}{c|}{ Description } \\
\hline \hline PACT & Processing Active & $\begin{array}{l}\text { See Chapter 2, Section "Database Common: Field } \\
\text { Descriptions" on page 5 for descriptions. }\end{array}$ \\
\cline { 1 - 2 } DPVT & Device Private & \\
\cline { 1 - 2 } UDF & VAL Undefined & \\
\cline { 1 - 2 } NSEV & New Alarm Severity & \\
\hline NSTA & New Alarm Status & This field is set by a device support routines only if it \\
VAL & Value Field & $\begin{array}{l}\text { This field is used by the device support routines to locate } \\
\text { its input. }\end{array}$ \\
\hline INP & Input Link & $\begin{array}{l}\text { It is the responsibility of the device support routine to give } \\
\text { this field a value. }\end{array}$ \\
\hline RVAL & Raw Value &
\end{tabular}




\begin{tabular}{|l|l|l|}
\hline \multicolumn{1}{|c|}{ Name } & \multicolumn{1}{|c|}{ Summary } & \multicolumn{1}{c|}{ Description } \\
\hline \hline MASK & Hardware mask. & $\begin{array}{l}\text { The device support routine must give this field a value if it } \\
\text { needs to use it. }\end{array}$ \\
\hline
\end{tabular}

\section{Device Support routines}

report

init

init_record

get_ioint_info

read_bi report (FILE $f p, p a d d r)$

Not currently used.

init ()

This routine is called once during IOC initialization.

init_record (precord)

This routine is optional. If provided, it is called by the record support init_record routine.

get_ioint_info(int cmd,struct dbCommon *precord, IOSCANPVT *ppvt)

This routine is called by the ioEventScan system each time the record is added or deleted from an I/O event scan list. cma has the value $(0,1)$ if the record is being (added to, deleted from) an I/O event list. It must be provided for any device type that can use the ioEvent scanner.

read_bi (precord)

This routine must provide a new input value. It returns the following values:

- 0: Success. A new raw value is placed in RVAL. The record support module forces VAL to be $(0,1)$ if RVAL is $(0$, not 0$)$.

- 2: Success, but don't modify VaI.

- other: Error.

\section{Device Support For Soft Records}

Two soft device support modules Soft Channel and Raw Soft Channel are provided for input records not related to actual hardware devices. The INP link type must be either CONSTANT, DB_LINR, or CA_LINK.

\section{Soft Channel}

read_bi always returns a value of 2 , which means that no conversion is performed.

If the INP link type is constant, then the constant value is stored into VAL by init_record, and UDF is set to FALSE. VAL can be changed via dbPut requests. If the INP link type is PV_IINK, then dbCaAddInlink is called by init_record. 
read_bi calls recGblGetLinkValue to read the current value of vaL. See Chapter 3 , Section "Soft Input" on page 10 for details.

If the return status of recGblGetLinkValue is zero, then read_bi sets UDF to FALSE. The status of recGblGetLinkValue is returned.

Raw Soft

Channel
This module is like the previous except that values are read into RVAI. read_bi returns a value of 0 . Thus the record processing routine will force VAI to be 0 or 1 . 


\section{Chapter 7: bo - Binary Output}

\section{Introduction}

The normal use for this record type is to store a binary ( 0 or 1$)$ value to be sent to a Digital Output module. It can also be used to write binary values into other records via database or channel access links.

\section{Field Summary}

\begin{tabular}{|l|l|l|l|l|l|l|l|}
\hline \multicolumn{1}{|c|}{ Field } & \multicolumn{1}{|c|}{ Type } & \multicolumn{1}{c|}{ DCT } & \multicolumn{1}{c|}{ Initial } & Access & Modify & $\begin{array}{l}\text { Rec Proc } \\
\text { Monitor }\end{array}$ & \multicolumn{1}{c|}{ PP } \\
\hline \hline VAL & ENUM & No & 0 & Yes & Yes & Yes & Yes \\
\hline OMSL & GBLCHOICE & Yes & 0 & Yes & Yes & No & No \\
\hline OUT & OUTLINK & Yes & 0 & No & No & N/A & No \\
\hline DOL & INLINK & Yes & 0 & No & No & N/A & No \\
\hline HIGH & FLOAT & Yes & 0 & Yes & Yes & No & No \\
\hline ZNAM & STRING & Yes & Null & Yes & Yes & No & Yes \\
\hline ONAM & STRING & Yes & Null & Yes & Yes & No & Yes \\
\hline RVAL & ULONG & No & 0 & Yes & Yes & Yes & Yes \\
\hline ORAW & ULONG & No & 0 & Yes & No & No & No \\
\hline MASK & ULONG & No & compute & Yes & No & No & No \\
\hline
\end{tabular}




\begin{tabular}{|l|l|l|l|l|l|l|l|}
\hline \multicolumn{1}{|c|}{ Field } & \multicolumn{1}{|c|}{ Type } & DCT & \multicolumn{1}{c|}{ Initial } & Access & Modify & $\begin{array}{l}\text { RecProc } \\
\text { Monitor }\end{array}$ & \multicolumn{1}{c|}{ PP } \\
\hline \hline RPVT & NOACCESS & No & 0 & No & No & & No \\
\hline WDPT & NOACCESS & No & 0 & No & No & & No \\
\hline ZSV & GBLCHOICE & Yes & 0 & Yes & Yes & No & Yes \\
\hline OSV & GBLCHOICE & Yes & 0 & Yes & Yes & No & Yes \\
\hline COSV & GBLCHOICE & Yes & 0 & Yes & Yes & No & Yes \\
\hline RBV & ULONG & No & 0 & Yes & No & Yes & No \\
\hline ORBV & ULONG & No & 0 & Yes & No & No & No \\
\hline MLST & USHORT & No & 0 & Yes & No & No & No \\
\hline LALM & USHORT & No & 0 & Yes & No & No & No \\
\hline SIOL & INLINK & Yes & 0 & No & No & N/A & No \\
\hline SIML & INLINK & Yes & 0 & No & No & N/A & No \\
\hline SIMM & GBLCHOICE & No & 0 & Yes & Yes & No & No \\
\hline SIMS & GBLCHOICE & Yes & 0 & Yes & Yes & No & No \\
\hline IVOA & GBLCHOICE & Yes & 0 & Yes & Yes & No & No \\
\hline IVOV & USHORT & Yes & 0 & Yes & Yes & No & No \\
\hline
\end{tabular}

\section{Field Descriptions}

\begin{tabular}{|l|l|l|}
\hline \multicolumn{1}{|c|}{ Name } & \multicolumn{1}{|c|}{ Summary } & \multicolumn{1}{c|}{ Description } \\
\hline \hline VAL & Value Field & $\begin{array}{l}\text { This is the value to be sent to OUT. It is either obtained } \\
\text { from DOL or else given a value via dbPuts. }\end{array}$ \\
\hline OMSL & Output Mode Select & $\begin{array}{l}\text { This field has either the value SUPERVISORY or } \\
\text { CLOSED_LOOP. DOL is used to determine VAL only if } \\
\text { OMSL has the value CLOSED_LOOR. By setting this field } \\
\text { the record can be switched between supervisory and } \\
\text { closed loop mode of operation. While in closed loop } \\
\text { mode, the VAL field cannot be set via dbPuts. }\end{array}$ \\
\hline DOL & $\begin{array}{l}\text { Desired Output } \\
\text { Location Input }\end{array}$ & $\begin{array}{l}\text { If DOL is a database or channel access link and OMSL is } \\
\text { CLOSED_LOOP, then VAL is read from DOL. }\end{array}$ \\
\hline OUT & Output Link & $\begin{array}{l}\text { This field is used by the device support routines to decide } \\
\text { where to send output. For soft records, it can be a } \\
\text { constant, a database link, or a channel access link. If the } \\
\text { link is a constant, the result is no output. }\end{array}$ \\
\hline HIGH & $\begin{array}{l}\text { Seconds to Hold } \\
\text { High }\end{array}$ & $\begin{array}{l}\text { If this value is greater than zero, then whenever VAL is set } \\
\text { equal to 1, it is reset to zero after HIGH seconds. }\end{array}$ \\
\hline
\end{tabular}




\begin{tabular}{|c|c|c|}
\hline Name & Summary & Description \\
\hline ZNAM & Zero Name & ASCII string defining state zero. \\
\hline ONAM & One Name & ASCII string defining state one. \\
\hline RVAL & Raw Data Value & $\begin{array}{l}\text { RVAL is the value written by the device support routine. If } \\
\text { MASK is set by the device support routine, RVAL is } \\
\text { computed by record support. }\end{array}$ \\
\hline ORAW & $\begin{array}{l}\text { Old Raw Data } \\
\text { Value }\end{array}$ & $\begin{array}{l}\text { ORAW is used to decide if monitors should be triggered for } \\
\text { RVAL at the same time monitors are triggered for changes } \\
\text { in VAL. }\end{array}$ \\
\hline MASK & Hardware Mask & $\begin{array}{l}\text { This value can be set by the device support routine. It is } \\
\text { the value sent to the hardware when VAL is not zero. }\end{array}$ \\
\hline RPVT & Record Private & \\
\hline WDPT & Watchdog Pointer & Private field for honoring second to hold HIGH. \\
\hline ZSV & Zero Severity & Alarm Severity for state zero. \\
\hline OSV & One Severity & Alarm Severity for state one. \\
\hline COSV & $\begin{array}{l}\text { Change of State } \\
\text { Severity }\end{array}$ & Alarm Severity for change of state. \\
\hline RBV & Read Back Value & $\begin{array}{l}\text { This is the actual read back value obtained from the } \\
\text { hardware itself or from the associated device driver. It is } \\
\text { the responsibility of the device support routine to give this } \\
\text { field a value. }\end{array}$ \\
\hline ORBV & $\begin{array}{l}\text { Old Read Back } \\
\text { Value }\end{array}$ & $\begin{array}{l}\text { ORBV is used to decide if monitors should be triggered for } \\
\text { RBV at the same time monitors are triggered for changes } \\
\text { in VAL. }\end{array}$ \\
\hline MLST & Monitor Last & Value when last monitor for value changes was triggered \\
\hline LALM & Last Alarmed & Value when last change of state alarm was issued. \\
\hline SIMM & Simulation Mode & \multirow{4}{*}{$\begin{array}{l}\text { Simulation mode process variables. Refer to Chapter } 3 \text {, } \\
\text { Section "Simulation Mode" on page } 13 \text { for more } \\
\text { information. }\end{array}$} \\
\hline SIML & $\begin{array}{l}\text { Simulation Mode } \\
\text { Location }\end{array}$ & \\
\hline SIOL & $\begin{array}{l}\text { Simulation Value } \\
\text { Location }\end{array}$ & \\
\hline SIMS & $\begin{array}{l}\text { Simulation Mode } \\
\text { Alarm Severity }\end{array}$ & \\
\hline IVOA & $\begin{array}{l}\text { Invalid Alarm } \\
\text { Output Action }\end{array}$ & \multirow{2}{*}{$\begin{array}{l}\text { Whenever the record is put into INVALID alarm severity } \\
\text { IVOA specifies an action. See Chapter } 3 \text {, Section "Invalid } \\
\text { Alarm Output Action" on page } 14 \text { for more information. }\end{array}$} \\
\hline IVOV & $\begin{array}{l}\text { Invalid Alarm } \\
\text { Output Value }\end{array}$ & \\
\hline
\end{tabular}

\section{Record Support Routines}




\section{init_record}

get_value

get_enum_str

get_enum_strs

put_enum_str

See next section.

Fills in the values of struct valueDes so that they refer to VAL.

This routine initializes SIMM if SIML is a constant or creates a channel access link if SIMU is PV_LINK. If SIOL is PV_LINK a channel access link is created.

This routine next checks to see that device support is available. The routine next checks to see if the device support write routine is defined. If either device support or the device support write routine does not exist, an error message is issued and processing is terminated.

If DOL is a constant, then VAL is initialized to 1 if its value is nonzero or initialized to 0 if DOL is zero, and UDF is set to FALSE.

If device support includes init_record, it is called. VAL is set using RVAL, and UDF is set to FALSE.

Retrieves ASCII string corresponding to VAL.

Retrieves ASCII strings for ZNAM and ONAM.

Checks if string matches ZNAM or ONAM, and if it does, sets VAL.

\section{Record Processing}

Routine process implements the following algorithm:

1. Check to see that the appropriate device support module exists. If it doesn't, an error message is issued and processing is terminated with the PACT field still set to TRUE. This ensures that processes will no longer be called for this record. Thus error storms will not occur.

2. If PACT is FALSE

- if DOL is DB_LINK and OMSL is CLOSED_LOOP

- get value from DOL

- check for link alarm

- force val to be 0 or 1

- if Mask is defined

- if VAL is 0 set RVAT $=0$

- else set RVAL = MASK

3. Check alarms: This routine checks to see if the new VA工 causes the alarm status and severity to change. If so, NSEV, NSTA and LALM are set.

4. Check severity and write the new value. See Chapter 3, Section "Invalid Alarm Output Action" on page 14 for details. 
5. If PACT has been changed to TRUE, the device support write output routine has started but has not completed writing the new value. In this case, the processing routine merely returns, leaving PACT TRUE.

6. Check WAIT. If VAL is 1 and WAIT is greater than 0 , process again with a VAL $=0$ after WAIT seconds.

7. Check to see if monitors should be invoked.

- Alarm monitors are invoked if the alarm status or severity has changed.

- Archive and value change monitors are invoked if MLST is not equal to VAL.

- Monitors for RVAI and for RBV are checked whenever other monitors are invoked.

- NSEV and NSTA are reset to 0 .

8. Scan forward link if necessary, set PACT FALSE, and return.

\section{Device Support}

\section{Fields Of Interest}

\section{To Device}

Support
Each binary output record must have an associated set of device support routines. The primary responsibility of the device support routines is to write a new value whenever write_bo is called. The device support routines are primarily interested in the following fields:

\begin{tabular}{|c|c|c|}
\hline Name & Summary & Description \\
\hline PACT & Processing Active & \multirow{4}{*}{$\begin{array}{l}\text { See Chapter 2, Section "Database Common: Field } \\
\text { Descriptions" on page } 5 \text { for descriptions. }\end{array}$} \\
\hline DPVT & Device Private & \\
\hline NSEV & New Alarm Severity & \\
\hline NSTA & New Alarm Status & \\
\hline VAL & Value Field & $\begin{array}{l}\text { This field is only of interest to device support routines that } \\
\text { do not use MASK and RVAL. }\end{array}$ \\
\hline OUT & Output Link & $\begin{array}{l}\text { This field is used by the device support routines to locate } \\
\text { its output. }\end{array}$ \\
\hline RVAL & Raw Data Value & $\begin{array}{l}\text { If MASK is defined then record support sets } \\
\text { RVAL }=(0, \text { MASK) if VAL is }(0, \text { not zero). }\end{array}$ \\
\hline MASK & Hardware mask. & $\begin{array}{l}\text { The device support module must set this field. Not that if } \\
\text { VAL is } 1 \text {, then record processing sets RVAI = MASK. }\end{array}$ \\
\hline RBV & Read Back Value & $\begin{array}{l}\text { This is the actual read back value obtained from the } \\
\text { hardware itself or from the associated device driver. It is } \\
\text { the responsibility of the device support routine to give this } \\
\text { field a value. }\end{array}$ \\
\hline
\end{tabular}

Device Support Device support consists of the following routines: routines 
report

init

init_record

get_ioint_info

write_bo report (FILE fp, padar)

Not currently used.

$$
\text { init() }
$$

This routine is called once during IOC initialization.

$$
\text { init_record (precord) }
$$

This routine is optional. If provided, it is called by the record support init_record routine. It should determine MASK if it is needed.

get_ioint_info(int cmd, struct dbCommon *precord, IOSCANPVT *ppvt)

This routine is called by the ioEventScan system each time the record is added or deleted from an I/O event scan list. cma has the value $(0,1)$ if the record is being (added to, deleted from) an I/O event list. It must be provided for any device type that can use the ioEvent scanner.

write_bo (precord)

This routine must output an new value. It returns the following values:

- 0: Success.

- other: Error.

\section{Device Support For Soft Records}

Two soft device support modules Soft Channel and Raw Soft Channel are provided for output records not related to actual hardware devices. The OUT link type must be either a CONSTANT, DB_LINK, or CA_LINK.

This module writes the current value of VAL.

If the ouT link type is PV_LINK, then dbcaAddInlink is called by init_.record. init_record always returns a value of 2 , which means that no conversion will ever be attempted.

write_bo calls recGb1PutLinkValue to write the current value of VAL. See Chapter 3, Section "Soft Output" on page 13 for details.

Raw Soft

This module is like the previous except that it writes the current value of RVAL.

\section{Channel}




\section{Chapter 8: calc-Calculation}

\section{Introduction}

This record calculates an expression.

2. Field Summary

\begin{tabular}{|l|l|l|l|l|l|l|l|}
\hline \multicolumn{1}{|c|}{ Field } & \multicolumn{1}{|c|}{ Type } & DCT & Initial & Access & Modify & $\begin{array}{l}\text { RecProc } \\
\text { Monitor }\end{array}$ & \multicolumn{1}{c|}{ PP } \\
\hline \hline VAL & DOUBLE & No & 0 & Yes & Yes & Yes & No \\
\hline CALC & STRING & Yes & Null & Yes & Yes & Yes & Yes \\
\hline INPA & INLINK & Yes & 0 & No & No & N/A & No \\
\hline INPB & INLINK & Yes & 0 & No & No & N/A & No \\
\hline INPC & INLINK & Yes & 0 & No & No & N/A & No \\
\hline INPD & INLINK & Yes & 0 & No & No & N/A & No \\
\hline INPE & INLINK & Yes & 0 & No & No & N/A & No \\
\hline INPF & INLINK & Yes & 0 & No & No & N/A & No \\
\hline INPG & INLINK & Yes & 0 & No & No & N/A & No \\
\hline INPH & INLINK & Yes & 0 & No & No & N/A & No \\
\hline INPI & INLINK & Yes & 0 & No & No & N/A & No \\
\hline INPJ & INLINK & Yes & 0 & No & No & N/A & No \\
\hline
\end{tabular}




\begin{tabular}{|c|c|c|c|c|c|c|c|}
\hline Field & Type & DCT & Initial & Access & Modify & $\begin{array}{l}\text { Rec Proc } \\
\text { Monitor }\end{array}$ & PP \\
\hline INPK & INLINK & Yes & 0 & No & No & N/A & No \\
\hline INPL & INLINK & Yes & 0 & No & No & N/A & No \\
\hline A & DOUBLE & No & 0 & Yes & Yes/No & Yes & Yes \\
\hline B & DOUBLE & No & 0 & Yes & Yes/No & Yes & Yes \\
\hline $\mathrm{C}$ & DOUBLE & No & 0 & Yes & Yes/No & Yes & Yes \\
\hline D & DOUBLE & No & 0 & Yes & Yes/No & Yes & Yes \\
\hline $\mathrm{E}$ & DOUBLE & No & 0 & Yes & Yes/No & Yes & Yes \\
\hline F & DOUBLE & No & 0 & Yes & Yes/No & Yes & Yes \\
\hline G & DOUBLE & No & 0 & Yes & Yes/No & Yes & Yes \\
\hline $\mathrm{H}$ & DOUBLE & No & 0 & Yes & Yes/No & Yes & Yes \\
\hline I & DOUBLE & No & 0 & Yes & Yes/No & Yes & Yes \\
\hline $\mathrm{J}$ & DOUBLE & No & 0 & Yes & Yes/No & Yes & Yes \\
\hline K & DOUBLE & No & 0 & Yes & Yes/No & Yes & Yes \\
\hline $\mathrm{L}$ & DOUBLE & No & 0 & Yes & Yes/No & Yes & Yes \\
\hline LA & DOUBLE & No & 0 & Yes & No & No & No \\
\hline LB & DOUBLE & No & 0 & Yes & No & No & No \\
\hline LC & DOUBLE & No & 0 & Yes & No & No & No \\
\hline LD & DOUBLE & No & 0 & Yes & No & No & No \\
\hline LE & DOUBLE & No & 0 & Yes & No & No & No \\
\hline LF & DOUBLE & No & 0 & Yes & No & No & No \\
\hline LG & DOUBLE & No & 0 & Yes & No & No & No \\
\hline LH & DOUBLE & No & 0 & Yes & No & No & No \\
\hline LI & DOUBLE & No & 0 & Yes & No & No & No \\
\hline LJ & DOUBLE & No & 0 & Yes & No & No & No \\
\hline LK & DOUBLE & No & 0 & Yes & No & No & No \\
\hline LL & DOUBLE & No & 0 & Yes & No & No & No \\
\hline EGU & STRING & Yes & Null & Yes & Yes & No & No \\
\hline PREC & SHORT & Yes & 0 & Yes & Yes & No & No \\
\hline HOPR & FLÖAT & Yes & 0 & Yes & Yes & No & No \\
\hline LOPR & FLOAT & Yes & 0 & Yes & Yes & No & No \\
\hline HIHI & FLOAT & Yes & 0 & Yes & Yes & No & Yes \\
\hline LOLO & FLOAT & Yes & 0 & Yes & Yes & No & Yes \\
\hline
\end{tabular}




\begin{tabular}{|l|l|l|l|l|l|l|l|}
\hline \multicolumn{1}{|c|}{ Field } & \multicolumn{1}{|c|}{ Type } & DCT & Initial & Access & Modify & $\begin{array}{l}\text { Rec Proc } \\
\text { Monitor }\end{array}$ & \multicolumn{1}{c|}{ PP } \\
\hline \hline HIGH & FLOAT & Yes & 0 & Yes & Yes & No & Yes \\
\hline LOW & FLOAT & Yes & 0 & Yes & Yes & No & Yes \\
\hline HHSV & GBLCHOICE & Yes & 0 & Yes & Yes & No & Yes \\
\hline LLSV & GBLCHOICE & Yes & 0 & Yes & Yes & No & Yes \\
\hline HSV & GBLCHOICE & Yes & 0 & Yes & Yes & No & Yes \\
\hline LSV & GBLCHOICE & Yes & 0 & Yes & Yes & No & Yes \\
\hline HYST & DOUBLE & Yes & 0 & Yes & Yes & No & No \\
\hline ADEL & DOUBLE & Yes & 0 & Yes & Yes & No & No \\
\hline MDEL & DOUBLE & Yes & 0 & Yes & Yes & No & No \\
\hline LALM & DOUBLE & No & 0 & Yes & No & No & No \\
\hline ALST & DOUBLE & No & 0 & Yes & No & No & No \\
\hline MLST & DOUBLE & No & 0 & Yes & No & No & No \\
\hline RPCL & NOACCESS & No & 0 & No & No & & No \\
\hline
\end{tabular}

3. Field Descriptions

\begin{tabular}{|l|l|l|}
\hline \multicolumn{1}{|c|}{ Name } & \multicolumn{1}{|c|}{ Summary } & \multicolumn{1}{c|}{ Description } \\
\hline \hline VAL & Value Field & $\begin{array}{l}\text { This field is calculated, via the CALC expression, each } \\
\text { time the record is processed. }\end{array}$ \\
\hline CALC & Infix Expression & See below for details \\
\hline INPA,...,INPL & Input Links & $\begin{array}{l}\text { Each may be a constant, a database link, or a channel } \\
\text { access link. Any link not defined is ignored. }\end{array}$ \\
\hline A,...,L & Input Values & $\begin{array}{l}\text { If the corresponding INP field is a constant, this field is } \\
\text { initialized with the constant value but can be changed via } \\
\text { dbPuts. }\end{array}$ \\
\hline LA,...,LL & Previous Input & $\begin{array}{l}\text { These fields are used to decide when to trigger monitors } \\
\text { on A,...,L. }\end{array}$ \\
\hline EGU & Engineering Units & $\begin{array}{l}\text { A 16 character ASCII string describing Engineering units. } \\
\text { This field is used by record support to supply a units } \\
\text { description string when get_units is called. }\end{array}$ \\
\hline PREC & Display Precision & $\begin{array}{l}\text { Precision with which to display vAL. This field is used by } \\
\text { record support to supply a value when get_precision } \\
\text { is called. }\end{array}$ \\
\hline
\end{tabular}




\begin{tabular}{|c|c|c|}
\hline Name & Summary & Description \\
\hline HOPR & $\begin{array}{l}\text { High Operating } \\
\text { Range }\end{array}$ & \multirow{2}{*}{$\begin{array}{l}\text { These fields determine the upper and lower display limits } \\
\text { for graphics displays and the upper and lower control } \\
\text { limits for control displays. The fields are used by record } \\
\text { support to honor calls to get_graphic_double or } \\
\text { get_control_double. }\end{array}$} \\
\hline LOPR & $\begin{array}{l}\text { Low Operating } \\
\text { Range }\end{array}$ & \\
\hline HIHI & Hihi Alarm Limit & \multirow[t]{8}{*}{ These fields specify the alarm limits and severities. } \\
\hline HIGH & High Alarm Limit & \\
\hline LOW & Low Alarm Limit & \\
\hline LOLO & Lolo Alarm Limit & \\
\hline HHSV & $\begin{array}{l}\text { Severity for a Hihi } \\
\text { Alarm }\end{array}$ & \\
\hline HSV & $\begin{array}{l}\text { Severity for a High } \\
\text { Alarm }\end{array}$ & \\
\hline LSV & $\begin{array}{l}\text { Severity for a Low } \\
\text { Alarm }\end{array}$ & \\
\hline LLSV & $\begin{array}{l}\text { Severity for a Lolo } \\
\text { Alarm }\end{array}$ & \\
\hline HYST & Alarm Deadband & \multirow{3}{*}{$\begin{array}{l}\text { These parameters specify hysteresis factors for triggering } \\
\text { monitor callbacks, i.e. monitors specified by calls to } \\
\text { caAddEvent or dbAddEvent. A monitor will not be } \\
\text { triggered until VAL changes by more than the specified } \\
\text { amount. }\end{array}$} \\
\hline ADEL & Archive Deadband & \\
\hline MDEL & $\begin{array}{l}\text { Monitor, i.e. value } \\
\text { change, Deadband }\end{array}$ & \\
\hline LALM & $\begin{array}{l}\text { Last Alarmed } \\
\text { Value }\end{array}$ & \multirow[t]{3}{*}{$\begin{array}{l}\text { Values when monitors were last triggered. These fields } \\
\text { are used to implement the hysteresis factors for monitors. }\end{array}$} \\
\hline ALST & Archive Last Value & \\
\hline MLST & Monitor Last Value & \\
\hline RPCL & $\begin{array}{l}\text { Expression in } \\
\text { reverse polish }\end{array}$ & \\
\hline
\end{tabular}

\section{Record Support Routines}

init_record

For each constant input link, the corresponding value field is initialized with the constant value if the input link is CONSTANT or a channel access link is created if the input link is PV_LINK.

A routine postfix is called to convert the infix expression in CALC to reverse polish notation. The result is stored in RPCL. 
special

get_value

get_units

get_precision

get_graphic_double

get_control_double

get_alarm_double
This is called if CALC is changed. special calls postfix.

Fills in the values of struct valueDes so that they refer to VAL.

Retrieves EGU.

Retrieves PREC.

Sets the upper display and lower display limits for a field. If the field is VAL, HIHI, HIGH, LOW, or LOLO, the limits are set to HOPR and LOPR, else if the field has upper and lower limits defined they will be used, else the upper and lower maximum values for the field type will be used.

Sets the upper control and the lower control limits for a field. If the field is VAI, HIHI, HIGH, LOW, or LOLO, the limits are set to HOPR and LOPR, else if the field has upper and lower limits defined they will be used, else the upper and lower maximum values for the field type will be used.

Sets the following values:

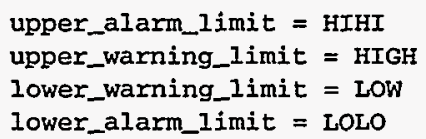

\section{Record Processing}

Routine process implements the following algorithm:

1. Fetch all arguments.

2. Call routine calcPerform, which calculates VAL from the postfix version of the expression given in CALC. If calcPerform returns success UDF is set to FALSE.

3. Check alarms. This routine checks to see if the new vaI causes the alarm status and severity to change. If So, NSEV, NSTA and LALM are set. It also honors the alarm hysteresis factor (HYST). Thus the value must change by at least HYST before the alarm status and severity changes.

4. Check to see if monitors should be invoked.

- Alarm monitors are invoked if the alarm status or severity has changed.

- Archive and value change monitors are invoked if $\mathrm{ADEL}$ and MDEL conditions are met.

- Monitors for A-L are checked whenever other monitors are invoked.

- NSEV and NSTA are reset to 0 .

5. Scan forward link if necessary, set PACT FALSE, and return. 


\section{Allowed Expressions}

The calculation can express algebraic, relational, and logical expressions. The expression is converted to opcode and stored as reverse polish notation in the calculation record. The database fields are as follows:

- CALC: infix expression as entered

- RPCL: reverse polish expression

The reverse polish calculation is most efficient to evaluate during run-time. The range of expressions supported by the calculation record are separated into operands, algebraic operations, trigonometric, relational operations, logical operations, parenthesis, and the question mark operator.

\section{Operands}

- A: Use the value specified by input A

- B: Use the value specified by input $B$

- C: Use the value specified by input $C$

- D: Use the value specified by input D

- E: Use the value specified by input $E$

- F: Use the value specified by input $F$

- G: Use the value specified by input $G$

- H: Use the value specified by input $\mathrm{H}$

- I: Use the value specified by input I

- J: Use the value specified by input $\mathbf{J}$

- $\mathrm{K}$ : Use the value specified by input $\mathrm{K}$

- L: Use the value specified by input $\mathrm{L}$

- RNDM: Random number (unary), random number between 0-1

\section{Algebraic \\ Operators}

- ABS: Absolute value (unary)

- SQR: Square root (unary)

- MIN: Minimum (binary function)

- MAX: Maximum (binary function)

- CEIL: Ceiling (unary)

- FLOOR: Floor (unary)

- LOG: Log base 10 (unary)

- LOGE: Natural log (unary)

- EXP: Exponential function (unary)

- $\wedge$ : Exponential (binary)

-**: Exponential (binary)

++ Addition (binary)

- . : Subtraction (binary)

-*: Multiplication (binary)

- /: Division (binary)

- \% : Modulo (binary)

- NOT: Negate (unary) 


\section{Trigonometric \\ Operators}

- SIN: Sine

- SINH: Hyperbolic sine

- ASIN: Arc sine

- COS: Cosine

- COSH: Hyperbolic cosine

- ACOS: Arc cosine

- TAN: Tangent

- TANH: Hyperbolic tangent

- ATAN: Arc tangent

Relational

Operators

Logical
Operators

Bitwise

Operators
- >= : Greater than or equal to

- > : Greater than

- $<=$ : Less than or equal to

- <: Less than

- \# : Not equal to

- = : Equal to

- \&\&: And

- II: Or

- !: Not

- 1: Bitwise Or

- \& : Bitwise And

- OR : Bitwise Or

- AND: Bitwise And

- XOR: Bitwise Exclusive Or

- : One's Complement

- $\ll$ : Left shift

- > : Right shift
Parenthesis and Comma

Conditional

Expression
The open and close parenthesis are supported. Nested parenthesis are supported.

The comma is supported when used to separate the arguments of a binary function.

The "C" question mark operator is supported. The format is:

(condition)? True result : False result 


\section{Example Expressions}

Algebraic $\quad A+B$

- Result is $A+B$

Relational $(\mathrm{A}+\mathrm{B})<(\mathrm{C}+\mathrm{D})$

- Result is 1 if $(A+B)<(C+D)$

- Result is 0 if $(A+B)>=(C+D)$

Question Mark $\quad(\mathrm{A}+\mathrm{B})<(\mathrm{C}+\mathrm{D})$ ? $\mathrm{E}$ : $\mathrm{F}$

- Result is $E$ if $(A+B)<(C+D)$

- Result is $F$ if $(A+B)>=(C+D)$

$(\mathrm{A}+\mathrm{B})<(\mathrm{C}+\mathrm{D})$ ? $\mathrm{E}$

- Result is $E$ if $(A+B)<(C+D)$

- Result is unchanged if $(A+B)>=(C+D)$

Logical A\&B

- Causes the following to occur:

- Convert A to integer

- Convert B to integer

- Bit-wise And A and B

- Convert result to floating point 


\section{Chapter 9: compress - Compression}

\section{Introduction}

The VAr field of this record refers to an array of length NSAM. Unless INP is a database link, the compression algorithm is ignored. If, however, INP is a database link, then this record type supports several algorithms: CIRBUF, AVERAGE, NTO1LOW, NTO1HIGH, and NTO1AVE. Each will be discussed separately.

CIRBUF keeps a circular buffer of length NSAM. Each time the record is processed, it gets the data referenced by INP and puts it into the circular buffer referenced by VAL. Note that when INP refers to a scalar, VAL is just a time ordered circular buffer of values obtained from INP.

If AVERAGE is chosen, then VAL refers to an array of length NSAM that contains an element by element time average of values taken from the array referenced by INP. N successive samples of INP are averaged in order to compute VAL.

If NTOILOW, NTO1HIGH, or NTO1AVE are chosen, then VAL is a circular buffer of length NSAM. The actual algorithm depends on whether INP references a scalar or an array. If INP refers to a scalar, then N successive time ordered samples of INP are taken. After the Nth sample is obtained a new value, determined by the algorithm (LOW, HIGH, or AVE), is written to the circular buffer referenced by VAL. If INP refers to an array, then each time the record is processed, the array referenced by INP is obtained, divided into sub-arrays each of length $\mathrm{N}$, and the algorithm applied to each sub-array. The result obtained from each subarray is written to the circular buffer referenced by VAL. 


\section{Field Summary}

\begin{tabular}{|l|l|l|l|l|l|l|l|}
\hline \multicolumn{1}{|c|}{ Field } & \multicolumn{1}{|c|}{ Type } & DCT & \multicolumn{1}{c|}{ Initial } & Access & Modify & $\begin{array}{l}\text { Rec Proc } \\
\text { Monitor }\end{array}$ & \multicolumn{1}{c|}{ PP } \\
\hline \hline VAL & DOUBLE & No & 0 & Yes & Yes & Yes & Yes \\
\hline INP & INLINK & Yes & 0 & No & No & N/A & No \\
\hline RES & SHORT & No & 0 & Yes & Yes & No & No \\
\hline ALG & RECCHOICE & Yes & 0 & Yes & No & No & No \\
\hline NSAM & ULONG & Yes & 1 & Yes & No & No & No \\
\hline N & ULONG & Yes & 1 & Yes & No & No & No \\
\hline ILIL & FLOAT & Yes & 0 & Yes & Yes & No & No \\
\hline IHIL & FLOAT & Yes & 0 & Yes & Yes & No & No \\
\hline HOPR & FLOAT & Yes & 0 & Yes & Yes & No & No \\
\hline LOPR & FLOAT & Yes & 0 & Yes & Yes & No & No \\
\hline PREC & SHORT & Yes & 0 & Yes & Yes & No & No \\
\hline EGU & STRING & Yes & null & Yes & Yes & No & No \\
\hline OFF & ULONG & No & 0 & Yes & No & No & No \\
\hline NUSE & ULONG & No & 0 & Yes & No & No & No \\
\hline BPTR & NOACCESS & No & 0 & No & No & & No \\
\hline SPTR & NOACCESS & No & 0 & No & No & & No \\
\hline WPTR & NOACCESS & No & 0 & No & No & & No \\
\hline CVB & DOUBLE & No & 0 & Yes & No & No & No \\
\hline INX & ULONG & No & 0 & Yes & No & No & No \\
\hline
\end{tabular}

\section{Field Descriptions}

\begin{tabular}{|l|l|l|}
\hline \multicolumn{1}{|c|}{ Name } & \multicolumn{1}{c|}{ Summary } & \multicolumn{1}{c|}{ Description } \\
\hline \hline VAL & Value Field & $\begin{array}{l}\text { This field is determined as a result of record processing. It } \\
\text { is a double precision array of length NSAM. }\end{array}$ \\
\hline INP & Input Link & $\begin{array}{l}\text { INP can be a constant, a database link, or a channel access } \\
\text { link. Unless it is a database link, ALG is meaningless. }\end{array}$ \\
\hline RES & Reset & $\begin{array}{l}\text { Setting this field causes the algorithm to start over from } \\
\text { the beginning. }\end{array}$ \\
\hline ALG & Algorithm & $\begin{array}{l}\text { CIRBUF, AVERAGE, NTO1LOW, NTO1HIGH, or } \\
\text { NTO1AVE. }\end{array}$ \\
\hline
\end{tabular}




\begin{tabular}{|c|c|c|}
\hline Name & Summary & Description \\
\hline NSAM & Number in Sample & Number of elements in VAL. \\
\hline $\mathrm{N}$ & Number & Value of $\mathrm{N}$ for AVERAGE and NTO1 $\times x \times$ algorithms. \\
\hline ILIL & $\begin{array}{l}\text { Initial Low } \\
\text { Interest Value }\end{array}$ & \multirow[t]{2}{*}{ Applies to NTO1xxx applied to INP arrays. } \\
\hline IHIL & $\begin{array}{l}\text { Initial High Interest } \\
\text { Value }\end{array}$ & \\
\hline HOPR & $\begin{array}{l}\text { High Operating } \\
\text { Range }\end{array}$ & \multirow{2}{*}{$\begin{array}{l}\text { These fields determine the upper and lower display limits } \\
\text { for graphics displays and the upper and lower control } \\
\text { limits for control displays. The fields are used by record } \\
\text { support to honor calls to get_graphic_double or } \\
\text { get_control_double. }\end{array}$} \\
\hline LOPR & $\begin{array}{l}\text { Low Operating } \\
\text { Range }\end{array}$ & \\
\hline PREC & Display Precision & $\begin{array}{l}\text { Precision with which to display VAL. This field is used by } \\
\text { record support to supply a value when get_precision } \\
\text { is called. }\end{array}$ \\
\hline EGU & Engineering Units & $\begin{array}{l}\text { ASCII string describing Engineering units. This field is } \\
\text { used by record support to supply a units description string } \\
\text { when get_units is called. }\end{array}$ \\
\hline OFF & Current Offset & \\
\hline NUSE & Number Used & Number of elements currently stored. \\
\hline BPTR & Buffer Pointer & Holds array referenced by VAI \\
\hline SPTR & $\begin{array}{l}\text { Summing Buffer } \\
\text { Pointer }\end{array}$ & For array averages. \\
\hline WPTR & $\begin{array}{l}\text { Work Buffer } \\
\text { Pointer }\end{array}$ & For dbGetLinks. \\
\hline CVB & $\begin{array}{l}\text { Compress Value } \\
\text { Buffer }\end{array}$ & \\
\hline INX & $\begin{array}{l}\text { Current Index of } \\
1, \ldots, N\end{array}$ & \\
\hline
\end{tabular}

\section{Record Support Routines}

init_record

process

special
Space for all necessary arrays is allocated. The addresses are stored in the appropriate fields in the record.

See next section.

This routine is called when RSET is set. It performs a reset. 


\section{get_value}

cvt_dbaddr

get_array_info

put_array_info

get_units

get_precision

get_graphic_double

get_control_double
Fills in the values of struct valueDes so that they refer to VAL.

This is called by dbNameToAddr. It makes the dbAddr structure refer to the actual buffer holding the result.

Obtains values from the circular buffer referenced by vas.

Writes values into the circular buffer referenced by VAL.

Retrieves EGU.

Retrieves PREC.

Sets the upper display and lower display limits for a field. If the field is VAL, HIHI, HIGH, LOW, or LOLO, the limits are set to HOPR and LOPR, else if the field has upper and lower limits defined they will be used, else the upper and lower maximum values for the field type will be used.

Sets the upper control and the lower control limits for a field. If the field is VAL, HIHI, HIGH, LOW, or LOLO, the limits are set to HOPR and LOPR, else if the field has upper and lower limits defined they will be used, else the upper and lower maximum values for the field type will be used.

\section{Record Processing}

Routine process implements the following algorithm:

1. If INP is not a database link, check monitors and the forward link and return.

2. Get the current data referenced by INP.

3. Perform the appropriate algorithm:

a. AVERAGE: Read N successive instances of INP and perform an element by element average. Until $\mathrm{N}$ instances have been obtained it just return without checking monitors or the forward link. When $\mathrm{N}$ instances have been obtained complete the algorithm, store the result in the VAL array, check monitors and the forward link, and return.

b. CIRBUF: Write the values obtained from INP into the VAI array as a circular buffer, check monitors and the forward link, and return.

c. NTO1 $x \times x$ and INP refers to a scalar: Obtain $N$ successive values from INP and apply the NTO1 $\times \mathrm{XXX}$ algorithm to these values. Until $\mathrm{N}$ values are obtained monitors and forward links are not checked. When $N$ successive values have been obtained, complete the algorithm, check monitors and the forward link, and return. 
d. NTO1xxx and INP refers to an array: The ILIL and IHIL are honored if ILIL<IHIL. The input array is divided into subarrays of length $\mathrm{N}$. The specified NTO1 $\times x \times$ compression algorithm is applied to each subarray and the result stored in the array referenced by VAL. The monitors and forward link are checked.

4. If success, set UDF to FALSE.

5. Check to see if monitors should be invoked:

- Alarm monitors are invoked if the alarm status or severity has changed.

- NSEV and NSTA are reset to 0.

6. Scan forward link if necessary, set PACT FALSE, and return. 
Chapter 9: compress - Compression

Record Processing 


\section{Chapter 10: dfanout}

Johnny Tang, Matthew Bickley, and Chip Watson

Continuous Electron Beam Accelerator Facility

Southeastern Universities Research Association

\section{Introduction}

This record is used to forward data to up to eight other records. It has no associated device support.

2. Field Summary

\begin{tabular}{|l|l|l|l|l|l|l|l|}
\hline \multicolumn{1}{|c|}{ Field } & \multicolumn{1}{|c|}{ Type } & DCT & Initial & Access & Modify & $\begin{array}{l}\text { Rec Proc } \\
\text { Monitor }\end{array}$ & \multicolumn{1}{|c|}{ PP } \\
\hline \hline VAL & LONG & No & 0 & Yes & Yes & No & Yes \\
\hline OUTA & OUTLINK & Yes & 0 & No & No & N/A & No \\
\hline OUTB & OUTLINK & Yes & 0 & No & No & N/A & No \\
\hline OUTC & OUTLINK & Yes & 0 & No & No & N/A & No \\
\hline OUTD & OUTLINK & Yes & 0 & No & No & N/A & No \\
\hline OUTE & OUTLINK & Yes & 0 & No & No & N/A & No \\
\hline OUTF & OUTLINK & Yes & 0 & No & No & N/A & No \\
\hline OUTG & OUTLINK & Yes & 0 & No & No & N/A & No \\
\hline OUTH & OUTLINK & Yes & 0 & No & No & N/A & No \\
\hline DOL & INLINK & Yes & 0 & No & No & N/A & No \\
\hline OMSL & GBLCHOICE & Yes & 0 & Yes & Yes & No & No \\
\hline
\end{tabular}




\begin{tabular}{|l|l|l|l|l|l|l|l|}
\hline \multicolumn{1}{|c|}{ Field } & \multicolumn{1}{|c|}{ Type } & DCT & Initial & Access & Modify & $\begin{array}{l}\text { Rec Proc } \\
\text { Monitor }\end{array}$ & \multicolumn{1}{|c|}{ PP } \\
\hline \hline EGU & STRING & Yes & Null & Yes & Yes & No & No \\
\hline HOPR & FLOAT & Yes & 0 & Yes & Yes & No & No \\
\hline LOPR & FLOAT & Yes & 0 & Yes & Yes & No & No \\
\hline HIHI & FLOAT & Yes & 0 & Yes & Yes & No & Yes \\
\hline LOLO & FLOAT & Yes & 0 & Yes & Yes & No & Yes \\
\hline HIGH & FLOAT & Yes & 0 & Yes & Yes & No & Yes \\
\hline LOW & FLOAT & Yes & 0 & Yes & Yes & No & Yes \\
\hline HHSV & GBLCHOICE & Yes & 0 & Yes & Yes & No & Yes \\
\hline LLSV & GBLCHOICE & Yes & 0 & Yes & Yes & No & Yes \\
\hline HSV & GBLCHOICE & Yes & 0 & Yes & Yes & No & Yes \\
\hline LSV & GBLCHOICE & Yes & 0 & Yes & Yes & No & Yes \\
\hline HYST & DOUBLE & Yes & 0 & Yes & Yes & No & No \\
\hline ADEL & DOUBLE & Yes & 0 & Yes & Yes & No & No \\
\hline MDEL & DOUBLE & Yes & 0 & Yes & Yes & No & No \\
\hline LALM & DOUBLE & No & 0 & Yes & No & No & No \\
\hline ALST & DOUBLE & No & 0 & Yes & No & No & No \\
\hline MLST & DOUBLE & No & 0 & Yes & No & No & No \\
\hline SIOL & INLINK & Yes & 0 & No & No & N/A & No \\
\hline SIML & INLINK & Yes & 0 & No & No & N/A & No \\
\hline SIMM & GBLCHOICE & No & 0 & Yes & Yes & No & No \\
\hline SIMS & GBLCHOICE & Yes & 0 & Yes & Yes & No & No \\
\hline IVOA & GBLCHOICE & Yes & 0 & Yes & Yes & No & No \\
\hline IVOV & DOUBLE & Yes & 0 & Yes & Yes & No & No \\
\hline
\end{tabular}

\section{Field Descriptions}

\begin{tabular}{|l|l|l|}
\hline \multicolumn{1}{|c|}{ Name } & \multicolumn{1}{c|}{ Summary } & \multicolumn{1}{c|}{ Description } \\
\hline \hline VAL & Value Field & $\begin{array}{l}\text { This field is the input value which is used for passing data } \\
\text { for all of the output links. }\end{array}$ \\
\hline $\begin{array}{l}\text { OUTA,..., } \\
\text { OUTH }\end{array}$ & Output Link & $\begin{array}{l}\text { On processing of this record, each of these links to which } \\
\text { another record is connected will be triggered. }\end{array}$ \\
\hline
\end{tabular}




\begin{tabular}{|c|c|c|}
\hline Name & Summary & Description \\
\hline DOL & $\begin{array}{l}\text { Desired Output } \\
\text { Location (Input } \\
\text { Link) }\end{array}$ & $\begin{array}{l}\text { If DOL is a database or channel access link and OMSL is } \\
\text { CLOSED_LOOP, then VAL is read from DOL. After the } \\
\text { check for drive limits, VAL will be set to the value } \\
\text { determined by DOL. }\end{array}$ \\
\hline OMSL & Output Mode Select & $\begin{array}{l}\text { This field has either the value SUPERVISORY or } \\
\text { CLOSED_LOOP. DOL is used to determine VAL only if } \\
\text { OMSL has the value CLOSED_LOOP. By setting this field } \\
\text { the record can be switched between supervisory and } \\
\text { closed loop mode of operation. While in closed loop } \\
\text { mode, the VAL field cannot be set via dbPuts. }\end{array}$ \\
\hline EGU & Engineering Units & $\begin{array}{l}\text { ASCII string describing Engineering units. This field is } \\
\text { used by record support to supply a units description string } \\
\text { when get_units is called. }\end{array}$ \\
\hline HOPR & $\begin{array}{l}\text { High Operating } \\
\text { Range }\end{array}$ & \multirow{2}{*}{$\begin{array}{l}\text { These fields determine the upper and lower display limits } \\
\text { for graphics displays and the upper and lower control } \\
\text { limits for control displays. The fields are used by record } \\
\text { support to honor calls to get_graphic_double or } \\
\text { get_control_double. If these values are defined, } \\
\text { they must be in the range: } \\
\text { DRVL<=LOPR<=HOPR<=DRVH. }\end{array}$} \\
\hline LOPR & $\begin{array}{l}\text { Low Operating } \\
\text { Range }\end{array}$ & \\
\hline HIHI & Hihi Alarm Limit & \multirow[t]{8}{*}{ These fields specify the alarm limits and severities. } \\
\hline HIGH & High Alarm Limit & \\
\hline LOW & Low Alarm Limit & \\
\hline LOLO & Lolo Alarm Limit & \\
\hline HHSV & Hihi Alarm Severity & \\
\hline HSV & High Alarm Severity & \\
\hline LSV & Low Alarm Severity & \\
\hline LLSV & Lolo Alarm Severity & \\
\hline HYST & Alarm Deadband & \multirow{3}{*}{$\begin{array}{l}\text { These parameters specify hysteresis factors for triggering } \\
\text { monitor callbacks, i.e. callbacks specified by calls to } \\
\text { caAddEvent or dbAddEvent. A monitor will not be } \\
\text { triggered until VAI changes by more than the specified } \\
\text { amount. }\end{array}$} \\
\hline ADEL & Archive Deadband & \\
\hline MDEL & $\begin{array}{l}\text { Monitor, i.e. value } \\
\text { change, Deadband }\end{array}$ & \\
\hline LALM & Last Alarm Value & \multirow{3}{*}{$\begin{array}{l}\text { These fields are used to implement the hysteresis factors } \\
\text { for monitors. }\end{array}$} \\
\hline ALST & Last Archiver Value & \\
\hline MLST & $\begin{array}{l}\text { Last Monitored } \\
\text { Value }\end{array}$ & \\
\hline
\end{tabular}




\begin{tabular}{|c|c|c|}
\hline Name & Summary & Description \\
\hline SIMM & Simulation Mode & \multirow{4}{*}{$\begin{array}{l}\text { Simulation mode process variables. Refer to Chapter } 3 \text {, } \\
\text { Section "Simulation Mode" on page } 13 \text { for more } \\
\text { information. }\end{array}$} \\
\hline SIML & $\begin{array}{l}\text { Simulation Mode } \\
\text { Location }\end{array}$ & \\
\hline SIOL & $\begin{array}{l}\text { Simulation Value } \\
\text { Location }\end{array}$ & \\
\hline SIMS & $\begin{array}{l}\text { Simulation Mode } \\
\text { Alarm Severity }\end{array}$ & \\
\hline IVOA & $\begin{array}{l}\text { Invalid Alarm } \\
\text { Output Action }\end{array}$ & \multirow{2}{*}{$\begin{array}{l}\text { Whenever the record is put into INVALID alarm severity } \\
\text { IVOA specifies an action. See Chapter 3, Section "Invalid } \\
\text { Alarm Output Action" on page } 14 \text { for more information }\end{array}$} \\
\hline IVOV & $\begin{array}{l}\text { Invalid Alarm } \\
\text { Output Value }\end{array}$ & \\
\hline
\end{tabular}

\section{Record Support Routines}

\section{init_record}

process

See next section.

\section{Record Processing}

Routine process implements the following algorithm:

1. 


\title{
Chapter 11: eg - Event Generator
}

\author{
John Winans \\ Advanced Photon Source \\ Argonne National Laboratory
}

\section{Introduction}

The Event

Generator

EG Records
The support for the global event system has been designed to allow application developers to control the APS event generator and receiver boards. This is done by the use of four new record types: eg, egevent, er, erevent. These records are customized and are only supported by the device support modules for the APS event generator and receiver boards.

The use of the global event system and its associated records should not be confused with the vanilla EPICS events and the associated event records. They are very different.

The Event Generator is used to generate global event codes and send them out to one or more Event Receivers. A group of interconnected event generators and receivers is referred to as an 'event circuit.' There may be more than one event generator on the same event circuit. And it is possible for a single IOC to be part of multiple event circuits.

The eg record type is used to select the options of a specific event generator card. In order to properly configure it, you should first be familiar with its operating modes. This is specified in the document "Event System" by Frank Lenksus. 


\section{Field Summary}

\begin{tabular}{|c|c|c|c|c|c|c|c|}
\hline Field & Type & DCT & Initial & Access & Modify & $\begin{array}{l}\text { Rec Proc } \\
\text { Monitor }\end{array}$ & $\mathbf{P P}$ \\
\hline OUT & OUTLINK & Yes & & No & No & No & No \\
\hline MOD1 & RECCHOICE & Yes & 0 & Yes & Yes & No & Yes \\
\hline R1SP & DOUBLE & Yes & 0 & Yes & No & No & Yes \\
\hline MOD2 & RECCHOICE & Yes & 0 & Yes & Yes & No & Yes \\
\hline R2SP & DOUBLE & Yes & 0 & Yes & No & No & Yes \\
\hline LMD1 & RECCHOICE & No & 0 & Yes & No & No & Yes \\
\hline LMD2 & RECCHOICE & No & 0 & Yes & No & No & Yes \\
\hline FIFO & GBLCHOICE & Yes & 0 & Yes & Yes & No & Yes \\
\hline LFFO & GBLCHOICE & No & 0 & Yes & No & No & Yes \\
\hline CLR1 & CHAR & No & 0 & Yes & Yes & No & Yes \\
\hline CLR2 & CHAR & No & 0 & Yes & Yes & No & Yes \\
\hline TRG1 & CHAR & No & 0 & Yes & Yes & No & Yes \\
\hline TRG2 & CHAR & No & 0 & Yes & Yes & No & Yes \\
\hline ENAB & GBLCHOICE & Yes & 0 & Yes & Yes & No & Yes \\
\hline LENA & LONG & No & 0 & Yes & No & No & Yes \\
\hline TAXI & LONG & No & 0 & Yes & Yes & Yes & No \\
\hline LTAX & LONG & No & 0 & Yes & No & No & No \\
\hline VME & LONG & No & 0 & Yes & Yes & No & Yes \\
\hline ETE0 & GBLCHOICE & Yes & 0 & Yes & Yes & No & Yes \\
\hline ET0 & LONG & Yes & 0 & Yes & Yes & No & Yes \\
\hline LET0 & LONG & No & 0 & Yes & No & No & Yes \\
\hline ETE1 & GBLCHOICE & Yes & 0 & Yes & Yes & No & Yes \\
\hline ET1 & LONG & Yes & 0 & Yes & Yes & No & Yes \\
\hline LET1 & LONG & No & 0 & Yes & No & No & Yes \\
\hline ETE2 & GBLCHOICE & Yes & 0 & Yes & Yes & No & Yes \\
\hline ET2 & LONG & Yes & 0 & Yes & Yes & No & Yes \\
\hline LET2 & LONG & No & 0 & Yes & No & No & Yes \\
\hline ETE3 & GBLCHOICE & Yes & $\mathbf{0}$ & Yes & Yes & No & Yes \\
\hline ET3 & LONG & Yes & 0 & Yes & Yes & No & Yes \\
\hline LET3 & LONG & No & 0 & Yes & No & No & Yes \\
\hline
\end{tabular}




\begin{tabular}{|l|l|l|l|l|l|l|l|}
\hline \multicolumn{1}{|c|}{ Field } & \multicolumn{1}{|c|}{ Type } & DCT & Initial & Access & Modify & $\begin{array}{l}\text { Rec Proc } \\
\text { Monitor }\end{array}$ & \multicolumn{1}{|c|}{ PP } \\
\hline \hline ETE4 & GBLCHOICE & Yes & 0 & Yes & Yes & No & Yes \\
\hline ET4 & LONG & Yes & 0 & Yes & Yes & No & Yes \\
\hline LET4 & LONG & No & 0 & Yes & No & No & Yes \\
\hline ETE5 & GBLCHOICE & Yes & 0 & Yes & Yes & No & Yes \\
\hline ET5 & LONG & Yes & 0 & Yes & Yes & No & Yes \\
\hline LET5 & LONG & No & 0 & Yes & No & No & Yes \\
\hline ETE6 & GBLCHOICE & Yes & 0 & Yes & Yes & No & Yes \\
\hline ET6 & LONG & Yes & 0 & Yes & Yes & No & Yes \\
\hline LET6 & LONG & No & 0 & Yes & No & No & Yes \\
\hline ETE7 & GBLCHOICE & Yes & 0 & Yes & Yes & No & Yes \\
\hline ET7 & LONG & Yes & 0 & Yes & Yes & No & Yes \\
\hline LET7 & LONG & No & 0 & Yes & No & No & Yes \\
\hline VAL & CHAR & No & 0 & Yes & No & Yes & No \\
\hline
\end{tabular}

\section{Field Descriptions}

\begin{tabular}{|l|l|l|}
\hline \multicolumn{1}{|c|}{ Name } & \multicolumn{1}{|c|}{ Summary } & \multicolumn{1}{|c|}{ Description } \\
\hline \hline OUT & Output Link & $\begin{array}{l}\text { Specifies the link number of the event generator board. } \\
\text { Only the 'Card' value of the link specification is used. }\end{array}$ \\
\hline MOD1 & $\begin{array}{l}\text { Mode Select for } \\
\text { RAM 1 }\end{array}$ & $\begin{array}{l}\text { Used to select the operating mode of event sequence } \\
\text { RAM1 or RAM2. It is important to know that the } \\
\text { configuration of the events in the RAM may not be altered } \\
\text { unless it is either 'Off' or in 'Alternate Mode'. } \\
\text { Should a configuration attempt be made when the RAM is } \\
\text { not in one of these modes, it will be deferred until the } \\
\text { RAM mode is changed to either 'Off' or 'Alternate'. } \\
\text { When MOD1 is set to alternate from any other mode, MOD2 } \\
\text { will also be set to alternate. If MOD1 is changed from } \\
\text { alternate to any other mode, MOD2 will be set to off. }\end{array}$ \\
\hline R1SP & RAM 1 Speed & $\begin{array}{l}\text { Event clock 1 rate in Hz. This must be set to the clock rate } \\
\text { of the signal source on the Event CLK 1 input. It is only } \\
\text { used to calculate the 'desired position' value of events } \\
\text { that are placed into the sequence RAM. These events are } \\
\text { specified by the use of 'egevent' records. } \\
\text { If all 'egevent' record types that use the generator being } \\
\text { configured will be using 'Clock Ticks' as their 'Delay } \\
\text { Units' the value placed into R1sP is not used and may be } \\
\text { left as zero. }\end{array}$ \\
\hline R2SP & RAM 2 Speed & \\
\hline
\end{tabular}




\begin{tabular}{|c|c|c|}
\hline Name & Summary & Description \\
\hline LMD1 & $\begin{array}{l}\text { Last Operating } \\
\text { Mode } 1\end{array}$ & \\
\hline LMD2 & $\begin{array}{l}\text { Last Operating } \\
\text { Mode } 2\end{array}$ & \\
\hline FIFO & FIFO Enable & $\begin{array}{l}\text { Used to enable or disable the input-fifo on the generator } \\
\text { board. The fifo is used to allow more than one event } \\
\text { generator to exist on the same fiber-optic line. }\end{array}$ \\
\hline LFFO & Last FIFO Enable & \\
\hline CLR1 & Clear RAM 1 & \multirow{2}{*}{$\begin{array}{l}\text { Performing a 'put' operation on this field causes sequence } \\
\text { RAM1 or RAM2 to be cleared. The use of this field is } \\
\text { undefined (and will cause great problems) if there are any } \\
\text { 'egevent' records configured in the database. This is } \\
\text { provided for testing purposes. }\end{array}$} \\
\hline CLR2 & Clear RAM 2 & \\
\hline TRG1 & $\begin{array}{l}\text { Manual Trigger } \\
\text { RAM } 1\end{array}$ & \multirow{2}{*}{$\begin{array}{l}\text { If a 'put' operation is performed on this field, a one-time } \\
\text { trigger on sequence RAM1 or RAM2 will be initiated. The } \\
\text { result would be that same as if there were a hardware } \\
\text { trigger applied to the 'Event TRG1' input on the card. }\end{array}$} \\
\hline TRG2 & $\begin{array}{l}\text { Manual Trigger } \\
\text { RAM } 2\end{array}$ & \\
\hline ENAB & Master Enable & $\begin{array}{l}\text { Master card enable. No events are generated unless the } \\
\text { card is enabled. In general, there should never be any } \\
\text { reason to disable an event generator. This is provided for } \\
\text { testing purposes. }\end{array}$ \\
\hline LENA & Last Master Enable & \\
\hline TAXI & Taxi Violation Flag & $\begin{array}{l}\text { This is set to a non-zero value when there has been a taxi } \\
\text { violation. It simply reflects that state of the violation } \\
\text { signal on the taxi receiver module. Taxi violations can not } \\
\text { occur when FIFO is set to 'Off.' }\end{array}$ \\
\hline LTAX & Last Taxi Violation & \\
\hline VME & $\begin{array}{l}\text { Manual Event } \\
\text { Generation via } \\
\text { VME Access }\end{array}$ & $\begin{array}{l}\text { Used to send out a one-shot event code. A put to this field } \\
\text { will cause the event to be sent. It appears to be zero if it is } \\
\text { ever read. This can be 'OUT-LINKed' to by an other } \\
\text { record in order to generate an arbitrary event when it is } \\
\text { processed. }\end{array}$ \\
\hline ETEn & $\begin{array}{l}\text { Event Trigger } \\
\text { Enable }\end{array}$ & $\begin{array}{l}\text { ( } n=0-7) \text { These are the enables for the trigger event inputs } \\
\text { on the card. They must be set to 'On' in order to send the } \\
\text { trigger event codes. }\end{array}$ \\
\hline ETn & Event Trigger & $\begin{array}{l}(n=0-7) \text { These are used to program the event codes that } \\
\text { correspond to the trigger event inputs on the card. }\end{array}$ \\
\hline LETn & Last Trigger Event & $(n=0-7)$ \\
\hline VAL & Value & Not Used. \\
\hline
\end{tabular}




\section{Record Processing}

It is intended that eg records be set to passive processing only. They are not altered by the device support code in response to being processed. Their purpose is only to specify the operating modes of the event generator and, as such, are processed if and when a value in it is altered by a put operation. To start things going, however, they should have their 'process at init' flag set to YES.

As an observation, it is not advisable to alter the R1SP or R2SP fields. You may, but then all related egevent records must be processed again, in order to recalculate their desired position values. The MOD1 and MOD2 fields can also cause some nasty side effects if they are altered between any two non-off modes. In general, the operating mode should be set to OFF and then to some other mode if it is desired to switch between two modes.

\section{Device Support}

The device support module for the event generator may be used by eg and egevent record types.

In order to configure the event generator device support, a call must be made to set the address for each of the event generator cards present in the IOC. This configuration call is as follows:

Egconfigure (<card number>, <Base address in A16>)

The <card number> field may be $0-4$ and is used to specify which card is to be configured. This is the card number that is referenced in the eg and egevent records when building the database. The <Base address in A16> field is a 16-bit number that represents the address of the card in the A16 memory space.

Database records that specify card numbers that are not configured will generate 'bad field' errors when they are initialized by iocInit. And will then be ignored by the event generator device support if ever processed.

\section{Event Records}

The regular EPICS event records may be used when it is desired to cause a record to process upon a given event code by the global event system. This is accomplished by configuring an event record (the regular EPICS event record) and selecting the APS event receiver for the DTYP field. The card and signal are then used to select the event receiver card and event number, respectively. Any time the event number specified is received by the event receiver, that event record will be processed.

This is the only relationship between the vanilla EPICS event codes (and their associated records) and the global APS event system. 


\section{Event System Observations}

Event Generator Sequence RAM Modes

EGevent Records
This section describes a few observations that would otherwise be left to experimentation for the user figure out. Much of the annoyances described here have ben left in the system because there are simple work arounds, or they represent situations that should never be encountered on a running system.

It is intended that the modes of the eg never be altered. It was considered that the MOD1 and MOD2 fields be made SPC_NOMOD fields. But, during the system testing of the event hardware itself, it became useful to be able to make adjustments to the operating mode. Thus the ability to change the mode was put into the record and device support. However, exactly what is done when the mode is changed is probably not useful to the database designer.

First of all, remember that the sequence RAMS can not be updated unless they are either in ALT mode or OFF. This is due to the hardware constraints. In order to alter a sequence RAM that is not set to ALT or OFF, the RAM must be changed to one of those modes, altered, and then reset back to the desired mode. (No it is not reasonable to do this automatically.) Should the mode be carelessly altered, the EG card will have the mode updated, but the sequence RAM(s) will not be updated again until the mode is set to ALT or OFF. (In an actual application program, it is not reasonable to think that the operating modes of the sequence RAMS will be changed.)

Unless you have a strong need to use more than one sequence RAM at the same time, it is strongly recommended that the ALT mode be used. This is so that you may alter the event positions on the fly when debugging.

The delay selected in an egevent record is done by specifying the desired period of delay. The period is converted to click ticks by the use of the R1SP and R2SP values specified in the eg record. Since only one event code may be in any single sequence RAM position at any given time, any collisions are resolved at RAM load time by scanning for the 'next' unused position. Thus it is possible that the same database end up loading the RAMs in two different images depending on the order that the records get processed (that earlier records get higher priority.) If this causes problems, it is recommended that the units of delay be specified in 'clock ticks' and that the same delay values not be used in multiple records.

The use of 'clock ticks' as the delay units specification will eliminate the rounding caused by the conversion from alternate units into clock ticks.

It should be obvious that the event system is capable of generating VME interrupts at a rate that far exceeds the CPUs ability to process them. Much care should be put into the design of the databases that control the event system so that this does not happen. It has been observed that when such a problem does occur, vxWorks dies and prints "Work queue overflow" on its console. 


\section{Example Database for Global Time Synchronization}

This section describes a few example database records that are used to set up the event system. The records shown here are those used by the global synchronous timing system. This provides a good example of event generation from database records as well as from trigger inputs. It also includes a heartbeat generator that is required by the event system itself.

\section{Timing System Overview}

Event Generator Database Records

The example timing system uses a free running 1000 hertz clock. This clock is input on the TRGO line of the EG card on the master timing IOC. Each time the TRGO input is pulsed, an Increment Time Stamp (0x7C) event should be sent out so that the ER cards can update their notion of the time.

Additionally, the timing system has to take care of high order counter truncation and slave resynchronization. This is handled by the use of the Reset Time Stamp Counters (0x7D) event (the processing of the time stamp information is described in more detail in the document on the global timing system.)

The records related to the event generator card are used to initialize and generate events. The eg record used on the timing system master is:

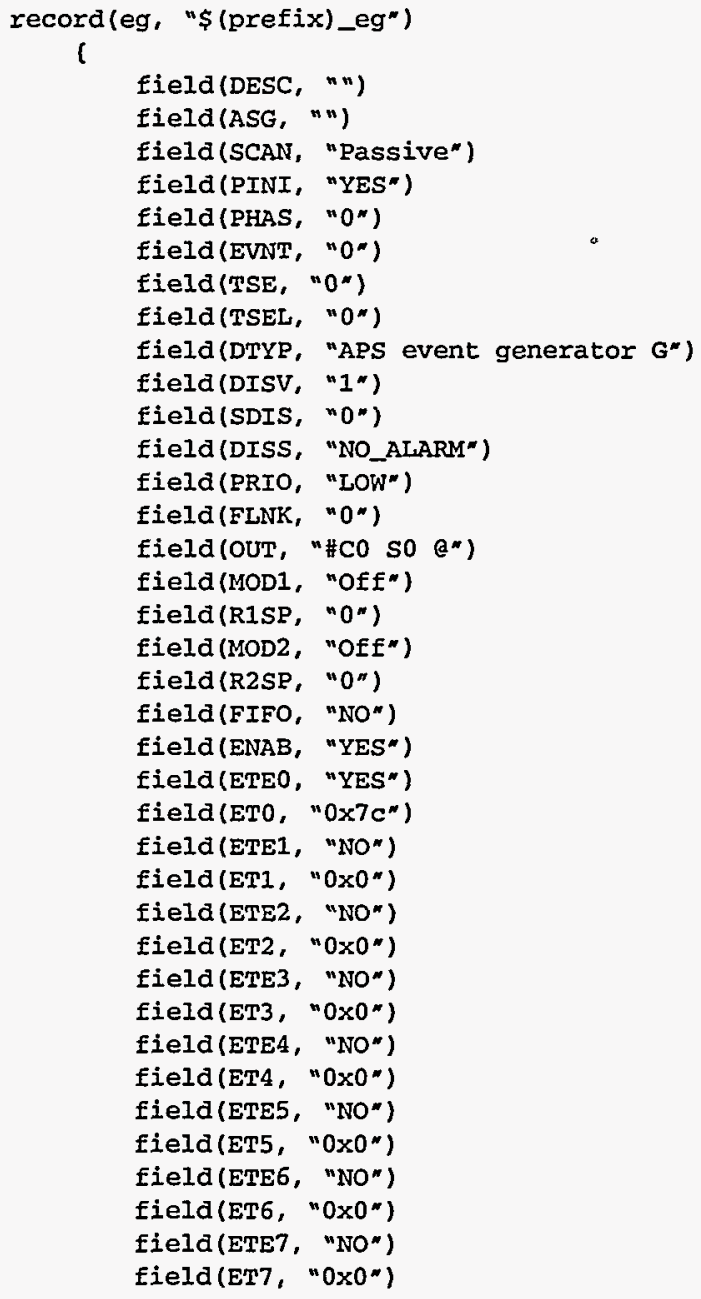


The important items of note are that ENAB is YES, ETEO is YES, ETO is set to $0 \times 7 \mathrm{C}$, and that the record be set to process at init time. The scan should always be set to passive since it only makes sense to process the record when the field values change.

In order to take care of the heart beat (0x7A) and time stamp reset/resync (0x7D) events, longout records are used that have their output links pointed to the VME field on the above eg record. When they are processed, the VAL field of the longout record is sent out on the event system.

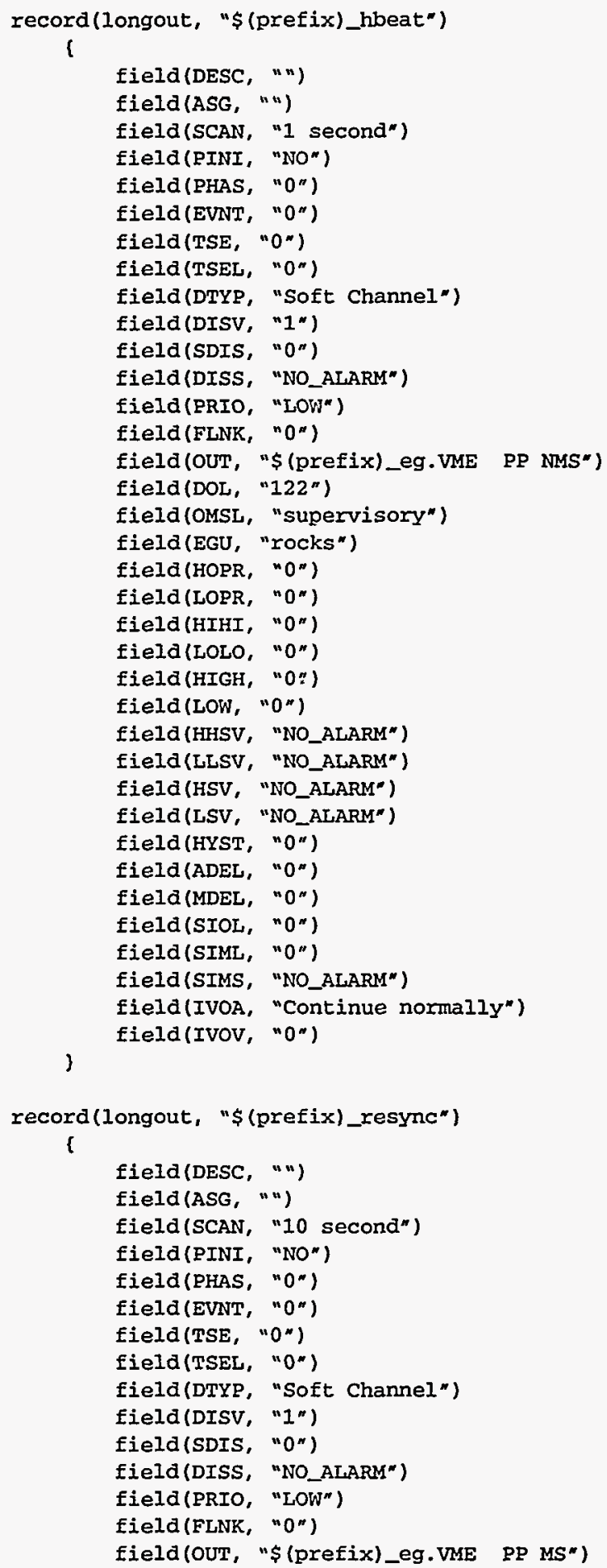




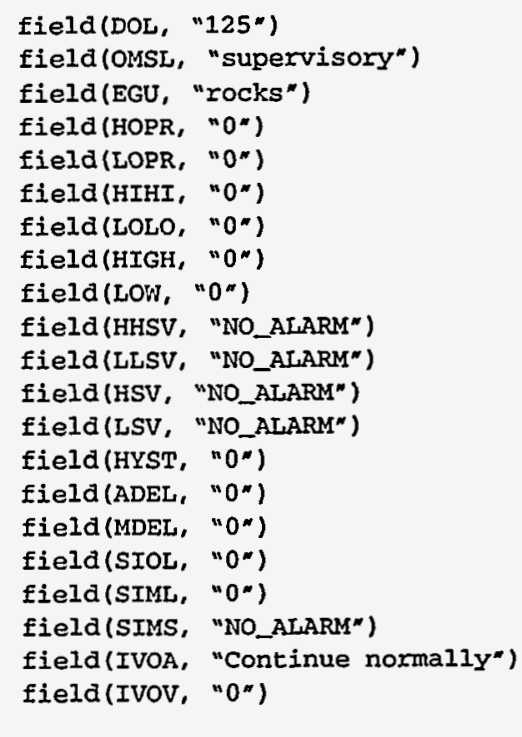

There should be nothing interesting about the longout records described above. The only important thing is that they properly point to the VME field of the eg record.

Event Receiver Database Records
The records used in the event receiver database are used to initialize the event receiver card. The er record used in the receiver database is:

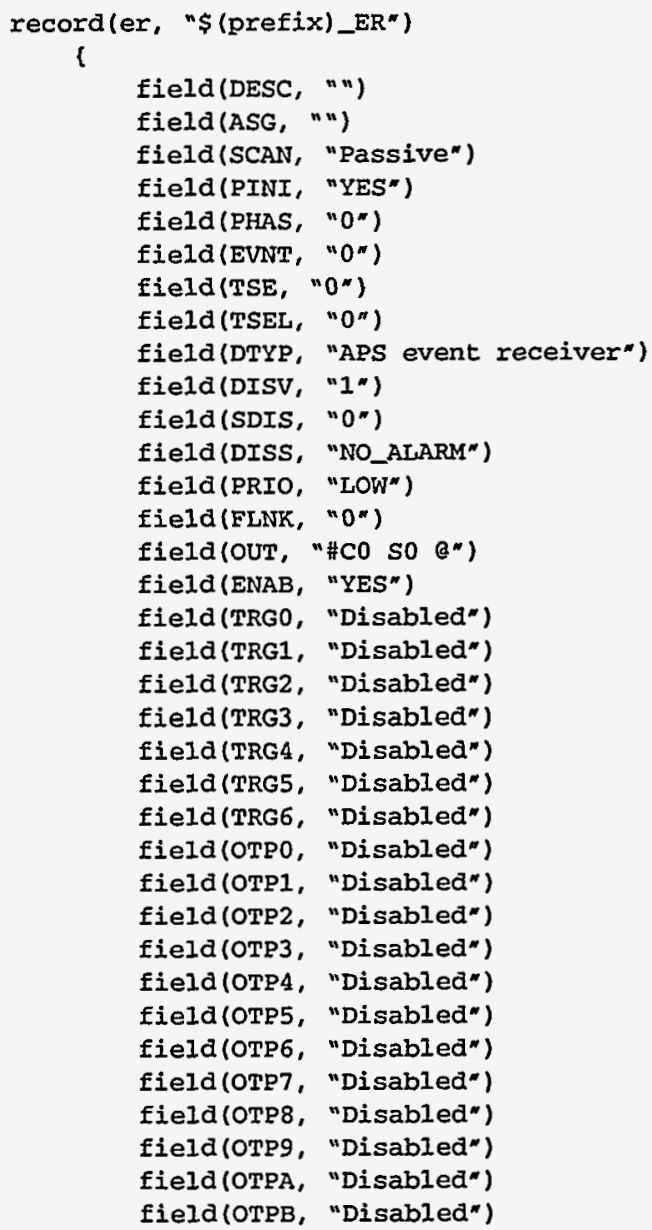




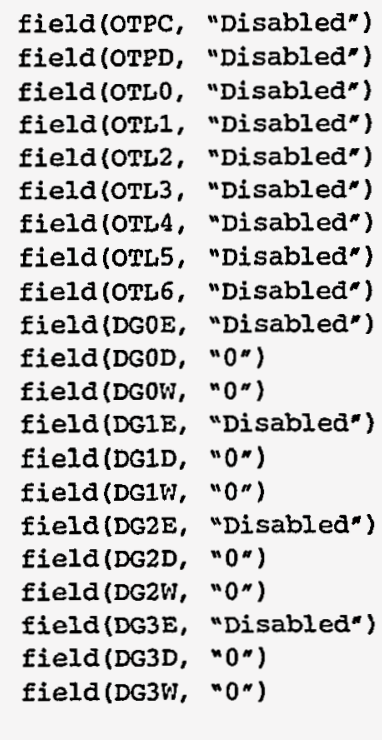

Much like the eg record, the only interesting to note is that this record is passive and processed at init time.

Now, in order to cause an IRQ to occur when the reset/resync time stamp event is received, we use the following erevent record:

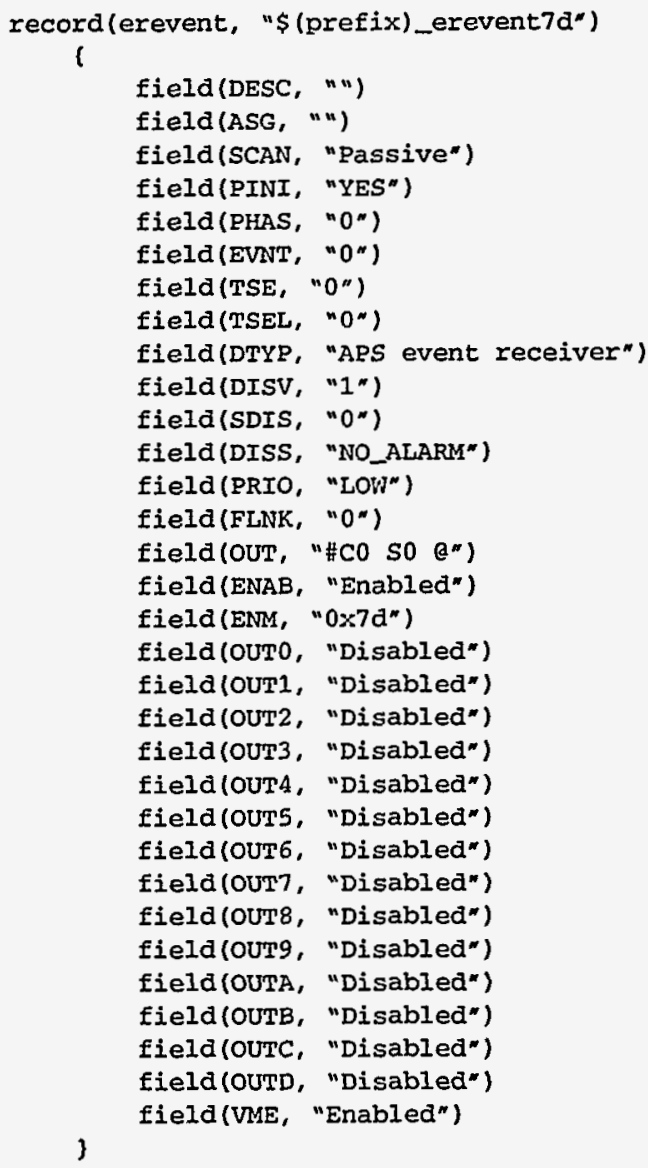


Interesting points here are that the output link field points to the same ER card as the above er record. The event number specified in the ENM field is the reset/resync time stamp event, and we can see that the VME field is set to ENABLED. This does nothing more than to tell the ER card that we want an IRQ on event number $0 \times 7 \mathrm{D}$. Note that we could also have turned on any of the output pulse/level outputs as well.

We need not include a record to enable anything on the increment time stamp or heart beat events as they are handled by the ER card automatically.

Exactly what happens when the IRQ arrives for event $0 \times 7 \mathrm{D}$ is described in detail in the global timing documentation. Suffice it to say that the timing system registers a callback with the event receiver driver that gets called upon receipt of the event.

Should you desire to process a database record upon the receipt of an event (in this case event number $0 \times 7 D$ ) you may use a regular EPICS event record and set it up like this:

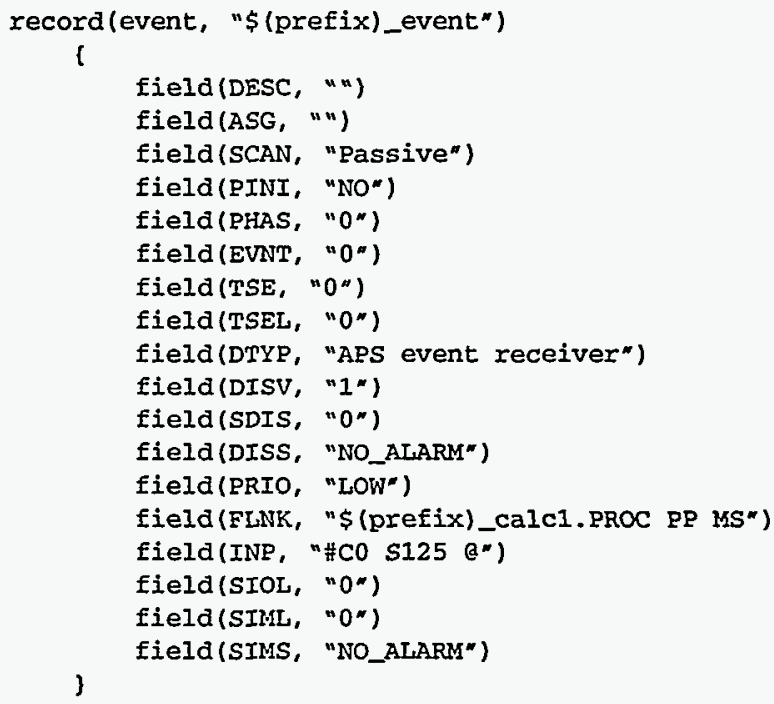

Interesting tidbits here are that the record's INP link is set to the ER card, the signal number is set to the event number of interest, and that the forward link field be set to the record you wish to process upon receipt of the event code. Remember also that the VME interrupt must be enabled for the desired event code (in this case, $125(0 \times 7 D)$ ) by the use of an erevent record type for the same event number, that has the VME field set to ENABLED.

\section{Event System Observations}

This section describes those items that might otherwise be overlooked by the overwhelming detail of the record support fields. Here we provide a simple overview of the ways events can be generated by the EG card and what can be done with them by the ER card. 


\section{Event Generator Input Sources}

\author{
$50 \mathrm{ohm}$ Trigger \\ Inputs
}

\author{
Software ( $E G$ \\ records)
}

Sequence RAMs

\section{Event Receiver Outputs}

\author{
One Time Output \\ Pulse
}

\section{Programmable \\ Delay and Width \\ Pulse}

Level Outputs

Special One Time

Output Pulse
The Event Generator hardware can generate event codes from 50 ohm input sources. The event codes generated are configured in the ETO-ETn fields and enabled by the ETEO-ETEn fields in the event generator record. The trigger inputs are edge sensitive and generate the event code placed in the corresponding ETn field of the EG record.

It is possible to generate any event code at any time by writing it to the VME field of the eg record. The VME field has a 'write-only' kind-of operation. Reading it will always return the value zero and not cause any events to be transmitted.

The sequence RAMS are programmed by the use of the egevent records. Each record represents a single event code that is placed into a sequence RAM. The record describes the event code number and its position in the RAM (in terms of time offset from trigger.) If the RAM is enabled in the eg record, and a trigger is present (either $50 \mathrm{ohm}$ input or by writing a value to the eg records TRGn field) the sequence RAM will be cycled thru and the present events will be sent out.

The event receiver has many output configurations available. This section provides an overview of each one.

Any given event can generate a one-time one microsecond output pule if the output pulse enable is set for the desired signal in the er record and the related trigger bits are set in the mapping RAM via an erevent record.

Any given event that is received can cause a pulse to be generated after a specified delay, and last for a specified width. The delay and width values are specified for the desired signal by the er record's DGnD and DGnW fields. It has to be enabled by the use of the DGnE field as well and the corresponding bits have to be set in the mapping RAM by the use of erevent records.

Any pair of events may be used to toggle an output signal by enabling it in the er record and by setting the corresponding bits in the mapping RAM by use of a erevent records.

These outputs are designed such that if the event code has its high order bit set, the seven low order bits are presented on these output lines as 1 microsecond pulses. The idea here is that you can have up to seven pulses generated simultaneously. This mode is NOT configurable, but can be enabled on a per-bit basis.

The er board is capable of generating a VME interrupt upon receipt of an event code. This is enabled via an erevent record that has the VME field enabled. When this is done, an regular EPICS event record can be processed when the IRQs are received. The event record to be processed has to have its scan rate set to "I/O Intr" mode. The card and signal fields in the event record's link are used to specify the ER card number and the event number that is to cause the record to be processed. 


\section{Chapter 12: egevent - Event Generator Event}

John Winans

Advanced Photon Source

Argonne National Laboratory

\section{Introduction}

The Event

Generator

EGEVENT

Records
The support for the global event system has been designed to allow an application developer to control the APS event generator and receiver boards. This is done by the use of four new record types: eg, egevent, er, erevent. These records are customized and are only supported by the device support modules for the APS event generator and receiver boards.

For more detailed information on the APS event generator and receiver records refer to Chapter 11 on page 65.

The Event Generator is used to generate global event codes and send them out to one or more Event Receivers. A group of interconnected event generators and receivers is referred to as an 'event circuit.' There may be more than one event generator on the same event circuit. And it is possible for a single IOC to be part of multiple event circuits.

The egevent record is used in conjunction with an eg record in order to specify a single event that is to be placed into a sequence RAM. The event code and its time displacement from the trigger are specified in this record. 


\section{Field Summary}

\begin{tabular}{|l|l|l|l|l|l|l|l|}
\hline \multicolumn{1}{|c|}{ Field } & \multicolumn{1}{|c|}{ Type } & DCT & Initial & Access & Modify & $\begin{array}{l}\text { RecProc } \\
\text { Monitor }\end{array}$ & \multicolumn{1}{c|}{ PP } \\
\hline \hline OUT & OUTLINK & Yes & 0 & No & No & No & No \\
\hline ENM & LONG & Yes & 0 & Yes & Yes & No & Yes \\
\hline LEVT & LONG & No & 0 & Yes & No & No & Yes \\
\hline RAM & RECCHOICE & Yes & 0 & Yes & Yes & No & Yes \\
\hline LRAM & RECCHOICE & No & 0 & Yes & No & No & Yes \\
\hline DELY & FLOAT & Yes & 0 & Yes & Yes & No & Yes \\
\hline ADLY & FLOAT & No & 0 & Yes & No & No & No \\
\hline DPOS & LONG & No & 0 & Yes & No & No & No \\
\hline APOS & LONG & No & 0 & Yes & No & No & No \\
\hline LDLY & FLOAT & No & 0 & Yes & No & No & No \\
\hline UNIT & RECCHOICE & Yes & 0 & Yes & Yes & No & Yes \\
\hline VAL & CHAR & No & 0 & Yes & No & Yes & No \\
\hline ELN & NOACCESS & No & 12 & No & No & No & No \\
\hline SELF & NOACCESS & No & 4 & No & No & No & No \\
\hline
\end{tabular}

3. Field Descriptions

\begin{tabular}{|c|c|c|}
\hline Name & Summary & Description \\
\hline OUT & Output Link & $\begin{array}{l}\text { Used to specify what event generator link that this event is } \\
\text { related to. Only the Card number is used }\end{array}$ \\
\hline ENM & Event Number & $\begin{array}{l}\text { The event number that is to be placed into the sequence } \\
\text { RAM. }\end{array}$ \\
\hline LEVT & Last Event Number & \\
\hline RAM & $\begin{array}{l}\text { Sequence RAM } \\
\text { Specifier }\end{array}$ & $\begin{array}{l}\text { Which RAM the event is to be placed into. (Ignored when } \\
\text { the generator is in 'Alternate' mode.) }\end{array}$ \\
\hline LRAM & Last RAM & \\
\hline DELY & Desired Delay & $\begin{array}{l}\text { The desired time delay between the trigger that starts the } \\
\text { RAM sequence and when this event should be sent. This } \\
\text { field must be expressed in the units selected in the UNIT } \\
\text { field described below. }\end{array}$ \\
\hline
\end{tabular}




\begin{tabular}{|l|l|l|}
\hline \multicolumn{1}{|c|}{ Name } & \multicolumn{1}{|c|}{ Summary } & \multicolumn{1}{c|}{ Description } \\
\hline \hline ADLY & Actual Delay & $\begin{array}{l}\text { This is a read-only field that is set to the actual delay value } \\
\text { after accounting for rounding caused by the clock } \\
\text { resolution as well as collisions that can occur if more than } \\
\text { one event is placed into the same sequence RAM location. }\end{array}$ \\
\hline DPOS & Desired Position & $\begin{array}{l}\text { This is a read-only field that represents desired position in } \\
\text { the sequence RAM that the event should be placed. It is } \\
\text { expressed in clock ticks. }\end{array}$ \\
\hline APOS & Actual Position & $\begin{array}{l}\text { This is a read-only field that represents the actual position } \\
\text { in the sequence RAM that the event is placed. It is } \\
\text { expressed in clock ticks. }\end{array}$ \\
\hline LDLY & Last Desired Delay & $\begin{array}{l}\text { The time units used to express the delay value in the DELY } \\
\text { and ADLY fields. }\end{array}$ \\
\hline UNIT & Delay Specifier & Units
\end{tabular}

\section{Record Processing}

It is intended that egevent records be set to passive processing only. They are not altered by the device support code in response to being processed. Their purpose is only to specify the desired position and code of an event in a sequence RAM. The read-only fields will be updated as necessary when ever the sequence RAM is reloaded. To start things going, however, they should have their 'process at init' flag set to YES.

Sequence RAMs are reloaded when ever any of the egevent records related to it has its DELY, ENM or UNIT values changed. It is not advisable to alter the UNIT field unless the associated sequence RAM mode is set to 'Off'.

\section{Device Support}

The device support module for the event generator may be used by eg and egevent record types.

In order to configure the event generator device support, a call must be made to set the address for each of the event generator cards present in the IOC. This configuration call is as follows:

EgConfigure(<card number>, <Base address in A16>)

The <card number > field may be $0-4$ and is used to specify which card is to be configured. This is the card number that is referenced in the eg and egevent records when building the database. The <Base address in A16> field is a 16-bit number that represents the address of the card in the A16 memory space. 
Database records that specify card numbers that are not configured will generate 'bad field' errors when they are initialized by iocInit. And will then be ignored by the event generator device support if ever processed. 


\section{Chapter 13: er - Event Receiver}

John Winans

Advanced Photon Source

Argonne National Laboratory

\section{Introduction}

The support for the global event system has been designed to allow an application developer to control the APS event generator and receiver boards. This is done by the use of four new record types: eg, egevent, ex, erevent. These records are customized and are only supported by the device support modules for the APS event generator and receiver boards.

For more detailed information on the APS event generator and receiver records refer to Chapter 11 on page 65 .

ER Records

The er record type is used to select the options of a specific event receiver card. In order to properly configure it, you should first be familiar with its operating modes. This is specified in the document "Event System" by Frank Lenksus.

\section{Field Summary}

\begin{tabular}{|l|l|l|l|l|l|l|l|}
\hline \multicolumn{1}{|c|}{ Field } & \multicolumn{1}{|c|}{ Type } & DCT & Initial & Access & Modify & $\begin{array}{l}\text { Rec Proc } \\
\text { Monitor }\end{array}$ & \multicolumn{1}{c|}{ PP } \\
\hline \hline VAL & CHAR & No & 0 & Yes & No & Yes & No \\
\hline OUT & OUTLINK & Yes & 0 & No & No & No & No \\
\hline ENAB & GBLCHOICE & Yes & 0 & Yes & Yes & No & Yes \\
\hline TAXI & LONG & No & 0 & Yes & No & Yes & No \\
\hline LTAX & LONG & No & 0 & Yes & No & No & No \\
\hline
\end{tabular}




\begin{tabular}{|c|c|c|c|c|c|c|c|}
\hline Field & Type & DCT & Initial & Access & Modify & \begin{tabular}{|l|} 
Rec Proc \\
Monitor \\
\end{tabular} & $\mathbf{P P}$ \\
\hline TRG0 & RECCHOICE & Yes & 0 & Yes & Yes & No & Yes \\
\hline TRG1 & RECCHOICE & Yes & 0 & Yes & Yes & No & Yes \\
\hline TRG2 & RECCHOICE & Yes & 0 & Yes & Yes & No & Yes \\
\hline TRG3 & RECCHOICE & Yes & 0 & Yes & Yes & No & Yes \\
\hline TRG4 & RECCHOICE & Yes & 0 & Yes & Yes & No & Yes \\
\hline TRG5 & RECCHOICE & Yes & 0 & Yes & Yes & No & Yes \\
\hline TRG6 & RECCHOICE & Yes & 0 & Yes & Yes & No & Yes \\
\hline OTP0 & RECCHOICE & Yes & 0 & Yes & Yes & No & Yes \\
\hline OTP1 & RECCHOICE & Yes & 0 & Yes & Yes & No & Yes \\
\hline OTP2 & RECCHOICE & Yes & 0 & Yes & Yes & No & Yes \\
\hline OTP3 & RECCHOICE & Yes & 0 & Yes & Yes & No & Yes \\
\hline OTP4 & RECCHOICE & Yes & 0 & Yes & Yes & No & Yes \\
\hline OTP5 & RECCHOICE & Yes & 0 & Yes & Yes & No & Yes \\
\hline OTP6 & RECCHOICE & Yes & 0 & Yes & Yes & No & Yes \\
\hline OTP7 & RECCHOICE & Yes & 0 & Yes & Yes & No & Yes \\
\hline OTP8 & RECCHOICE & Yes & 0 & Yes & Yes & No & Yes \\
\hline OTP9 & RECCHOICE & Yes & 0 & Yes & Yes & No & Yes \\
\hline OTPA & RECCHOICE & Yes & 0 & Yes & Yes & No & Yes \\
\hline ОТРВ & RECCHOICE & Yes & 0 & Yes & Yes & No & Yes \\
\hline OTPC & RECCHOICE & Yes & 0 & Yes & Yes & No & Yes \\
\hline OTPD & RECCHOICE & Yes & 0 & Yes & Yes & No & Yes \\
\hline OTLO & RECCHOICE & Yes & 0 & Yes & Yes & No & Yes \\
\hline OTL1 & RECCHOICE & Yes & 0 & Yes & Yes & No & Yes \\
\hline OTL2 & RECCHOICE & Yes & 0 & Yes & Yes & No & Yes \\
\hline OTL3 & RECCHOICE & Yes & 0 & Yes & Yes & No & Yes \\
\hline OTLA & RECCHOICE & Yes & 0 & Yes & Yes & No & Yes \\
\hline OTL5 & RECCHOICE & Yes & 0 & Yes & Yes & No & Yes \\
\hline OTL6 & RECCHOICE & Yes & 0 & Yes & Yes & No & Yes \\
\hline DGCM & LONG & No & 0 & Yes & No & No & No \\
\hline DGOE & RECCHOICE & Yes & 0 & Yes & Yes & No & Yes \\
\hline DG0D & USHORT & Yes & 0 & Yes & Yes & No & Yes \\
\hline DGOW & USHORT & Yes & 0 & Yes & Yes & No & Yes \\
\hline
\end{tabular}




\begin{tabular}{|l|l|l|l|l|l|l|l|}
\hline \multicolumn{1}{|c|}{ Field } & \multicolumn{1}{|c|}{ Type } & DCT & Initial & Access & Modify & $\begin{array}{l}\text { Rec Proc } \\
\text { Monitor }\end{array}$ & \multicolumn{1}{c|}{ PP } \\
\hline \hline DG1E & RECCHOICE & Yes & 0 & Yes & Yes & No & Yes \\
\hline DG1D & USHORT & Yes & 0 & Yes & Yes & No & Yes \\
\hline DG1W & USHORT & Yes & 0 & Yes & Yes & No & Yes \\
\hline DG2E & RECCHOICE & Yes & 0 & Yes & Yes & No & Yes \\
\hline DG2D & USHORT & Yes & 0 & Yes & Yes & No & Yes \\
\hline DG2W & USHORT & Yes & 0 & Yes & Yes & No & Yes \\
\hline DG3E & RECCHOICE & Yes & 0 & Yes & Yes & No & Yes \\
\hline DG3D & USHORT & Yes & 0 & Yes & Yes & No & Yes \\
\hline DG3W & USHORT & Yes & 0 & Yes & Yes & No & Yes \\
\hline
\end{tabular}

\section{Field Descriptions}

\begin{tabular}{|c|c|c|}
\hline Name & Summary & Description \\
\hline OUT & Output Link & $\begin{array}{l}\text { Used to specify which event receiver board is represented } \\
\text { by this record. }\end{array}$ \\
\hline ENAB & Master Enable & $\begin{array}{l}\text { Master card enable. No events will be received if the card } \\
\text { is disabled. }\end{array}$ \\
\hline TAXI & Taxi Violation Flag & $\begin{array}{l}\text { Set to a non-zero value if there is a taxi violation on the } \\
\text { event receiver board. }\end{array}$ \\
\hline LTAX & Last Taxi Violation & \\
\hline TRGn & Trigger Enable & $\begin{array}{l}(n=0-6) \text { Trigger event enables. Setting these allows the } \\
\text { corresponding bit to be set on the event receiver. }\end{array}$ \\
\hline OTPn & $\begin{array}{l}\text { One Time Pulse } \\
\text { Enable }\end{array}$ & $\begin{array}{l}\text { ( } n=0-D) \text { Setting these allows the corresponding bit to be } \\
\text { set in the event receiver. }\end{array}$ \\
\hline OTLn & $\begin{array}{l}\text { Output Level } \\
\text { Enable }\end{array}$ & $\begin{array}{l}\text { ( } n=0-6 \text { ) Output level enables. Setting these allows the } \\
\text { corresponding bit to be set in the event receiver. }\end{array}$ \\
\hline DGCM & $\begin{array}{l}\text { Delay Generator } \\
\text { Change Mask }\end{array}$ & \\
\hline DGnE & $\begin{array}{l}\text { Delay Generator } \\
\text { Enable }\end{array}$ & $(n=1-3)$ Programmable pulse delay enables. \\
\hline DGnD & $\begin{array}{l}\text { Delay Generator } \\
\text { Delay Value }\end{array}$ & $\begin{array}{l}(\mathrm{n}=1-3) \text { Delay value used for the programmable pulse } \\
\text { delay outputs. These values must be expressed in } 10-\mathrm{mHz} \\
\text { clock periods and has no other selectable resolution. }\end{array}$ \\
\hline DGnW & $\begin{array}{l}\text { Delay generator } \\
\text { Width Value }\end{array}$ & $\begin{array}{l}\text { ( } n=1-3 \text { ) Width of the programmable pulse. These values } \\
\text { must be expressed in } 10-\mathrm{mHz} \text { clock periods. }\end{array}$ \\
\hline VAL & Value Field & Not used. \\
\hline
\end{tabular}




\section{Record Processing}

It is intended that ex records be set to passive processing only. They are not altered by the device support code in response to being processed. Their purpose is only to specify the operating modes of the event receiver and, as such, are processed if and when a value in it is altered by a put operation. To start things going, however, they should have their 'process at init' flag set to YES.

\section{Device Support}

The device support for the event receiver may be used by ex, erevent and event record types.

In order to configure the event receiver device support, a call must be made to set the address for each of the event receiver cards present in the IOC. This configuration call is as follows:

ErConfigure (<card>, <AI6 board address>, <IRQ Vector>, <IRQ Level>)

Where $\langle$ car $\delta>$ is the card to be configured, $<A 16$ board address $>$ is the 16-bit address of the board in A16 space, <IRQ Vector> is the vector number to use when generating VME interrupts, and <IRQ Level $>$ is the VME backplane. 


\section{Chapter 14: erevent - Event Receiver Event}

John Winans

Advanced Photon Source

Argonne National Laboratory

\section{Introduction}

The support for the global event system has been designed to allow an application developer to control the APS event generator and receiver boards. This is done by the use of four new record types: eg, egevent, er, erevent. These records are customized and are only supported by the device support modules for the APS event generator and receiver boards.

For more detailed information on the APS event generator and receiver records refer to Chapter 11 on page 65 .

EREVENT Records
The erevent records are used to specify what bits are to be set in the event receiver mapping RAM. The use of these bits depend on the which outputs are enabled on the event receiver card (specified in the er record.) Additionally, this record type is used to select the VME interrupt and time-latch option.

\section{Field Summary}

\begin{tabular}{|l|l|l|l|l|l|l|l|}
\hline \multicolumn{1}{|c|}{ Field } & \multicolumn{1}{c|}{ Type } & DCT & Initial & Access & Modify & $\begin{array}{l}\text { Rec Proc } \\
\text { Monitor }\end{array}$ & \multicolumn{1}{c|}{ PP } \\
\hline \hline VAL & CHAR & No & 0 & Yes & No & Yes & No \\
\hline OUT & OUTLINK & Yes & 0 & No & No & No & No \\
\hline ENAB & RECCHOICE & Yes & 0 & Yes & Yes & No & Yes \\
\hline
\end{tabular}




\begin{tabular}{|l|l|l|l|l|l|l|l|}
\hline \multicolumn{1}{|c|}{ Field } & \multicolumn{1}{|c|}{ Type } & DCT & Initial & Access & Modify & $\begin{array}{l}\text { Rec Proc } \\
\text { Monitor }\end{array}$ & \multicolumn{1}{|c|}{ PP } \\
\hline \hline ENM & LONG & Yes & 0 & Yes & Yes & No & Yes \\
\hline LENM & LONG & No & 0 & Yes & No & No & Yes \\
\hline LOUT & LONG & No & 0 & Yes & No & No & Yes \\
\hline OUT0 & RECCHOICE & Yes & 0 & Yes & Yes & No & Yes \\
\hline OUT1 & RECCHOICE & Yes & 0 & Yes & Yes & No & Yes \\
\hline OUT2 & RECCHOICE & Yes & 0 & Yes & Yes & No & Yes \\
\hline OUT3 & RECCHOICE & Yes & 0 & Yes & Yes & No & Yes \\
\hline OUT4 & RECCHOICE & Yes & 0 & Yes & Yes & No & Yes \\
\hline OUT5 & RECCHOICE & Yes & 0 & Yes & Yes & No & Yes \\
\hline OUT6 & RECCHOICE & Yes & 0 & Yes & Yes & No & Yes \\
\hline OUT7 & RECCHOICE & Yes & 0 & Yes & Yes & No & Yes \\
\hline OUT8 & RECCHOICE & Yes & 0 & Yes & Yes & No & Yes \\
\hline OUT9 & RECCHOICE & Yes & 0 & Yes & Yes & No & Yes \\
\hline OUTA & RECCHOICE & Yes & 0 & Yes & Yes & No & Yes \\
\hline OUTB & RECCHOICE & Yes & 0 & Yes & Yes & No & Yes \\
\hline OUTC & RECCHOICE & Yes & 0 & Yes & Yes & No & Yes \\
\hline OUTD & RECCHOICE & Yes & 0 & Yes & Yes & No & Yes \\
\hline VME & RECCHOICE & Yes & 0 & Yes & Yes & No & Yes \\
\hline
\end{tabular}

\section{Field Descriptions}

\begin{tabular}{|l|l|l|}
\hline \multicolumn{1}{|c|}{ Name } & \multicolumn{1}{|c|}{ Summary } & \multicolumn{1}{c|}{ Description } \\
\hline \hline OUT & Output Link & $\begin{array}{l}\text { Specifies the card containing the mapping RAM to be } \\
\text { programmed. }\end{array}$ \\
\hline ENAB & Event Enable & $\begin{array}{l}\text { Enables the operation of this record. If this is set to } \\
\text { 'Disabled', then the values in the record are ignored. }\end{array}$ \\
\hline ENM & Event Number & $\begin{array}{l}\text { The event number to be described. This indicates the } \\
\text { position in the mapping RAM that is to be programmed. }\end{array}$ \\
\hline LENM & Last Event Number & \\
\hline LOUT & $\begin{array}{l}\text { Last Output Enable } \\
\text { Mask }\end{array}$ & \\
\hline
\end{tabular}




\begin{tabular}{|l|l|l|}
\hline \multicolumn{1}{|c|}{ Name } & \multicolumn{1}{|c|}{ Summary } & \multicolumn{1}{c|}{ Description } \\
\hline \hline OUTn & Output Enable & $\begin{array}{l}\text { (n=0-D) May be set to 'Enable' or 'Disable' in order } \\
\text { to set or clear the corresponding bit in the mapping RAM. } \\
\text { The meanings of these bits depend on what outputs are } \\
\text { enabled on the event receiver board (selected in the } \\
\text { related er record) and are described in the document } \\
\text { "Event System" by Frank Lenksus. }\end{array}$ \\
\hline VME & $\begin{array}{l}\text { VME Interrupt } \\
\text { Enable }\end{array}$ & $\begin{array}{l}\text { May be set to 'Enable' or 'Disable' in order to select a } \\
\text { VME interrupt upon the occurrence of event ENM. The } \\
\text { time is automatically latched when the VME internupt is } \\
\text { generated. }\end{array}$ \\
\hline VAL & Value Field & Not used. \\
\hline
\end{tabular}

\section{Record Processing}

It is intended that erevent records be set to passive processing only. They are not altered by the device support code in response to being processed. Their purpose is only to specify the desired actions to be performed upon receipt of a specific event code. To start things going, however, they should have their 'process at init' flag set to YES.

\section{Device Support}

The device support for the event receiver may be used by ex, erevent and event record types.

In order to configure the event receiver device support, a call must be made to set the address for each of the event receiver cards present in the IOC. This configuration call is as follows:

ErConfigure (<card>, <A16 board address>, <IRQ Vector>, <IRQ Level>)

Where $<$ card $>$ is the card to be configured, $<A 16$ board address $>$ is the 16-bit address of the board in A16 space, <IRQ Vector> is the vector number to use when generating VME interrupts, and $<$ IRQ Level $>$ is the VME backplane. 


\section{Chapter 15: Event}

\section{Introduction}

The normal use for this record type is to post an event and/or process a forward link. Device support for this record can provide a hardware interrupt handler routine for I/O Event scanned records.

\section{Field Summary}

\begin{tabular}{|l|l|l|l|l|l|l|l|}
\hline \multicolumn{1}{|c|}{ Field } & \multicolumn{1}{|c|}{ Type } & \multicolumn{1}{c|}{ DCT } & \multicolumn{1}{c|}{ Initial } & Access & Modify & $\begin{array}{l}\text { Rec Proc } \\
\text { Monitor }\end{array}$ & PP \\
\hline \hline VAL & SHORT & Yes & 0 & Yes & Yes & Yes & No \\
\hline INP & INLINK & Yes & 0 & No & No & N/A & No \\
\hline SIOL & INLINK & Yes & 0 & No & No & N/A & No \\
\hline SVAL & USHORT & No & 0 & Yes & Yes & No & No \\
\hline SIML & INLINK & Yes & 0 & No & No & N/A & No \\
\hline SIMM & GBLCHOICE & No & 0 & Yes & Yes & No & No \\
\hline SIMS & GBLCHOICE & Yes & 0 & Yes & Yes & No & No \\
\hline
\end{tabular}




\section{Field Descriptions}

\begin{tabular}{|c|c|c|}
\hline Name & Summary & Description \\
\hline VAL & Value Field & Event number to post. \\
\hline INP & Input Link & $\begin{array}{l}\text { This field is used by the device support routines to obtain } \\
\text { input. For soft records, it can be a constant, a database } \\
\text { link, or a channel access link. }\end{array}$ \\
\hline SIMM & Simulation Mode & \multirow{5}{*}{$\begin{array}{l}\text { Simulation mode process variables. Refer to Chapter } 3 \text {, } \\
\text { Section "Simulation Mode" on page } 11 \text { for more } \\
\text { information. }\end{array}$} \\
\hline SIML & $\begin{array}{l}\text { Simulation Mode } \\
\text { Location }\end{array}$ & \\
\hline SVAL & Simulation Value & \\
\hline SIOL & $\begin{array}{l}\text { Simulation Value } \\
\text { Location }\end{array}$ & \\
\hline SIMS & $\begin{array}{l}\text { Simulation Mode } \\
\text { Alarm Severity }\end{array}$ & \\
\hline
\end{tabular}

\section{Record Support Routines}

init_record

process

get_value
This routine initializes SIMM with the value of SIMU if SIMU type is CONSTANT link or creates a channel access link if SIML type is PV_LIINK. SVAL is likewise initialized if SIOL is CONSTANT or PV_IINK.

If device support includes init_record, it is called.

See next section.

Fills in the values of struct valueDes so that they refer to VAL.

\section{Record Processing}

Routine process implements the following algorithm:

1. readValue is called. See Chapter 3, Section "Simulation Mode" on page 11 for details.

2. If PACT has been changed to TRUE, the device support read routine has started but has not completed reading a new input value. In this case, the processing routine merely returns, leaving PACT TRUE.

3. If VAL $>0$, post event number VAL.

4. Check to see if monitors should be invoked. Alarm monitors are invoked if the alarm status or severity has changed NSEV and NSTA are reset to 0 . 
5. Scan forward link if necessary, set PACT FALSE, and return.

\section{Device Support}

Fields Of Interest To Device Support

\section{Device Support} Routines

report

init

init_record

get_ioint_info
Each record must have an associated set of device support routines. The device support routines are primarily interested in the following fields:

\begin{tabular}{|l|l|l|}
\hline \multicolumn{1}{|c|}{ Name } & \multicolumn{1}{|c|}{ Summary } & \multicolumn{1}{c|}{ Description } \\
\hline \hline PACT & Processing Active & $\begin{array}{l}\text { See Chapter 2, Section "Database Common: Field } \\
\text { Descriptions" on page 5 for descriptions. }\end{array}$ \\
\cline { 1 - 2 } DPVT & Device Private & \\
\cline { 1 - 2 } UDF & VAL Undefined & \\
\cline { 1 - 2 } NSEV & New Alarm Severity & \\
\cline { 1 - 2 } NSTA & New Alarm Status & $\begin{array}{l}\text { This field is used by the device support routines to locate } \\
\text { its input. }\end{array}$ \\
\cline { 1 - 2 } INP & Input Link & $\begin{array}{l}\text { This value must be used by the device support interrupt } \\
\text { handler to set the scheduling priority for processing this } \\
\text { record. }\end{array}$ \\
\hline PRIO & Priority & \multicolumn{1}{|l}{} \\
\hline
\end{tabular}

Device support consists of the following routines:

report (FILE fp, interest)

Not currently used.

init ()

This routine is called once during IOC initialization.

init_record (precord)

This routine is optional. If provided, it is called by the record support init_record routine.

get_ioint_info(int cmd,struct dbCommon *precord, IOSCANPVT *ppvt)

This routine is called by the ioEventScan system each time the record is added or deleted from an I/O event scan list. cmd has the value $(0,1)$ if the record is being (added to, deleted from) an I/O event list. It must be provided for any device type that can use the ioEvent scanner.

read_event (precord) 
This routine returns the following values:

- 0: Success.

- Other: Error.

\section{Device Support For Soft Records}

A soft device support module is provided. The INP link type must be either CONSTANT, DB_LINK, or CA_LINK.

If the INP link type is CONSTANT, then the constant value is stored into VAL by init_record, and UDF is set to FALSE. If the INP link type is PV_LINK, then dbCaAddInlink is called by init_record.

read_event calls recGbigetLinkValue to read the current value of VAL. See Chapter 3, Section "Soft Input" on page 10 for details.

If the return status of recGblGetLinkValue is zero, then read_event sets UDF to FALSE. The status of recGblGetLinkValue is returned. 


\section{Chapter 16: Fanout}

\section{Introduction}

This record is used to trigger the processing of up to six other records. It has no associated device support.

2. Field Summary

\begin{tabular}{|l|l|l|l|l|l|l|l|}
\hline \multicolumn{1}{|c|}{ Field } & \multicolumn{1}{|c|}{ Type } & DCT & Initial & Access & Modify & $\begin{array}{l}\text { Rec Proc } \\
\text { Monitor }\end{array}$ & PP \\
\hline \hline VAL & LONG & No & 0 & Yes & Yes & No & Yes \\
\hline SELM & RECCHOICE & Yes & 0 & Yes & Yes & No & No \\
\hline SELN & USHORT & No & 1 & Yes & Yes & No & No \\
\hline SELL & INLINK & Yes & 0 & No & No & N/A & No \\
\hline LNK1 & FWDLINK & Yes & 0 & No & No & N/A & No \\
\hline LNK2 & FWDLINK & Yes & 0 & No & No & N/A & No \\
\hline LNK3 & FWDLINK & Yes & 0 & No & No & N/A & No \\
\hline LNK4 & FWDLINK & Yes & 0 & No & No & N/A & No \\
\hline LNK5 & FWDLINK & Yes & 0 & No & No & N/A & No \\
\hline LNK6 & FWDLINK & Yes & 0 & No & No & N/A & No \\
\hline
\end{tabular}


3. Field Descriptions

\begin{tabular}{|l|l|l|}
\hline \multicolumn{1}{|c|}{ Name } & \multicolumn{1}{|c|}{ Summary } & \multicolumn{1}{c|}{ Description } \\
\hline \hline VAL & Value Field & $\begin{array}{l}\text { This field exits only because every record type must have } \\
\text { a VAL field so that dNameToAddr succeeds when a field } \\
\text { name is not specified. }\end{array}$ \\
\hline SELM & Select Mechanism: & $\begin{array}{l}\text { SELECT_ALL: Select all links } \\
\text { SELECTED: Use SELN as index (1 to 6) } \\
\text { MASK: Use SELN as a mask to select an arbitrary } \\
\text { combination of links. }\end{array}$ \\
\hline SELN & Link Selection & $\begin{array}{l}\text { If SELM=SELECT_ALI then this field is not used. } \\
\text { If SELM=SELECTED then this is the index (1 to 6) of the } \\
\text { link to select. } \\
\text { If SELM=MASK then this is the mask (in decimal) used to } \\
\text { determine the selected links. For example, if SELN=1, } \\
\text { then LNK1 will be processed. If SELN=3 then LNK1 and } \\
\text { LNK2 will be processed. If SELN=63 then all links LNK1, } \\
\text { LNK2, ... LNK6 will be processed. }\end{array}$ \\
\hline SELL & $\begin{array}{l}\text { Link Selection } \\
\text { Location }\end{array}$ & $\begin{array}{l}\text { SELN is read from SELL. SELL can be a constant, a } \\
\text { database link, or a channel access link. }\end{array}$ \\
\hline LNK1,...,LNK6 & $\begin{array}{l}\text { Link Selection } \\
\text { Forward Links }\end{array}$ & $\begin{array}{l}\text { Link selection forward links are always processed in } \\
\text { numeric order. That is INK1 is always processed before } \\
\text { LNK2, LNK2 before LNK3, etc. }\end{array}$ \\
\hline
\end{tabular}

\section{Record Support Routines}

\section{init_record}

process
This routine initializes SELN with the value of SELL, if SELI type is CONSTANT link, or creates a channel access link if SELL type is PV_LINK.

See next section.

\section{Record Processing}

Routine process implements the following algorithm:

1. PACT is set to TRUE.

2. The link selection SELN is fetched.

3. Depending on the selection mechanism, the link selection forward links are processed. and UDF is set to FALSE.

4. Check to see if monitors should be invoked.

- Alarm monitors are invoked if the alarm status or severity has changed. 
- NSEV and NSTA are reset to 0 .

5. Scan forward link if necessary, set PACT FALSE, and return. 


\section{Chapter 17: Histogram}

\section{Introduction}

The histogram record type is used to store frequency counts of a signal into an array of arbitrary length.

\section{Field Summary}

\begin{tabular}{|l|l|l|l|l|l|l|l|}
\hline \multicolumn{1}{|c|}{ Field } & \multicolumn{1}{|c|}{ Type } & \multicolumn{1}{c|}{ DCT } & \multicolumn{1}{c|}{ Initial } & Access & Modify & $\begin{array}{l}\text { Rec Proc } \\
\text { Monitor }\end{array}$ & \multicolumn{1}{c|}{ PP } \\
\hline \hline VAL & See BPTR & No & 0 & Yes & No & No & No \\
\hline NELM & USHORT & Yes & 1 & Yes & No & No & No \\
\hline CSTA & SHORT & No & 1 & Yes & No & & No \\
\hline CMD & RECCHOICE & No & 0 & Yes & Yes & & No \\
\hline ULIM & DOUBLE & Yes & 0 & Yes & Yes & No & No \\
\hline LLIM & DOUBLE & Yes & 0 & Yes & Yes & No & No \\
\hline WDTH & DOUBLE & No & 0 & Yes & No & & No \\
\hline SGNL & DOUBLE & No & 0 & Yes & Yes & Yes & No \\
\hline SVL & INLINK & Yes & 0 & No & No & N/A & No \\
\hline BPTR & NOACCESS & No & 0 & No & No & & No \\
\hline WDOG & NOACCESS & No & 0 & No & No & & No \\
\hline
\end{tabular}




\begin{tabular}{|l|l|l|l|l|l|l|l|}
\hline \multicolumn{1}{|c|}{ Field } & \multicolumn{1}{|c|}{ Type } & DCT & \multicolumn{1}{c|}{ Initial } & Access & Modify & $\begin{array}{l}\text { Rec Proc } \\
\text { Monitor }\end{array}$ & \multicolumn{1}{c|}{ PP } \\
\hline \hline MCNT & SHORT. & No & 0 & Yes & No & & No \\
\hline MDEL & SHORT & Yes & 0 & Yes & Yes & No & No \\
\hline SDEL & FLOAT & Yes & 0 & Yes & No & & No \\
\hline SIOL & INLINK & Yes & 0 & No & No & N/A & No \\
\hline SVAL & DOUBLE & No & 0 & Yes & Yes & No & No \\
\hline SIML & INLINK & Yes & 0 & No & No & N/A & No \\
\hline SIMM & GBLCHOICE & No & 0 & Yes & Yes & No & No \\
\hline SIMS & GBLCHOICE & Yes & 0 & Yes & Yes & No & No \\
\hline
\end{tabular}

3. Field Descriptions

\begin{tabular}{|c|c|c|}
\hline Name & Summary & Description \\
\hline VAL & Value Field & This field is used to reference the array. \\
\hline NELM & $\begin{array}{l}\text { Number of } \\
\text { elements in array }\end{array}$ & \\
\hline CSTA & Collections Status & \\
\hline CMD & Collections Control & \\
\hline ULIM & Upper Signal Limit & \multirow{2}{*}{$\begin{array}{l}\text { These fields determine the range of signal values to be } \\
\text { used. This range is subdivided into NELM equal intervals. } \\
\text { The histogram array elements contain frequency counts of } \\
\text { SGNL values for these intervals. Values of the signal } \\
\text { outside these limits are not used by the record support } \\
\text { routines. Whenever ULIM or LLIM are changed, the array } \\
\text { elements counts will be reset to zero. }\end{array}$} \\
\hline LLIM & Lower Signal Limit & \\
\hline WDTH & Element Width & \\
\hline SGNL & Signal Value & \\
\hline SVL & $\begin{array}{l}\text { Signal Value } \\
\text { Location (input } \\
\text { link) }\end{array}$ & $\begin{array}{l}\text { This field can be a constant, a database link, or a channel } \\
\text { access link. If SVL is a database or channel access link, } \\
\text { then SGNL is read from SVL. If SVL is a constant link } \\
\text { then SGNL is initialized with the constant value but can be } \\
\text { changed via dbPuts. }\end{array}$ \\
\hline BPTR & Buffer Pointer & Address of unsigned long array of frequency values. \\
\hline WDOG & Watchdog Callback & \\
\hline MCNT & Monitor Counts & Number of counts since last monitor. \\
\hline MDEL & Monitor Delta & Monitor count deadband. \\
\hline
\end{tabular}




\begin{tabular}{|l|l|l|}
\hline \multicolumn{1}{|c|}{ Name } & \multicolumn{1}{|c|}{ Summary } & \multicolumn{1}{|c|}{ Description } \\
\hline \hline SDEL & $\begin{array}{l}\text { Monitor Seconds } \\
\text { Dband }\end{array}$ & \\
\hline SIMM & Simulation Mode & $\begin{array}{l}\text { Simulation mode process variables. Refer to Chapter 3, } \\
\text { Section "Simulation Mode" on page 11 for more } \\
\text { information. }\end{array}$ \\
\hline SIML & $\begin{array}{l}\text { Simulation Mode } \\
\text { Location }\end{array}$ & \\
\hline SVAL & Simulation Value & \\
\hline SIOL & $\begin{array}{l}\text { Simulation Value } \\
\text { Location }\end{array}$ & $\begin{array}{l}\text { Simulation Mode } \\
\text { Alarm Severity }\end{array}$ \\
\hline SIMS &
\end{tabular}

\section{Record Support Routines}

\section{init_record}

process

special

get_value

cvt_dbaddr
Using NELM, space for the unsigned long array is allocated and the width WDTH of the array is calculated

This routine initializes SIMM with the value of SIML if SIML type is CONSTANT link or creates a channel access link if SIML type is PV_LINK. SVAL is likewise initialized if SIOL is CONSTANT or PV_LINK.

This routine next checks to see that device supportand a device support read routine are available. If device support includes init_record, it is called.

See next section.

Special is invoked whenever the fields CMD, SGN, ULIM, or LLIM are changed. If SGNL is changed, add_count is called.

If ULIM or LLIM are changed, WDTH is recalculated and clear_histogram is called.

If CMD is less or equal to 1, clear_histogram is called and CMD is reset to 0 . If CMD is 2 , CSTA is set to TRUE and CMD is reset to 0. If CMD is 3, CSTA is set to FALSE and CMD is reset to 0 .

clear_histogram zeros out the histogram array. add_count increments the frequency in the histogram array.

Fills in the values of struct valueDes so that they refer to the array.

This is called by dbNameToAddr. It makes the dbAddr structure refer to the actual buffer holding the array. 
get_array_info Obtains values from the array referenced by VAL.

put_array_info Writes values into the array referenced by vaL.

\section{Record Processing}

Routine process implements the following algorithm:

1. Check to see that the appropriate device support module exists. If it doesn't, an error message is issued and processing is terminated with the PACT field set to TRUE. This ensures that processes will no longer be called for this record. Thus error storms will not occur.

2. readvalue is called. See Chapter 3 , Section "Simulation Mode" on page 11 for details.

3. If PACT has been changed to TRUE, the device support read routine has started but has not completed writing the new value. In this case, the processing routine merely returns, leaving PACT TRUE.

4. Add count to histogram array.

5. Check to see if monitors should be invoked. Alarm monitors are invoked if the alarm status or severity has changed. Archive and value change monitors are invoked if MDEL conditions are met. NSEV and NSTA are reset to 0 .

6. Scan forward link if necessary, set PACT and INIT to FALSE, and return. 


\section{Chapter 18: longin - Long Input}

\section{Introduction}

The normal use for the longin record type is to input an integer value of up to 32 bits. Soft device modules are provided to obtain input via database or channel access links or via dbPutField or dbPutLink requests.

2. Field Summary

\begin{tabular}{|l|l|l|l|l|l|l|l|}
\hline \multicolumn{1}{|c|}{ Field } & \multicolumn{1}{|c|}{ Type } & \multicolumn{1}{c|}{ DCT } & \multicolumn{1}{c|}{ Initial } & Access & Modify & $\begin{array}{l}\text { Rec Proc } \\
\text { Monitor }\end{array}$ & \multicolumn{1}{c|}{ PP } \\
\hline \hline VAL & LONG & No & 0 & Yes & Yes & Yes & Yes \\
\hline INP & INLINK & Yes & 0 & No & No & N/A & No \\
\hline EGU & STRING & Yes & Null & Yes & Yes & No & No \\
\hline HOPR & LONG & Yes & 0 & Yes & Yes & No & No \\
\hline LOPR & LONG & Yes & 0 & Yes & Yes & No & No \\
\hline HIHI & LONG & Yes & 0 & Yes & Yes & No & Yes \\
\hline LOLO & LONG & Yes & 0 & Yes & Yes & No & Yes \\
\hline HIGH & LONG & Yes & 0 & Yes & Yes & No & Yes \\
\hline LOW & LONG & Yes & 0 & Yes & Yes & No & Yes \\
\hline HHSV & GBLCHOICE & Yes & 0 & Yes & Yes & No & Yes \\
\hline
\end{tabular}




\begin{tabular}{|l|l|l|l|l|l|l|l|}
\hline \multicolumn{1}{|c|}{ Field } & \multicolumn{1}{|c|}{ Type } & DCT & \multicolumn{1}{c|}{ Initial } & Access & Modify & $\begin{array}{l}\text { Rec Proc } \\
\text { Monitor }\end{array}$ & \multicolumn{1}{c|}{ PP } \\
\hline \hline LLSV & GBLCHOICE & Yes & 0 & Yes & Yes & No & Yes \\
\hline HSV & GBLCHOICE & Yes & 0 & Yes & Yes & No & Yes \\
\hline LSV & GBLCHOICE & Yes & 0 & Yes & Yes & No & Yes \\
\hline HYST & LONG & Yes & 0 & Yes & Yes & No & No \\
\hline ADEL & LONG & Yes & 0 & Yes & Yes & No & No \\
\hline MDEL & LONG & Yes & 0 & Yes & Yes & No & No \\
\hline LALM & LONG & No & 0 & Yes & No & No & No \\
\hline ALST & LONG & No & 0 & Yes & No & No & No \\
\hline MLST & LONG & No & 0 & Yes & No & No & No \\
\hline SIOL & INLINK & Yes & 0 & No & No & N/A & No \\
\hline SVAL & LONG & No & 0 & Yes & Yes & No & No \\
\hline SIML & INLINK & Yes & 0 & No & No & N/A & No \\
\hline SIMM & GBLCHOICE & No & 0 & Yes & Yes & No & No \\
\hline SIMS & GBLCHOICE & Yes & 0 & Yes & Yes & No & No \\
\hline
\end{tabular}

\section{Field Descriptions}

\begin{tabular}{|l|l|l|}
\hline \multicolumn{1}{|c|}{ Name } & \multicolumn{1}{|c|}{ Summary } & \multicolumn{1}{c|}{ Description } \\
\hline \hline VAL & Value Field & $\begin{array}{l}\text { This is the value resulting form record processing. If INP } \\
\text { is a constant, then VAL is initialized to the INP value but } \\
\text { it can be changed dynamically via dbPutField or } \\
\text { dbPutLink. }\end{array}$ \\
\hline INP & Input Link & $\begin{array}{l}\text { This field is used by the device support routines to obtain } \\
\text { input. For soft records, it can be a constant, a database } \\
\text { link, or a channel access link. }\end{array}$ \\
\hline EGU & Engineering Units & $\begin{array}{l}\text { ASCII string describing Engineering units. This field is } \\
\text { used by record support to supply a units description string } \\
\text { when get_units is called. }\end{array}$ \\
\hline HOPR & $\begin{array}{l}\text { High Operating } \\
\text { Range }\end{array}$ & $\begin{array}{l}\text { These fields determine the upper and lower display limits } \\
\text { for graphics displays and the upper and lower control } \\
\text { limits for control displays. The fields are used by record } \\
\text { support to honor calls to get_graphic_double or } \\
\text { get_control_double. }\end{array}$ \\
\hline LOPR & $\begin{array}{l}\text { Low Operating } \\
\text { Range }\end{array}$ &
\end{tabular}




\begin{tabular}{|c|c|c|}
\hline Name & Summary & Description \\
\hline HIHI & Hihi Alarm Limit & \multirow[t]{8}{*}{ These fields specify the alarm limits and severities. } \\
\hline $\mathrm{HIGH}$ & High Alarm Limit & \\
\hline LOW & Low Alarm Limit & \\
\hline LOLO & Lolo Alarm Limit & \\
\hline HHSV & $\begin{array}{l}\text { Severity for a Hihi } \\
\text { Alarm }\end{array}$ & \\
\hline HSV & $\begin{array}{l}\text { Severity for a High } \\
\text { Alarm }\end{array}$ & \\
\hline LSV & $\begin{array}{l}\text { Severity for a Low } \\
\text { Alarm }\end{array}$ & \\
\hline LLSV & $\begin{array}{l}\text { Severity for a Lolo } \\
\text { Alarm }\end{array}$ & \\
\hline HYST & Alarm Deadband & \multirow{3}{*}{$\begin{array}{l}\text { These parameters specify hysteresis factors for triggering } \\
\text { monitor callbacks, i.e. callbacks specified by calls to } \\
\text { caAddEvent or dbAddEvent. A monitor will not be } \\
\text { triggered until VAL changes by more than the specified } \\
\text { amount. }\end{array}$} \\
\hline ADEL & Archive Deadband & \\
\hline MDEL & $\begin{array}{l}\text { Monitor, i.e. value } \\
\text { change, Deadband }\end{array}$ & \\
\hline LALM & $\begin{array}{l}\text { Last Alarmed } \\
\text { Value }\end{array}$ & \multirow{3}{*}{$\begin{array}{l}\text { Value when last monitors for alarm/archiver/value } \\
\text { changes were triggered. These fields are used to } \\
\text { implement the hysteresis factors for monitor callbacks. }\end{array}$} \\
\hline ALST & Archive Last Value & \\
\hline MLST & Monitor Last Value & \\
\hline SIMM & Simulation Mode & \multirow{5}{*}{$\begin{array}{l}\text { Simulation mode process variables. Refer to Chapter } 3 \text {, } \\
\text { Section "Simulation Mode" on page } 11 \text { for more } \\
\text { information. }\end{array}$} \\
\hline SIML & $\begin{array}{l}\text { Simulation Mode } \\
\text { Location }\end{array}$ & \\
\hline SVAL & Simulation Value & \\
\hline SIOL & $\begin{array}{l}\text { Simulation Value } \\
\text { Location }\end{array}$ & \\
\hline SIMS & $\begin{array}{l}\text { Simulation Mode } \\
\text { Alarm Severity }\end{array}$ & \\
\hline
\end{tabular}

\section{Record Support Routines}

init_record

This routine initializes SIMM with the value of SIML if SIMU type is CONSTANT link or creates a channel access link if SIML type is PV_LINK. SVAL is likewise initialized if SIOL is CONSTANT or PV_LINK. 
This routine next checks to see that device support is available and a device support read routine is defined. If either does not exist, an error message is issued and processing is terminated.

If device support includes init_record, it is called.

\section{process}

get_value

get_units

get_graphic_double

get_control_double

get_alarm_double
See next section.

Fills in the values of struct valueDes so that they refer to VAL.

\section{Retrieves EGU.}

Sets the upper display and lower display limits for a field. If the field is VAL, HIHI, HIGH, LOW, or LOLO, the limits are set to HOPR and LOPR, else if the field has upper and lower limits defined they will be used, else the upper and lower maximum values for the field type will be used.

Sets the upper control and the lower control limits for a field. If the field is VAL, HIHI, HIGH, LOW, or LOLO, the limits are set to HOPR and LOPR, else if the field has upper and lower limits defined they will be used, else the upper and lower maximum values for the field type will be used.

Sets the following values:

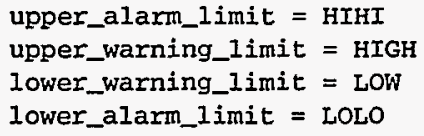

\section{Record Processing}

Routine process implements the following algorithm:

1. Check to see that the appropriate device support module exists. If it doesn't, an error message is issued and processing is terminated with the PACT field still set to TRUE. This ensures that processes will no longer be called for this record. Thus error storms will not occur.

2. readvalue is called. See Chapter 3, Section "Simulation Mode" on page 11 for details.

3. If PACT has been changed to TRUE, the device support read routine has started but has not completed reading a new input value. In this case, the processing routine merely returns, leaving PACT TRUE.

4. Check alarms. This routine checks to see if the new Vau causes the alarm status and severity to change. If So, NSEV, NSTA and LALM are set. It also honors the alarm hysteresis factor (HYST). Thus the value must change by more than HYST before the alarm status and severity is lowered. 
5. Check to see if monitors should be invoked.

- Alarm monitors are invoked if the alarm status or severity has changed.

- Archive and value change monitors are invoked if ADEL and MDEL conditions are met.

- NSEV and NSTA are reset to 0 .

6. Scan forward link if necessary, set PACT FAISE, and return.

\section{Device Support}

Fields Of Interest To Device Support

\section{Device Support} routines

report

init

init_record

get_ioint_info
Each long input record must have an associated set of device support routines. The primary responsibility of the device support routines is to obtain a new input value whenever read_longin is called. The device support routines are primarily interested in the following fields:

\begin{tabular}{|l|l|l|}
\multicolumn{1}{|c|}{ Name } & \multicolumn{1}{|c|}{ Summary } & \multicolumn{1}{c|}{ Description } \\
\hline \hline PACT & Processing Active & $\begin{array}{l}\text { See Chapter 2, Section "Database Common: Field } \\
\text { Descriptions" on page 5 for descriptions. }\end{array}$ \\
\cline { 1 - 2 } DPVT & Device Private & \\
\cline { 1 - 2 } UDF & VAL Undefined & \\
\cline { 1 - 2 } NSEV & New Alarm Severity & \\
\cline { 1 - 2 } NSTA & New Alarm Status & \\
\hline VAL & Value Field & This field is set by device support routines. \\
\hline INP & Input Link & $\begin{array}{l}\text { This field is used by the device support routines to locate } \\
\text { its input. }\end{array}$ \\
\hline
\end{tabular}

Device support consists of the following routines:

report (FILE fp, paddr)

Not currently used.

init ()

This routine is called once during IOC initialization.

init_record(precord)

This routine is optional. If provided, it is called by the record support init_record routine.

get_ioint_info(int cmd, struct dbCommon *precord, IOSCANPVT *ppvt) 
This routine is called by the ioEventscan system each time the record is added or deleted from an $\mathrm{I} / \mathrm{O}$ event scan list. cma has the value $(0,1)$ if the record is being (added to, deleted from) an I/O event list. It must be provided for any device type that can use the joEvent scanner.

read_longin

read_longin(precord)

This routine must provide a new input value. It returns the following values:

- 0: Success. A new value is placed in VAI.

- Other: Error.

\section{Device Support For Soft Records}

This module places a value directly in VAL.

If the INP link type is constant, then the constant value is stored into VAI by init_record, and UDF is set to FALSE. If the INP link type is PV_LINK, then dbCaAddInlink is called by init_record.

read_longin calls recGblGetLinkValue to read the current value of VAL. See Chapter 3 , Section "Soft Input" on page 10 for details.

If the return status of recGblGetLinkValue is zero then read_longin sets UDF to FALSE. read_longin returns the status of recGblGetLinkValue. 


\section{Chapter 19: longout - Long Output}

\section{Introduction}

The normal use for the longout record type is to store integer values of up to $31 \mathrm{bits}$. It can also be used to write values to other records via database or channel access links. The OUT field determines how the record is used. The record supports alarm limits and graphics and control limits.

2. Field Summary

\begin{tabular}{|l|l|l|l|l|l|l|l|}
\hline \multicolumn{1}{|c|}{ Field } & \multicolumn{1}{|c|}{ Type } & DCT & \multicolumn{1}{c|}{ Initial } & Access & Modify & $\begin{array}{l}\text { Rec Proc } \\
\text { Monitor }\end{array}$ & \multicolumn{1}{c|}{ PP } \\
\hline \hline VAL & LONG & No & 0 & Yes & Yes & Yes & Yes \\
\hline OUT & OUTLINK & Yes & 0 & No & No & N/A & No \\
\hline DOL & INLINK & Yes & 0 & No & No & N/A & No \\
\hline OMSL & GBLCHOICE & Yes & 0 & Yes & Yes & No & No \\
\hline EGU & STRING & Yes & Null & Yes & Yes & No & No \\
\hline HOPR & LONG & Yes & 0 & Yes & Yes & No & No \\
\hline LOPR & LONG & Yes & 0 & Yes & Yes & No & No \\
\hline HIHI & LONG & Yes & 0 & Yes & Yes & No & Yes \\
\hline LOLO & LONG & Yes & 0 & Yes & Yes & No & Yes \\
\hline HIGH & LONG & Yes & 0 & Yes & Yes & No & Yes \\
\hline
\end{tabular}




\begin{tabular}{|l|l|l|l|l|l|l|l|}
\hline \multicolumn{1}{|c|}{ Field } & \multicolumn{1}{|c|}{ Type } & DCT & \multicolumn{1}{c|}{ Initial } & Access & Modify & $\begin{array}{l}\text { Rec Proc } \\
\text { Monitor }\end{array}$ & \multicolumn{1}{|c|}{ PP } \\
\hline \hline LOW & LONG & Yes & 0 & Yes & Yes & No & Yes \\
\hline HHSV & GBLCHOICE & Yes & 0 & Yes & Yes & No & Yes \\
\hline LLSV & GBLCHOICE & Yes & 0 & Yes & Yes & No & Yes \\
\hline HSV & GBLCHOICE & Yes & 0 & Yes & Yes & No & Yes \\
\hline LSV & GBLCHOICE & Yes & 0 & Yes & Yes & No & Yes \\
\hline HYST & LONG & Yes & 0 & Yes & Yes & No & No \\
\hline ADEL & LONG & Yes & 0 & Yes & Yes & No & No \\
\hline MDEL & LONG & Yes & 0 & Yes & Yes & No & No \\
\hline LALM & LONG & No & 0 & Yes & No & No & No \\
\hline ALST & LONG & No & 0 & Yes & No & No & No \\
\hline MLST & LONG & No & 0 & Yes & No & No & No \\
\hline SIOL & INLINK & Yes & 0 & No & No & N/A & No \\
\hline SIML & INLINK & Yes & 0 & No & No & N/A & No \\
\hline SIMM & GBLCHOICE & No & 0 & Yes & Yes & No & No \\
\hline SIMS & GBLCHOICE & Yes & 0 & Yes & Yes & No & No \\
\hline IVOA & GBLCHOICE & Yes & 0 & Yes & Yes & No & No \\
\hline IVOV & LONG & Yes & 0 & Yes & Yes & No & No \\
\hline
\end{tabular}

\section{Field Descriptions}

\begin{tabular}{|l|l|l|}
\hline \multicolumn{1}{|c|}{ Name } & \multicolumn{1}{|c|}{ Summary } & \multicolumn{1}{c|}{ Description } \\
\hline \hline VAL & Value & $\begin{array}{l}\text { This is the desired output value, in engineering units. If } \\
\text { DRVH and DRVL are defined, VAL is forced to be within } \\
\text { the drive limits. VAL is either obtained from DOL or set } \\
\text { via dbPuts. }\end{array}$ \\
\hline OUT & Output Link & $\begin{array}{l}\text { This field is used by the device support routines to decide } \\
\text { where to send output. For soft records, it can be a } \\
\text { constant, a database link, or a channel access link. If the } \\
\text { link is a constant, the result is no output. }\end{array}$ \\
\hline DOL & $\begin{array}{l}\text { Desired Output } \\
\text { Location (input } \\
\text { link) }\end{array}$ & $\begin{array}{l}\text { If DOL is a database or channel access link and OMSL is } \\
\text { CLOSED_LOOP, then VAL is read from DOL. After the } \\
\text { check for drive limits VAL will be set to the value } \\
\text { determined by DOL. }\end{array}$ \\
\hline
\end{tabular}




\begin{tabular}{|c|c|c|}
\hline Name & Summary & Description \\
\hline OMSL & Output Mode Select & $\begin{array}{l}\text { This field has either the value SUPERVISORY or } \\
\text { CLOSED_LOOP. DOL is used to determine VAI only if } \\
\text { OMSL has the value CLOSED_LOOP. By setting this field } \\
\text { the record can be switched between supervisory and } \\
\text { closed loop mode of operation. While in closed loop } \\
\text { mode, the VAL field cannot be set via dbPuts. }\end{array}$ \\
\hline EGU & Engineering Units & $\begin{array}{l}\text { ASCII string describing Engineering units. This field is } \\
\text { used by record support to supply a units description string } \\
\text { when get_units is called. }\end{array}$ \\
\hline HOPR & $\begin{array}{l}\text { High Operating } \\
\text { Range }\end{array}$ & \multirow{2}{*}{$\begin{array}{l}\text { These fields determine the upper and lower display limits } \\
\text { for graphics displays and the upper and lower control } \\
\text { limits for control displays. The fields are used by record } \\
\text { support to honor calls to get_graphic_double or } \\
\text { get_control_double. If these values are defined, } \\
\text { they must be in the range } \\
\text { DRVL }<=\text { LOPR }<=\text { HOPR }<=\text { DRVH. }\end{array}$} \\
\hline LOPR & $\begin{array}{l}\text { Low Operating } \\
\text { Range }\end{array}$ & \\
\hline HIHI & Hihi Alarm Limit & \multirow{8}{*}{ These fields specify the alarm limits and severities. } \\
\hline $\mathrm{HIGH}$ & High Alarm Limit & \\
\hline LOW & Low Alarm Limit & \\
\hline LOLO & Lolo Alarm Limit & \\
\hline HHSV & $\begin{array}{l}\text { Hihi Alarm } \\
\text { Severity }\end{array}$ & \\
\hline HSV & $\begin{array}{l}\text { High Alarm } \\
\text { Severity }\end{array}$ & \\
\hline LSV & $\begin{array}{l}\text { Low Alarm } \\
\text { Severity }\end{array}$ & \\
\hline LLSV & $\begin{array}{l}\text { Lolo Alarm } \\
\text { Severity }\end{array}$ & \\
\hline HYST & Alarm Deadband & \multirow{3}{*}{$\begin{array}{l}\text { These parameters specify hysteresis factors for triggering } \\
\text { monitor callbacks, i.e. callbacks specified by calls to } \\
\text { caAddEvent or dbAddEvent. A monitor will not be } \\
\text { triggered until VAL changes by more than the specified } \\
\text { amount. }\end{array}$} \\
\hline ADEL & Archive Deadband & \\
\hline MDEL & $\begin{array}{l}\text { Monitor, i.e. value } \\
\text { change, Deadband }\end{array}$ & \\
\hline LALM & $\begin{array}{l}\text { Last Alarmed } \\
\text { Value }\end{array}$ & \multirow{3}{*}{$\begin{array}{l}\text { Value when last monitors for alarm/archiver/value change } \\
\text { were triggered. These fields are used to implement the } \\
\text { hysteresis factors for monitors. }\end{array}$} \\
\hline ALST & Archive Last Value & \\
\hline MLST & Monitor Last Value & \\
\hline
\end{tabular}




\begin{tabular}{|c|c|c|}
\hline Name & Summary & Description \\
\hline SIMM & Simulation Mode & \multirow{4}{*}{$\begin{array}{l}\text { Simulation mode process variables. Refer to Chapter } 3 \\
\text { Section "Simulation Mode" on page } 13 \text { for more } \\
\text { information. }\end{array}$} \\
\hline SIML & $\begin{array}{l}\text { Simulation Mode } \\
\text { Location }\end{array}$ & \\
\hline SIOL & $\begin{array}{l}\text { Simulation Value } \\
\text { Location }\end{array}$ & \\
\hline SIMS & $\begin{array}{l}\text { Simulation Mode } \\
\text { Alarm Severity }\end{array}$ & \\
\hline IVOA & $\begin{array}{l}\text { Invalid Alarm } \\
\text { Output Action }\end{array}$ & \multirow{2}{*}{$\begin{array}{l}\text { Whenever the record is put into INVALID alarm severity } \\
\text { IVOA specifies an action. See Chapter } 3 \text { Section "Invalid } \\
\text { Alarm Output Action" on page } 14 \text { for more information. }\end{array}$} \\
\hline IVOV & $\begin{array}{l}\text { Invalid Alarm } \\
\text { Output Value }\end{array}$ & \\
\hline
\end{tabular}

\section{Record Support Routines}

\section{init_record}

process

get_value

get_units

get_graphic_double
This routine initializes SIMM if SIMU is a constant or creates a channel access link if SIMU is PV_LINK. If SIOL is PV_LINK a channel access link is created.

This routine next checks to see that device support is available. The routine next checks to see if the device support write routine is defined. If either device support or the device support write routine does not exist, an error message is issued and processing is terminated.

If DOL is a constant, then VAL is initialized to its value and UDF is set to FALSE. If DOL type is a PV_LINK then dbcaAddInlink is called to create a channel access link.

If device support includes init_record, it is called.

See next section.

Fills in the values of struct valueDes so that they refer to VAL.

Retrieves EGU.

Sets the upper display and lower display limits for a field. If the field is VAI, HIHI, HIGH, LOW, or LOLO, the limits are set to HOPR and LOPR, else if the field has upper and lower limits defined they will be used, else the upper and lower maximum values for the field type will be used. 
get_control_double

get_alarm_double
Sets the upper control and the lower control limits for a field. If the field is VAL, HIHI, HIGH, LOW, or LOLO, the limits are set to HOPR and LOPR, else if the field has upper and lower limits defined they will be used, else the upper and lower maximum values for the field type will be used.

Sets the following values:

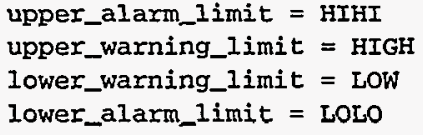

\section{Record Processing}

Routine process implements the following algorithm:

1. Check to see that the appropriate device support module exists. If it doesn't, an error message is issued and processing is terminated with the PACT field still set to TRUE. This ensures that processes will no longer be called for this record. Thus error storms will not occur.

2. If PACT is FALSE and OMSL is CLOSED_LOOP recGbIGetIinkValue is called to read the current value of VAI. See Chapter 3 Section "Soft Input" on page 10 for details. If the return status of recGblGetLinkValue is zero then UDF is set to FALSE.

3. Check alarms. This routine checks to see if the new vaL causes the alarm status and severity to change. If so, NSEV, NSTA and LALM are set. It also honors the alarm hysteresis factor (HYST). Thus the value must change by more than HYST before the alarm status and severity is lowered.

4. Check severity and write the new value. See Chapter 3 Section "Simulation Mode" on page 13 and Chapter 3 Section "Invalid Alarm Output Action" on page 14 for details.

5. If PACT has been changed to TRUE, the device support write output routine has started but has not completed writing the new value. In this case, the processing routine merely returns, leaving PACT TRUE.

6. Check to see if monitors should be invoked.

- Alarm monitors are invoked if the alarm status or severity has changed.

- Archive and value change monitors are invoked if ADEL and MDEL contitions are met.

- NSEV and NSTA are reset to 0.

7. Scan forward link if necessary, set PACT FALSE, and return. 


\section{Device Support}

Fields Of Interest To Device Support

\section{Device Support Routines}

init

init_record

get_ioint_info

write_longout
Each long output record must have an associated set of device support routines. The primary responsibility of the device support routines is to output a new value whenever write__longout is called. The device support routines are primarily interested in the following fields:

\begin{tabular}{|l|l|l|}
\hline \multicolumn{1}{|c|}{ Name } & \multicolumn{1}{c|}{ Summary } & \multicolumn{1}{c|}{ Description } \\
\hline \hline PACT & Processing Active & \multirow{2}{*}{$\begin{array}{l}\text { See Chapter 2 Section "Database Common: Field } \\
\text { Descriptions" on page 5 for descriptions. }\end{array}$} \\
\cline { 1 - 2 } DPVT & Device Private & \\
\cline { 1 - 2 } NSEV & New Alärm Severity & \\
\cline { 1 - 2 } NSTA & New Alarm Status & \\
\hline OUT & Output Link & $\begin{array}{l}\text { This field is used by the device support routines to locate } \\
\text { its output. }\end{array}$ \\
\hline
\end{tabular}

Device support consists of the following routines:

init ()

This routine is called once during IOC initialization.

init_record (precord)

This routine is optional. If provided, it is called by the record support init_record routine.

get_ioint_info(int cmd,struct dbCommon *precord,IOSCANPVT *ppvt)

This routine is called by the ioEventscan system each time the record is added or deleted from an I/O event scan list. cma has the value $(0,1)$ if the record is being (added to, deleted from) an I/O event list. It must be provided for any device type that can use the ioEvent scanner.

write_longout (precord)

This routine must output a new value. It returns the following values:

- 0: Success.

- Other: Error.

\section{Device Support For Soft Records}

This module writes the current value of VAL. 
If the ouT link type is PV_LINK, then dbCaAddInlink is called by init_record.

write_longout calls recGblPutLinkValue to write the current value of VAL. See Chapter 3 Section "Soft Output" on page 13 for details. 
Chapter 19: longout - Long Output

Device Support For Soft Records 


\section{Chapter 20: mbbi - MultiBit Binary Input}

\section{Introduction}

The normal use for the mbbi record type is to obtain a binary value that represents one of up to 16 states. Most device support modules obtain values from hardware and place the value in RVAL. For these devices record processing uses RVAL to determine the current state (VAL is given a value between 0 and 15 ). Devices may optionally read a value directly into VAL. Soft device modules are provided to obtain input via database or channel access links or via dbPutField or dbPutLink requests. Two soft device support modules are provided. One allows VAL to be an arbitrary unsigned short integer. The other reads the value into RVAL just like normal hardware modules.

\section{Field Summary}

\begin{tabular}{|l|l|l|l|l|l|l|l|}
\hline \multicolumn{1}{|c|}{ Field } & \multicolumn{1}{|c|}{ Type } & \multicolumn{1}{c|}{ DCT } & \multicolumn{1}{c|}{ Initial } & Access & Modify & $\begin{array}{l}\text { RecProc } \\
\text { Monitor }\end{array}$ & \multicolumn{1}{|c|}{ PP } \\
\hline \hline VAL & ENUM & No & 0 & Yes & Yes & Yes & Yes \\
\hline NOBT & SHORT & Yes & 0 & Yes & No & & No \\
\hline INP & INLINK & Yes & 0 & No & No & N/A & No \\
\hline ZRVL & ULONG & Yes & 0 & Yes & Yes & No & Yes \\
\hline ONVL & ULONG & Yes & 0 & Yes & Yes & No & Yes \\
\hline TWVL & ULONG & Yes & 0 & Yes & Yes & No & Yes \\
\hline THVL & ULONG & Yes & 0 & Yes & Yes & No & Yes \\
\hline
\end{tabular}




\begin{tabular}{|c|c|c|c|c|c|c|c|}
\hline Field & Type & DCT & Initial & Access & Modify & $\begin{array}{l}\text { Rec Proc } \\
\text { Monitor }\end{array}$ & PP \\
\hline FRVL & ULONG & Yes & 0 & Yes & Yes & No & Yes \\
\hline FVVL & ULONG & Yes & 0 & Yes & Yes & No & Yes \\
\hline SXVL & ULONG & Yes & 0 & Yes & Yes & No & Yes \\
\hline SVVL & ULONG & Yes & 0 & Yes & Yes & No & Yes \\
\hline EIVL & ULONG & Yes & 0 & Yes & Yes & No & Yes \\
\hline NIVL & ULONG & Yes & 0 & Yes & Yes & No & Yes \\
\hline TEVL & ULONG & Yes & 0 & Yes & Yes & No & Yes \\
\hline ELVL & ULONG & Yes & 0 & Yes & Yes & No & Yes \\
\hline TVVL & ULONG & Yes & 0 & Yes & Yes & No & Yes \\
\hline TTVL & ULONG & Yes & 0 & Yes & Yes & No & Yes \\
\hline FTVL & ULONG & Yes & 0 & Yes & Yes & No & Yes \\
\hline FFVL & ULONG & Yes & 0 & Yes & Yes & No & Yes \\
\hline ZRST & STRING & Yes & Null & Yes & Yes & No & Yes \\
\hline ONST & STRING & Yes & Null & Yes & Yes & No & Yes \\
\hline TWST & STRING & Yes & Null & Yes & Yes & No & Yes \\
\hline THST & STRING. & Yes & Null & Yes & Yes & No & Yes \\
\hline FRST & STRING & Yes & Null & Yes & Yes & No & Yes \\
\hline FVST & STRING & Yes & Null & Yes & Yes & No & Yes \\
\hline SXST & STRING & Yes & Null & Yes & Yes & No & Yes \\
\hline SVST & STRING & Yes & Null & Yes & Yes & No & Yes \\
\hline EIST & STRING & Yes & Null & Yes & Yes & No & Yes \\
\hline NIST & STRING & Yes & Null & Yes & Yes & No & Yes \\
\hline TEST & STRING & Yes & Null & Yes & Yes & No & Yes \\
\hline ELST & STRING & Yes & Null & Yes & Yes & No & Yes \\
\hline TVST & STRING & Yes & Null & Yes & Yes & No & Yes \\
\hline TTST & STRING & Yes & Null & Yes & Yes & No & Yes \\
\hline FTST & STRING & Yes & Null & Yes & Yes & No & Yes \\
\hline FFST & STRING & Yes & Null & Yes & Yes & No & Yes \\
\hline ZRSV & GBLCHOICE & Yes & 0 & Yes & Yes & No & Yes \\
\hline ONSV & GBLCHOICE & Yes & 0 & Yes & Yes & No & Yes \\
\hline TWSV & GBLCHOICE & Yes & 0 & Yes & Yes & No & Yes \\
\hline THSV & GBLCHOICE & Yes & 0 & Yes & Yes & No & Yes \\
\hline
\end{tabular}




\begin{tabular}{|c|c|c|c|c|c|c|c|}
\hline Field & Type & DCT & Initial & Access & Modify & $\begin{array}{l}\text { RecProc } \\
\text { Monitor } \\
\end{array}$ & PP \\
\hline FRSV & GBLCHOICE & Yes & 0 & Yes & Yes & No & Yes \\
\hline FVSV & GBLCHOICE & Yes & 0 & Yes & Yes & No & Yes \\
\hline SXSV & GBLCHOICE & Yes & 0 & Yes & Yes & No & Yes \\
\hline SVSV & GBLCHOICE & Yes & 0 & Yes & Yes & No & Yes \\
\hline EISV & GBLCHOICE & Yes & 0 & Yes & Yes & No & Yes \\
\hline NISV & GBLCHOICE & Yes & 0 & Yes & Yes & No & Yes \\
\hline TESV & GBLCHOICE & Yes & 0 & Yes & Yes & No & Yes \\
\hline ELSV & GBLCHOICE & Yes & 0 & Yes & Yes & No & Yes \\
\hline TVSV & GBLCHOICE & Yes & 0 & Yes & Yes & No & Yes \\
\hline TTSV & GBLCHOICE & Yes & 0 & Yes & Yes & No & Yes \\
\hline FTSV & GBLCHOICE & Yes & 0 & Yes & Yes & No & Yes \\
\hline FFSV & GBLCHOICE & Yes & 0 & Yes & Yes & No & Yes \\
\hline UNSV & GBLCHOICE & Yes & 0 & Yes & Yes & No & Yes \\
\hline COsV & GBLCHOICE & Yes & 0 & Yes & Yes & No & Yes \\
\hline RVAL & ULONG & No & 0 & Yes & Yes & Yes & Yes \\
\hline ORAW & ULONG & No & 0 & Yes & No & No & No \\
\hline MASK & ULONG & No & 0 & Yes & No & No & No \\
\hline MLST & USHORT & No & 0 & Yes & No & No & No \\
\hline LALM & USHORT & No & 0 & Yes & No & No & No \\
\hline SDEF & SHORT & No & 0 & Yes & No & No & No \\
\hline SHFT & USHORT & No & 0 & Yes & No & No & No \\
\hline SIOL & INLINK & Yes & 0 & No & No & N/A & No \\
\hline SVAL & USHORT & No & 0 & Yes & Yes & No & No \\
\hline SIML & INLINK & Yes & 0 & No & No & N/A & No \\
\hline SIMM & GBLCHOICE & No & 0 & Yes & Yes & No & No \\
\hline SIMS & GBLCHOICE & Yes & 0 & Yes & Yes & No & No \\
\hline
\end{tabular}




\section{Field Descriptions}

\begin{tabular}{|c|c|c|}
\hline Name & Summary & Description \\
\hline VAL & Value Field & $\begin{array}{l}\text { Unless INP is a constant link, this is the value resulting } \\
\text { from the record being processed. If INP is a constant, then } \\
\text { VAL is initialized to the INP value but can be changed } \\
\text { dynamically via dbPutField or dbPutLink. It } \\
\text { normally is the index ( } 0 \text { to } 15) \text { of the current state. }\end{array}$ \\
\hline NOBT & Number of Bits & Number of bits set in hardware mask. \\
\hline INP & Input Link & $\begin{array}{l}\text { This field is used by the device support routines to obtain } \\
\text { input. For soft records, it can be a constant, a database } \\
\text { link, or a channel access link. }\end{array}$ \\
\hline ZRVL,...,FFVL & $\begin{array}{l}\text { Zero Value, One } \\
\text { Value ... }\end{array}$ & Masks for hardware value associated with each state. \\
\hline ZRST,...,FFST & $\begin{array}{l}\text { Zero String, One } \\
\text { String ... }\end{array}$ & Strings associated with each state. \\
\hline $\mathrm{ZRSV}, \ldots, \mathrm{FFSV}$ & $\begin{array}{l}\text { Zero Severity, One } \\
\text { Severity,... }\end{array}$ & Alarm severity associated with each state. \\
\hline UNSV & $\begin{array}{l}\text { Unknown State } \\
\text { Severity }\end{array}$ & \\
\hline $\operatorname{cosv}$ & $\begin{array}{l}\text { Change of State } \\
\text { Severity }\end{array}$ & \\
\hline RVAL & Raw Data Value & $\begin{array}{l}\text { RVAL is the value obtained by the device support routine. } \\
\text { Unless the device support routine specifies no conversion, } \\
\text { VAL is determined as follows: A temporary variable rval } \\
\text { is set equal to RVAL. It is then shifted right SHFT bits. } \\
\text { After shifting, the result should match one of the values } \\
\text { ZRVL,...,FFVL. }\end{array}$ \\
\hline ORAW & $\begin{array}{l}\text { Old Raw Data } \\
\text { Value }\end{array}$ & $\begin{array}{l}\text { ORAW is used to decide if monitors should be triggered for } \\
\text { RVAL at the same time monitors are triggered for changes } \\
\text { in VAL. }\end{array}$ \\
\hline MASK & Mask & $\begin{array}{l}\text { Mask used by device support routine to read hardware } \\
\text { register. Record support sets low order NOBT bits. Device } \\
\text { support can shift this value. }\end{array}$ \\
\hline SHFT & Shift & Number of bits to shift values obtained from RVAL. \\
\hline LALM & Last Alarmed & Value when last change of state alarm was issued. \\
\hline MLST & Monitor Last & Value when last monitor for value changes was triggered \\
\hline SDEF & States Defined? & $\begin{array}{l}\text { Record support uses this field to save time if no states are } \\
\text { defined }\end{array}$ \\
\hline
\end{tabular}




\begin{tabular}{|l|l|l|}
\hline \multicolumn{1}{|c|}{ Name } & \multicolumn{1}{|c|}{ Summary } & \multicolumn{1}{c|}{ Description } \\
\hline \hline SIMM & Simulation Mode & $\begin{array}{l}\text { Simulation mode process variables. Refer to Chapter 3, } \\
\text { Section "Simulation Mode" on page 11 for more } \\
\text { information. }\end{array}$ \\
\hline SIML & $\begin{array}{l}\text { Simulation Mode } \\
\text { Location }\end{array}$ & \\
\hline SVAL & Simulation Value & \\
\hline SIOL & $\begin{array}{l}\text { Simulation Value } \\
\text { Location }\end{array}$ & \\
\hline SIMS & $\begin{array}{l}\text { Simulation Mode } \\
\text { Alarm Severity }\end{array}$ & \\
\hline
\end{tabular}

\section{Record Support Routines}

init_record

process

special

get_value

get_enum_str

get_enum_strs

put_enum_str
This routine initializes SIMM with the value of SIML if SIML type is CONSTANT link or creates a channel access link if SIMU type is PV_LINK. SVAL is likewise initialized if SIOL is CONSTANT or PV_LINK.

This routine next checks to see that device support is available and a device support read routine is defined. If either does not exist, an error message is issued and processing is terminated.

Clears MASK and then sets the NOBT low order bits.

If device support includes init_record, it is called.

init_common is then called to determine if any states are defined. If states are defined, SDEF is set to TRUE.

See next section.

Calls init_common to compute SDEF when any of the fields ZRVL, ... FFVL change value.

Fills in the values of struct valueDes so that they refer to VAL.

Retrieves ASCI string corresponding to VAL.

Retrieves ASCII strings for ZRST,...FFST.

Checks if string matches ZRST,...FFST and if it does, sets VAL. 


\section{Record Processing}

Routine process implements the following algorithm:

1. Check to see that the appropriate device support module exists. If it doesn't, an error message is issued and processing is terminated with the PACT field still set to TRUE. This ensures that processes will no longer be called for this record. Thus error storms will not occur.

2. readvalue is called. See Chapter 3, Section "Simulation Mode" on page 11 for details.

3. If PACT has been changed to TRUE, the device support read routine has started but has not completed reading a new input value. In this case, the processing routine merely returns, leaving PACT TRUE.

4. Convert.

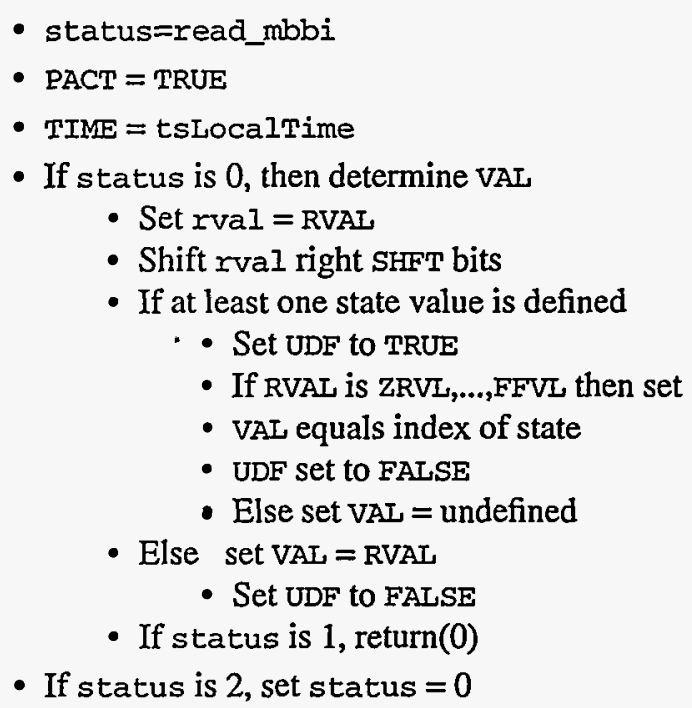

5. Check alarms. This routine checks to see if the new VAL causes the alarm status and severity to change. If so, NSEV, NSTA and LALM are set.

6. Check to see if monitors should be invoked.

- Alarm monitors are invoked if the alarm status or severity has changed.

- Archive and value change monitors are invoked if MLST is not equal to VAL.

- Monitors for RVAL are checked whenever other monitors are invoked.

- NSEV and NSTA are reset to 0 .

7. Scan forward link if necessary, set PACT FALSE, and return. 


\section{Device Support}

Fields Of Interest

To Device

Support
Device Support

\section{Routines}

report

init

init_record
Each input record must have an associated set of device support routines. The primary responsibility of the device support routines is to obtain a new raw input value whenever read_mbbi is called. The device support routines are primarily interested in the following fields:

\begin{tabular}{|c|c|c|}
\hline Name & Summary & Description \\
\hline PACT & Processing Active & \multirow{5}{*}{$\begin{array}{l}\text { See Chapter 2, Section "Database Common: Field } \\
\text { Descriptions" on page } 5 \text { for descriptions. }\end{array}$} \\
\hline DPVT & Device Private & \\
\hline UDF & VAL Undefined & \\
\hline NSEV & New Alarm Severity & \\
\hline NSTA & New Alarm Status & \\
\hline NOBT & Number of Bits & $\begin{array}{l}\text { Number of hardware bits accessed. They must be } \\
\text { consecutive. }\end{array}$ \\
\hline VAL & Value Field & $\begin{array}{l}\text { This field is set by the device support routines if they } \\
\text { don't want record support to set it. }\end{array}$ \\
\hline INP & Input Link & $\begin{array}{l}\text { This field is used by the device support routines to locate } \\
\text { its input. }\end{array}$ \\
\hline RVAL & Raw Data Value & $\begin{array}{l}\text { It is the responsibility of the device support routine to give } \\
\text { this field a value. }\end{array}$ \\
\hline MASK & Mask & $\begin{array}{l}\text { This is a mask used to read the hardware. Record support } \\
\text { sets the low order NOBT bits. The device support routine } \\
\text { can shift the bits. The device support routine should } \\
\text { perform the shift in in init_record. }\end{array}$ \\
\hline SHFT & Shift & $\begin{array}{l}\text { This can be set by the device support module at } \\
\text { init_record time. }\end{array}$ \\
\hline
\end{tabular}

Device support consists of the following routines:

$$
\text { report (FILE fp, paddr) }
$$

Not currently used.

$$
\text { init) }
$$

This routine is called once during IOC initialization. 
This routine is optional. If provided, it is called by the record support init_record routine. If it uses MASK, it should shift it as necessary and also give SHFT a value.

get_ioint_info

read_mbbi get_ioint_info(int cmd, struct dbcommon *precord, roscanpvT *ppvt)

This routine is called by the ioEventScan system each time the record is added or deleted from an I/O event scan list. cmi has the value $(0,1)$ if the record is being (added to, deleted from) an I/O event list. It must be provided for any device type that can use the ioEvent scanner.

read_mbbi (precord)

This routine must provide a new input value. It returns the following values:

- 0: Success. A new raw value is placed in RVAL. The record support module determines VAL from RVAL, SHFT, and ZEVL ... FFVL.

- 2: Success, but don't modify val.

- Other: Error.

\section{Device Support For Soft Records}

Two soft device support modules Soft Channel and Raw Soft Channel are provided for multibit binary input records not related to actual hardware devices. The INP link type must be either CONSTANT, DB_IINK, or CA_LINK.

Soft Channel

read_mbbi always returns a value of 2 , which means that no conversion is performed.

If the INP link type is constant, then the constant value is stored into VAI by init_record, and UDF is set to FALSE. VAL can be changed via dbPut requests. If the INP link type is PV_LINK, then dbCaAddInlink is called by init_record.

read_mbbi calls recGblGetLinkValue to read the current value of VAL. See Chapter 3, Section "Soft Input" on page 10 for details.

If the return status of recGblGetLinkValue is zero, then read_mbbi sets UDF to FALSE. The status of recGblGetLinkValue is returned.

Raw Soft

Channel
This module is like the previous except that values are read into RVAL, VAL is computed from RVAL, and read_mbbi returns a value of 0 . Thus the record processing routine will determine VAL in the normal way. 


\section{Chapter 21: mbbo - MultiBit Binary Output}

\section{Introduction.}

The normal use for the mbbo record type is to send a binary value (representing one of up to 16 states) to a Digital Output module. It can also be used to write to other records via database or channel access links.

\section{Field Summary}

\begin{tabular}{|l|l|l|l|l|l|l|l|}
\hline \multicolumn{1}{|c|}{ Field } & \multicolumn{1}{|c|}{ Type } & DCT & Initial & Access & Modify & $\begin{array}{l}\text { RecProc } \\
\text { Monitor }\end{array}$ & \multicolumn{1}{|c|}{ PP } \\
\hline \hline VAL & ENUM & No & 0 & Yes & Yes & Yes & Yes \\
\hline DOL & INLINK & Yes & 0 & No & No & N/A & No \\
\hline OMSL & GBLCHOICE & Yes & 0 & Yes & Yes & No & No \\
\hline NOBT & SHORT & Yes & 0 & Yes & No & & No \\
\hline OUT & OUTLINK & Yes & 0 & No & No & N/A & No \\
\hline ZRVL & ULONG & Yes & 0 & Yes & Yes & No & Yes \\
\hline ONVL & ULONG & Yes & 0 & Yes & Yes & No & Yes \\
\hline TWVL & ULONG & Yes & 0 & Yes & Yes & No & Yes \\
\hline THVL & ULONG & Yes & 0 & Yes & Yes & No & Yes \\
\hline FRVL & ULONG & Yes & 0 & Yes & Yes & No & Yes \\
\hline
\end{tabular}




\begin{tabular}{|c|c|c|c|c|c|c|c|}
\hline Field & Type & DCT & Initial & Access & Modify & \begin{tabular}{|l|} 
Rec Proc \\
Monitor \\
\end{tabular} & PP \\
\hline FVVL & ULONG & Yes & 0 & Yes & Yes & No & Yes \\
\hline SXVL & ULONG & Yes & 0 & Yes & Yes & No & Yes \\
\hline SVVL & ULONG & Yes & 0 & Yes & Yes & No & Yes \\
\hline EIVL & ULONG & Yes & 0 & Yes & Yes & No & Yes \\
\hline NIVL & ULONG & Yes & 0 & Yes & Yes & No & Yes \\
\hline TEVL & ULONG & Yes & 0 & Yes & Yes & No & Yes \\
\hline ELVL & ULONG & Yes & 0 & Yes & Yes & No & Yes \\
\hline TVVL & ULONG & Yes & 0 & Yes & Yes & No & Yes \\
\hline TTVL & ULONG & Yes & 0 & Yes & Yes & No & Yes \\
\hline FTVL & ULONG & Yes & 0 & Yes & Yes & No & Yes \\
\hline FFVL & ULONG & Yes & 0 & Yes & Yes & No & Yes \\
\hline ZRST & STRING & Yes & Null & Yes & Yes & No & Yes \\
\hline ONST & STRING & Yes & Null & Yes & Yes & No & Yes \\
\hline TWST & STRING & Yes & Null & Yes & Yes & No & Yes \\
\hline THST & STRING & Yes & Null & Yes & Yes & No & Yes \\
\hline FRST & STRING & Yes & Null & Yes & Yes & No & Yes \\
\hline FVST & STRING & Yes & Null & Yes & Yes & No & Yes \\
\hline SXST & STRING & Yes & Null & Yes & Yes & No & Yes \\
\hline SVST & STRING & Yes & Null & Yes & Yes & No & Yes \\
\hline EIST & STRING & Yes & Null & Yes & Yes & No & Yes \\
\hline NIST & STRING & Yes & Null & Yes & Yes & No & Yes \\
\hline TEST & STRING & Yes & Null & Yes & Yes & No & Yes \\
\hline ELST & STRING & Yes & Null & Yes & Yes & No & Yes \\
\hline TVST & STRING & Yes & Null & Yes & Yes & No & Yes \\
\hline TTST & STRING & Yes & Null & Yes & Yes & No & Yes \\
\hline FTST & STRING & Yes & Null & Yes & Yes & No & Yes \\
\hline FFST & STRING & Yes & Null & Yes & Yes & No & Yes \\
\hline ZRSV & GBLCHOICE & Yes & 0 & Yes & Yes & No & Yes \\
\hline ONSV & GBLCHOICE & Yes & 0 & Yes & Yes & No & Yes \\
\hline TWSV & GBLCHOICE & Yes & 0 & Yes & Yes & No & Yes \\
\hline THSV & GBLCHOICE & Yes & 0 & Yes & Yes & No & Yes \\
\hline FRSV & GBLCHOICE & Yes & 0 & Yes & Yes & No & Yes \\
\hline
\end{tabular}




\begin{tabular}{|c|c|c|c|c|c|c|c|}
\hline Field & Type & DCT & Initial & Access & Modify & \begin{tabular}{|l|} 
Rec Proc \\
Monitor \\
\end{tabular} & PP \\
\hline FVSV & GBLCHOICE & Yes & 0 & Yes & Yes & No & Yes \\
\hline SXSV & GBLCHOICE & Yes & 0 & Yes & Yes & No & Yes \\
\hline SVSV & GBLCHOICE & Yes & 0 & Yes & Yes & No & Yes \\
\hline EISV & GBLCHOICE & Yes & 0 & Yes & Yes & No & Yes \\
\hline NISV & GBLCHOICE & Yes & 0 & Yes & Yes & No & Yes \\
\hline TESV & GBLCHOICE & Yes & 0 & Yes & Yes & No & Yes \\
\hline ELSV & GBLCHOICE & Yes & 0 & Yes & Yes & No & Yes \\
\hline TVSV & GBLCHOICE & Yes & 0 & Yes & Yes & No & Yes \\
\hline TTSV & GBLCHOICE & Yes & 0 & Yes & Yes & No & Yes \\
\hline FTSV & GBLCHOICE & Yes & 0 & Yes & Yes & No & Yes \\
\hline FFSV & GBLCHOICE & Yes & 0 & Yes & Yes & No & Yes \\
\hline UNSV & GBLCHOICE & Yes & 0 & Yes & Yes & No & Yes \\
\hline $\operatorname{cosv}$ & GBLCHOICE & Yes & 0 & Yes & Yes & No & Yes \\
\hline RVAL & ULONG & No & 0 & Yes & Yes & Yes & Yes \\
\hline ORAW & ULONG & No & 0 & Yes & No & No & No \\
\hline RBV & ULONG & No & 0 & Yes & No & Yes & No \\
\hline ORBV & ULONG & No & 0 & Yes & No & No & No \\
\hline MASK & ULONG & No & 0 & Yes & No & No & No \\
\hline MLST & USHORT & No & 0 & Yes & No & No & No \\
\hline LALM & USHORT & No & 0 & Yes & No & No & No \\
\hline SDEF & SHORT & No & 0 & Yes & No & No & No \\
\hline SHFT & USHORT & No & 0 & Yes & No & No & No \\
\hline SIOL & INLINK & Yes & 0 & No & No & N/A & No \\
\hline SIML & INLINK & Yes & 0 & No & No & N/A & No \\
\hline SIMM & GBLCHOICE & No & 0 & Yes & Yes & No & No \\
\hline SIMS & GBLCHOICE & Yes & 0 & Yes & Yes & No & No \\
\hline IVOA & GBLCHOICE & Yes & 0 & Yes & Yes & No & No \\
\hline IVOV & USHORT & Yes & 0 & Yes & Yes & No & No \\
\hline
\end{tabular}


3. Field Descriptions

\begin{tabular}{|c|c|c|}
\hline Name & Summary & Description \\
\hline VAL & Value Field & This is the index of the state value to be sent to OUT. \\
\hline DOL & $\begin{array}{l}\text { Desired Output } \\
\text { Location (an Input } \\
\text { Link) }\end{array}$ & $\begin{array}{l}\text { If DOL is a database or channel access link and OMSL is } \\
\text { CLOSED_LOOP, then VAL is read from DOL. }\end{array}$ \\
\hline OMSL & Output Mode Select & $\begin{array}{l}\text { This field has either the value SUPERVISORY or } \\
\text { CLOSED_LOOP. DOL is used to determine VAI only if } \\
\text { OMSL has the value CLOSED_LOOR. By setting this field, } \\
\text { the record can be switched between supervisory and } \\
\text { closed loop mode of operation. While in closed loop } \\
\text { mode, the VAI field cannot be set via dbPuts. }\end{array}$ \\
\hline NOBT & Number of Bits & Number of bits in hardware mask. \\
\hline OUT & Output Link & $\begin{array}{l}\text { This field is used by the device support routines to decide } \\
\text { where to send output. For soft records, it can be a } \\
\text { constant, a database link, or a channel access link. If the } \\
\text { link is a constant, the result is no output. }\end{array}$ \\
\hline ZRVL,...,FFVL & $\begin{array}{l}\text { Zero Value, One } \\
\text { Value, ... }\end{array}$ & Masks for hardware value associated with each state. \\
\hline ZRST,...,FFST & $\begin{array}{l}\text { Zero State, One } \\
\text { State, ... }\end{array}$ & Strings associated with each state. \\
\hline $\mathrm{ZRSV}, \ldots, \mathrm{FFSV}$ & $\begin{array}{l}\text { Zero Severity, One } \\
\text { Severity, ... }\end{array}$ & Alarm severity associated with each state. \\
\hline UNSV & $\begin{array}{l}\text { Unknown State } \\
\text { Severity }\end{array}$ & \\
\hline COSV & $\begin{array}{l}\text { Change of State } \\
\text { Severity }\end{array}$ & \\
\hline RVAL & Raw Data Value & $\begin{array}{l}\text { RVAL is the value to be written to the hardware device. It } \\
\text { is determined by the record support module using VAL as } \\
\text { the index of the values stored in ZRVL,...FFVL. The value } \\
\text { is also shifted left SHFT bits. }\end{array}$ \\
\hline ORAW & $\begin{array}{l}\text { Old Raw Data } \\
\text { Value }\end{array}$ & $\begin{array}{l}\text { ORAW is used to decide if monitors should be triggered for } \\
\text { RVAL at the same time monitors are generated for changes } \\
\text { in VAL. }\end{array}$ \\
\hline RBV & Read Back Value & $\begin{array}{l}\text { This is the actual read back value obtained from the } \\
\text { hardware itself or from the associated device driver. It is } \\
\text { the responsibility of the device support routine to give this } \\
\text { field a value. }\end{array}$ \\
\hline ORAW & $\begin{array}{l}\text { Old Read Back } \\
\text { Value }\end{array}$ & $\begin{array}{l}\text { ORBV is used to decide if monitors should be triggered for } \\
\mathrm{RBV} \text { at the same time monitors are triggered for changes } \\
\text { in VAL. }\end{array}$ \\
\hline MASK & Mạsk & $\begin{array}{l}\text { Mask used by device support routine to read hardware } \\
\text { register. Record support sets low order NOBT bits. Device } \\
\text { support can shift this value. }\end{array}$ \\
\hline
\end{tabular}




\begin{tabular}{|c|c|c|}
\hline Name & Summary & Description \\
\hline MLST & Monitor Last & Value when last monitor for value changes was triggered. \\
\hline LALM & Last Alarmed & Value when last change of state alarm was issued. \\
\hline SDEF & States Defined? & $\begin{array}{l}\text { Record support uses this field to save time if no states are } \\
\text { defined. }\end{array}$ \\
\hline SHFT & Shift & $\begin{array}{l}\text { Number of bits to shift values obtained from } \\
\text { ZRVL,...,FFVL. }\end{array}$ \\
\hline SIMM & Simulation Mode & \multirow{4}{*}{$\begin{array}{l}\text { Simulation mode process variables. Refer to Chapter } 3 \text {, } \\
\text { Section "Simulation Mode" on page } 13 \text { for more } \\
\text { information. }\end{array}$} \\
\hline SIML & $\begin{array}{l}\text { Simulation Mode } \\
\text { Location }\end{array}$ & \\
\hline SIOL & $\begin{array}{l}\text { Simulation Value } \\
\text { Location }\end{array}$ & \\
\hline SIMS & $\begin{array}{l}\text { Simulation Mode } \\
\text { Alarm Severity }\end{array}$ & \\
\hline IVOA & $\begin{array}{l}\text { Invalid Alarm } \\
\text { Output Action }\end{array}$ & \multirow{2}{*}{$\begin{array}{l}\text { Whenever the record is put into INVALID alarm severity } \\
\text { IVOA specifies an action. See Chapter 3, Section "Invalid } \\
\text { Alarm Output Action" on page } 14 \text { for more information }\end{array}$} \\
\hline IVOV & $\begin{array}{l}\text { Invalid Alarm } \\
\text { Output Value }\end{array}$ & \\
\hline
\end{tabular}

\section{Record Support Routines}

\section{init_record}

process

special
This routine initializes SIMM if SIML is a constant or creates a channel access link if SIML is PV_LINK. If SIOL is PV_LINK a channel access link is created.

This routine next checks to see that device support is available. The routine next checks to see if the device support write routine is defined. If either device support or the device support write routine does not exist, an error message is issued and processing is terminated.

If DOL is a constant, then VAL is initialized to its value and UDF is set to FALSE.

MASK is cleared and then the NOBT low order bits are set.

If device support includes init_record, it is called.

init_common is then called to determine if any states are defined. If states are defined, SDEF is set to TRUE.

If device support returns success, VAL is then set from RVAL and UDF is set to FALSE.

See next section.

Computes SDEF when any of the fields ZRVL,...FFVL change value. 
get_value Fills in the values of struct valueDes so that they refer to VAI.

get_enum_str Retrieves ASCII string corresponding to VAI.

get_enum_strs $\quad$ Retrieves ASCII strings for ZRST,...FFST.

put_enum_str Checks if string matches ZRST,...FFST and if it does, sets VAI.

\section{Record Processing}

Routine process implements the following algorithm:

1. Check to see that the appropriate device support module exists. If it doesn't, an error message is issued and processing is terminated with the PACT field still set to TRUE. This ensures that processes will no longer be called for this record. Thus error storms will not occur.

2. If PACT is FALSE

- If DOL is DB_LINK and OMSL is CLOSED_LOOP

- Get value from DOL

- Set UDF to FALSE

- Check for link alarm

- If any state values are defined

- If VAL $>15$, then raise alarm and go to 4

- Else using VAL as index set RVAL = one of ZRVL,...FFVL

- Else set RVAL = VAL

- Shift RVAL left SHFT bits

3. Convert

- If PaCT is False, compute RVal

- If VAL is $0, \ldots, 15$, set RVAL from $\mathrm{ZRVL}, \ldots$, ,FFV

- If VAL out of range, set RVAL = undefined

- Status=write_mbbo

4. Check alarms. This routine checks to see if the new VAI causes the alarm status and severity to change. If SO, NSEV, NSTA and LALM are set.

5. Check severity and write the new value. See Chapter 3, Section "Simulation Mode" on page 13 and Chapter 3, Section "Invalid Alarm Output Action" on page 14 for details.

6. If PACT has been changed to TRUE, the device support write output routine has started but has not completed writing the new value. In this case, the processing routine merely returns, leaving PACT TRUE.

7. Check to see if monitors should be invoked.

- Alarm monitors are invoked if the alarm status or severity has changed.

- Archive and value change monitors are invoked if MLST is not equal to VAL.

- Monitors for RVAL and RBV are checked whenever other monitors are invoked.

- NSEV and NSTA are reset to 0 . 
8. Scan forward link if necessary, set PACT FALSE, and return.

\section{Device Support}

Fields Of Interest

To Device

Support
Device Support Device support consists of the following routines:

\section{Routines}

report

init

init_record

report (FILE fp, paddr)

Not currently used.

init ()

init_record(precord)
Each mbbo record must have an associated set of device support routines. The primary responsibility of the device support routines is to obtain a new raw mbbo value whenever write_mbbo is called. The device support routines are primarily interested in the following fields:

\begin{tabular}{|c|c|c|}
\hline Name & Summary & Description \\
\hline PACT & Processing Active & \multirow{4}{*}{$\begin{array}{l}\text { See Chapter 2, Section "Database Common: Field } \\
\text { Descriptions" on page } 5 \text { for descriptions. }\end{array}$} \\
\hline DPVT & Device Private & \\
\hline NSEV & New Alarm Severity & \\
\hline NSTA & New Alarm Status & \\
\hline NOBT & Number of Bits & $\begin{array}{l}\text { Number of hardware bits accessed. They must be } \\
\text { consecutive. }\end{array}$ \\
\hline OUT & Output Link & $\begin{array}{l}\text { This field is used by the device support routines to locate } \\
\text { its output. }\end{array}$ \\
\hline RVAL & Raw data value. & This is the value to be written to OuT. \\
\hline RBV & Read Back Value & $\begin{array}{l}\text { It is the responsibility of the device support modules to } \\
\text { set this field. }\end{array}$ \\
\hline MASK & Mask & $\begin{array}{l}\text { This is a mask used to read the hardware. Record support } \\
\text { sets the low order NOBT bits. The device support routine } \\
\text { can shift the bits. The device support routine should } \\
\text { perform the shift in in init_record. }\end{array}$ \\
\hline SHFT & Shift & $\begin{array}{l}\text { This can be set by the device support module at } \\
\text { init_record time. }\end{array}$ \\
\hline
\end{tabular}

This routine is called once during IOC initialization. 
This routine is optional. If provided, it is called by the record support init_record routine. If MASK is used, it should be shifted if necessary and SHFT given a value.

get_ioint_info

get_ioint_info(int cmd, struct dbCommon *precord, IOSCANPVT *ppvt)

This routine is called by the ioEventscan system each time the record is added or deleted from an $\mathrm{I} / \mathrm{O}$ event scan list. cmd has the value $(0,1)$ if the record is being (added to, deleted from) an I/O event list. It must be provided for any device type that can use the ioEvent scanner.

write_mbbo

write_mbbo (precord)

This routine must output a new value. It returns the following values:

- 0: Success.

- Other: Error.

\section{Device Support For Soft Records}

This module writes the current value of VAL.

If the our link type is PV_IINK, then dbcaAddInIink is called by init_record.

write_mbbo calls recGbIPutLinkValue to write the current value of VAL. See Chapter 3 , Section "Soft Output" on page 13 for details. 


\section{Chapter 22: mbbiDirect - MultiBit Binary Input Direct}

Johnny Tang, Matthew Bickley, and Chip Watson

Continuous Electron Beam Accelerator Facility

Southeastern Universities Research Association

\section{Introduction}

The mbbiDirect record retrieves a sixteen bit hardware value and converts it to an array of sixteen unsigned characters, each representing a bit of the word. These fields (B0-B15) are set to one if a bit is set, and zero if not. This record's operation is similar to that of an mbbi, and it has many fields in common with it.

2. Field Summary

\begin{tabular}{|l|l|l|l|l|l|l|l|}
\hline \multicolumn{1}{|c|}{ Field } & \multicolumn{1}{|c|}{ Type } & DCT & \multicolumn{1}{c|}{ Initial } & Access & Modify & $\begin{array}{l}\text { Rec Proc } \\
\text { Monitor }\end{array}$ & \multicolumn{1}{|c|}{ PP } \\
\hline \hline VAL & USHORT & No & 0 & Yes & No & Yes & Yes \\
\hline NOBT & SHORT & Yes & 0 & Yes & No & & No \\
\hline INP & INLINK & Yes & 0 & No & No & N/A & No \\
\hline RVAL & ULONG & No & 0 & Yes & Yes & Yes & Yes \\
\hline ORAW & ULONG & No & 0 & Yes & No & No & No \\
\hline MASK & ULONG & No & 0 & Yes & No & No & No \\
\hline MLST & USHORT & No & 0 & Yes & No & No & No \\
\hline LALM & USHORT & No & 0 & Yes & No & No & No \\
\hline SDEF & SHORT & No & 0 & Yes & No & No & No \\
\hline SHFT & USHORT & No & 0 & Yes & No & No & No \\
\hline
\end{tabular}




\begin{tabular}{|l|l|l|l|l|l|l|l|}
\hline \multicolumn{1}{|c|}{ Field } & \multicolumn{1}{|c|}{ Type } & DCT & \multicolumn{1}{|c|}{ Initial } & Access & Modify & $\begin{array}{l}\text { Rec Proc } \\
\text { Monitor }\end{array}$ & \multicolumn{1}{|c|}{ PP } \\
\hline \hline SIOL & INLINK & Yes & 0 & No & No & No & No \\
\hline SVAL & USHORT & No & 0 & Yes & Yes & No & No \\
\hline SIML & INLINK & Yes & 0 & No & No & No & No \\
\hline SIMM & GBLCHOICE & No & 0 & Yes & Yes & No & No \\
\hline SIMS & GBLCHOICE & Yes & 0 & Yes & Yes & No & No \\
\hline B0 & UCHAR & Yes & 0 & Yes & Yes & Yes & Yes \\
\hline B1 & UCHAR & Yes & 0 & Yes & Yes & Yes & Yes \\
\hline B2 & UCHAR & Yes & 0 & Yes & Yes & Yes & Yes \\
\hline B3 & UCHAR & Yes & 0 & Yes & Yes & Yes & Yes \\
\hline B4 & UCHAR & Yes & 0 & Yes & Yes & Yes & Yes \\
\hline B5 & UCHAR & Yes & 0 & Yes & Yes & Yes & Yes \\
\hline B6 & UCHAR & Yes & 0 & Yes & Yes & Yes & Yes \\
\hline B7 & UCHAR & Yes & 0 & Yes & Yes & Yes & Yes \\
\hline B8 & UCHAR & Yes & 0 & Yes & Yes & Yes & Yes \\
\hline B9 & UCHAR & Yes & 0 & Yes & Yes & Yes & Yes \\
\hline BA & UCHAR & Yes & 0 & Yes & Yes & Yes & Yes \\
\hline BB & UCHAR & Yes & 0 & Yes & Yes & Yes & Yes \\
\hline BC & UCHAR & Yes & 0 & Yes & Yes & Yes & Yes \\
\hline BD & UCHAR & Yes & 0 & Yes & Yes & Yes & Yes \\
\hline BE & UCHAR & Yes & 0 & Yes & Yes & Yes & Yes \\
\hline BF & UCHAR & Yes & 0 & Yes & Yes & Yes & Yes \\
\hline
\end{tabular}

\section{Field Descriptions}

\begin{tabular}{|l|l|l|}
\hline \multicolumn{1}{|c|}{ Name } & \multicolumn{1}{|c|}{ Summary } & \multicolumn{1}{c|}{ Description } \\
\hline \hline VAL & Value Field & $\begin{array}{l}\text { Unless INP is a constant link, this is the value resulting } \\
\text { from the record being processed. If INP is a constant, then } \\
\text { VAL is initialized to the INP value but can be changed } \\
\text { dynamically via dbPutField or dbPutLink. }\end{array}$ \\
\hline NOBT & Number of Bits & Number of bits set in hardware mask. \\
\hline INP & Input Link & $\begin{array}{l}\text { This field is used by the device support routines to obtain } \\
\text { input. For soft records, it can be a constant, a database } \\
\text { link, or a channel access link. }\end{array}$ \\
\hline
\end{tabular}




\begin{tabular}{|c|c|c|}
\hline Name & Summary & Description \\
\hline $\mathrm{B} 0, \ldots, \mathrm{BF}$ & $\begin{array}{l}\text { Bit } 0 \text { Value, Bit } 1 \\
\text { Value ... }\end{array}$ & Each represents a bit of the word. \\
\hline RVAL & Raw Data Value & $\begin{array}{l}\text { RVAL is the value obtained by the device support routine. } \\
\text { Unless the device support routine specifies no conversion, } \\
\text { VAL is determined as follows: A temporary variable rval } \\
\text { is set equal to RVAL. }\end{array}$ \\
\hline ORAW & $\begin{array}{l}\text { Old Raw Data } \\
\text { Value }\end{array}$ & $\begin{array}{l}\text { ORAW is used to decide if monitors should be triggered for } \\
\text { RVAL at the same time monitors are triggered for changes } \\
\text { in VAL. }\end{array}$ \\
\hline MASK & Mask & $\begin{array}{l}\text { Mask used by device support routine to read hardware } \\
\text { register. Record support sets low order NOBT bits. Device } \\
\text { support can shift this value. }\end{array}$ \\
\hline SHFT & Shift & Number of bits to shift values obtained from RVAL. \\
\hline LALM & Last Alarmed & Value when last change of state alarm was issued. \\
\hline MLST & Monitor Last & Value when last monitor for value changes was triggered. \\
\hline SDEF & States Defined & \\
\hline SIMM & Simulation Mode & \multirow{5}{*}{$\begin{array}{l}\text { Simulation mode process variables. Refer to Chapter } 3 \text {, } \\
\text { Section "Simulation Mode" on page } 11 \text { for more } \\
\text { information. }\end{array}$} \\
\hline SIML & $\begin{array}{l}\text { Simulation Mode } \\
\text { Location }\end{array}$ & \\
\hline SVAL & Simulation Value & \\
\hline SIOL & $\begin{array}{l}\text { Simulation Value } \\
\text { Location }\end{array}$ & \\
\hline SIMS & $\begin{array}{l}\text { Simulation Mode } \\
\text { Alarm Severity }\end{array}$ & \\
\hline
\end{tabular}

\section{Record Support Routines}

This routine initializes SIMM with the value of SIML if SIML type is CONSTANT link or creates a channel access link if SIML type is PV_LINK. SVAL is likewise initialized if SIOL is CONSTANT or PV_LINK.

This routine next checks to see that device support is available and a device support read routine is defined. If either does not exist, an error message is issued and processing is terminated.

Clears MASK and then sets the NOBT low order bits.

If device support includes init_record, it is called.

refresh_bits is then called to refresh all the bit fields based on a hardware value. 
process

get_value
See next section.

Fills in the values of struct valueDes so that they refer to VAL.

\section{Record Processing}

Routine process implements the following algorithm:

1. Check to see that the appropriate device support module exists. If it doesn't, an error message is issued and processing is terminated with the PACT field still set to TRUE. This ensures that processes will no longer be called for this record. Thus error storms will not occur.

2. readValue is called. See Chapter 3, Section "Simulation Mode" on page 11 for details.

3. If PACT has been changed to TRUE, the device support read routine has started but has not completed reading a new input value. In this case, the processing routine merely returns, leaving PACT TRUE.

4. Convert.

- status=read_mbbiDirect

- PACT $=$ TRUE

- TIME = tsLocalTime

- If status is 0 , then determine VaI

- Set rval = RVAL

- Shift rval right SHFT bits

- Set VAI = RVAL

- If status is 1 , return(0)

- If status is 2 , set status $=0$

5. Check to see if monitors should be invoked.

- Alarm monitors are invoked if the alarm status or severity has changed.

- Archive and value change monitors are invoked if MLST is not equal to VAL.

- Monitors for RVAL are checked whenever other monitors are invoked.

- NSEV and NSTA are reset to 0.

6. Scan forward link if necessary, set PACT FALSE, and return. 


\section{Device Support}

Fields Of Interest To Device Support

\section{Device Support}

\section{Routines}

report

init
Each input record must have an associated set of device support routines. The primary responsibility of the device support routines is to obtain a new raw input value whenever read_mbbiDirect is called. The device support routines are primarily interested in the following fields:

\begin{tabular}{|c|c|c|}
\hline Name & Summary & Description \\
\hline PACT & Processing Active & \multirow{5}{*}{$\begin{array}{l}\text { See Chapter 2, Section "Database Common: Field } \\
\text { Descriptions" on page } 5 \text { for descriptions. }\end{array}$} \\
\hline DPVT & Device Private & \\
\hline UDF & VAL Undefined & \\
\hline NSEV & New Alarm Severity & \\
\hline NSTA & New Alarm Status & \\
\hline NOBT & Number of Bits & $\begin{array}{l}\text { Number of hardware bits accessed. They must be } \\
\text { consecutive. }\end{array}$ \\
\hline VAL & Value Field & $\begin{array}{l}\text { This field is set by the device support routines if they } \\
\text { don't want record support to set it. }\end{array}$ \\
\hline INP & Input Link & $\begin{array}{l}\text { This field is used by the device support routines to locate } \\
\text { its input. }\end{array}$ \\
\hline RVAL & Raw Data Value & $\begin{array}{l}\text { It is the responsibility of the device support routine to give } \\
\text { this field a value. }\end{array}$ \\
\hline MASK & Mask & $\begin{array}{l}\text { This is a mask used to read the hardware. Record support } \\
\text { sets the low order NOBT bits. The device support routine } \\
\text { can shift the bits. The device support routine should } \\
\text { perform the shift in init_record. }\end{array}$ \\
\hline SHFT & Shift & $\begin{array}{l}\text { This can be set by the device support module at } \\
\text { init_record time. }\end{array}$ \\
\hline
\end{tabular}

Device support consists of the following routines:

report(FILE fp, paddr)

Not currently used.

$$
\text { init) }
$$

This routine is called once during IOC initialization. 
This routine is optional. If provided, it is called by the record support init_record routine. If it uses MASK, it should shift it as necessary and also give SHFT a value.

get_ioint_info

read_mbbiDirect get_ioint_info(int cmd,struct dbCommon *precord, IOSCANPVT *ppvt)

This routine is called by the ioEventScan system each time the record is added or deleted from an I/O event scan list. cma has the value $(0,1)$ if the record is being (added to, deleted from) an V/O event list. It must be provided for any device type that can use the ioEvent scanner.

read_mbbiDirect (precord)

This routine must provide a new input value. It returns the following values:

- 0: Success. A new raw value is placed in RVAL. The record support module determines VAL from RVAL and SHFT.

- 2: Success, but don't modify var.

- Other: Error.

\section{Device Support For Soft Records}

Two soft device support modules Soft Channel and Raw Soft Channel are provided for multibit binary input direct records not related to actual hardware devices. The INP link type must be either CONSTANT, DB_LINK, or CA_LINK.

Soft Channel read_mbbiDirect always returns a value of 2, which means that no conversion is performed.

If the INP link type is constant, then the constant value is stored into VAL by init_record, and UDF is set to FALSE. VAI can be changed via dbPut requests. If the INP link type is PV_LINK, then dbCaAddInlink is called by init_record.

read_mbbiDirect calls recGblGetIinkValue to read the current value of VAL. See Chapter 3, Section "Soft Input" on page 10 for details.

If the return status of recGblGetLinkValue is zero, then read_mbbi sets UDF to FALSE. The status of recGblGetLinkValue is returned.

Raw Soft

Channel
This module is like the previous except that values are read into RVAL, VAL is computed from RVAL, and read_mbbiDirect returns a value of 0 . Thus the record processing routine will determine VAL in the normal way. 


\section{Chapter 23: mbboDirect - MultiBit Binary Output Direct}

Johnny Tang, Matthew Bickley, and Chip Watson

Continuous Electron Beam Accelerator Facility

Southeastern Universities Research Association

\section{Introduction}

The mbboDirect record performs the opposite function to that of the mbbiDirect record. It accumulates bits (in the fields $\mathrm{BO}-\mathrm{BF}$ ) as unsigned characters, and converts them to a word which is then written out to hardware. If a bit field is non-zero, it is interpreted as a binary one. On the other hand, if it is zero, it is interpreted as a binary zero.

\section{Field Summary}

\begin{tabular}{|l|l|l|l|l|l|l|l|}
\hline \multicolumn{1}{|c|}{ Field } & \multicolumn{1}{|c|}{ Type } & DCT & \multicolumn{1}{c|}{ Initial } & Access & Modify & $\begin{array}{l}\text { RecProc } \\
\text { Monitor }\end{array}$ & \multicolumn{1}{|c|}{ PP } \\
\hline \hline VAL & USHORT & No & 0 & Yes & No & Yes & Yes \\
\hline DOL & INLINK & Yes & 0 & No & No & N/A & No \\
\hline OMSL & GBLCHOICE & Yes & 0 & Yes & Yes & No & Yes \\
\hline NOBT & SHORT & Yes & 0 & Yes & No & & No \\
\hline OUT & OUTLINK & Yes & 0 & No & No & N/A & No \\
\hline B0 & UCHAR & No & 0 & Yes & Yes & No & Yes \\
\hline B1 & UCHAR & No & 0 & Yes & Yes & No & Yes \\
\hline B2 & UCHAR & No & 0 & Yes & Yes & No & Yes \\
\hline B3 & UCHAR & No & 0 & Yes & Yes & No & Yes \\
\hline B4 & UCHAR & No & 0 & Yes & Yes & No & Yes \\
\hline
\end{tabular}




\begin{tabular}{|c|c|c|c|c|c|c|c|}
\hline Field & Type & DCT & Initial & Access & Modify & $\begin{array}{l}\text { RecProc } \\
\text { Monitor } \\
\end{array}$ & $\mathbf{P P}$ \\
\hline B5 & UCHAR & No & 0 & Yes & Yes & No & Yes \\
\hline B6 & UCHAR & No & 0 & Yes & Yes & No & Yes \\
\hline B7 & UCHAR & No & 0 & Yes & Yes & No & Yes \\
\hline B8 & UCHAR & No & 0 & Yes & Yes & No & Yes \\
\hline B9 & UCHAR & No & 0 & Yes & Yes & No & Yes \\
\hline $\mathrm{BA}$ & UCHAR & No & 0 & Yes & Yes & No & Yes \\
\hline BB & UCHAR & No & 0 & Yes & Yes & No & Yes \\
\hline $\mathrm{BC}$ & UCHAR & No & 0 & Yes & Yes & No & Yes \\
\hline $\mathrm{BD}$ & UCHAR & No & 0 & Yes & Yes & No & Yes \\
\hline $\mathrm{BE}$ & UCHAR & No & 0 & Yes & Yes & No & Yes \\
\hline $\mathrm{BF}$ & UCHAR & No & 0 & Yes & Yes & No & Yes \\
\hline RVAL & ULONG & No & 0 & Yes & No & Yes & Yes \\
\hline ORAW & ULONG & No & 0 & Yes & No & No & No \\
\hline RBV & ULONG & No & 0 & Yes & No & Yes & No \\
\hline ORBV & ULONG & No & 0 & Yes & No & No & No \\
\hline MASK & ULONG & No & 0 & Yes & No & No & No \\
\hline MLST & ULONG & No & 0 & Yes & No & No & No \\
\hline LALM & ULONG & No & 0 & Yes & No & No & No \\
\hline SHFT & ULONG & No & 0 & Yes & No & No & No \\
\hline SIOL & INLINK & Yes & 0 & No & No & N/A & No \\
\hline SIML & INLINK & Yes & 0 & No & No & N/A & No \\
\hline SIMM & GBLCHOICE & No & 0 & Yes & Yes & No & No \\
\hline SIMS & GBLCHOICE & Yes & 0 & Yes & Yes & No & No \\
\hline IVOA & GBLCHOICE & Yes & 0 & Yes & Yes & No & No \\
\hline IVOV & USHORT & Yes & 0 & Yes & Yes & No & No \\
\hline
\end{tabular}

3. Field Descriptions

\begin{tabular}{|l|l|l|}
\hline \multicolumn{1}{|c|}{ Name } & \multicolumn{1}{c|}{ Summary } & \multicolumn{1}{c|}{ Description } \\
\hline \hline VAL & Value Field & This is the value to be sent to OUT. \\
\hline
\end{tabular}




\begin{tabular}{|c|c|c|}
\hline Name & Summary & Description \\
\hline DOL & $\begin{array}{l}\text { Desired Output } \\
\text { Location (Input } \\
\text { Link) }\end{array}$ & $\begin{array}{l}\text { If DOL is a database or channel access link and OMSL is } \\
\text { CLOSED_LOOP, then VAL is read from DOL. }\end{array}$ \\
\hline OMSL & Output Mode Select & $\begin{array}{l}\text { This field has either the value SUPERVISORY or } \\
\text { CLOSED_LOOP. DOL is used to determine VAL only if } \\
\text { OMSL has the value CLOSED_LOOP. By setting this field, } \\
\text { the record can be switched between supervisory and } \\
\text { closed loop mode of operation. While in closed loop } \\
\text { mode, the VAL field cannot be set via dbPuts. }\end{array}$ \\
\hline NOBT & Number of Bits & Number of bits in hardware mask. \\
\hline OUT & Output Link & $\begin{array}{l}\text { This field is used by the device support routines to decide } \\
\text { where to send output. For soft records, it can be a } \\
\text { constant, a database link, or a channel access link. If the } \\
\text { link is a constant, the result is no output. }\end{array}$ \\
\hline $\mathrm{B} 0, \ldots, \mathrm{BF}$ & $\begin{array}{l}\text { Bit } 0 \text { Value, Bit } 1 \\
\text { Value, ... }\end{array}$ & Each represents a bit of the word to be output. \\
\hline RVAL & Raw Data Value & $\begin{array}{l}\text { RVAL is the value to be written to the hardware device. It } \\
\text { is determined by the record support module using VAL as } \\
\text { the bit values stored in } \mathrm{BO}, \ldots \mathrm{BF} \text {. The value is also shifted } \\
\text { left SHFT bits. }\end{array}$ \\
\hline ORAW & $\begin{array}{l}\text { Old Raw Data } \\
\text { Value }\end{array}$ & $\begin{array}{l}\text { ORAW is used to decide if monitors should be triggered for } \\
\text { RVAL at the same time monitors are generated for changes } \\
\text { in VAL. }\end{array}$ \\
\hline RBV & Read Back Value & $\begin{array}{l}\text { This is the actual read back value obtained from the } \\
\text { hardware itself or from the associated device driver. It is } \\
\text { the responsibility of the device support routine to give this } \\
\text { field a value }\end{array}$ \\
\hline ORBV & $\begin{array}{l}\text { Old Read Back } \\
\text { Value }\end{array}$ & $\begin{array}{l}\text { ORBV is used to decide if monitors should be triggered for } \\
\text { RBV at the same time monitors are triggered for changes } \\
\text { in VAI. }\end{array}$ \\
\hline MASK & Mask & $\begin{array}{l}\text { Mask used by device support routine to read hardware } \\
\text { register. Record support sets low order NOBT bits. Device } \\
\text { support can shift this value. }\end{array}$ \\
\hline MLST & Monitor Last & Value when last monitor for value changes was triggered. \\
\hline LALM & Last Alarmed & Value when last change of state alarm was issued. \\
\hline SHFT & Shift & Number of bits to shift values obtained from VAL. \\
\hline SIMM & Simulation Mode & \multirow{4}{*}{$\begin{array}{l}\text { Simulation mode process variables. Refer to Chapter } 3 \text {, } \\
\text { Section "Simulation Mode" on page } 13 \text { for more } \\
\text { information. }\end{array}$} \\
\hline SIML & $\begin{array}{l}\text { Simulation Mode } \\
\text { Location }\end{array}$ & \\
\hline SIOL & $\begin{array}{l}\text { Simulation Value } \\
\text { Location }\end{array}$ & \\
\hline SIMS & $\begin{array}{l}\text { Simulation Mode } \\
\text { Alarm Severity }\end{array}$ & \\
\hline
\end{tabular}




\begin{tabular}{|l|l|l|}
\hline \multicolumn{1}{|c|}{ Name } & \multicolumn{1}{|c|}{ Summary } & \multicolumn{1}{c|}{ Description } \\
\hline \hline IVOA & $\begin{array}{l}\text { Invalid Alarm } \\
\text { Output Action }\end{array}$ & $\begin{array}{l}\text { Whenever the record is put into INVALID alarm severity } \\
\text { IVOA specifies an action. See Chapter 3, Section "Invalid } \\
\text { Alarm Output Action" on page 14 for more information }\end{array}$ \\
\cline { 1 - 2 } IVOV & $\begin{array}{l}\text { Invalid Alarm } \\
\text { Output Value }\end{array}$ & \\
\hline
\end{tabular}

\section{Record Support Routines}

\section{init_record}

\section{process}

get_value
This routine initializes SIMM if SIML is a constant or creates a channel access link if SIML is PV_LINK. If SIOL is PV_LINK a channel access link is created.

This routine next checks to see that device support is available.The routine next checks to see if the device support write routine is defined. If either device support or the device support write routine does not exist, an error message is issued and processing is terminated.

If DOL is a constant, then VAL is initialized to its value and UDF is set to FALSE.

MASK is cleared and then the NOBT low order bits are set.

If device support includes init_record, it is called.

init_common is then called to determine if any states are defined. If states are defined, SDEF is set to TRUE.

If device support returns success, VAL is then set from RVAL and UDF is set to FALSE.

See next section.

Fills in the values of struct valueDes so that they refer to VAL.

\section{Record Processing}

Routine process implements the following algorithm:

1. Check to see that the appropriate device support module exists. If it doesn't, an error message is issued and processing is terminated with the PACT field still set to TRUE. This ensures that processes will no longer be called for this record. Thus error storms will not occur.

2. If PACT is FALSE

- If DOL is DB_LINK and OMSL is CLOSED_LOOP

- Get value from DOL

- Set PACT to FALSE

3. Convert

- If PACT is FALSE, compute RVAL

- Set RVAL = VAL 


\section{- Shift RVAL left SHFT bits}

- Status=write_mbboDirect

4. If PACT has been changed to TRUE, the device support write output routine has started but has not completed writing the new value. In this case, the processing routine merely returns, leaving PACT TRUE.

5. Check to see if monitors should be invoked.

- Alarm monitors are invoked if the alarm status or severity has changed.

- Archive and value change monitors are invoked if MLST is not equal to VAL.

- Monitors for RVAL and RBV are checked whenever other monitors are invoked.

- NSEV and NSTA are reset to 0 .

6. Scan forward link if necessary, set PACT FALSE, and return.

\section{Device Support}

Fields Of Interest To Device Support
Each mbboDirect record must have an associated set of device support routines. The primary responsibility of the device support routines is to obtain a new raw mbbo value whenever write_mbboDirect is called. The device support routines are primarily interested in the following fields:

\begin{tabular}{|c|c|c|}
\hline Name & Summary & Description \\
\hline PACT & Processing Active & \multirow{5}{*}{$\begin{array}{l}\text { See Chapter 2, Section "Database Common: Field } \\
\text { Descriptions" on page } 5 \text { for descriptions. }\end{array}$} \\
\hline DPVT & Device Private & \\
\hline UDF & VAL Undefined & \\
\hline NSEV & New Alarm Severity & \\
\hline NSTA & New Alarm Status & \\
\hline NOBT & Number of Bits & $\begin{array}{l}\text { Number of hardware bits accessed. They must be } \\
\text { consecutive. }\end{array}$ \\
\hline OUT & Output Link & $\begin{array}{l}\text { This field is used by the device support routines to locate } \\
\text { its output. }\end{array}$ \\
\hline RVAL & Raw data value & This is the value to be written to our? \\
\hline RBV & Read Back Value & $\begin{array}{l}\text { It is the responsibility of the device support modules to } \\
\text { set this field. }\end{array}$ \\
\hline MASK & Mask & $\begin{array}{l}\text { This is a mask used to read the hardware. Record support } \\
\text { sets the low order NOBT bits. The device support routine } \\
\text { can shift the bits. The device support routine should } \\
\text { perform the shift in in init_record. }\end{array}$ \\
\hline SHFT & Shift & $\begin{array}{l}\text { This can be set by the device support module at } \\
\text { init_record time. }\end{array}$ \\
\hline
\end{tabular}


Device Support Device support consists of the following routines:

\section{Routines}

report

report(FILE fp, paddr)

Not currently used.

init

init()

This routine is called once during IOC initialization.

init_record

init_record (precord)

This routine is optional. If provided, it is called by the record support init_record routine. If MASK is used, it should be shifted if necessary and SHFT given a value.

get_ioint_info

get_ioint_info(int cmd, struct dbCommon *precord,IOSCANPVT *ppvt)

This routine is called by the ioEventScan system each time the record is added or deleted from an I/O event scan list. cma has the value $(0,1)$ if the record is being (added to, deleted from) an I/O event list. It must be provided for any device type that can use the ioEvent scanner.

write_mbboDirect

write_mbboDirect (precord)

This routine must output a new value. It returns the following values:

- 0: Success.

- Other: Error.

\section{Device Support For Soft Records}

This module writes the current value of VAL.

If the OUT link type is PV_LINK, then dbCaAddInlink is called by init_record.

write_mbboDirect calls recGblPutLinkValue to write the current value of VAL. See Chapter 3, Section "Soft Output" on page 13 for details. 


\section{Chapter 24: Permissive}

\section{Introduction}

The permissive record is for communication between a server and a client. An example is a sequence program client and an operator interface server. Two fields are used VAL and WFLG. The method of use is as follows:

1. Initially both VAI and WFLG are 0 , which means OFF.

2. When the server is ready to accept a request, it sets WFLG equal to 1 , which means ON.

3. The client monitors WFLG. Until it turns ON, the client must not change VAI.

4. When the client wants to notify the server it turns VAL ON.

5. The server notices that VAL is ON. He sets both WFLG and VAL OFF. Performs whatever action is associated with this permissive (a private matter server and client), and when ready to accept a new request sets WFLG ON.

By using multiple permissive records a sequence program can communicate its current state to a client.

2. Field Summary

\begin{tabular}{|l|l|l|l|l|l|l|l|}
\hline \multicolumn{1}{|c|}{ Field } & \multicolumn{1}{|c|}{ Type } & \multicolumn{1}{c|}{ DCT } & \multicolumn{1}{c|}{ Initial } & Access & Modify & $\begin{array}{l}\text { Rec Proc } \\
\text { Monitor }\end{array}$ & \multicolumn{1}{c|}{ PP } \\
\hline \hline LABL & STRING & Yes & Null & Yes & Yes & No & Yes \\
\hline VAL & USHORT & No & 0 & Yes & Yes & Yes & Yes \\
\hline OVAL & USHORT & No & 0 & Yes & No & & No \\
\hline
\end{tabular}




\begin{tabular}{|l|l|l|l|l|l|l|l|}
\hline \multicolumn{1}{|c|}{ Field } & \multicolumn{1}{|c|}{ Type } & \multicolumn{1}{|c|}{ DCT } & \multicolumn{1}{|c|}{ Initial } & Access & Modify & $\begin{array}{l}\text { RecProc } \\
\text { Monitor }\end{array}$ & \multicolumn{1}{c|}{ PP } \\
\hline \hline WFLG & USHORT & No & 0 & Yes & Yes & Yes & Yes \\
\hline OFLG & USHORT & No & 0 & Yes & No & & No \\
\hline
\end{tabular}

\section{Field Descriptions}

\begin{tabular}{|l|l|l|}
\hline \multicolumn{1}{|c|}{ Name } & \multicolumn{1}{|c|}{ Summary } & \multicolumn{1}{c|}{ Description } \\
\hline \hline LABL & Label & A descriptive string. \\
\hline VAL & Value & $\begin{array}{l}\text { Client sets this field when it wants service from server. } \\
\text { Only the client should set this field. The server clears it. }\end{array}$ \\
\hline OVAL & Old Value & $\begin{array}{l}\text { Used to decide if monitors should be triggered. Value } \\
\text { change monitors are invoked if OVAL is not equal to VAL. }\end{array}$ \\
\hline WFLG & Watchdog Flag & $\begin{array}{l}\text { Server sets this field when it is ready to accept a request. } \\
\text { Only the server should modify this field. }\end{array}$ \\
\hline OFLG & Old Flag Value & Used to decide if monitors should be triggered. \\
\hline
\end{tabular}

\section{Record Support Routines}

Two record support routines are provided: process, and get_value.

process

process sets UDF to FALSE, triggers monitors on VAL and WFLG when they change, and scans the forward link if necessary.

get_value

get_value fills in struct valueDes so that it refers to VAL. 


\section{Chapter 25: pid - PID Control}

\section{Introduction}

The pid record type provides a Proportional, Integral, and Derivative (PID) control algorithm. A discrete form of the PID algorithm is:

$$
M_{n}=K P *\left(E_{n}+K I * \operatorname{SUMi}\left(E_{i} * d T_{i}\right)\right)+K D *\left(E_{n}-E_{n-1}\right) / d T_{n}+M r
$$

Where:

- $\mathrm{M}_{\mathrm{n}}$ : Value of manipulated variable at $\mathrm{nth}$ sampliing instant

- KP, KI, KD: 'Proportional, Integral, and Derivative gains

- $\mathrm{E}_{\mathrm{n}}$ : Error at nth sampling instant

- $\mathrm{SUM}_{\mathrm{i}}:$ Sum from $\mathrm{i}=0$ to $\mathrm{i}=\mathrm{n}$

- $\mathrm{dT}_{\mathrm{n}}$ : Time difference between $\mathrm{n}-\mathbf{1}$ and $\mathrm{n}$

- Mr: Midrange adjustment

Taking the first difference yields:

$\operatorname{deIM}(n)=K P *\left(\left(E_{n}-E_{n-1}\right)+E_{n} * d T_{n} * K I+K D *\left(\left(E_{n}-E_{n-1}\right) / d T_{n}-\left(E_{n-1}-E_{n-2}\right) / d T_{n-1}\right)\right)$

For this record:

- DM: This is delM(n)

- VAL: This is the setpoint

- CVAL: This is current value

- ERR: $E_{n}=$ VAL - CVAL 
2. Field Summary

\begin{tabular}{|c|c|c|c|c|c|c|c|}
\hline Field & Type & DCT & Initial & Access & Modify & $\begin{array}{l}\text { Rec Proc } \\
\text { Monitor } \\
\end{array}$ & PP \\
\hline VAL & FLOAT & No & 0 & Yes & Yes & Yes & Yes \\
\hline CVL & INLINK & Yes & 0 & No & No & N/A & No \\
\hline STPL & INLINK & Yes & 0 & No & No & N/A & No \\
\hline SMSL & GBLCHOICE & Yes & 0 & Yes & Yes & No & No \\
\hline PREC & SHORT & Yes & 0 & Yes & Yes & No & No \\
\hline MDT & FLOAT & Yes & 0 & Yes & Yes & No & No \\
\hline $\mathrm{KP}$ & FLOAT & Yes & 0 & Yes & Yes & No & No \\
\hline $\mathrm{KI}$ & FLOAT & Yes & 0 & Yes & Yes & No & No \\
\hline $\mathrm{KD}$ & FLOAT & Yes & 0 & Yes & Yes & No & No \\
\hline EGU & STRING & Yes & Null & Yes & Yes & No & No \\
\hline HOPR & FLOAT & Yes & 0 & Yes & Yes & No & No \\
\hline LOPR & FLOAT & Yes & 0 & Yes & Yes & No & No \\
\hline HIHI & FLOAT & Yes & 0 & Yes & Yes & No & No \\
\hline LOLO & FLOAT & Yes & 0 & Yes & Yes & No & No \\
\hline HIGH & FLOAT & Yes & 0 & Yes & Yes & No & No \\
\hline LOW & FLOAT & Yes & 0 & Yes & Yes & No & No \\
\hline HHSV & GBLCHOICE & Yes & 0 & Yes & Yes & No & No \\
\hline LLSV & GBLCHOICE & Yes & 0 & Yes & Yes & No & No \\
\hline HSV & GBLCHOICE & Yes & 0 & Yes & Yes & No & No \\
\hline LSV & GBLCHOICE & Yes & 0 & Yes & Yes & No & No \\
\hline HYST & FLOAT & Yes & 0 & Yes & Yes & No & No \\
\hline ADEL & FLOAT & Yes & 0 & Yes & Yes & No & No \\
\hline MDEL & FLOAT & Yes & 0 & Yes & Yes & No & No \\
\hline ODEL & FLOAT & Yes & 0 & Yes & Yes & No & No \\
\hline CVAL & FLOAT & No & 0 & Yes & Yes & No & No \\
\hline $\mathrm{DM}$ & FLOAT & No & 0 & Yes & No & Yes & No \\
\hline ODM & FLOAT & No & 0 & Yes & No & Yes & No \\
\hline$P$ & FLOAT & No & 0 & Yes & No & Yes & No \\
\hline I & FLOAT & No & 0 & Yes & No & Yes & No \\
\hline D & FLOAT & No & 0 & Yes & No & Yes & No \\
\hline
\end{tabular}




\begin{tabular}{|l|l|l|l|l|l|l|l|}
\hline \multicolumn{1}{|c|}{ Field } & \multicolumn{1}{|c|}{ Type } & DCT & \multicolumn{1}{|c|}{ Initial } & Access & Modify & $\begin{array}{l}\text { Rec Proc } \\
\text { Monitor }\end{array}$ & \multicolumn{1}{c|}{ PP } \\
\hline \hline CT & ULONG & No & 0 & Yes & No & Yes & No \\
\hline DT & FLOAT & No & 0 & Yes & No & Yes & No \\
\hline ERR & FLOAT & No & 0 & Yes & No & Yes & No \\
\hline DERR & FLOAT & No & 0 & Yes & No & Yes & No \\
\hline LALM & FLOAT & No & 0 & Yes & No & No & No \\
\hline ALST & FLOAT & No & 0 & Yes & No & No & No \\
\hline MLST & FLOAT & No & 0 & Yes & No & No & No \\
\hline
\end{tabular}

\section{Field Descriptions}

\begin{tabular}{|c|c|c|}
\hline Name & Summary & Description \\
\hline VAL & $\begin{array}{l}\text { Setpoint Value, in } \\
\text { engineering units }\end{array}$ & $\begin{array}{l}\text { This is the value that the control algorithm attempts to } \\
\text { achieve. }\end{array}$ \\
\hline CVL & $\begin{array}{l}\text { Controlled Value } \\
\text { Location (input } \\
\text { link) }\end{array}$ & $\begin{array}{l}\text { This is a link specifying the location of the controlled } \\
\text { variable. This must be a database link. Each time the } \\
\text { record is processed the current value referenced by CVL is } \\
\text { read into CVAI. }\end{array}$ \\
\hline STPL & $\begin{array}{l}\text { Setpoint Location } \\
\text { (input link) }\end{array}$ & $\begin{array}{l}\text { If STPL is a database or channel access link and SMSL is } \\
\text { CLOSED_LOOP, then VAL is read from STPL. STPL and } \\
\text { SMSL act just like DOL and OMSL. }\end{array}$ \\
\hline SMSL & $\begin{array}{l}\text { Setpoint Mode } \\
\text { Select }\end{array}$ & $\begin{array}{l}\text { This is SUPERVISORY or CLOSED_LOOP. VAL is } \\
\text { obtained from STPL only when this is CLOSED_LOOP. } \\
\text { By setting this field, the record can be switched between } \\
\text { supervisory and closed loop. Note that closed loop is } \\
\text { useful for cascaded control records. }\end{array}$ \\
\hline PREC & Display Precision & $\begin{array}{l}\text { Precision with which to display VAL. This field is used by } \\
\text { record support to supply a value when get_precision } \\
\text { is called. }\end{array}$ \\
\hline MDT & $\begin{array}{l}\text { Minimum Delta } \\
\text { Time, in seconds }\end{array}$ & $\begin{array}{l}\text { Minimum time difference between processing in seconds. } \\
\text { If this is zero, the minimum time is one clock tick. }\end{array}$ \\
\hline $\mathrm{KP}$ & Proportional Gain & \\
\hline $\mathrm{KI}$ & $\begin{array}{l}\text { Integral Gain, in } \\
\text { repeats per minute }\end{array}$ & $\begin{array}{l}\text { The number of times per minute that the integral } \\
\text { contribution repeats the proportional contribution. }\end{array}$ \\
\hline $\mathrm{KD}$ & $\begin{array}{l}\text { Derivative Gain, in } \\
\text { minutes per repeat }\end{array}$ & $\begin{array}{l}\text { The number of minutes until the derivative contribution } \\
\text { repeats the proportional contribution. }\end{array}$ \\
\hline $\mathrm{EGU}$ & Engineering Units & $\begin{array}{l}\text { ASCII string describing Engineering units. This field is } \\
\text { used by record to supply a units description string when } \\
\text { get_units is called. }\end{array}$ \\
\hline
\end{tabular}




\begin{tabular}{|c|c|c|}
\hline Name & Summary & Description \\
\hline HOPR & $\begin{array}{l}\text { High Operating } \\
\text { Range }\end{array}$ & \multirow{2}{*}{$\begin{array}{l}\text { These fields determine the upper and lower display limits } \\
\text { for graphics displays and the upper and lower control } \\
\text { limits for control displays. The fields are used by record } \\
\text { support to honor calls to get_graphic_double or } \\
\text { get_control_double. }\end{array}$} \\
\hline LOPR & $\begin{array}{l}\text { Low Operating } \\
\text { Range }\end{array}$ & \\
\hline HIHI & Hihi Alarm Limit & \multirow[t]{8}{*}{ These fields specify the alarm limits and severities. } \\
\hline HIGH & High Alarm Limit & \\
\hline LOW & Low Alarm Limit & \\
\hline LOLO & Lolo Alarm Limit & \\
\hline HHSV & $\begin{array}{l}\text { Severity for a Hihi } \\
\text { Alarm }\end{array}$ & \\
\hline HSV & $\begin{array}{l}\text { Severity for a High } \\
\text { Alarm }\end{array}$ & \\
\hline LSV & $\begin{array}{l}\text { Severity for a Low } \\
\text { Alarm }\end{array}$ & \\
\hline LLSV & $\begin{array}{l}\text { Severity for a Lolo } \\
\text { Alarm }\end{array}$ & \\
\hline HYST & Alarm Deadband & \multirow{3}{*}{$\begin{array}{l}\text { These parameters specify hysteresis factors for triggering } \\
\text { monitor callbacks, i.e. monitors specified by calls to } \\
\text { caAddEvent or dbAddEvent. A monitor will not be } \\
\text { triggered until VAL changes by more than the specified } \\
\text { amount. }\end{array}$} \\
\hline ADEL & Archive Deadband & \\
\hline MDEL & $\begin{array}{l}\text { Monitor, i.e. value } \\
\text { change, Deadband }\end{array}$ & \\
\hline ODEL & Output Delta & $\begin{array}{l}\text { This parameter specifies a hysteresis factor for triggering } \\
\text { monitor callbacks for DM, } P, I, D, C T, D T, E R R \text {, and DERR. } \\
\text { It refers to the change in DM. Whenever monitors are } \\
\text { triggered for DM, monitors for the other fields are also } \\
\text { triggered. }\end{array}$ \\
\hline CVAL & $\begin{array}{l}\text { Value of Controlled } \\
\text { Variable, in } \\
\text { engineering units }\end{array}$ & $\begin{array}{l}\text { This value is obtained from CVL each time the record is } \\
\text { processed. }\end{array}$ \\
\hline $\mathrm{DM}$ & $\begin{array}{l}\text { Change in } \\
\text { Manipulated } \\
\text { Variable }\end{array}$ & $\begin{array}{l}\text { This is the value computed by the pid algorithm. It is an } \\
\text { increment to be added to the controller output. Note that } \\
\text { in most cases this will be read via the DOL field of an } \\
\text { analog output record. The analog output record will be } \\
\text { configured with oIF set to incremental. }\end{array}$ \\
\hline ODM & Old DM & $\begin{array}{l}\text { ODM is used to decide if monitors should be triggered for } \\
\text { DM. }\end{array}$ \\
\hline$P$ & $\begin{array}{l}\text { Proportional } \\
\text { contribution }\end{array}$ & Proportional contribution to $\mathrm{DM}$, in engineering units. \\
\hline I & $\begin{array}{l}\text { Integral } \\
\text { contribution to } \\
\text { DM, in repeats per } \\
\text { minute }\end{array}$ & $\begin{array}{l}\text { The number of times per minute that the integral } \\
\text { contribution repeats the proportional contribution. }\end{array}$ \\
\hline
\end{tabular}




\begin{tabular}{|c|c|c|}
\hline Name & Summary & Description \\
\hline $\mathrm{D}$ & $\begin{array}{l}\text { Derivative } \\
\text { contribution to } \\
\text { DM, in minutes }\end{array}$ & $\begin{array}{l}\text { The number of minutes until the derivative contribtuion } \\
\text { repeats the proportional contribution. }\end{array}$ \\
\hline $\mathrm{CT}$ & Clocks Ticks & Clock ticks when previous process occurred. \\
\hline DT & Time difference & Time difference in seconds between processing steps. \\
\hline ERR & Error & Current error (VAI - CVAL). \\
\hline DERR & Delta Error & Change in error since last time step. \\
\hline LALM & $\begin{array}{l}\text { Value when last } \\
\text { monitors for alarm } \\
\text { were triggered }\end{array}$ & \multirow[t]{3}{*}{$\begin{array}{l}\text { These fields are used to implement the hysteresis factors } \\
\text { for monitors. }\end{array}$} \\
\hline ALST & $\begin{array}{l}\text { Value when last } \\
\text { monitors for } \\
\text { archiver were } \\
\text { triggered }\end{array}$ & \\
\hline MLST & $\begin{array}{l}\text { Value when last } \\
\text { monitors for value } \\
\text { changes were } \\
\text { triggered }\end{array}$ & \\
\hline
\end{tabular}

\section{Record Support Routines}

\section{init_record}

process

get_value

get_units

get_precision

get_graphic_double
This routine initializes VAL with the value of STPL and sets UDF to FALSE if STPL type is CONSTANT link or creates a channel access link if STPL type is PV_IINK.

See next section.

Fills in the values of struct valueDes so that they refer to VAL.

Retrieves EGU.

Retrieves PREC.

Sets the upper display and lower display limits for a field. If the field is $P, I, D, C V A L$, VAL, HIHI, HIGH, LOW, or LOLO, the limits are set to HOPR and LOPR, else if the field has upper and lower limits defined they will be used, else the upper and lower maximum values for the field type will be used. 
get_control_double

get_alarm_double
Sets the upper control and the lower control limits for a field. If the field is P, I, D, CVAL, VAL, HIHI, HIGH, LOW, Or LOLO, the limits are set to HOPR and LOPR, else if the field has upper and lower limits defined they will be used, else the upper and lower maximum values for the field type will be used.

Sets the following values:

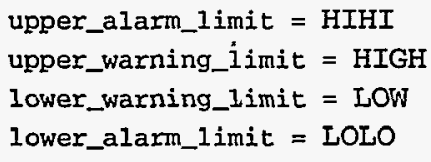

5. Record Processing

Routine process implements the following algorithm:

1. If CVL is not a database link, a major alarm is declared and the algorithm completes.

2. The current value of CVAL is obtained from CVL.

3. If STPL is a database or channel access link and SMSL is CLOSED_LOOP, then VAL is obtained from STPL and UDF is set to FALSE.

4. The time difference since the last time step is calculated. If it is less than MDT or if no ticks have occurred since the last time the algorithm was executed, process just completes without raising any alarms, checking monitors, or scanning the forward link.

5. The new values of $P, I, D$, OUT, CT, DT, ERR, and DERR are computed.

6. Check alarms. This routine checks to see if the new VAL causes the alarm status and severity to change. If So, NSEV, NSTA and LAIM are set. It also honors the alarm hysteresis factor (HYST). Thus the value must change by more than HYST before the alarm status and severity is lowered.

7. Check to see if monitors should be invoked.

- Alarm monitors are invoked if the alarm status or severity has changed.

- Archive and value change monitors are invoked if ADEL and MDEL conditions are met.

- Value change monitors on DM are invoked if ODEL conditions are met. If monitors are triggered from DM, they are also triggered for $P, I, D, C T, D T$, ERR, and DERR.

- NSEV and NSTA are reset to 0 .

8. Scan forward link if necessary, set PACT FALSE, and return. 


\section{Chapter 26: pulseCounter}

\section{Introduction}

The normal use for the pulseCounter record type is to record counts.

\section{Field Summary}

\begin{tabular}{|l|l|l|l|l|l|l|l|}
\hline \multicolumn{1}{|c|}{ Field } & \multicolumn{1}{|c|}{ Type } & DCT & Initial & Access & Modify & $\begin{array}{l}\text { Rec Proc } \\
\text { Monitor }\end{array}$ & \multicolumn{1}{c|}{ PP } \\
\hline \hline VAL & ULONG & No & 0 & Yes & Yes & Yes & No \\
\hline OUT & OUTLINK & Yes & 0 & No & No & N/A & No \\
\hline GTYP & RECCHOICE & Yes & 0 & Yes & Yes & No & No \\
\hline HGV & SHORT & Yes & 0 & Yes & Yes & No & No \\
\hline SGL & INLINK & Yes & 0 & No & No & N/A & No \\
\hline SGV & RECCHOICE & Yes & 0 & Yes & Yes & No & No \\
\hline OSGV & SHORT & No & 0 & Yes & No & & No \\
\hline CSIZ & RECCHOICE & Yes & 1 & Yes & Yes & & No \\
\hline CNTE & RECCHOICE & Yes & 0 & Yes & Yes & No & No \\
\hline CNTS & SHORT & Yes & 0 & Yes & Yes & No & No \\
\hline HOPR & FLOAT & Yes & $4.3 e+9$ & Yes & Yes & No & No \\
\hline LOPR & FLOAT & Yes & 0 & Yes & Yes & No & No \\
\hline
\end{tabular}




\begin{tabular}{|l|l|l|l|l|l|l|l|}
\hline \multicolumn{1}{|c|}{ Field } & \multicolumn{1}{|c|}{ Type } & DCT & Initial & Access & Modify & $\begin{array}{l}\text { RecProc } \\
\text { Monitor }\end{array}$ & \multicolumn{1}{|c|}{ PP } \\
\hline \hline CMD & RECCHOICE & No & 0 & Yes & Yes & Yes & Yes \\
\hline SCMD & USHORT & No & 0 & Yes & No & & No \\
\hline CPTR & ULONG & No & 0 & Yes & No & & No \\
\hline
\end{tabular}

3. Field Descriptions

\begin{tabular}{|c|c|c|}
\hline Name & Summary & Description \\
\hline VAL & Counter Value & $\begin{array}{l}\text { The read command places the current value of the counter } \\
\text { into the VAL field. }\end{array}$ \\
\hline OUT & Output Link & $\begin{array}{l}\text { This field is used by the device support routines to decide } \\
\text { where to send output. For soft records, it can be a } \\
\text { constant, a database link, or a channel access link. If the } \\
\text { link is a constant, the result is no output. }\end{array}$ \\
\hline GTYP & Gate Type & $\begin{array}{l}\text { This can be Hardware or software. If GTYP is hardware, } \\
\text { then HGV determines gating control. If GTYP is software, } \\
\text { the SGV determines gating control. }\end{array}$ \\
\hline HGV & $\begin{array}{l}\text { Hardware Gate } \\
\text { Value }\end{array}$ & If GTYP is hardware, then this field is device dependent. \\
\hline SGL & $\begin{array}{l}\text { Soft Gate Location } \\
\text { (Input Link) }\end{array}$ & $\begin{array}{l}\text { If SGL is a database link and GTYP is software, then SGV } \\
\text { will be set to the value read from SGL. }\end{array}$ \\
\hline SGV & Soft Gate Value & $\begin{array}{l}\text { This can be inactive or active. This will enable and } \\
\text { disable counting if GTYP is software. }\end{array}$ \\
\hline OSGV & Old Soft Gate Value & This is the previous value of SGV. \\
\hline CSIZ & Counter size & 16 bit or 32 bit counter. \\
\hline CNTE & Count Edge & $\begin{array}{l}\text { This can be Rising Edge or Falling Edge. This field forces } \\
\text { counting on rising or falling edge of source signal. }\end{array}$ \\
\hline CNTS & Count Source & \\
\hline HOPR & $\begin{array}{l}\text { High Operating } \\
\text { Range }\end{array}$ & \multirow{2}{*}{$\begin{array}{l}\text { These fields determine the upper and lower display limits } \\
\text { for graphics displays and the upper and lower control } \\
\text { limits for control displays. The fields are used by record } \\
\text { support routines to honor calls to } \\
\text { get_graphic_double or get_control_double. }\end{array}$} \\
\hline LOPR & $\begin{array}{l}\text { Low Operating } \\
\text { Range }\end{array}$ & \\
\hline CMD & Command & $\begin{array}{l}\text { Read: Read the current value of the counter. } \\
\text { Clear: Clear the counter. Note theat the counter is also } \\
\text { stopped. The Start command must be issued to restart the } \\
\text { counter. } \\
\text { Start: Start counting. } \\
\text { Stop: Stop counting. } \\
\text { Setup: Setup the counter. Counting will not begin until } \\
\text { the Start command is issued. }\end{array}$ \\
\hline
\end{tabular}




\begin{tabular}{|l|l|l|}
\hline \multicolumn{1}{|c|}{ Name } & \multicolumn{1}{c|}{ Summary } & \multicolumn{1}{c|}{ Description } \\
\hline \hline SCMD & Save Command & This is the saved value of CMD. \\
\hline CPTR & Callback & \\
\hline
\end{tabular}

\section{Record Support Routines}

init_record

process

get_value

get_graphic_double

get_control_double
This routine next checks to see that device support is available. If it does not exist, an error message is issued and processing is terminated.

If SGL is a constant and GTYP is software, then SGV is initialized with its value. If SGL type is PV_LINK a channel access link is created.

Device support is then checked to see if cmd_pc is defined.

If device support includes init_record, it is called.

See next section.

Fills in the values of struct valuedes so that they refer to VAL.

Sets the upper display and lower display limits for a field. If the field is VAL the limits are set to HOPR and LOPR, else if the field has upper and lower limits defined they will be used, else the upper and lower maximum values for the field type will be used.

Sets the upper control and the lower control limits for a field. If the field is VAL the limits are set to HOPR and LOPR, else if the field has upper and lower limits defined they will be used, else the upper and lower maximum values for the field type will be used.

\section{Record Processing}

The routine process implements the following algorithm:

1. Check to see that the appropriate device support module exists. If it doesn't, an error message is issued and processing is terminated with the PACT field still set to TRUE. This ensures that processes will no longer be called for this record. Thus error storms will not occur.

2. If SGL is DB_LINK and GTYP is Software, get SGV from SGL. If SGV has changed, save the CMD value, call the command routine with START if SGV $=0$ or with STOP if SGV is 1 , reset the command to the saved value, and set alarms if return status not zero. If the device is not done (PACT TRUE), then issue a callback request for this record to process and return 
3. If $C M D$ is not READ, call command routine and set CMD to READ. If the device is not done (PACT TRUE), then issue a callback request for this record to process again and return.

4. Call command routine. If device support set PACT to TRUE, then return.

5. Check to see if monitors should be invoked.

- Alarm monitors are invoked if the alarm status or severity has changed.

- Archive and value change monitors on CMD are invoked if values have changed.

- NSEV and NSTA are reset to 0.

6. Scan forward link if necessary, set PACT FALSE, and return.

\section{Device Support}

Fields Of Interest

To Device Support

\section{Device Support Routines}

report

init

init_record
Each record must have an associated set of device support routines. The primary responsibility of the device support routines is to issue commands to the output device. The device support routines are primarily interested in the following fields:

\begin{tabular}{|l|l|l|}
\hline \multicolumn{1}{|c|}{ Name } & \multicolumn{1}{|c|}{ Summary } & \multicolumn{1}{c|}{ Description } \\
\hline \hline CSIZ & Counter size & $\begin{array}{l}\text { This will determine to a } 16 \text { bit or 32 bit count is to be } \\
\text { used. With 32 bit, two counters are used. }\end{array}$ \\
\hline CMD & Command & $\begin{array}{l}\text { The device support routine is responsible for processing } \\
\text { the commands READ, CLEAR, START, STOP, and SETUP. }\end{array}$ \\
\hline GTYP,IGV & Gate Type & $\begin{array}{l}\text { If GTYP is internal, device support is responsible for using } \\
\text { IGV to determine gating control. }\end{array}$ \\
\hline CNTE & Count Edge & $\begin{array}{l}\text { This field is used by the device support routines to force } \\
\text { counting on leading or falling edge of signal. }\end{array}$ \\
\hline CNTS & Count Source & $\begin{array}{l}\text { Device support must use CNTS to set count source during } \\
\text { setup. }\end{array}$ \\
\hline
\end{tabular}

Device support consists of the following routines:

report ()

This routine is optional. If provided, it prints a report of all device modules.

$$
\text { init) }
$$

This routine is called once during IOC initialization.

$$
\text { init_record(precord) }
$$

This routine is optional. If provided, it is called by the record support init_record routine. 
get_ioint_info

$c m d \_c$ get_ioint_info(int cmd,struct dbCommon *precord, IOSCANPVT *ppvt)

This routine is called by the ioEventScan system each time the record is added or deleted from an I/O event scan list. cma has the value $(0,1)$ if the record is being (added to, deleted from) an I/O event list. It must be provided for any device type that can use the ioEvent scanner.

cmd_pc (precord)

This routine issues commands to the output device. It returns the following values:

- 0: Success.

- Other: Error. 
Chapter 26: pulseCounter

Device Support

: 


\section{Chapter 27: pulseDelay}

\section{Introduction}

The normal use for the pulseDelay record type is to generate output pulses.

\section{Field Summary}

\begin{tabular}{|l|l|l|l|l|l|l|l|}
\hline \multicolumn{1}{|c|}{ Field } & \multicolumn{1}{|c|}{ Type } & DCT & \multicolumn{1}{c|}{ Initial } & Access & Modify & $\begin{array}{l}\text { RecProc } \\
\text { Monitor }\end{array}$ & \multicolumn{1}{c|}{ PP } \\
\hline \hline OUT & OUTLINK & Yes & 0 & No & No & N/A & No \\
\hline UNIT & RECCHOICE & Yes & 0 & Yes & Yes & No & No \\
\hline DLY & DOUBLE & Yes & 0 & Yes & Yes & Yes & Yes \\
\hline WIDE & DOUBLE & Yes & 0 & Yes & Yes & Yes & Yes \\
\hline ODLY & DOUBLE & No & 0 & Yes & No & & No \\
\hline OWID & DOUBLE & No & 0 & Yes & No & & No \\
\hline CTYP & RECCHOICE & Yes & 0 & Yes & Yes & No & No \\
\hline CEDG & RECCHOICE & Yes & 0 & Yes & Yes & No & No \\
\hline ECS & SHORT & Yes & 0 & Yes & Yes & No & No \\
\hline ECR & DOUBLE & Yes & 0 & Yes & Yes & No & No \\
\hline VAL & RECCHOICE & No & 0 & Yes & Yes & Yes & No \\
\hline PFLD & USHORT & No & 0 & Yes & No & & No \\
\hline
\end{tabular}




\begin{tabular}{|l|l|l|l|l|l|l|l|}
\hline \multicolumn{1}{|c|}{ Field } & \multicolumn{1}{|c|}{ Type } & \multicolumn{1}{c|}{ DCT } & \multicolumn{1}{c|}{ Initial } & Access & Modify & $\begin{array}{l}\text { RecProc } \\
\text { Monitor }\end{array}$ & \multicolumn{1}{c|}{ PP } \\
\hline \hline LLOW & RECCHOICE & Yes & 0 & Yes & Yes & No & No \\
\hline TTYP & RECCHOICE & Yes & 0 & Yes & Yes & No & No \\
\hline HTS & ENUM & Yes & 0 & Yes & Yes & No & Yes \\
\hline STL & INLINK & Yes & 0 & No & No & N/A & No \\
\hline STV & RECCHOICE & Yes & 0 & Yes & Yes & No & Yes \\
\hline HOPR & FLOAT & Yes & 0 & Yes & Yes & No & No \\
\hline LOPR & FLOAT & Yes & 0 & Yes & Yes & No & No \\
\hline PREC & SHORT & Yes & 0 & Yes & Yes & No & No \\
\hline GATE & RECCHOICE & Yes & 1 & Yes & Yes & No & Yes \\
\hline GLNK & INLINK & Yes & 0 & Yes & No & N/A & No \\
\hline
\end{tabular}

\section{Field Descriptions}

\begin{tabular}{|c|c|c|}
\hline Name & Summary & Description \\
\hline OUT & Output Link & $\begin{array}{l}\text { This field is used by the device support routines to decide } \\
\text { where to send output. For soft records, it can be a } \\
\text { constant, a database link, or a channel access link. If the } \\
\text { link is a constant, the result is no output. }\end{array}$ \\
\hline UNIT & Time units & $\begin{array}{l}\text { Time units of delay and width. (Seconds, Milliseconds, } \\
\text { Microseconds, Nanoseconds, Picoseconds). }\end{array}$ \\
\hline DLY & $\begin{array}{l}\text { Pulse Delay, in } \\
\text { UNITS of time }\end{array}$ & Delay after trigger edge until beginning of pulse. \\
\hline WIDE & $\begin{array}{l}\text { Pulse Width, in } \\
\text { UNITS of time }\end{array}$ & Width of pulse generated. \\
\hline ODLY & Old Delay & Value when last monitors for delay were triggered. \\
\hline OWID & Old Width & Value when last monitors for width were triggered. \\
\hline CTYP & .Clock Type & $\begin{array}{l}\text { Hardware/Software. If software selected, then clock } \\
\text { automatically determined by software. If hardware } \\
\text { selected, then clock determined by ECS and ECR. }\end{array}$ \\
\hline CEDG & Clock Signal Edge & $\begin{array}{l}\text { This can be Rising Edge or Falling Edge. This field forces } \\
\text { clock timing on rising or falling edge of source signal. }\end{array}$ \\
\hline ECS & $\begin{array}{l}\text { External Clock } \\
\text { Source }\end{array}$ & $\begin{array}{l}\text { If CTYP is internal, this field is ignored. If CTYP is } \\
\text { external, then this field is device dependent. }\end{array}$ \\
\hline ECR & $\begin{array}{l}\text { External Clock } \\
\text { Rate, in } \mathrm{Hz}\end{array}$ & Clock rate for external clock source. \\
\hline
\end{tabular}




\begin{tabular}{|c|c|c|}
\hline Name & Summary & Description \\
\hline VAL & Value & $\begin{array}{l}\text { This field is will contain value } 1 \text { if a trigger was detected } \\
\text { since the last time the record was processed and a } 0 \\
\text { otherwise. }\end{array}$ \\
\hline PFLD & Processing Field & $\begin{array}{l}\text { This field is set to indicate if which of the following fields } \\
\text { changed since last processed: DLY, WIDE, STV, GATE, or } \\
\text { HTS. }\end{array}$ \\
\hline LLOW & Low Logic Level & $\begin{array}{l}\text { 0: Logic Low }=0 \\
\text { 1: Logic Low }=1\end{array}$ \\
\hline TTYP & $\begin{array}{l}\text { Trigger Type. } \\
\text { (Hardware/ } \\
\text { Software) }\end{array}$ & $\begin{array}{l}\text { This field indicates where the pulse trigger will come } \\
\text { from. Hardware indicates HTS will be used, software will } \\
\text { use STL, STV. }\end{array}$ \\
\hline HTS & $\begin{array}{l}\text { Hardware Trigger } \\
\text { source }\end{array}$ & The source of the delayed pulse trigger. \\
\hline STL & $\begin{array}{l}\text { Soft Trigger } \\
\text { Location (Input } \\
\text { link) }\end{array}$ & This value for STV will be read from here if this is set. \\
\hline STV & Soft Trigger Value & $\begin{array}{l}\text { This can be enabled or disable. This will trigger a delayed } \\
\text { pulse if TTYP set to software and device allows it. }\end{array}$ \\
\hline HOPR & $\begin{array}{l}\text { High Operating } \\
\text { Range }\end{array}$ & \multirow{2}{*}{$\begin{array}{l}\text { These fields determine the upper and lower display limits } \\
\text { for graphics displays and the upper and lower control } \\
\text { limits for control displays. The fields are used by record } \\
\text { support to honor calls to get_graphic_double or } \\
\text { get_control_double. }\end{array}$} \\
\hline LOPR & $\begin{array}{l}\text { Low Operating } \\
\text { Range }\end{array}$ & \\
\hline PREC & Display Precision & $\begin{array}{l}\text { Precision with which to display DLY. This field is used by } \\
\text { record support to supply a value when get_precision } \\
\text { is called. }\end{array}$ \\
\hline GATE & $\begin{array}{l}\text { Gate for enablel } \\
\text { disable of pulse } \\
\text { generation }\end{array}$ & This field can be used to enable and disable the pulses. \\
\hline GLNK & Gate Location & $\begin{array}{l}\text { This field is used to determine where to get the value for } \\
\text { GATE. }\end{array}$ \\
\hline
\end{tabular}

\section{Record Support Routines}

init_record

This routine first checks that device support is available. Device support is then checked to see if write_pd is defined.

Next this routine initializes STV with the value of STL if STL type is CONSTANT link or creates a channel access link if STL type is PV_LINK.

GATE is likewise initialized if GLNK is CONSTANT or PV_LINK.

If device support includes init_record, it is called. 
process

special

get_value

get_precision

get_graphic_double

get_control_double
See next section.

Sets the PFLD field to indicate if write to DLY, STV, GATE or HTS field caused processing of the record.

Fills in the values of struct valueDes so that they refer to VAL.

Retrieves PREC. ,

Sets the upper display and lower display limits for a field. If the field is VAL, DLY, ODLY, WIDE or OWID the limits are set to HOPR and LOPR, else if the field has upper and lower limits defined they will be used, else the upper and lower maximum values for the field type will be used.

Sets the upper control and the lower control limits for a field. If the field is VAL, DLY, ODLY, WIDE or OWID the limits are set to HOPR and LOPR, else if the field has upper and lower limits defined they will be used, else the upper and lower maximum values for the field type will be used.

\section{Record Processing}

Routine process implements the following algorithm:

1. Check to see that the appropriate device support module exists. If it doesn't, an error message is issued and processing is terminated with the PACT field still set to TRUE. This ensures that processes will no longer be called for this record. Thus error storms will not occur.

2. The values for STV and GATE are then fetched.

3. Call write_pd routine.

4. PFLD is reset to zero.

5. If device support set PACT to TRUE, then return.

6. Set UDF to FALSE.

7. Check to see if monitors should be invoked.

- Alarm monitors are invoked if the alarm status or severity has changed.

- Archive and value change monitors on DLY and WIDE are invoked if values have changed.

- NSEV and NSTA are reset to 0.

8. Scan forward link if necessary, set PACT FALSE, and return. 


\section{Device Support}

Fields Of Interest

To Device Support
Each record must have an associated set of device support routines. The primary responsibility of the device support routines is to issue commands to the output device. The device support routines are primarily interested in the following fields:

\begin{tabular}{|c|c|c|}
\hline Name & Summary & Description \\
\hline OUT & Output Link & $\begin{array}{l}\text { This field is used by the device support routines to locate } \\
\text { its output. }\end{array}$ \\
\hline WIDE & Pulse Width & Device support must use WIDE for pulse width \\
\hline DLY & Pulse Delay & $\begin{array}{l}\text { Device support must use DLY for the delay after trigger } \\
\text { edge until beginning of pulse. }\end{array}$ \\
\hline LLOW & Low Logic Level & Device support must use to determine logic low level. \\
\hline UNIT & Time Units & $\begin{array}{l}\text { All values that refer to time measure will be in this time } \\
\text { unit. }\end{array}$ \\
\hline VAL & Value & $\begin{array}{l}\text { This field will contain a } 1 \text { if a trigger occured since the } \\
\text { last time the record was processed if the device supports } \\
\text { it. }\end{array}$ \\
\hline PFLD & Processing Field & $\begin{array}{l}\text { This field is used by some devices to indicate if the record } \\
\text { was scanned to adjust certain fields such as delay or } \\
\text { trigger source. If the device has a destructive read, then } \\
\text { changes to these types of fields will only could writes to } \\
\text { the device instead of a read and a write. }\end{array}$ \\
\hline TTYP & Trigger Type & $\begin{array}{l}\text { This field is used by the device support routines to force } \\
\text { triggering on leading or falling edge of signal if the } \\
\text { specified device supports it. }\end{array}$ \\
\hline HTS & $\begin{array}{l}\text { Hardware Trigger } \\
\text { Source }\end{array}$ & $\begin{array}{l}\text { This field wil be used to set the hardware trigger source if } \\
\text { the device supports it. }\end{array}$ \\
\hline STV & Soft Trigger Soure & $\begin{array}{l}\text { This field will be used for software to trigger an output } \\
\text { delayed pulse if the device supports it. }\end{array}$ \\
\hline CEDG & Clock Signal Edge & $\begin{array}{l}\text { This field is used by the device support routines to force } \\
\text { clock timing on leading or falling edge of signal. }\end{array}$ \\
\hline CTYP & Clock Type & \multirow{3}{*}{$\begin{array}{l}\text { If CTYP is external, device support is responsible for } \\
\text { using ECR for the clock rate and if CTYP is internal, ECS } \\
\text { is the clock source. }\end{array}$} \\
\hline ECS & $\begin{array}{l}\text { External Clock } \\
\text { Source }\end{array}$ & \\
\hline ECR & External Clock Rate & \\
\hline
\end{tabular}

Device Support Routines
Device support consists of the following routines: 
This routine is optional. If provided, it prints a report of all device modules.

init init ()

This routine is called once during IOC initialization.

init_record init_record (precord)

This routine is optional. If provided, it is called by the record support init_record routine.

get_ioint_info get_ioint_info(int cmd, struct abcommon *precord, IOSCANPVT *ppvt)

This routine is called by the ioEventScan system each time the record is added or deleted from an I/O event scan list. cma has the value $(0,1)$ if the record is being (added to, deleted from) an $\mathrm{I} / \mathrm{O}$ event list. It must be provided for any device type that can use the ioEvent scanner.

write_pd

write_pd(precord)

This routine issues commands to the output device. 


\section{Chapter 28: pulseTrain}

\section{Introduction}

The normal use for the pulseTrain record type is to generate an output pulse train.

2. Field Summary

\begin{tabular}{|l|l|l|l|l|l|l|l|}
\hline \multicolumn{1}{|c|}{ Field } & \multicolumn{1}{|c|}{ Type } & DCT & \multicolumn{1}{c|}{ Initial } & Access & Modify & $\begin{array}{l}\text { RecProc } \\
\text { Monitor }\end{array}$ & \multicolumn{1}{c|}{ PP } \\
\hline \hline OUT & OUTLINK & Yes & 0 & No & No & N/A & No \\
\hline UNIT & RECCHOICE & Yes & 0 & Yes & Yes & No & No \\
\hline PER & DOUBLE & Yes & 0 & Yes & Yes & Yes & No \\
\hline DCY & DOUBLE & Yes & 0 & Yes & Yes & Yes & No \\
\hline OPER & DOUBLE & No & 0 & Yes & No & & Yes \\
\hline ODCY & DOUBLE & No & 0 & Yes & No & & Yes \\
\hline GTYP & RECCHOICE & Yes & 0 & Yes & Yes & No & No \\
\hline HGV & SHORT & Yes & 0 & Yes & Yes & No & No \\
\hline SGL & INLINK & Yes & 0 & No & No & N/A & No \\
\hline SGV & RECCHOICE & Yes & 0 & Yes & Yes & No & No \\
\hline OSGV & SHORT & No & 0 & Yes & No & & No \\
\hline VAL & SHORT & No & 0 & Yes & Yes & Yes & Yes \\
\hline
\end{tabular}




\begin{tabular}{|l|l|l|l|l|l|l|l|}
\hline \multicolumn{1}{|c|}{ Field } & \multicolumn{1}{|c|}{ Type } & DCT & \multicolumn{1}{c|}{ Initial } & Access & Modify & $\begin{array}{l}\text { RecProc } \\
\text { Monitor }\end{array}$ & \multicolumn{1}{c|}{ PP } \\
\hline \hline CTYP & RECCHOICE & Yes & 0 & Yes & Yes & No & No \\
\hline CEDG & RECCHOICE & Yes & 0 & Yes & Yes & No & No \\
\hline ECS & SHORT & Yes & 0 & Yes & Yes & No & No \\
\hline ECR & DOUBLE & Yes & 0 & Yes & Yes & No & No \\
\hline HOPR & FLOAT & Yes & 0 & Yes & Yes & No & No \\
\hline LOPR & FLOAT & Yes & 0 & Yes & Yes & No & No \\
\hline PREC & SHORT & Yes & 0 & Yes & Yes & No & No \\
\hline LLOW & RECCHOICE & Yes & 0 & Yes & Yes & No & No \\
\hline
\end{tabular}

\section{Field Descriptions}

\begin{tabular}{|l|l|l|}
\hline \multicolumn{1}{|c|}{ Name } & \multicolumn{1}{|c|}{ Summary } & \multicolumn{1}{c|}{ Description } \\
\hline \hline OUT & Output Link & $\begin{array}{l}\text { This field is used by the device support routines to decide } \\
\text { where to send output. For soft records, it can be a } \\
\text { constant, a database link, or a channel access link. If the } \\
\text { link is a constant, the result is no output. }\end{array}$ \\
\hline UNIT & Units of time & $\begin{array}{l}\text { Units of time (Seconds, milliseconds, microseconds, } \\
\text { nanoseconds, picoseconds). }\end{array}$ \\
\hline PER & Period, in UNITs & Pulse train period. \\
\hline DCY & Duty Cycle, percent & Percent of time that signal is high. \\
\hline OPER & Old Period, in & Value when last monitors for period were triggered. \\
\hline UNITS & $\begin{array}{l}\text { Old Duty Cycle, } \\
\text { percent }\end{array}$ & Value when last monitors for duty cycle were triggered. \\
\hline GTYP & Gate Type & $\begin{array}{l}\text { This can be hardware or software. If GTYP is hardware, } \\
\text { then HGV determines gating control. If GTYP is software, } \\
\text { the SGV determines gating control. }\end{array}$ \\
\hline HGV & $\begin{array}{l}\text { Hardware Gate } \\
\text { Value }\end{array}$ & This field is device dependant. \\
\hline SGL & $\begin{array}{l}\text { Soft Gate Location } \\
\text { (Input Link) }\end{array}$ & $\begin{array}{l}\text { If SGL is a database link and GTYP is software, then SGV } \\
\text { will be set to the value read from SGL. }\end{array}$ \\
\hline SGV & Soft Gate Value & This can be inactive (no gating) or active. \\
\hline OSGV & Old Soft Gate Value & This is the previous value of SGV. \\
\hline VAL & Value & This field is not used. \\
\hline CTYP. & Clock Type & This can be internal or external. \\
\hline
\end{tabular}




\begin{tabular}{|c|c|c|}
\hline Name & Summary & Description \\
\hline CEDG & Clock Signal Edge & $\begin{array}{l}\text { This can be Rising Edge or Falling Edge. This field forces } \\
\text { counting on rising or falling edge of source signal. }\end{array}$ \\
\hline ECS & $\begin{array}{l}\text { External Clock } \\
\text { Source }\end{array}$ & $\begin{array}{l}\text { If CTYP is internal, this field is ignored. If CTYP is } \\
\text { external, then this field is device dependent. }\end{array}$ \\
\hline ECR & $\begin{array}{l}\text { External Clock } \\
\text { Rate, in } \mathrm{Hz}\end{array}$ & Clock rate for external clock source. \\
\hline HOPR & $\begin{array}{l}\text { High Operating } \\
\text { Range }\end{array}$ & \multirow{2}{*}{$\begin{array}{l}\text { These fields determine the upper and lower display limits } \\
\text { for graphics displays and the upper and lower control } \\
\text { limits for control displays. The fields are used by record } \\
\text { support to honor calls to get_graphic_double or } \\
\text { get_control_double. }\end{array}$} \\
\hline LOPR & $\begin{array}{l}\text { Low Operating } \\
\text { Range }\end{array}$ & \\
\hline PREC & Display Precision & $\begin{array}{l}\text { Precision with which to display DLY. This field is used by } \\
\text { record support to supply a value when get_precision } \\
\text { is called. }\end{array}$ \\
\hline LLOW & Low Logic Level & $\begin{array}{l}\text { Logic Low }=0 \\
\text { Logic Low }=1\end{array}$ \\
\hline
\end{tabular}

\section{Record Support Routines}

\section{init_record}

process

get_value

get_precision

get_graphic_double

get_control_double
This routine first checks that device support is available. If SGL is a constant then HGV is initialized with its value or a channel access link is created if SGL type is PV_LINK.

Device support is then checked to see if write_pt is defined.

If device support includes init_record, it is called.

See next section.

Fills in the values of struct valueDes so that they refer to VAL.

Retrieves PREC.

Sets the upper display and lower display limits for a field. If the field is VAL, PER, or OPER the limits are set to HOPR and LOPR, else if the field has upper and lower limits defined they will be used, else the upper and lower maximum values for the field type will be used.

Sets the upper control and the lower control limits for a field. If the field is VAL or PER the limits are set to HOPR and LOPR, else if the field has upper and lower limits defined they will be used, else the upper and lower maximum values for the field type will be used. 


\section{Record Processing}

Routine process implements the following algorithm:

1. Check to see that the appropriate device support module exists. If it doesn't, an error message is issued and processing is terminated with the PACT field still set to TRUE. This ensures that processes will no longer be called for this record. Thus error storms will not occur.

2. If SGL is DB_LINK and GTYP is Software, get SGV from SGL. If SGV has changed, save the duty cycle DCY value, call the write_pt routine with duty cycle $=0$, reset the duty cycle to the saved value, and set alarms if return status not zero. Then set the old soft gate value OSGV to SGV.

3. Call write_pt routine. If device support set PACT to TRUE, then return.

4. Set UDF to FALSE.

5. Check to see if monitors should be invoked.

- Alarm monitors are invoked if the alarm status or severity has changed.

- Archive and value change monitors on PER and DCY are invoked if values have changed.

- NSEV and NSTA are reset to 0.

6. Scan forward link if necessary, set PACT FALSE, and return.

\section{Device Support}

Fields Of Interest To Device Support
Each record must have an associated set of device support routines. The primary responsibility of the device support routines is to issue commands to the output device. The device support routines are primarily interested in the following fields:

\begin{tabular}{|l|l|l|}
\hline \multicolumn{1}{|c|}{ Name } & \multicolumn{1}{|c|}{ Summary } & \multicolumn{1}{|c|}{ Description } \\
\hline \hline UNIT & Units of time & $\begin{array}{l}\text { This field will be used to identify the time units used for } \\
\text { time fields. }\end{array}$ \\
\hline OUT & Output Link & $\begin{array}{l}\text { This field is used by the device support routines to locate } \\
\text { its output. }\end{array}$ \\
\hline PER & Period, in UNITs & Device support must use PER for pulse period. \\
\hline DCY & Duty Cycle, percent & $\begin{array}{l}\text { Device support must use DCY for the percent of time the } \\
\text { signal is high. }\end{array}$ \\
\hline LLOW & Low Logic Level & Device support must use to determine logic low level. \\
\hline CEDG & Clock Signal Edge & $\begin{array}{l}\text { This field is used by the device support routines to force } \\
\text { counting on leading or falling edge of signal. }\end{array}$ \\
\hline GTYP & Gate Type & $\begin{array}{l}\text { Device support is responsible for using IGV to determine } \\
\text { gating control if GTYP is internal, or SGV if GTYP is } \\
\text { external. }\end{array}$ \\
\hline IGV & Soft Gate Value & \\
\hline SGV & &
\end{tabular}




\begin{tabular}{|l|l|l|}
\hline \multicolumn{1}{|c|}{ Name } & \multicolumn{1}{|c|}{ Summary } & \multicolumn{1}{c|}{ Description } \\
\hline \hline CTYP & Clock Type & $\begin{array}{l}\text { If CTYP is external, device support is responsible for } \\
\text { using ECR for the clock rate and if CTYP is internal, ECS } \\
\text { is the clock source. }\end{array}$ \\
\hline ECS & $\begin{array}{l}\text { External Clock } \\
\text { Source }\end{array}$ & \\
\hline ECR & $\begin{array}{l}\text { External Clock } \\
\text { Rate, in Hz }\end{array}$ & \\
\hline
\end{tabular}

\section{Device Support Device support consists of the following routines:}

\section{Routines}

report

report()

This routine is optional. If provided, it prints a report of all device modules.

init

init)

This routine is called once during IOC initialization.

init_record

init_record (precord)

This routine is optional. If provided, it is called by the record support init_record routine.

get_ioint_info

get_ioint_info(int cmd, struct dbCommon *precord, IOSCANPVT *ppvt)

This routine is called by the ioEventScan system each time the record is added or deleted from an I/O event scan list. cma has the value $(0,1)$ if the record is being (added to, deleted from) an I/O event list. It must be provided for any device type that can use the ioEvent scanner.

write_pt

write_pt (precord)

This routine issues commands to the output device. It returns the following values:

- 0: Success.

- Other: Error. 


\title{
Chapter 29: scan
}

\author{
Ned D. Arnold
}

Advanced Photon Source

Argonne National Laboratory

\section{Introduction}

The basic function of a scan record is to move "positioners" through a series of steps and record "detector" data at each of the positions (the whole sequence is referred to as a "scan"). Once the scan parameters are properly initialized, the scan record coordinates the entire scan and notifies any interested "clients" when the scan is complete. The data is stored in arrays within the record rather than collected point by point by an external application program. This allows for much faster scans than those coordinated from an external application program on a point to point basis.

A single scan record supports a one dimensional scan. It is also possible to link scan records together to define multi-dimensional scans in a quite complex configuration.

Each scan record can control up to four "positioners" and acquire data from up to four process variables (typically detector data or measured positions of devices) during a scan. Two additional output variables can be defined to trigger other process variables (usually "detectors") between the positioning phase and the data acquisition phase. These outputs will be referred to as "detector triggers".

Although the typical use of a scan record is to move "positioners" and record "detector" data at each position, it can also be used for other applications. Any controllable device can be scanned through incremental values while recording data from any other process variables. For example, one of the "positioner" PVs could be used to vary the gain of a detector or the speed of a motor during a scan. Another example would be to use the scan record to vary several power supplies and record the beam position at each value of the supplies. In this context, the scan record becomes a general purpose "Vary $w, x, y, z$ and record $a, b, c$, d" record. Therefore, throughout this document the word "positioner" and "controller" will be used synonymously. When referring to the data being recorded at each point, the word "detector" will be used. 
All of the process variable names used to identify controllers, detectors, and detector triggers are specified using "reassignable links". This allows a scan to be configured on the fly. Scan parameters, including the names of controllers and detectors, can be saved and restored using the BURT.

NOTE: In this version, the PVs used in the "reassignable links" fields must reside in the same IOC.

\section{A Simple Single Dimensional Scan}

The simplest database configuration for using a scan record is shown in Figure 1. A thorough understanding of the -operation of this configuration will allow more complex scans to be developed easily.

In Figure 1, when the scan is initiated, the scan record commands several positioners (transform record and motor record) to move to their starting positions. The WAIT_1 record detects when all movement is complete and forces the SCAN record to process again. The SCAN record realizes that the positioning is complete and thus triggers the Detectors. The WAIT_2 record detects when data is valid and forces the SCAN record to process yet again. The SCAN record will then read the Detector Data and command the positioners to their next step. This will continue until the SCAN record has completed the appropriate number of steps. At the end of the scan, the SCAN record contains data arrays for each of the "detectors", as well as arrays that contain the positions to which each controller was commanded at each point. A simple $x-y$ plot using this data will provide the detector data vs. position results.

Figure 1: Typical Database Support for a SCAN

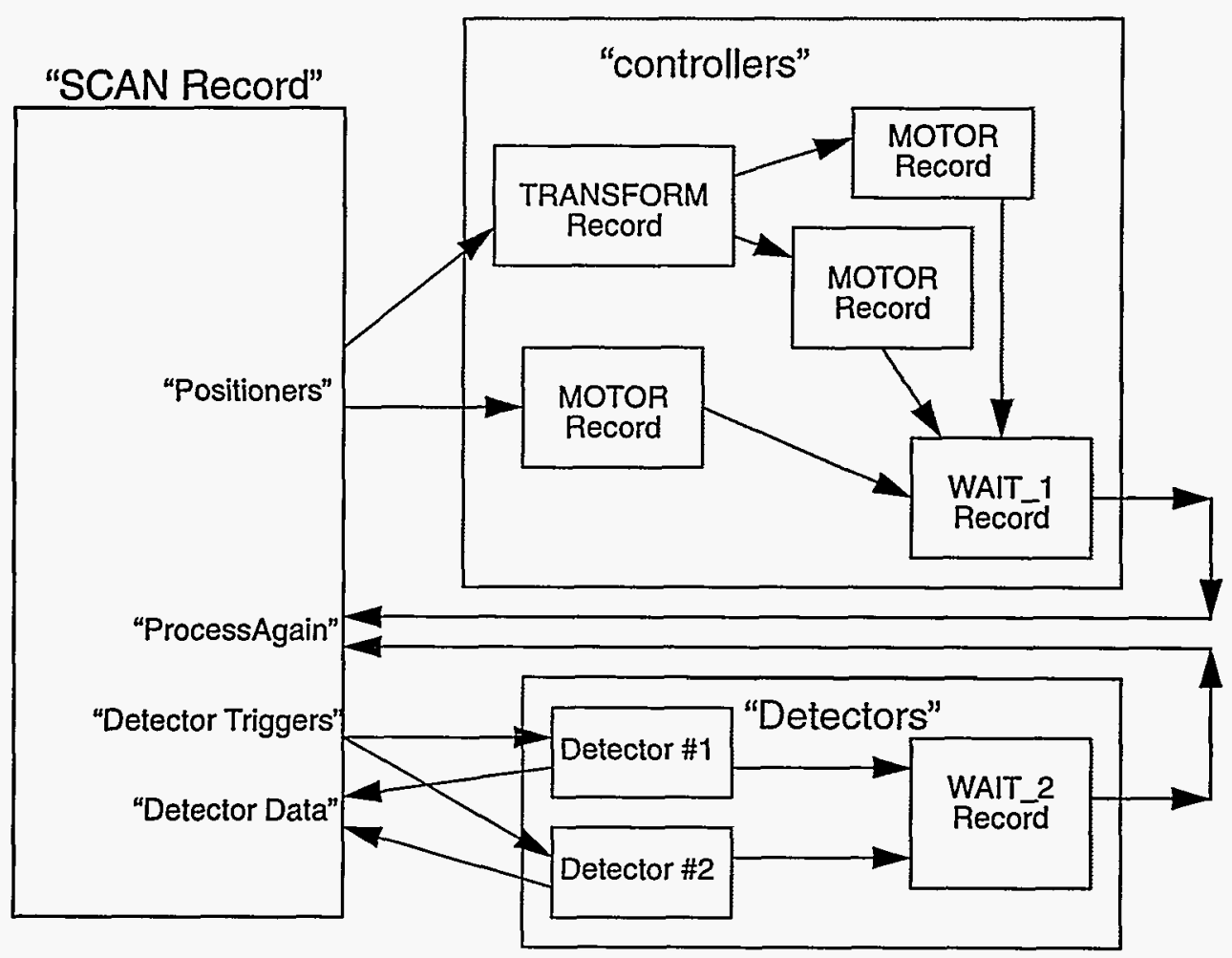


Figure 2: A Two Dimensional Scan Implementation

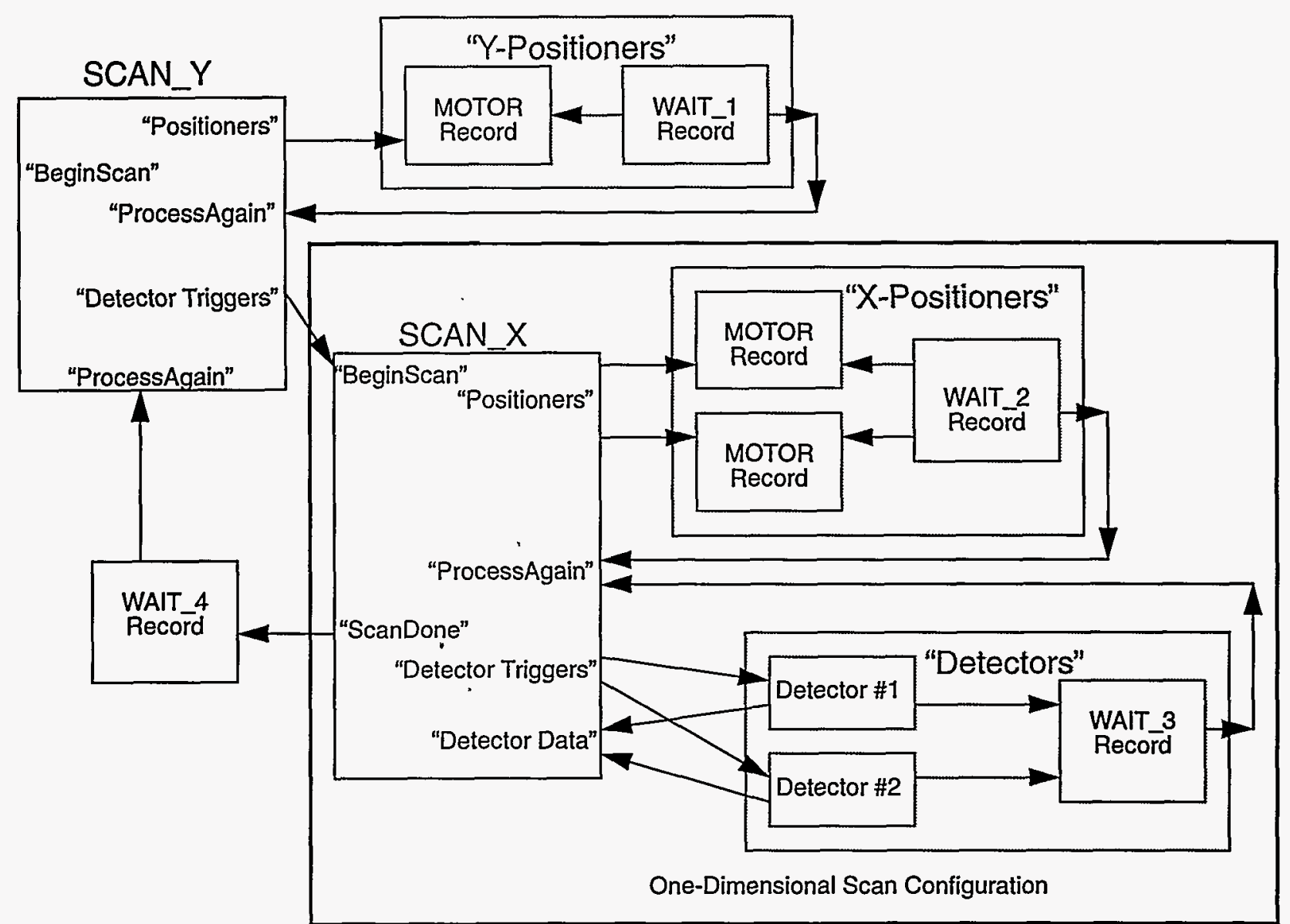

Two

Dimensional Scanning
Figure 2 illustrates using two scan records to accomplish a two dimensional scan. The SCAN_X record controls the positioners for the $\mathrm{X}$ axis, the SCAN_Y record controls the $\mathrm{Y}$ positioner.

To initiate a scan, the SCAN_Y record is commanded to begin. It commands its "positioners" to the specified starting point. The WAIT_1 record detects when all motors are stopped and forces the SCAN_Y record to process again. The SCAN_Y record will now write to its "Detector Trigger", which in this case begins a scan of the SCAN_X record. The SCAN_X record will now go through its entire programmed scan, acquiring data from the detectors at each point.

When the SCAN_X record is complete, the WAIT_4 record will force the processing of SCAN_Y, which will increment the position of the $y$-controller and initiate the $x$ scan once again.

This approach to configuring a two dimensional scan is very flexible. Note that to "test" the $\mathrm{x}$ scan, one could write to the "BeginScan" field of SCAN_X which would perform an entire $\mathrm{X}$ scan. Although the SCAN_Y record would get processed after the $\mathrm{x}$ scan was complete (via the WAIT_4 record), nothing would happen because it was not in the middle of a scan. In addition, any of the motors can be moved individually when a scan is not in process without 
any unexpected behavior (detectors would not be triggered unless the operator did it deliberately). One could even build a three dimensional scan by adding an additional scan record that initiates the $y$-scan after positioning a $z$-controller.

Defining a Scan

Positioners
Several options are available to control the execution of a scan. All parameters must be properly configured prior to initiating the scan. This section describes the options that are available while the next section itemizes all the parameters required.

Each scan record may control up to four "positioners" that are commanded to a new "desired position" prior to collecting data at each point. The positioners are defined by typing in an ASCII string that represents the process variable name of the controller.

There are three modes'for determining the desired value for the positioner. If a positioner is specified as "linear", its desired value is determined by using parameters such as start_position, step_increment, number_of_steps, and end_position. This mode will be discussed in more detail in the next paragraph. If a positioner is specified as "lookup", its next position is found in an array that has been loaded into the record prior to initiating a scan. If the positioner is specified as "on-the-fly", it is commanded to the end_position after the first data point is collected and not changed again for the duration of the scan.

A linear scan involving a single positioner is fully defined by three parameters, e.g., the start position, the step size, and the number of data points. A scan involving $\mathrm{N}$ controllers is defined by merely $2 \mathrm{~N}+1$ parameters, since the number of data points must be the same for all controllers. For the convenience of interactive users, and to support channel-access clients that define scans differently, the scan record provides for six redundant scan-definition parameters (for the first controller only): START, END, CENTER, WIDTH, STEP, and NPTS. The record calculates values for unspecified parameters so that the set is always self consistent, and it imposes an upper limit (MAXPTS) on NPTS. WIDTH may be negative.

There is no unique prescription for removing inconsistencies among redundant parameters, and no hardcoded set of preferences among parameters is likely to please everyone. Therefore, the scan record allows the user to "freeze" parameters, so that they will not be changed in the record's internal attempts to ensure self-consistency of the parameter set. Frozen parameters can be changed by the user and by any other client. It is the user's responsibility to ensure that frozen parameters do not prevent freely specifying unfrozen parameters. For example, if both STEP and NPTS are frozen, changes to WIDTH will be rejected. Similarly, if both START and CENTER are frozen, changes to END and WIDTH will have no effect. By default, START, STEP, and NPTS are frozen. When the record cannot adjust the parameters to be consistent, $a$ flag is raised (ALRT) and a message reported (SMSG).

Although this approach may seem to present the user with an overwhelming number of choices, it should be noted that "by default" the user only has to enter START, STER, and NPTS to fully define the scan of a controller. The "user interface" (usually medm or another CA client) need only present the user with these fields. However, by changing the "freeze flags" from the default and presenting the user with different fields to fill in, the scan can be defined in a completely flexible way. The result is that a simple scan can be defined easily, but advanced users are not limited in flexibility.

For those controllers defined as "linear", each desired position is placed in the "desired position" array that is used for lookup mode. Therefore, after the scan is complete, this array will always contain the sequence of desired positions to which the controller was commanded. 
Position

Verification

Readback

Process Variable

and Delta

Detector Trigger

Process Variables

and Desired

Command

Data to be

Acquired
These values will have been provided by the user for "lookup" mode and calculated by the scan record for "linear" mode. This array will contain no useful data if "on-the-fly" mode was used.

For each positioner, the user may specify a process variable that corresponds to the actual (or measured) position of the motor. If this readback field is configured, the scan record will confirm after each movement that the actual position is within a specified delta to the desired position. If the delta is exceeded, the scan will abort and the record will go into an alarm state. A text field within the record (SMSG) will inform the operator of the error condition.

If valid process variable names are entered into the "Detector Trigger" fields, the scan record will write the specified "Desired Command" (a floating point number) to that process variable between the positioning phase and the data acquisition phase.

If neither Detector Trigger contains a valid PV, the scan record will skip this step and acquire the data immediately. Note that specifying a "Detector Trigger" requires the scan record to be processed an additional time each point.

Each scan record can acquire data from four process variables at each point in the scan. This data will most commonly be from a detector or from a position readback (which would record the actual motor positions at each point and could then be compared to the desired position array).

The scan results will most frequently be read as arrays of positions and arrays of detector data where each detector data element corresponds to the position element.

For single dimension scans, the scan is complete when the ExecuteScan flag is set back to zero by the record processing routine. The application program can then read the position arrays and the data arrays (or have a monitor set on them so the record will "post_monitors" when complete).

For two dimension scans similar to Figure 2, the application program should read the arrays from the SCAN_X record after the completion of each $\mathrm{x}$ scan and correlate it to the current $\mathrm{y}$ controller information. This will allow the application program to display data after each $\mathrm{x}$ scan. The scan record will buffer the data for only one $x$ scan, so the application must read the arrays before the next $x$ scan is completed. If the scan is fast enough that this may prevent a problem, the application program can contribute to the wait record algorithm such that the $y$ controllers are not moved until the application program has completely read the previous SCAN_X data.

On slow scans, the application program may want to see the scan is process on a point by point basis. Therefore, the scan record will "post_monitors" on fields that it updates each point, but it will not post monitors faster than 20 times per second. If a scan is proceeding at a rate less than 20 points per second, every point will be posted. If a scan is proceeding at 100 steps per second, scalar values will be posted every 5th point (approx). In either case, the array data will contain every point at the completion of the scan. It is not recommended that the application program use the point to point data except for keeping the operator aware of the progress of the scan. 
Checking Scan

Parameters

Against Limits
Prior to beginning an actual scan, the record can be commanded to check the scan parameters to ensure that all positioner requests are within reasonable limits. The record will do a "dry run" by calculating every positioner value (or looking it up in the table) and comparing it with the "drive limits" associated with that positioner's Process Variable (drive limits are an attribute of most process variables). If any step would exceed the drive limits, the operator is notified via the SMSG field.

\section{Configurable Parameters}

A brief summary of the configurable parameters within a scan record is presented below. For a more detailed explanation, see Field Description section.

- Record Initialization

- Maximum Number of Steps in any scan (used to allocate memory)

- SCAN Definition Parameters

- Number of steps for This Scan

- SCAN Record SCAN Mechanism (Normal Choices for any record)

- Positioner Definition (Four positioners)

- PV Name

- PV Name Valid Flag (monitor only)

- "Lookup/Linear/On-the-Fly" Mode Selection

- Start Position and Freeze Flag

- Width and Freeze Flag

- Center and Freeze Flag

- Step Increment and Freeze Flag

- End Position and Freeze Flag

- Desired Position Array

- Position Verification Readback PV Name

- Position Verification Readback PV Name Valid Flag (monitor only)

- Position Verification Delta

- Current Position (monitor only)

- Detector Definition (Four Detectors)

- PV Namé

- PV Name Valid Flag (monitor only)

- Current value (monitor only)

- Detector Data Array (monitor only)

- Detector Trigger (if desired)

- PV Name

- Command to write 


\section{Field Summary}

\begin{tabular}{|c|c|c|c|c|c|c|c|}
\hline Field & Type & DCT & Initial & Access & Modify & $\begin{array}{l}\text { Rec Proc } \\
\text { Monitor }\end{array}$ & $\mathbf{P P}$ \\
\hline VERS & FLOAT & No & 1.0 & Yes & No & No & No \\
\hline VAL & DOUBLE & No & 0 & Yes & Yes & No & No \\
\hline SMSG & STRING & No & Null & Yes & Yes & Yes & No \\
\hline CMND & ENUM & No & 0 & Yes & Yes & Yes & No \\
\hline ALRT & UCHAR & No & 0 & Yes & No & Yes & No \\
\hline RPVT & NOACCESS & No & Null & No & No & No & No \\
\hline MPTS & SHORT & Yes & 100 & Yes & No & No & No \\
\hline EXSC & SHORT & No & 0 & Yes & Yes & Yes & No \\
\hline PXSC & UCHAR & No & 0 & Yes & No & No & No \\
\hline NPTS & SHỌT & Yes & 100 & Yes & Yes & Yes & No \\
\hline FPTS & RECCHOICE & Yes & 1 & Yes & Yes & No & No \\
\hline $\mathrm{CPT}$ & SHORT & No & 0 & Yes & No & Yes* & No \\
\hline PCPT & SHORT & No & 0 & Yes & No & No & No \\
\hline TOLP & ULONG & No & 0 & Yes & No & No & No \\
\hline P1PV & STRING & Yes & Null & Yes & Yes & No & No \\
\hline P2PV & STRING & Yes & Null & Yes & Yes & No & No \\
\hline P3PV & STRING & Yes & Null & Yes & Yes & No & No \\
\hline P4PV & STRING & Yes & Null & Yes & Yes & No & No \\
\hline R1PV & STRING & Yes & Null & Yes & Yes & No & No \\
\hline R2PV & STRING & Yes & Null & Yes & Yes & No & No \\
\hline R3PV & STRING & Yes & Null & Yes & Yes & No & No \\
\hline R4PV & STRING & Yes & Null & Yes & Yes & No & No \\
\hline TIPV & STRING & Yes & Null & Yes & Yes & No & No \\
\hline $\mathrm{T} 2 \mathrm{PV}$ & STRING & Yes & Null & Yes & Yes & No & No \\
\hline DIPV & STRING & Yes & Null & Yes & Yes & No & No \\
\hline D2PV & STRING & Yes & Null & Yes & Yes & No & No \\
\hline D3PV & STRING & Yes & Null & Yes & Yes & No & No \\
\hline D4PV & STRING & Yes & Null & Yes & Yes & No & No \\
\hline P1DB & NOACCESS & No & Null & No & No & No & No \\
\hline P2DB & NOACCESS & No & Null & No & No & No & No \\
\hline
\end{tabular}




\begin{tabular}{|c|c|c|c|c|c|c|c|}
\hline Field & Type & DCT & Initial & Access & Modify & \begin{tabular}{|l} 
Rec Proc \\
Monitor
\end{tabular} & PP \\
\hline P3DB & NOACCESS & No & Null & No & No & No & No \\
\hline P4DB & NOACCESS & No & Null & No & No & No & No \\
\hline RIDB & NOACCESS & No & Null & No & No & No & No \\
\hline $\mathrm{R} 2 \mathrm{DB}$ & NOACCESS & No & Null & No & No & No & No \\
\hline R3DB & NOACCESS & No & Null & No & No & No & No \\
\hline R4DB & NOACCESS & No & Null & No & No & No & No \\
\hline T1DB & NOACCESS & No & Null & No & No & No & No \\
\hline $\mathrm{T} 2 \mathrm{DB}$ & NOACCESS & No & Null & No & No & No & No \\
\hline D1DB & NOACCESŚ & No & Null & No & No & No & No \\
\hline D2DB & NOACCESS & No & Null & No & No & No & No \\
\hline D3DB & NOACCESS & No & Null & No & No & No & No \\
\hline D4DB & NOACCESS & No & Null & No & No & No & No \\
\hline PINV & LONG & No & 0 & Yes & Yes & Yes & No \\
\hline $\mathrm{P} 2 \mathrm{NV}$ & LONG & No & 0 & Yes & Yes & Yes & No \\
\hline P3NV & LONG & No & 0 & Yes & Yes & Yes & No \\
\hline P4NV & LONG & No & 0 & Yes & Yes & Yes & No \\
\hline RINV & LONG & No & 0 & Yes & Yes & Yes & No \\
\hline R2NV & LONG & No & 0 & Yes & Yes & Yes & No \\
\hline R3NV & LONG & No & 0 & Yes & Yes & Yes & No \\
\hline R4NV & LONG & No & 0 & Yes & Yes & Yes & No \\
\hline TINV & LONG & No & 0 & Yes & Yes & Yes & No \\
\hline $\mathrm{T} 2 \mathrm{NV}$ & LONG & No & 0 & Yes & Yes & Yes & No \\
\hline D1NV & LONG & No & 0 & Yes & Yes & Yes & No \\
\hline D2NV & LONG & No & 0 & Yes & Yes & Yes & No \\
\hline D3NV & LONG & No & 0 & Yes & Yes & Yes & No \\
\hline D4NV & LONG & No & 0 & Yes & Yes & Yes & No \\
\hline P1SM & RECCHOICE & Yes & 0 & Yes & Yes & No & No \\
\hline P1SP & FLOAT & Yes & 0 & Yes & Yes & Yes & No \\
\hline PIFS & RECCHOICE & Yes & 0 & Yes & Yes & No & No \\
\hline P1SI & FLOAT & Yes & 0 & Yes & Yes & Yes & No \\
\hline PIFI & RECCHOICE & Yes & 0 & Yes & Yes & No & No \\
\hline PICP & FLOAT & Yes & 0 & Yes & Yes & Yes & No \\
\hline
\end{tabular}




\begin{tabular}{|c|c|c|c|c|c|c|c|}
\hline Field & Type & DCT & Initial & Access & Modify & \begin{tabular}{|l|} 
Rec Proc \\
Monitor \\
\end{tabular} & PP \\
\hline P1FC & RECCHOICE & Yes & 0 & Yes & Yes & No & No \\
\hline P1EP & FLOAT & Yes & 0 & Yes & Yes & Yes & No \\
\hline P1FE & RECCHOICE & Yes & 0 & Yes & Yes & No & No \\
\hline P1WD & FLOAT & Yes & 0 & Yes & Yes & Yes & No \\
\hline P1FW & RECCHOICE & Yes & 0 & Yes & Yes & No & No \\
\hline PIDV & FLOAT & No & 0 & Yes & No & Yes* & No \\
\hline P1LV & FLOAT & No & 0 & Yes & No & No & No \\
\hline $\mathrm{R} 1 \mathrm{CV}$ & FLOAT & No & 0 & Yes & No & Yes* & No \\
\hline R1LV & FLOAT & No & 0 & Yes & No & No & No \\
\hline RIDL & FLOAT & Yes & 0 & Yes & Yes & No & No \\
\hline P1EU & STRING & Yes & 16 & Yes & Yes & No & No \\
\hline PIHR & FLOAT & Yes & 0 & Yes & Yes & No & No \\
\hline P1LR & FLOAT & Yes & 0 & Yes & Yes & No & No \\
\hline P1PR & SHORT & Yes & 0 & Yes & Yes & No & No \\
\hline P1PA & FLOAT ARRAY & No & Null & Yes & Yes & Yes & No \\
\hline P2SM & RECCHOICE & Yes & 0 & Yes & Yes & No & No \\
\hline P2SP & FLOAT & Yes & 0 & Yes & Yes & Yes & No \\
\hline P2FS & RECCHOICE & Yes & 0 & Yes & Yes & No & No \\
\hline P2SI & FLOAT & Yes & 0 & Yes & Yes & Yes & No \\
\hline P2FI & RECCHOICE & Yes & 0 & Yes & Yes & No & No \\
\hline $\mathrm{P} 2 \mathrm{CP}$ & FLOAT & Yes & 0 & Yes & Yes & Yes & No \\
\hline P2FC & RECCHOICE & Yes & 0 & Yes & Yes & No & No \\
\hline P2EP & FLOAT & Yes & 0 & Yes & Yes & Yes & No \\
\hline P2FE & RECCHOICE & Yes & 0 & Yes & Yes & No & No \\
\hline P2WD & FLOAT & Yes & 0 & Yes & Yes & Yes & No \\
\hline P2FW & RECCHOICE & Yes & 0 & Yes & Yes & No & No \\
\hline P2DV & FLOAT & No & 0 & Yes & No & Yes* & No \\
\hline P2LV & FLOAT & No & 0 & Yes & No & No & No \\
\hline $\mathrm{R} 2 \mathrm{CV}$ & FLOAT & No & 0 & Yes & No & Yes* & No \\
\hline R2LV & FLOAT & No & 0 & Yes & No & No & No \\
\hline R2DL & FLOAT & Yes & 0 & Yes & Yes & No & No \\
\hline P2EU & STRING & Yes & 16 & Yes & Yes & No & No \\
\hline
\end{tabular}




\begin{tabular}{|c|c|c|c|c|c|c|c|}
\hline Field & Type & DCT & Initial & Access & Modify & $\begin{array}{l}\text { Rec Proc } \\
\text { Monitor }\end{array}$ & $\mathbf{P P}$ \\
\hline P2HR & FLOAT & Yes & 0 & Yes & Yes & No & No \\
\hline P2LR & FLOAT & Yes & 0 & Yes & Yes & No & No \\
\hline P2PR & SHORT & Yes & 0 & Yes & Yes & No & No \\
\hline P2PA & FLOAT ARRAY & No & Null & Yes & Yes & Yes & No \\
\hline P3SM & RECCHOICE & Yes & 0 & Yes & Yes & No & No \\
\hline P3SP & FLOAT & Yes & 0 & Yes & Yes & Yes & No \\
\hline P3FS & RECCHOICE & Yes & 0 & Yes & Yes & No & No \\
\hline P3SI & FLOAT & Yes & 0 & Yes & Yes & Yes & No \\
\hline P3FI & RECCHOICE & Yes & 0 & Yes & Yes & No & No \\
\hline P3CP & FLOAT & Yes & 0 & Yes & Yes & Yes & No \\
\hline P3FC & RECCHOICE & Yes & 0 & Yes & Yes & No & No \\
\hline P3EP & FLOAT & Yes & 0 & Yes & Yes & Yes & No \\
\hline P3FE & RECCHOICE & Yes & 0 & Yes & Yes & No & No \\
\hline P3WD & FLOAT & Yes & 0 & Yes & Yes & Yes & No \\
\hline P3FW & RECCHOICE & Yes & 0 & Yes & Yes & No & No \\
\hline P3DV & FLOAT. & No & 0 & Yes & No & Yes* & No \\
\hline P3LV & FLOAT & No & 0 & Yes & No & No & No \\
\hline $\mathrm{R} 3 \mathrm{CV}$ & FLOAT & No & 0 & Yes & No & Yes* & No \\
\hline R3LV & FLOAT & No & 0 & Yes & No & No & No \\
\hline R3DL & FLOAT & Yes & 0 & Yes & Yes & No & No \\
\hline P3EU & STRING & Yes & 16 & Yes & Yes & No & No \\
\hline P3HR & FLOAT & Yes & 0 & Yes & Yes & No & No \\
\hline P3LR & FLOAT & Yes & 0 & Yes & Yes & No & No \\
\hline P3PR & SHORT & Yes & 0 & Yes & Yes & No & No \\
\hline P3PA & FLOAT ARRAY & No & Null & Yes & Yes & Yes & No \\
\hline P4SM & RECCHOICE & Yes & 0 & Yes & Yes & No & No \\
\hline P4SP & FLOAT & Yes & 0 & Yes & Yes & Yes & No \\
\hline P4FS & RECCHOICE & Yes & 0 & Yes & Yes & No & No \\
\hline P4SI & FLOAT & Yes & 0 & Yes & Yes & Yes & No \\
\hline P4FI & RECCHOICE & Yes & 0 & Yes & Yes & No & No \\
\hline P4CP & FLOAT & Yes & 0 & Yes & Yes & Yes & No \\
\hline P4FC & RECCHOICE & Yes & 0 & Yes & Yes & No & No \\
\hline
\end{tabular}




\begin{tabular}{|c|c|c|c|c|c|c|c|}
\hline Field & Type & $\mathrm{DCT}$ & Initial & Access & Modify & $\begin{array}{l}\text { Rec Proc } \\
\text { Monitor }\end{array}$ & PP \\
\hline P4EP & FLOAT & Yes & 0 & Yes & Yes & Yes & No \\
\hline P4FE & RECCHOICE & Yes & 0 & Yes & Yes & No & No \\
\hline P4WD & FLOAT & Yes & 0 & Yes & Yes & Yes & No \\
\hline P4FW & RECCHOICE & Yes & 0 & Yes & Yes & No & No \\
\hline P4DV & FLOAT & No & 0 & Yes & No & Yes* & No \\
\hline P4LV & FLOAT & No & 0 & Yes & No & No & No \\
\hline $\mathrm{R} 4 \mathrm{CV}$ & FLOAT & No & 0 & Yes & No & Yes* & No \\
\hline R4LV & FLOAT & No & 0 & Yes & No & No & No \\
\hline R4DL & FLOAT & Yes & 0 & Yes & Yes & No & No \\
\hline P4EU & STRING & Yes & 16 & Yes & Yes & No & No \\
\hline P4HR & FLOAT & Yes & 0 & Yes & Yes & No & No \\
\hline P4LR & FLOAT & Yes & 0 & Yes & Yes & No & No \\
\hline P4PR & SHORT & Yes & 0 & Yes & Yes & No & No \\
\hline P4PA & FLOAT ARRAY & No & Null & Yes & Yes & Yes & No \\
\hline $\mathrm{D} 1 \mathrm{CV}$ & FLOAT & No & 0 & Yes & No & Yes* & No \\
\hline DILV & FLOAT & No & 0 & Yes & No & No & No \\
\hline DIEU & STRING & Yes & 16 & Yes & Yes & No & No \\
\hline D1HR & FLOAT & Yes & 0 & Yes & Yes & No & No \\
\hline DILR & FLOAT & Yes & 0 & Yes & Yes & No & No \\
\hline DIPR & SHORT & Yes & 0 & Yes & Yes & No & No \\
\hline D1DA & FLOAT ARRAY & No & Null & Yes & No & Yes & No \\
\hline $\mathrm{D} 2 \mathrm{CV}$ & FLOAT & No & 0 & Yes & No & Yes* & No \\
\hline D2LV & FLOAT & No & 0 & Yes & No & No & No \\
\hline D2EU & STRING & Yes & 16 & Yes & Yes & No & No \\
\hline D2HR & FLOAT & Yes & 0 & Yes & Yes & No & No \\
\hline D2LR & FLOAT & Yes & 0 & Yes & Yes & No & No \\
\hline D2PR & SHORT & Yes & 0 & Yes & Yes & No & No \\
\hline D2DA & FLOAT ARRAY & No & Null & Yes & No & Yes & No \\
\hline $\mathrm{D} 3 \mathrm{CV}$ & FLOAT & No & 0 & Yes & No & Yes* & No \\
\hline D3LV & FLOAT & No & 0 & Yes & No & No & No \\
\hline D3EU & STRING & Yes & 16 & Yes & Yes & No & No \\
\hline D3HR & FLOAT & Yes & 0 & Yes & Yes & No & No \\
\hline
\end{tabular}




\begin{tabular}{|l|l|l|l|l|l|l|l|}
\hline \multicolumn{1}{|c|}{ Field } & \multicolumn{1}{|c|}{ Type } & \multicolumn{1}{c|}{ DCT } & Initial & Access & Modify & $\begin{array}{l}\text { Rec Proc } \\
\text { Monitor }\end{array}$ & \multicolumn{1}{|c|}{ PP } \\
\hline \hline D3LR & FLOAT & Yes & 0 & Yes & Yes & No & No \\
\hline D3PR & SHORT & Yes & 0 & Yes & Yes & No & No \\
\hline D3DA & FLOAT ARRAY & No & Null & Yes & No & Yes & No \\
\hline D4CV & FLOAT & No & 0 & Yes & No & Yes* & No \\
\hline D4LV & FLOAT & No & 0 & Yes & No & No & No \\
\hline D4EU & STRING & Yes & 16 & Yes & Yes & No & No \\
\hline D4HR & FLOAT & Yes & 0 & Yes & Yes & No & No \\
\hline D4LR & FLOAT & Yes & 0 & Yes & Yes & No & No \\
\hline D4PR & SHORT & Yes & 0 & Yes & Yes & No & No \\
\hline D4DA & FLOAT ARRAY & No & Null & Yes & No & Yes & No \\
\hline T1CD & FLOAT & Yes & 0 & Yes & Yes & No & No \\
\hline T2CD & FLOAT & Yes & 0 & Yes & Yes & No & No \\
\hline
\end{tabular}

* Monitors on these fields are not posted any faster than $20 \mathrm{~Hz}$. Some changes may not be posted! Do not rely on these fields for step-to-step info.

\section{Field Descriptions}

This section describes the fields that will be of interest to a typical application developer. All array field names end with the character "A". It is hoped that this convention will make it easier to remember field name abbreviations.

\begin{tabular}{|l|l|l|}
\hline \multicolumn{1}{|c|}{ Name } & \multicolumn{1}{|c|}{ Summary } & \multicolumn{1}{c|}{ Description } \\
\hline \hline VERS & Code Version & Reflects the version of scan record processing routines. \\
\hline VAL & Value Field & Not Used. \\
\hline SMSG & $\begin{array}{c}\text { State Message } \\
\therefore\end{array}$ & $\begin{array}{l}\text { This field contains a message from the record alerting the } \\
\text { operator to any error conditions. It can be cleared by } \\
\text { writing a '0' to the CMND field. }\end{array}$ \\
\hline CMND & Command Field & $\begin{array}{l}\text { This field is used to send commands to the record. The } \\
\text { following commands are currently defined: } \\
\text { - Clear the State Message Field } \\
\text { 1 - Execute a "dry run" scan and check the desired } \\
\text { positions against the control limits of the positioner(s). }\end{array}$ \\
\hline ALRT & Alert Field & $\begin{array}{l}\text { This field is set to one when an alert condition exists in the } \\
\text { record (e.g Scan parameters too constrained, defined scan } \\
\text { exceeds limits, scan aborted, etc). The cause of the alert } \\
\text { will be indicated in the State Message Field (SMSG). }\end{array}$ \\
\hline
\end{tabular}




\begin{tabular}{|c|c|c|}
\hline Name & Summary & Description \\
\hline RPVT & Record Private & $\begin{array}{l}\text { Pointer to a structure that maintains information about the } \\
\text { scan record. }\end{array}$ \\
\hline MPTS & $\begin{array}{l}\text { Maximum Number } \\
\text { of Points }\end{array}$ & $\begin{array}{l}\text { This field is used to specify the maximum number of } \\
\text { points that will be used for any scan defined for this } \\
\text { record. This value is used to allocate memory for all the } \\
\text { array oriented fields, so the value will significantly affect } \\
\text { memory usage. }\end{array}$ \\
\hline EXSC & Execute Scan & $\begin{array}{l}\text { Writing a ' } 1 \text { ' to this field will initiate a scan. Writing a ' } 0 \text { ' } \\
\text { will abort the scan. The record will reset this field to ' } 0 \text { ' } \\
\text { when the scan is finished. }\end{array}$ \\
\hline PXSC & $\begin{array}{l}\text { Previous Execute } \\
\text { Scan }\end{array}$ & $\begin{array}{l}\text { Status of the EXSC flag the last time the record was } \\
\text { processed. }\end{array}$ \\
\hline NPTS & Number of Points & \multirow{2}{*}{$\begin{array}{l}\text { This entry defines the number of points for the scan. If the } \\
\text { freeze flag is set, the record will not change this value in } \\
\text { its attempt to keep the scan definition parameters } \\
\text { consistent. This value is constrained to be less than or } \\
\text { equal to MPTS. }\end{array}$} \\
\hline FPTS & Freeze Flag & \\
\hline CPT & Current Point & $\begin{array}{l}\text { This field contains the current point of an active scan. The } \\
\text { posting of events on this field is throttled to } 20 \mathrm{~Hz} \text {, so for } \\
\text { fast scans not every new value will be posted. }\end{array}$ \\
\hline PCPT & $\begin{array}{l}\text { Previous Current } \\
\text { Point }\end{array}$ & $\begin{array}{l}\text { This field contains the value of CPT that was last posted } \\
\text { (not every change is posted, see CPT desctiption). }\end{array}$ \\
\hline TOLP & $\begin{array}{l}\text { Time of Last } \\
\text { Posting }\end{array}$ & $\begin{array}{l}\text { Tick count of last time monitors were posted on the } \\
\text { "throttled" fields (e.g. CPT) }\end{array}$ \\
\hline PnPV & $\begin{array}{l}\text { Positionern Process } \\
\text { Variable }\end{array}$ & $\begin{array}{l}\text { ( } n=1-4 \text { ): These fields contain the Process Variable names } \\
\text { of the controllers that will be commanded during the scan. }\end{array}$ \\
\hline PnNV & $\begin{array}{l}\text { Positioner n Name } \\
\text { Valid }\end{array}$ & $\begin{array}{l}\text { ( } n=1-4) \text { : These flags indicate if the ASCII string entered } \\
\text { in PnPV was found to be an existing Process Variable. }\end{array}$ \\
\hline PnDV & $\begin{array}{l}\text { Positioner } n \\
\text { Desired Value }\end{array}$ & $\begin{array}{l}(n=1-4) \text { : These fields contain the desired value for each } \\
\text { postioner for the current point in the scan. The posting of } \\
\text { events on these fields is throttled to } 20 \mathrm{~Hz} \text {, so for fast } \\
\text { scans not every "desired value" will be posted. }\end{array}$ \\
\hline PnLV & $\begin{array}{l}\text { Positioner n Last } \\
\text { Value }\end{array}$ & $(n=1-4)$ : Last value 'posted' for PnDv. \\
\hline RnPV & $\begin{array}{l}\text { Readback } n \\
\text { Process Variable }\end{array}$ & $\begin{array}{l}(n=1-4) \text { : If specified, the scan record will read this } \\
\text { "actual position" of the controller to confirm it has } \\
\text { reached its "desired position". If this value is within a } \\
\text { specified deadband of the desired position, the scan will } \\
\text { continue. }\end{array}$ \\
\hline RnNV & $\begin{array}{l}\text { Readback n Name } \\
\text { Valid }\end{array}$ & $\begin{array}{l}\text { ( } n=1-4) \text { : These flags indicate if the ASCII string entered } \\
\text { in RnPV was found to be an existing Process Variable. }\end{array}$ \\
\hline $\mathrm{RnCV}$ & $\begin{array}{l}\text { Readback n } \\
\text { Current Value }\end{array}$ & $\begin{array}{l}(n=1-4) \text { : These fields contain the current value for each } \\
\text { postioner readback for the current point in the scan. The } \\
\text { posting of events on these fields is throttled to } 20 \mathrm{~Hz} \text {, so } \\
\text { for fast scans not every new value will be posted. }\end{array}$ \\
\hline
\end{tabular}




\begin{tabular}{|c|c|c|}
\hline Name & Summary & Description \\
\hline RnLV & $\begin{array}{l}\text { Readback n Last } \\
\text { Value }\end{array}$ & ( $n=1-4$ ): Last value 'posted' for RnCV. \\
\hline $\mathrm{RnDL}$ & Readback n Delta & $\begin{array}{l}\text { ( } n=1-4) \text { : If RnPV is specified, the scan record will } \\
\text { confirm that the Read Back value is within this dead band, } \\
\text { or the scan will be halted. }\end{array}$ \\
\hline PnSM & $\begin{array}{l}\text { Positioner n Step } \\
\text { Mode }\end{array}$ & $\begin{array}{l}(\mathrm{n}=1-4) \text { : Indicates if the desired positions for a controller } \\
\text { are to be calculated in a linear fashion (incremented by } \\
\text { step size), found in a "desired position array", or given a } \\
\text { final position command at the beginning of the scan (on- } \\
\text { the-fly). }\end{array}$ \\
\hline $\mathrm{PnPA}$ & $\begin{array}{l}\text { Positioner n } \\
\text { Position Array }\end{array}$ & $\begin{array}{l}\text { ( } n=1-4) \text { : This array contains the step positions for a } \\
\text { controller if it uses the "lookup" mode (see PnSM). This } \\
\text { array is filled in by the record during a scan if the } \\
\text { controller was in "linear" mode. If the number of steps } \\
\text { was less than MPTS, the remainder of the array is filled } \\
\text { with the data from the last step. }\end{array}$ \\
\hline PnSP & $\begin{array}{l}\text { Positioner n Start } \\
\text { Position }\end{array}$ & \multirow{2}{*}{$\begin{array}{l}\text { ( } n=1-4) \text { : For controllers in the "linear" or "on-the- } \\
\text { fly" mode, this field specifies the start position for the } \\
\text { controller. If the freeze fiag is set, the record will not } \\
\text { change this value in its attempt to keep the scan definition } \\
\text { parameters consistent. }\end{array}$} \\
\hline PnFS & $\begin{array}{l}\text { Positioner n Freeze } \\
\text { Flag }\end{array}$ & \\
\hline PnSI & $\begin{array}{l}\text { Positioner n Step } \\
\text { Increment }\end{array}$ & \multirow{2}{*}{$\begin{array}{l}\text { ( } n=1-4) \text { : For controllers in the "I inear" mode, this field } \\
\text { specifies the step increment. If the freeze flag is set, the } \\
\text { record will not change this value in its attempt to keep the } \\
\text { scan definition parameters consistent. }\end{array}$} \\
\hline PnFI & $\begin{array}{l}\text { Positioner n Freeze } \\
\text { Flag }\end{array}$ & \\
\hline PnEP & End Position & \multirow{2}{*}{$\begin{array}{l}\text { ( } n=1-4) \text { : For controllers in the "linear" mode, this field } \\
\text { contains the last position to which the controller will be } \\
\text { commanded. If the freeze flag is set, the record will not } \\
\text { change this value in its attempt to keep the scan definition } \\
\text { parameters consistent. }\end{array}$} \\
\hline PnFE & $\begin{array}{l}\text { Positioner n Freeze } \\
\text { Flag }\end{array}$ & \\
\hline $\mathrm{PnCP}$ & $\begin{array}{l}\text { Positioner n Center } \\
\text { Position }\end{array}$ & \multirow{2}{*}{$\begin{array}{l}(n=1-4) \text { : For controllers in the "linear" mode, this field } \\
\text { may be used to define the center position of a scan. If the } \\
\text { freeze flag is set, the record will not change this value in } \\
\text { its attempt to keep the scan definition parameters } \\
\text { consistent. }\end{array}$} \\
\hline PnFC & $\begin{array}{l}\text { Positioner n Freeze } \\
\text { Flag }\end{array}$ & \\
\hline PnWD & Positioner n Width & \multirow{2}{*}{$\begin{array}{l}\text { ( } n=1-4) \text { : For controllers in the "linear" mode, this field } \\
\text { may be used to define the width of the scan (the distance } \\
\text { from the start position to the finish position). If the freeze } \\
\text { flag is set, the record will not change this value in its } \\
\text { attempt to keep the scan definition parameters consistent. }\end{array}$} \\
\hline PnFW & $\begin{array}{l}\text { Positioner n Freeze } \\
\text { Flag }\end{array}$ & \\
\hline PnLR & $\begin{array}{l}\text { Positioner n Low } \\
\text { Range }\end{array}$ & \multirow{2}{*}{$\begin{array}{l}\text { ( } n=1-4): \text { These are user configurable fields to describe low } \\
\text { and high ranges for the positioner data (used by some } \\
\text { channel access clients). }\end{array}$} \\
\hline PnHR & $\begin{array}{l}\text { Positioner n High } \\
\text { Range }\end{array}$ & \\
\hline
\end{tabular}




\begin{tabular}{|c|c|c|}
\hline Name & Summary & Description \\
\hline PnPR & $\begin{array}{l}\text { Positioner } n \\
\text { Precision }\end{array}$ & $\begin{array}{l}\text { ( } n=1-4) \text { : This is a user configurable fields to describe the } \\
\text { display precision for the positioner data (used by some } \\
\text { channel access clients). }\end{array}$ \\
\hline $\mathrm{PnEU}$ & $\begin{array}{l}\text { Positioner } \mathbf{n} \\
\text { Engineering Units }\end{array}$ & $\begin{array}{l}(n=1-4) \text { : This is a user configurable fields to describe the } \\
\text { units for the positioner data (used by some channel access } \\
\text { clients). }\end{array}$ \\
\hline TnPV & $\begin{array}{l}\text { Detector Trigger } n \\
\text { Process Variable }\end{array}$ & $\begin{array}{l}\text { ( } n=1-2) \text { : These fields contain the Process Variable names } \\
\text { of the "Detector Triggers" that are written to between the } \\
\text { positioning phase and the data acquisition phase of the } \\
\text { record. }\end{array}$ \\
\hline TnNV & $\begin{array}{l}\text { Trigger n Name } \\
\text { Valid }\end{array}$ & $\begin{array}{l}(\mathrm{n}=1-2) \text { : These flags indicate if the ASCII string entered } \\
\text { in TnPV was found to be an existing Process Variable. }\end{array}$ \\
\hline $\mathrm{TnCD}$ & Trigger $\mathrm{n}$ Command & $\begin{array}{l}\text { ( } n=1-2 \text { ): This is the data that is written to the Detector } \\
\text { Trigger PV's. }\end{array}$ \\
\hline DnPV & $\begin{array}{l}\text { Data n Process } \\
\text { Variable }\end{array}$ & $\begin{array}{l}(n=1-4): \text { These fields contain the Process Variable names } \\
\text { of the data that will be recorded at each point within the } \\
\text { scan. }\end{array}$ \\
\hline DnNV & Data n Name Valid & $\begin{array}{l}(\mathrm{n}=1-4): \text { These flags indicate if the ascii string entered in } \\
\text { DnPV was found to be an existing Process Variable. }\end{array}$ \\
\hline $\mathrm{DnCV}$ & $\begin{array}{l}\text { Detector n Current } \\
\text { Value }\end{array}$ & $\begin{array}{l}\text { ( } n=1-4) \text { : These fields contain the current value for each } \\
\text { detector for the current point in the scan. The posting of } \\
\text { events on these fields is throttled to } 20 \mathrm{~Hz} \text {, so for fast } \\
\text { scans not every new value will be posted. }\end{array}$ \\
\hline DnLV & $\begin{array}{l}\text { Detector } \mathrm{n} \text { Last } \\
\text { Value }\end{array}$ & (n-1-4): Last value 'posted' for DnCV. \\
\hline $\mathrm{DnDA}$ & $\begin{array}{l}\text { Detector n Data } \\
\text { Array } \\
\quad\end{array}$ & $\begin{array}{l}(n=1-4) \text { : This array (length }=\text { MPTS) contains the detector } \\
\text { data for each point in the scan. If the number of steps was } \\
\text { less than MPTS, the remainder of the array is filled with } \\
\text { the data from the last step. }\end{array}$ \\
\hline DnLR & $\begin{array}{l}\text { Detector } \mathrm{n} \text { Low } \\
\text { Range }\end{array}$ & \multirow{2}{*}{$\begin{array}{l}\text { ( } n=1-4) \text { : These are user configurable fields to describe low } \\
\text { and high ranges for the detector data (used by some } \\
\text { channel access clients). }\end{array}$} \\
\hline DnHR & $\begin{array}{l}\text { Detector } \mathrm{n} \text { High } \\
\text { Range }\end{array}$ & \\
\hline DnPR & $\begin{array}{l}\text { Detector } n \\
\text { Precision }\end{array}$ & $\begin{array}{l}\text { ( } \mathrm{n}=1-4) \text { : This is a user configurable fields to describe the } \\
\text { display precision for the detector data (used by some } \\
\text { channel access clients). }\end{array}$ \\
\hline DnEU & $\begin{array}{l}\text { Detector } \mathrm{n} \\
\text { Engineering Units }\end{array}$ & $\begin{array}{l}\text { ( } n=1-4) \text { : This is a user configurable fields to describe the } \\
\text { units for the detector data (used by some channel access } \\
\text { clients). }\end{array}$ \\
\hline $\mathrm{PnDB}$ & Positioner $\mathrm{n}$ dbAddr & $\begin{array}{l}(n=1-4): \text { Pointer to the dbAddr structure of the PV } \\
\text { entered in PnPV. If PV is not found, the value is NULL. }\end{array}$ \\
\hline $\mathrm{RnDB}$ & Readback n dbAddr & $\begin{array}{l}(n=1-4) \text { : Pointer to the dbAddr structure of the PV } \\
\text { entered in RnPV. If PV is not found, the value is NULL. }\end{array}$ \\
\hline
\end{tabular}




\begin{tabular}{|l|l|l|}
\hline \multicolumn{1}{|c|}{ Name } & \multicolumn{1}{|c|}{ Summary } & \multicolumn{1}{|c|}{ Description } \\
\hline \hline TnDB & Trigger $n$ dbAddr & $\begin{array}{l}\text { (n=1-2): Pointer to the dbAddr structure of the PV } \\
\text { entered in TnPV. If PV is not found, the value is NULL. }\end{array}$ \\
\hline DnDB & Detector $n$ dbAddr & $\begin{array}{l}(\mathrm{n}=1-4): \text { Pointer to the dbAddr structure of the PV } \\
\text { entered in DnPv. If PV is not found, the value is NULL. }\end{array}$ \\
\hline
\end{tabular}

\section{Record Support Routines}

6. Record Processing

7. Device Support

8. Device Support For Soft Records 


\section{Chapter 30: sel-Select}

\section{Introduction}

The sel record computes a value based on input obtained from up to 12 inputs. The selection algorithm can be one of the following: Specified, Highest, Lowest, Median. Each input can be a constant, a database link, or a channel access link.

\section{Field Summary}

\begin{tabular}{|l|l|l|l|l|l|l|l|}
\hline \multicolumn{1}{|c|}{ Field } & \multicolumn{1}{|c|}{ Type } & DCT & Initial & Access & Modify & $\begin{array}{l}\text { RecProc } \\
\text { Monitor }\end{array}$ & \multicolumn{1}{c|}{ PP } \\
\hline \hline VAL & DOUBLE & No & 0 & Yes & No & Yes & No \\
\hline SELM & RECCHOICE & Yes & 0 & Yes & Yes & No & No \\
\hline SELN & USHORT & No & 0 & Yes & Yes & No & No \\
\hline PREC & SHORT & Yes & 0 & Yes & Yes & No & No \\
\hline NVL & INLINK & Yes & 0 & No & No & N/A & No \\
\hline INPA & INLINK & Yes & 0 & No & No & N/A & No \\
\hline INPB & INLINK & Yes & 0 & No & No & N/A & No \\
\hline INPC & INLINK & Yes & 0 & No & No & N/A & No \\
\hline INPD & INLINK & Yes & 0 & No & No & N/A & No \\
\hline INPE & INLINK & Yes & 0 & No & No & N/A & No \\
\hline
\end{tabular}




\begin{tabular}{|c|c|c|c|c|c|c|c|}
\hline Field & Type & DCT & Initial & Access & Modify & $\begin{array}{l}\text { RecProc } \\
\text { Monitor }\end{array}$ & $\mathbf{P P}$ \\
\hline INPF & INLINK & Yes & 0 & No & No & $\mathrm{N} / \mathrm{A}$ & No \\
\hline INPG & INLINK & Yes & 0 & No & No & N/A & No \\
\hline INPH & INLINK & Yes & 0 & No & No & $\mathrm{N} / \mathrm{A}$ & No \\
\hline INPI & INLINK & Yes & 0 & No & No & N/A & No \\
\hline INPJ & INLINK & Yes & 0 & No & No & N/A & No \\
\hline INPK & INLINK & Yes & 0 & No & No & N/A & No \\
\hline INPL & INLINK & Yes & 0 & No & No & N/A & No \\
\hline A & DOUBLE & No & 0 & Yes & Yes/No & Yes & Yes \\
\hline B & DOUBLE & No & 0 & Yes & Yes/No & Yes & Yes \\
\hline $\mathrm{C}$ & DOUBLE & No & 0 & Yes & Yes/No & Yes & Yes \\
\hline D & DOUBLE & No & 0 & Yes & Yes/No & Yes & Yes \\
\hline $\mathrm{E}$ & DOUBLE & No & 0 & Yes & Yes/No & Yes & Yes \\
\hline $\mathrm{F}$ & DOUBLE & No & 0 & Yes & Yes/No & Yes & Yes \\
\hline G & DOUBLE & No & 0 & Yes & Yes/No & Yes & Yes \\
\hline H & DOUBLE & No & 0 & Yes & Yes/No & Yes & Yes \\
\hline I & DOUBLE & No & 0 & Yes & Yes/No & Yes & Yes \\
\hline $\mathbf{J}$ & DOUBLE & No & 0 & Yes & Yes/No & Yes & Yes \\
\hline K & DOUBLE & No & 0 & Yes & Yes/No & Yes & Yes \\
\hline L & DOUBLE & No & 0 & Yes & Yes/No & Yes & Yes \\
\hline LA & DOUBLE & No & 0 & Yes & No & No & No \\
\hline LB & DOUBLE & No & 0 & Yes & No & No & No \\
\hline LC & DOUBLE & No & 0 & Yes & No & No & No \\
\hline LD & DOUBLE & No & 0 & Yes & No & No & No \\
\hline LE & DOUBLE & No & 0 & Yes & No & No & No \\
\hline LF & DOUBLE & No & 0 & Yes & No & No & No \\
\hline LG & DOUBLE & No & 0 & Yes & No & No & No \\
\hline LH & DOUBLE & No & 0 & Yes & No & No & No \\
\hline LI & DOUBLE & No & 0 & Yes & No & No & No \\
\hline LJ & DOUBLE & No & 0 & Yes & No & No & No \\
\hline LK & DOUBLE & No & 0 & Yes & No & No & No \\
\hline LL & DOUBLE & No & 0 & Yes & No & No & No \\
\hline EGU & STRING & Yes & Null & Yes & Yes & No & No \\
\hline
\end{tabular}




\begin{tabular}{|l|l|l|l|l|l|l|l|}
\hline \multicolumn{1}{|c|}{ Field } & \multicolumn{1}{|c|}{ Type } & DCT & Initial & Access & Modify & $\begin{array}{l}\text { RecProc } \\
\text { Monitor }\end{array}$ & \multicolumn{1}{c|}{ PP } \\
\hline \hline HOPR & FLOAT & Yes & 0 & Yes & Yes & No & No \\
\hline LOPR & FLOAT & Yes & 0 & Yes & Yes & No & No \\
\hline HIHI & FLOAT & Yes & 0 & Yes & Yes & No & Yes \\
\hline LOLO & FLOAT & Yes & 0 & Yes & Yes & No & Yes \\
\hline HIGH & FLOAT & Yes & 0 & Yes & Yes & No & Yes \\
\hline LOW & FLOAT & Yes & 0 & Yes & Yes & No & Yes \\
\hline HHSV & GBLCHOICE & Yes & 0 & Yes & Yes & No & Yes \\
\hline LLSV & GBLCHOICE & Yes & 0 & Yes & Yes & No & Yes \\
\hline HSV & GBLCHOICE & Yes & 0 & Yes & Yes & No & Yes \\
\hline LSV & GBLCHOICE & Yes & 0 & Yes & Yes & No & Yes \\
\hline HYST & DOUBLE & Yes & 0 & Yes & Yes & No & No \\
\hline ADEL & DOUBLE & Yes & 0 & Yes & Yes & No & No \\
\hline MDEL & DOUBLE & Yes & 0 & Yes & Yes & No & No \\
\hline LALM & DOUBLE & No & 0 & Yes & No & No & No \\
\hline ALST & DOUBLE & No & 0 & Yes & No & No & No \\
\hline MLST & DOUBLE & No & 0 & Yes & No & No & No \\
\hline
\end{tabular}

3. Field Descriptions

\begin{tabular}{|l|l|l|}
\hline \multicolumn{1}{|c|}{ Name } & \multicolumn{1}{|c|}{ Summary } & \multicolumn{1}{c|}{ Description } \\
\hline \hline VAL & Value Field & $\begin{array}{l}\text { This field is the computed value, determined as a result of } \\
\text { record processing. }\end{array}$ \\
\hline SELM & Select Mechanism & $\begin{array}{l}\text { SELECTED: Use SELN as index (0 to 15) } \\
\text { SELECT_HIGH: Select highest } \\
\text { SELECT_LOW: Select lowest } \\
\text { SELECT_MEDIAN: Select median value. }\end{array}$ \\
\hline SELN & Select Number & $\begin{array}{l}\text { Index of selected input. If SELM=SELECTED, then this is } \\
\text { the index (0 to 15) of the input to select. }\end{array}$ \\
\hline PREC & Display Precision & $\begin{array}{l}\text { Precision with which to display VAL. This field is used by } \\
\text { record support to supply a value when get_precision } \\
\text { is called. }\end{array}$ \\
\hline NVL & $\begin{array}{l}\text { Index Value } \\
\text { Location, an input } \\
\text { link }\end{array}$ & $\begin{array}{l}\text { IF NVL is a constant, SELN is set to the constant value. If } \\
\text { NVL is a database or channel access link then SELN is } \\
\text { read from NVL. }\end{array}$ \\
\hline
\end{tabular}




\begin{tabular}{|c|c|c|}
\hline Name & Summary & Description \\
\hline INPA,...,INPL & Input $A$, Input $B, \ldots$ & $\begin{array}{l}\text { The input links. Each may be a constant, a database link, } \\
\text { or a channel access link. Any link not defined is ignored. } \\
\text { NOTE: In order to implement SELM it is necessary to } \\
\text { recognize missing values. The value } 1 \text { e } 30 \text { was selected } \\
\text { to represent MISSING. If a link is a constant with value } 0 \\
\text { (zero, the default) then at record initialization time the } \\
\text { corresponding A,... L field is set equal to MISSING. }\end{array}$ \\
\hline$A, \ldots, L$ & $\dot{A}, \mathrm{~B}, \ldots$ & $\begin{array}{l}\text { The input values If the corresponding INP field is a } \\
\text { constant, this field is initialized with the constant value } \\
\text { but can be changed via dbPuts. }\end{array}$ \\
\hline $\mathrm{LA}, \ldots, \mathrm{LL}$ & Last $A$, Last $B, \ldots$ & $\begin{array}{l}\text { Previous input values These fields are used to decide } \\
\text { when to trigger monitors on } \mathrm{A}, \ldots, \mathrm{L} \text {. }\end{array}$ \\
\hline EGU & Engineering Units & $\begin{array}{l}\text { ASCII string describing Engineering units. This field is } \\
\text { used by record support to supply a units description string } \\
\text { when get_units is called. }\end{array}$ \\
\hline HOPR & $\begin{array}{l}\text { High Operating } \\
\text { Range }\end{array}$ & \multirow{2}{*}{$\begin{array}{l}\text { These fields determine the upper and lower display limits } \\
\text { for graphics displays and the upper and lower control } \\
\text { limits for control displays. The fields are used by record } \\
\text { support to honor calls to get_graphic_double or } \\
\text { get_control_double. }\end{array}$} \\
\hline LOPR & $\begin{array}{l}\text { Low Operating } \\
\text { Range }\end{array}$ & \\
\hline HIHI & Hihi Alarm Limit & \multirow[t]{8}{*}{ These fields specify the alarm limits and severities. } \\
\hline HIGH & High Alarm Limit & \\
\hline LOW & Low Alarm Limit & \\
\hline LOLO & Lolo Alarm Limit & \\
\hline HHSV & $\begin{array}{l}\text { Severity for a Hihi } \\
\text { Alarm }\end{array}$ & \\
\hline HSV & $\begin{array}{l}\text { Severity for a High } \\
\text { Alarm }\end{array}$ & \\
\hline LSV & $\begin{array}{l}\text { Severity for a Low } \\
\text { Alarm }\end{array}$ & \\
\hline LLSV & $\begin{array}{l}\text { Severity for a Lolo } \\
\text { Alarm }\end{array}$ & \\
\hline HYST & Alarm Deadband & \multirow{3}{*}{$\begin{array}{l}\text { These parameters specify hysteresis factors for triggering } \\
\text { monitor callbacks, i.e. monitors specified by calls to } \\
\text { caAddEvent or.dbAddEvent. A monitor will not be } \\
\text { triggered until VAI changes by more than the specified } \\
\text { amount. }\end{array}$} \\
\hline ADEL & Archive Deadband & \\
\hline MDEL & $\begin{array}{l}\text { Monitor, i.e. value } \\
\text { change, Deadband }\end{array}$ & \\
\hline LALM & Last Alarmed Value & \multirow{3}{*}{$\begin{array}{l}\text { These fields are used to implement the hysteresis factors } \\
\text { for monitors. }\end{array}$} \\
\hline ALST & Archive Last Value & \\
\hline MLST & Monitor Last Value & \\
\hline
\end{tabular}




\section{Record Support Routines}

init_record

process

get_value

get_units

get_precision

get_graphic_double

get_control_double

get_alarm_double
IF NVL is a constant, SELN is set to its value. If NVL is a PV_LINK a channel access link is created.

For each constant input link, the corresponding value field is initialized with the constant value (or 1 e 30 if the constant has the value 0 ).

For each input link that is of type PV_LINK, a channel access link is created.

See next section. :

Fills in the values of struct valuedes so that they refer to VAL.

Retrieves EGU.

Retrieves PREC.

Sets the upper display and lower display limits for a field. If the field is VAL, HIHI, HIGH, LOW or LOLO, the limits are set to HOPR and LOPR, else if the field has upper and lower limits defined they will be used, else the upper and lower maximum values for the field type will be used.

Sets the upper control and the lower control limits for a field. If the field is VAL, HIHI, HIGH, LOW, or LOLO, the limits are set to HOPR and LOPR, else if the field has upper and lower limits defined they will be used, else the upper and lower maximum values for the field type will be used.

Sets the following values:

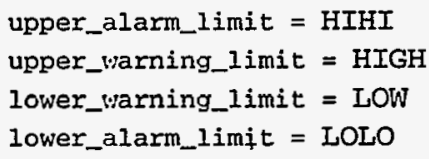

\section{Record Processing}

Routine process implements the following algorithm:

1. If NVL is a database or channel access link, SELN is obtained from NVL. Fetch all values if database or channel access links. If SELM is SELECTED, then only the selected link is fetched. 
2. Implement the appropriate selection algorithm. For SELECT_HIGH, SELECT_LOW, and SELECT_MEDIAN, input fields are ignored if they are undefined. If success, UDF is set to FALSE.

3. Check alarms. This routine checks to see if the new VAL causes the alarm status and severity to change. If So, NSEV, NSTA and LALM are set. It also honors the alarm hysteresis factor (HYST). Thus the value must change by more than HYST before the alarm status and severity is lowered.

4. Check to see if monitors should be invoked.

- Alarm monitors are invoked if the alarm status or severity has changed.

- Archive and value change monitors are invoked if ADEL and MDEL conditions are met

- Monitors for A-I are checked whenever other monitors are invoked

- NSEV and NSTA are reset to 0.

5. Scan forward link if necessary, set PACT FALSE, and return. 


\section{Chapter 31: seq-Sequence}

\section{Introduction}

The seg record is used to trigger the processing of up to ten other records. It has no associated device support. It is similar to the fanout record except it will fetch an input value and write an output value instead of simply processing a collection of forward links.

2. Field Summary

\begin{tabular}{|l|l|l|l|l|l|l|l|}
\hline \multicolumn{1}{|c|}{ Field } & \multicolumn{1}{|c|}{ Type } & DCT & Initial & Access & Modify & $\begin{array}{l}\text { Rec Proc } \\
\text { Monitor }\end{array}$ & \multicolumn{1}{c|}{ PP } \\
\hline \hline VAL & LONG & No & 0 & Yes & Yes & No & Yes \\
\hline SELM & RECCHOICE & Yes & 0 & Yes & Yes & No & No \\
\hline SELN & USHORT & No & 1 & Yes & Yes & No & No \\
\hline SELL & INLINK & Yes & 0 & No & No & N/A & No \\
\hline PREC & SHORT & Yes & 0 & Yes & Yes & No & No \\
\hline DLY1 & DOUBLE & Yes & 0 & Yes & Yes & No & No \\
\hline DOL1 & INLINK & Yes & 0 & No & No & N/A & No \\
\hline DO1 & DOUBLE & No & 0 & Yes & Yes & No & No \\
\hline LNK1 & OUTLINK & Yes & 0 & No & No & N/A & No \\
\hline DLY2 & DOUBLE & Yes & 0 & Yes & Yes & No & No \\
\hline
\end{tabular}




\begin{tabular}{|c|c|c|c|c|c|c|c|}
\hline Field & Type & DCT & Initial & Access & Modify & \begin{tabular}{|l|} 
Rec Proc \\
Monitor
\end{tabular} & PP \\
\hline DOL2 & INLINK & Yes & 0 & No & No & N/A & No \\
\hline $\mathrm{DO} 2$ & DOUBLE & No & 0 & Yes & Yes & No & No \\
\hline LNK2 & OUTLINK & Yes & 0 & No & No & N/A & No \\
\hline DLY3 & DOUBLE & Yes & 0 & Yes & Yes & No & No \\
\hline DOL3 & INLINK & Yes & 0 & No & No & N/A & No \\
\hline DO3 & DOUBLE & No & 0 & Yes & Yes & No & No \\
\hline LNK3 & OUTLINK & Yes & 0 & No & No & N/A & No \\
\hline DLY4 & DOUBLE & Yes & 0 & Yes & Yes & No & No \\
\hline DOL4 & INLINK & Yes & 0 & No & No & N/A & No \\
\hline DO4 & DOUBLE & No & 0 & Yes & Yes & No & No \\
\hline LNK4 & OUTLINK & Yes & 0 & No & No & N/A & No \\
\hline DLY5 & DOUBLE & Yes & 0 & Yes & Yes & No & No \\
\hline DOL5 & INLINK & Yes & 0 & No & No & N/A & No \\
\hline DO5 & DOUBLE & No & 0 & Yes & Yes & No & No \\
\hline LNK5 & OUTLINK & Yes & 0 & No & No & N/A & No \\
\hline DLY6 & DOUBLE & Yes & 0 & Yes & Yes & No & No \\
\hline DOL6 & INLINK & Yes & 0 & No & No & N/A & No \\
\hline DO6 & DOUBLE & No & 0 & Yes & Yes & No & No \\
\hline LNK6 & OUTLINK & Yes & 0 & No & No & N/A & No \\
\hline DLY7 & DOUBLE & Yes & 0 & Yes & Yes & No & No \\
\hline DOL7 & INLINK & Yes & 0 & No & No & N/A & No \\
\hline DO7 & DOUBLE & No & 0 & Yes & Yes & No & No \\
\hline LNK7 & OUTLINK & Yes & 0 & No & No & N/A & No \\
\hline DLY8 & DOUBLE & Yes & 0 & Yes & Yes & No & No \\
\hline DOL8 & INLINK & Yes & 0 & No & No & N/A & No \\
\hline D08 & DOUBLE & No & 0 & Yes & Yes & No & No \\
\hline LNK8 & OUTLINK & Yes & 0 & No & No & N/A & No \\
\hline DLY9 & DOUBLE & Yes & 0 & Yes & Yes & No & No \\
\hline DOL9 & INLINK & Yes & 0 & No & No & N/A & No \\
\hline DO9 & DOUBLE & No & 0 & Yes & Yes & No & No \\
\hline LNK9 & OUTLINK & Yes & 0 & No & No & N/A & No \\
\hline DLYA & DOUBLE & Yes & 0 & Yes & Yes & No & No \\
\hline
\end{tabular}




\begin{tabular}{|l|l|l|l|l|l|l|l|}
\hline \multicolumn{1}{|c|}{ Field } & \multicolumn{1}{|c|}{ Type } & DCT & \multicolumn{1}{|c|}{ Initial } & Access & Modify & $\begin{array}{l}\text { Rec Proc } \\
\text { Monitor }\end{array}$ & \multicolumn{1}{c|}{ PP } \\
\hline \hline DOLA & INLINK & Yes & 0 & No & No & N/A & No \\
\hline DOA & DOUBLE & No & 0 & Yes & Yes & No & No \\
\hline LNKA & OUTLINK & Yes & 0 & No & No & N/A & No \\
\hline
\end{tabular}

\section{Field Descriptions}

\begin{tabular}{|c|c|c|}
\hline Name & Summary & Description \\
\hline VAL & Value Field & Not used. \\
\hline SELM & Select Mechanism: & $\begin{array}{l}\text { SELECT_ALL: Select all links } \\
\text { SELECTED: Use SELN as index (1 to } 6) \\
\text { MASK: Use SELN as a mask to select an arbitrary } \\
\text { combination of links. }\end{array}$ \\
\hline SELN & Link Selection & $\begin{array}{l}\text { If SELM=SELECT_ALL then this field is not used. } \\
\text { If SELM=SELECTED then this is the index ( } 1 \text { to } 6 \text { ) of the } \\
\text { link to select. } \\
\text { If SELM=MASK then this is the mask (in decimal) used to } \\
\text { determine the selected links. For example, if SELN }=1 \text {, } \\
\text { then LNK } 1 \text { will be processed. If SELN=3 then INN } 1 \text { and } \\
\text { LNK } 2 \text { will be processed. If SELN=63 then links LNK1, } \\
\text { INKK } 2, \ldots \text { LNK6 will be processed. }\end{array}$ \\
\hline SELL & $\begin{array}{l}\text { Link Selection } \\
\text { Location }\end{array}$ & $\begin{array}{l}\text { SELN is read from SELL. SELL can be a constant, a } \\
\text { database link, or a channel access link. }\end{array}$ \\
\hline PREC & Display Precision & $\begin{array}{l}\text { Precision with which to display DLYI-DLYA and DO1- } \\
\text { DOA fields. This field is used by record support to supply } \\
\text { a value when get_precision is called. }\end{array}$ \\
\hline DLY1-DLYA & Delay time & $\begin{array}{l}\text { This represents the delay time (in seconds) to wait before } \\
\text { processing the input and output link pair (ie. DOLn and } \\
\text { LNKn.) }\end{array}$ \\
\hline DOL1-DOLA & Input link selection & $\begin{array}{l}\text { DO is read from DOL. DOL can be a constant, database } \\
\text { link or channel access link. If it is a constant, it is only } \\
\text { copied to the DO field once at initialization time. } \\
\text { Otherwise, it is re-fetched each time the record is } \\
\text { processed. }\end{array}$ \\
\hline DO1-DOA & $\begin{array}{l}\text { Desired output } \\
\text { value }\end{array}$ & $\begin{array}{l}\text { This field holds the desired output value that will be } \\
\text { placed in the output location indicated by the INK field. }\end{array}$ \\
\hline LNK1-LNKA & Output link field & $\begin{array}{l}\text { DO is written to LNK. LNK can be a database link or a } \\
\text { channel access link. }\end{array}$ \\
\hline
\end{tabular}




\section{Record Support Routines}

The only record support routine is process.

First, PACT is set to TRUE, and the link selection is fetched. Depending on the selection mechanism, the link selection output links are processed in order from LNK1 to LNKA. When LNKn is processed, the corresponding DLYn value is used to generate a delay via watchdog timer.

After DLYn seconds have expired, the input value is fetched from Don (if DOLn is constant) or DOLn (if DOLn is a database link or channel access link) and written to LNKn.

When all links are completed, an asynchronous completion call back to dbProcess is made (see the Application Developer's Guide for more information on asynchronous processing.)

Then UDF is set to FALSE.

Monitors are checked.

The forward link is scanned, PACT is set FALSE, and the process routine returns.

For the delay mechanism to operate properly, the record is processed asynchronously. The only time the record will not be processed asynchronously is when there are no non-NULI output links selected (ie. when it has nothing to do.) The processing of the links is done via callback tasks at the priority set in the PRIO field in dbcommon (see the Application Developer's Guide for more information on callback tasks.) 


\section{Chapter 32: State}

\section{Introduction}

The state record is used to store an arbitrary ASCII string.

\section{Field Summary}

\begin{tabular}{|l|l|l|l|l|l|l|l|}
\hline \multicolumn{1}{|c|}{ Field } & \multicolumn{1}{|c|}{ Type } & DCT & \multicolumn{1}{c|}{ Initial } & Access & Modify & $\begin{array}{c}\text { RecProc } \\
\text { Monitor }\end{array}$ & \multicolumn{1}{c|}{ PP } \\
\hline \hline VAL & STRING & Yes & Null & Yes & Yes & Yes & Yes \\
\hline OVAL & STRING & No & Null & Yes & No & & \\
\hline
\end{tabular}

3. Field Descriptions

\begin{tabular}{|l|l|l|}
\hline \multicolumn{1}{|c|}{ Name } & \multicolumn{1}{c|}{ Summary } & \multicolumn{1}{c|}{ Description } \\
\hline \hline VAL & Value Field & An arbitrary string value \\
\hline OVAL & Old Value & Used to decide when to invoke monitors. \\
\hline
\end{tabular}




\section{Record Support Routines}

Two record support routines are provided:

process

process triggers monitors on VAL when it changes and scans the forward link if necessary.

get_value

get_value fills in struct valueDes so that it refers to VAL. 


\section{Chapter 33: Stepper Motor}

\section{Introduction}

The steppermotor record type is used to control stepper motors.

\section{Field Summary}

\begin{tabular}{|l|l|l|l|l|l|l|l|}
\hline \multicolumn{1}{|c|}{ Field } & \multicolumn{1}{|c|}{ Type } & \multicolumn{1}{c|}{ DCT } & \multicolumn{1}{c|}{ Initial } & Access & Modify & $\begin{array}{l}\text { Rec Proc } \\
\text { Monitor }\end{array}$ & \multicolumn{1}{c|}{ PP } \\
\hline \hline VAL & FLOAT & No & 0 & Yes & Yes & Yes & Yes \\
\hline OUT & OUTLINK & Yes & 0 & No & No & N/A & No \\
\hline RDBL & INLINK & Yes & 0 & No & No & N/A & No \\
\hline DOL & INLINK & Yes & 0 & No & No & N/A & No \\
\hline OMSL & GBLCHOICE & Yes & 0 & Yes & Yes & No & No \\
\hline ACCL & FLOAT & Yes & 0 & Yes & Yes & No & No \\
\hline VELO & FLOAT & Yes & 0 & Yes & Yes & No & No \\
\hline DIST & FLOAT & Yes & 0 & Yes & Yes & No & No \\
\hline IVAL & FLOAT & Yes & 0 & Yes & Yes & No & No \\
\hline MODE & RECCHOICE & Yes & 0 & Yes & Yes & No & No \\
\hline CMOD & RECCHOICE & Yes & 0 & Yes & Yes & No & No \\
\hline IALG & RECCHOICE & Yes & 0 & Yes & Yes & No & No \\
\hline
\end{tabular}




\begin{tabular}{|c|c|c|c|c|c|c|c|}
\hline Field & Type & DCT & Initial & Access & Modify & $\begin{array}{l}\text { Rec Proc } \\
\text { Monitor }\end{array}$ & PP \\
\hline MRES & USHORT & Yes & 0 & Yes & Yes & No & No \\
\hline ERES & USHORT & Yes & 0 & Yes & Yes & No & No \\
\hline PREC & SHORT & Yes & 0 & Yes & Yes & No & No \\
\hline EGU & STRING & Yes & Null & Yes & Yes & No & No \\
\hline DRVH & FLOAT & Yes & 0 & Yes & Yes & No & Yes \\
\hline DRVL & FLOAT & Yes & 0 & Yes & Yes & No & Yes \\
\hline HOPR & FLOAT & Yes & 0 & Yes & Yes & No & No \\
\hline LOPR & FLOAT & Yes & 0 & Yes & Yes & No & No \\
\hline HIHI & FLOAT & Yes & 0 & Yes & Yes & No & Yes \\
\hline LOLO & FLOAT & Yes & 0 & Yes & Yes & No & Yes \\
\hline HIGH & FLOAT & Yes & 0 & Yes & Yes & No & Yes \\
\hline LOW & FLOAT & Yes & 0 & Yes & Yes & No & Yes \\
\hline HHSV & GBLCHOICE & Yes & 0 & Yes & Yes & No & Yes \\
\hline LLSV & GBLCHOICE & Yes & 0 & Yes & Yes & No & Yes \\
\hline HSV & GBLCHOICE & Yes & 0 & Yes & Yes & No & Yes \\
\hline LSV & GBLCHOICE & Yes & 0 & Yes & Yes & No & Yes \\
\hline HLSV & GBLCHOICE & Yes & 0 & Yes & Yes & No & Yes \\
\hline ADEL & FLOAT & Yes & 0 & Yes & Yes & No & No \\
\hline MDEL & FLOAT & Yes & 0 & Yes & Yes & No & No \\
\hline RDBD & FLOAT & Yes & 0 & Yes & Yes & No & No \\
\hline RTRY & SHORT & Yes & 0 & Yes & Yes & No & No \\
\hline STHM & SHORT & No & 0 & Yes & Yes & No & Yes \\
\hline STOP & SHORT & No & 0 & Yes & Yes & No & Yes \\
\hline DMOV & SHORT & No & 0 & Yes & Yes & No & No \\
\hline RVAL & LONG & No & 0 & Yes & Yes & Yes & Yes \\
\hline RBV & FLOAT & No & 0 & Yes & Yes & Yes & No \\
\hline RRBV & LONG & No & 0 & Yes & Yes & Yes & No \\
\hline ALST & FLOAT & No & 0 & Yes & No & No & No \\
\hline MLST & FLOAT & No & 0 & Yes & No & No & No \\
\hline INIT & SHORT & No & 0 & Yes & Yes & No & Yes \\
\hline $\mathrm{MCW}$ & SHORT & No & 0 & Yes & Yes & No & Yes \\
\hline $\mathrm{MCCW}$ & SHORT & No & 0 & Yes & Yes & No & Yes \\
\hline
\end{tabular}




\begin{tabular}{|l|l|l|l|l|l|l|l|}
\hline \multicolumn{1}{|c|}{ Field } & \multicolumn{1}{|c|}{ Type } & \multicolumn{1}{c|}{ DCT } & \multicolumn{1}{c|}{ Initial } & Access & Modify & $\begin{array}{l}\text { Rec Proc } \\
\text { Monitor }\end{array}$ & \multicolumn{1}{c|}{ PP } \\
\hline \hline CW & SHORT & No & 0 & Yes & Yes & No & Yes \\
\hline CCW & SHORT & No & 0 & Yes & Yes & No & Yes \\
\hline DIR & SHORT & No & 0 & Yes & Yes & No & Yes \\
\hline MOVN & SHORT & No & 0 & Yes & Yes & No & No \\
\hline CVEL & SHORT & No & 0 & Yes & Yes & No & No \\
\hline RCNT & SHORT & No & 0 & Yes & Yes & No & No \\
\hline POSM & SHORT & No & 0 & Yes & Yes & No & No \\
\hline LVAL & FLOAT & No & 0 & Yes & No & No & No \\
\hline EPOS & FLOAT & No & 0 & Yes & Yes & No & No \\
\hline MPOS & FLOAT & No & 0 & Yes & Yes & No & No \\
\hline MISS & FLOAT & No & 0 & Yes & Yes & No & No \\
\hline LVEL & FLOAT & No & 0 & Yes & Yes & No & No \\
\hline LACC & FLOAT & No & 0 & Yes & Yes & No & No \\
\hline
\end{tabular}

\section{Field Descriptions}

\begin{tabular}{|l|l|l|}
\hline Name & \multicolumn{1}{|c|}{ Summary } & \multicolumn{1}{|c|}{ Description } \\
\hline \hline VAL & Value & $\begin{array}{l}\text { This is the desired output value, in engineering units. If } \\
\text { DRVH and DRVL are defined, VAL is forced to be within } \\
\text { the drive limits. VAL is either obtained from DOL or set } \\
\text { via dbPuts. }\end{array}$ \\
\hline OUT & Output Link & $\begin{array}{l}\text { This field is used by the device support routines to locate } \\
\text { the stepper motor. }\end{array}$ \\
\hline RDBL & $\begin{array}{l}\text { Read Back } \\
\text { link) }\end{array}$ & $\begin{array}{l}\text { This link is used to obtain the read back value when a } \\
\text { physical read back is attached to the device being driven } \\
\text { from the stepper motor. }\end{array}$ \\
\hline DOL & $\begin{array}{l}\text { Lesired Output } \\
\text { Link) }\end{array}$ & $\begin{array}{l}\text { If DOL is a database or channel access link and OMSL is } \\
\text { CLOSED_LOOP, then VAL is read from DOL. After the } \\
\text { check for drive limits, VAL will be set to the value } \\
\text { determined by DOL. }\end{array}$ \\
\hline OMSL & Output Mode Select & $\begin{array}{l}\text { This field has either the value SUPERVISORY or } \\
\text { CLOSED_LOOR. DOL is used to determine VAL only if } \\
\text { OMSL has the value CLOSED_LOOR. By setting this field, } \\
\text { the record can be switched between supervisory and } \\
\text { closed loop mode of operation. While in closed loop } \\
\text { mode, the VAL field cannot be set via dbPuts. }\end{array}$ \\
\hline
\end{tabular}




\begin{tabular}{|c|c|c|}
\hline Name & Summary & Description \\
\hline VELO & Velocity & Rotations per second. \\
\hline DIST & Distance & Distance moved by each pulse of the stepper motor. \\
\hline IVAL & Initial Value & \\
\hline MODE & Mode & Velocity or Position. \\
\hline CMOD & Current Mode & Velocity or Position. \\
\hline IALG & $\begin{array}{l}\text { Initialization } \\
\text { Algorithm }\end{array}$ & None, Move to positive limit, Move to negative limit. \\
\hline MRES & $\begin{array}{l}\text { Motor Pulses per } \\
\text { Revolution }\end{array}$ & \\
\hline ERES & $\begin{array}{l}\text { Encoder Pulses per } \\
\text { Revolution }\end{array}$ & \\
\hline PREC & Display Precision & $\begin{array}{l}\text { Precision with which to display. This field is used by } \\
\text { record support to supply a value when get_precision } \\
\text { is called. }\end{array}$ \\
\hline EGU & Engineering Units & $\begin{array}{l}\text { ASCII string describing Engineering units. This field is } \\
\text { used by record support to supply a units description string } \\
\text { when get_units is called. }\end{array}$ \\
\hline DRVH & Drive High & \multirow{2}{*}{$\begin{array}{l}\text { If these values are defined, then VAL will forced to be in } \\
\text { the range DRVL }<=V A L<=D R V H\end{array}$} \\
\hline DRVL & Drive Low & \\
\hline HOPR & $\begin{array}{l}\text { High Operating } \\
\text { Range }\end{array}$ & \multirow{2}{*}{$\begin{array}{l}\text { These fields determine the upper and lower display limits } \\
\text { for graphics displays and the upper and lower control } \\
\text { limits for control displays. The fields are used by record } \\
\text { support to honor calls to get_graphic_double or } \\
\text { get_control_double. }\end{array}$} \\
\hline LOPR & Low Operating Range & \\
\hline HIHI & Hihi Alarm Limit & \multirow[t]{4}{*}{ These fields specify the alarm limits. } \\
\hline HIGH & High Alarm Limit & \\
\hline LOW & Low Alarm Limit & \\
\hline LOLO & Lolo Alarm Limit & \\
\hline HHSV & HiHi Alarm Severity & \multirow[t]{5}{*}{ These fields specify the alarm severities. } \\
\hline HSV & High Alarm Severity & \\
\hline LSV & Low Alarm Severity & \\
\hline LLSV & LoLo Alarm Severity & \\
\hline HLSV & $\begin{array}{l}\text { Hardware Limit } \\
\text { Violation Severity }\end{array}$ & \\
\hline ADEL & Archive Deadband & \multirow{2}{*}{$\begin{array}{l}\text { These parameters specify hysteresis factors for triggering } \\
\text { monitor callbacks, i.e. monitors specified by calls to } \\
\text { caAddEvent or dbAddEvent. A monitor will not be } \\
\text { triggered until vAL changes by more than the specified } \\
\text { amount. }\end{array}$} \\
\hline MDEL & $\begin{array}{l}\text { Monitor, i.e. value } \\
\text { change, Deadband }\end{array}$ & \\
\hline
\end{tabular}




\begin{tabular}{|c|c|c|}
\hline Name & Summary & Description \\
\hline RDBD & Retry Deadband & \\
\hline RTRY & $\begin{array}{l}\text { Number Of Retries } \\
\text { Before Failure }\end{array}$ & \\
\hline STHM & Set Home & $\begin{array}{l}\text { Setting this field to } 1 \text { via a dbPut is a command to set } \\
\text { home to the current position of the stepper motor. This } \\
\text { field will automatically be reset to } 0 \text { after the command is } \\
\text { accepted. }\end{array}$ \\
\hline STOP & Stop & $\begin{array}{l}\text { Setting this field to } 1 \text { will cause the motor to stop if it is } \\
\text { moving. This field will automatically be reset to } 0 \text { after } \\
\text { the command is accepted. }\end{array}$ \\
\hline DMOV & $\begin{array}{l}\text { Done Moving to } \\
\text { Value }\end{array}$ & \\
\hline RVAL & Raw Data Value & RVAL is the value actually sent to the device. \\
\hline RBV & Read Back Value & $\begin{array}{l}\text { This is the actual read back value obtained from the } \\
\text { hardware itself or from the associated device driver. It is } \\
\text { the responsibility of the device support routine to give this } \\
\text { field a value. }\end{array}$ \\
\hline RRBV & $\begin{array}{l}\text { Raw Read Back } \\
\text { Value }\end{array}$ & Raw read back value obtained from the encoder. \\
\hline ALST & Archive Last Value & \multirow{2}{*}{$\begin{array}{l}\text { Value when last monitors for archiver were triggered } \\
\text { These fields are used to implement the hysteresis factors } \\
\text { for monitors. }\end{array}$} \\
\hline MLST & Monitor Last Value & \\
\hline INIT & Initialize & \\
\hline $\mathrm{MCW}$ & $\begin{array}{l}\text { Motor Clockwise } \\
\text { Limit Switch Value }\end{array}$ & \\
\hline $\mathrm{MCCW}$ & $\begin{array}{l}\text { Motor Counter } \\
\text { Clockwise Limit } \\
\text { Switch Value }\end{array}$ & \\
\hline $\mathrm{CW}$ & & Is motor clockwise limit switch TRUE? \\
\hline $\mathrm{CCW}$ & & Is motor counter clockwise limit switch True? \\
\hline DIR & Current Direction & \\
\hline MOVN & & Is motor moving? \\
\hline CVEL & & Has Constant velocity been attained? \\
\hline RCNT & $\begin{array}{l}\text { Current Retry } \\
\text { Count }\end{array}$ & \\
\hline LVAL & Last Value & \\
\hline POSM & Positive Motion & \\
\hline EPOS & $\begin{array}{l}\text { Encoder Read } \\
\text { Back Position }\end{array}$ & \\
\hline MPOS & Motor Position & \\
\hline
\end{tabular}




\begin{tabular}{|l|l|l|}
\hline \multicolumn{1}{|c|}{ Name } & \multicolumn{1}{c|}{ Summary } & \multicolumn{1}{c|}{ Description } \\
\hline \hline MISS & First Attempt Error & \\
\hline LVEL & Last Velocity Set & \\
\hline LACC & $\begin{array}{l}\text { Last Acceleration } \\
\text { Set }\end{array}$ & \\
\hline
\end{tabular}

\section{Record Support Routines}

\section{init_record}

init_record

process

get_value

get_units

get_precision

get_graphic_double

get_control_double
This routine checks to see that device support is available. The routine next checks to see if the device support sm_command routine is defined. If either device support or the device support write routine does not exist, an error message is issued and processing is terminated.

If device support includes init_record, it is called.

If DOL is a constant, then VAL is initialized with its value and UDF is set to FALSE. If DOL is a PV_LINK then a channel access link is created.

init_.sm is then called.

Not written yet.

See next section.

Fills in the values of struct valueDes so that they refer to VAL.

Retrieves EGU.

Retrieves PREC.

Sets the upper display and lower display limits for a field. If the field is VAL, LVAL, MPOS, RBV, EPOS, HIHI, HIGH, LOW, or LOLO, the limits are set to HOPR and LOPR, else if the field has upper and lower limits defined they will be used, else the upper and lower maximum values for the field type will be used.

Sets the upper control and the lower control limits for a field. If the field is VAI, LVAL, MPOS, RBV, EPOS, HIHI, HIGH, LOW, Or LOLO, the limits are set to HOPR and LOPR, else if the field has upper and lower limits defined they will be used, else the upper and lower maximum values for the field type will be used. 
get_alarm_double Sets the following values:

upper_alarm_limit $=$ HIHI

upper_warning_limit $=$ HIGH

lower_warning_limit $=$ LOW

lower_alarm_limit $=$ LOLO

\section{Record Processing}

Not yet written

\section{Device Support}

At the present time, device support is intimately connected to record support. The compumotor 1830 and the OMS 6 axis controllers are supported. 


\section{Chapter 34: stringin - String Input}

\section{Introduction}

The stringin record is used to input an arbitrary ASCII string.

\section{Field Summary}

\begin{tabular}{|l|l|l|l|l|l|l|l|}
\hline \multicolumn{1}{|c|}{ Field } & \multicolumn{1}{|c|}{ Type } & DCT & \multicolumn{1}{c|}{ Initial } & Access & Modify & $\begin{array}{l}\text { Rec Proc } \\
\text { Monitor }\end{array}$ & \multicolumn{1}{c|}{ PP } \\
\hline \hline VAL & STRING & Yes & Null & Yes & Yes & Yes & Yes \\
\hline OVAL & STRING & No & Null & Yes & No & & No \\
\hline INP & INLINK & Yes & 0 & No & No & N/A & No \\
\hline SIOL & INLINK & Yes & 0 & No & No & N/A & No \\
\hline SVAL & STRING & No & Null & Yes & Yes & No & Yes \\
\hline SIML & INLINK & Yes & 0 & No & No & N/A & No \\
\hline SIMM & GBLCHOICE & No & 0 & Yes & Yes & No & No \\
\hline SIMS & GBLCHOICE & Yes & 0 & Yes & Yes & No & No \\
\hline
\end{tabular}


3. Field Descriptions

\begin{tabular}{|c|c|c|}
\hline Name & Summary & Description \\
\hline VAL & Value & $\begin{array}{l}\text { An arbitrary ASCII string of } 40 \text { characters. It is either } \\
\text { obtained from INP or else given a value via dbPuts. }\end{array}$ \\
\hline OVAL & Output Value & $\begin{array}{l}\text { Old ASCII string. Used to decide when to invoke } \\
\text { monitors. If VAL differs from OVAL, monitors will be } \\
\text { invoked. }\end{array}$ \\
\hline INP & Input Link & $\begin{array}{l}\text { This field is used by the device support routines to obtain } \\
\text { input. For soft records, it can be a constant, a database } \\
\text { link, or a channel access link. }\end{array}$ \\
\hline SIMM & Simulation Mode & \multirow{5}{*}{$\begin{array}{l}\text { Simulation mode process variables. Refer to Chapter } 3 \text {, } \\
\text { Section "Simulation Mode" on page } 11 \text { for more } \\
\text { information. }\end{array}$} \\
\hline SIML & $\begin{array}{l}\text { Simulation Mode } \\
\text { Location }\end{array}$ & \\
\hline SVAL & Simulation Value & \\
\hline SIOL & $\begin{array}{l}\text { Simulation Value } \\
\text { Location }\end{array}$ & \\
\hline SIMS & $\begin{array}{l}\text { Simulation Mode } \\
\text { Alarm Severity }\end{array}$ & \\
\hline
\end{tabular}

\section{Record Support Routines}

Three record support routines are provided: init_record, process, and get_value.

init_record

process

get_value
This routine initializes SIMM with the value of SIML if SIMU type is CONSTANT link or creates a channel access link if SIML type is PV_LINK. SVAL is likewise initialized if SIOL is CONSTANT or PV_LINK.

This routine next checks to see that device support is available and a record support read routine is defined. If either does not exist, an error message is issued and processing is terminated.

If device support includes init_record, it is called.

See next section.

Fills in the values of struct valueDes so that they refer to VAL. 


\section{Record Processing}

Routine process implements the following algorithm:

1. Check to see that the appropriate device support module exists. If it doesn't, an error message is issued and processing is terminated with the PACT field still set to TRUE. This ensures that processes will no longer be called for this record. Thus error storms will not occur.

2. readValue is called. See Chapter 3, Section "Simulation Mode" on page $\mathbf{1 1}$ for details.

3. If PACT has been changed to TRUE, the device support read routine has started but has not completed reading a new input value. In this case, the processing routine merely returns, leaving PACT TRUE.

4. TIME is set to tslocaltime

5. Check to see if monitors should be invoked.

- Alarm monitors are invoked if the alarm status or severity has changed.

- Archive and value change monitors are invoked if OVAL is not equal to VAL.

- NSEV and NSTA are reset to 0.

6. Scan forward link if necessary, set PACT FALSE, and return.

\section{Device Support}

Fields Of Interest

To Device Support

\section{Device Support} Routines

report
Each stringin input record must have an associated set of device support routines. The primary responsibility of the device support routines is to obtain a new ASCII string value whenever read_stringin is called. The device support routines are primarily interested in the following fields:

\begin{tabular}{|l|l|l|}
\hline \multicolumn{1}{|c|}{ Name } & \multicolumn{1}{|c|}{ Summary } & \multicolumn{1}{c|}{ Description } \\
\hline \hline PACT & Processing Active & $\begin{array}{l}\text { See Chapter 2, Section "Database Common: Field } \\
\text { Descriptions" on page 5 for descriptions. }\end{array}$ \\
\hline DPVT & Device Private & \\
\hline UDF & VAL Undefined & \\
\hline VAL & Value & This field is set by the device support routines. \\
\hline INP & Input Link. & $\begin{array}{l}\text { This field is used by the device support routines to locate } \\
\text { its input. }\end{array}$ \\
\hline
\end{tabular}

Device support consists of the following routines:

report (FILE fp, paddr)

Not currently used. 
init

init_record

get_ioint_info

read_stringin

init) ()

This routine is called once during IOC initialization.

init_record(precord)

This routine is optional. If provided, it is called by the record support init_record routine.

get_ioint_info(int cmd, struct dbcommon *precord,IOSCANPVT *ppvt)

This routine is called by the ioEventScan system each time the record is added or deleted from an I/O event scan list. omd has the value $(0,1)$ if the record is being (added to, deleted from) an $\mathrm{V} / \mathrm{O}$ event list. It must be provided for any device type that can use the ioEvent scanner.

read_stringin (precord)

This routine must provide a new input value. It returns the following values:

- 0: Success. A new ASCII string is stored into VAL.

- Other: Error.

\section{Device Support For Soft Records}

This module places a value directly in VAL.

If the INP link type is constant, the double constant, if non-zero, is converted to a string and stored into VAL by init_record, and UDF is set to FALSE. If the INP link type is PV_LINK, then dbcaAddinlink is called by init_record.

read_stringin calls recGblGetLinkValue to read the current value of VAL. See Chapter 3, Section "Soft Input" on page 10 for details.

If the return status of recGblGetLinkValue is zero, then read_stringin sets UDF to FALSE. The status of recGblGetLinkValue is returned. 


\section{Chapter 35: stringout - String Output}

\section{Introduction}

The stringout record is used to output an arbitrary ASCII string.

\section{Field Summary}

\begin{tabular}{|l|l|l|l|l|l|l|l|}
\hline \multicolumn{1}{|c|}{ Field } & \multicolumn{1}{|c|}{ Type } & \multicolumn{1}{c|}{ DCT } & \multicolumn{1}{c|}{ Initial } & Access & Modify & $\begin{array}{l}\text { Rec Proc } \\
\text { Monitor }\end{array}$ & \multicolumn{1}{c|}{ PP } \\
\hline \hline VAL & STRING & Yes & Null & Yes & Yes & Yes & Yes \\
\hline OVAL & STRING & No & Null & Yes & No & & No \\
\hline DOL & INLINK & Yes & 0 & No & No & N/A & No \\
\hline OMSL & GBLCHOICE & Yes & 0 & Yes & Yes & No & No \\
\hline OUT & OUTLINK & Yes & 0 & No & No & N/A & No \\
\hline SIOL & INLINK & Yes & 0 & No & No & N/A & No \\
\hline SIML & INLINK & Yes & 0 & No & No & N/A & No \\
\hline SIMM & GBLCHOICE & No & 0 & Yes & Yes & No & No \\
\hline SIMS & GBLCHOICE & Yes & 0 & Yes & Yes & No & No \\
\hline IVOA & GBLCHOICE & Yes & 0 & Yes & Yes & No & No \\
\hline IVOV & STRING & Yes & Null & Yes & Yes & No & No \\
\hline
\end{tabular}




\section{Field Descriptions}

\begin{tabular}{|c|c|c|}
\hline Name & Summary & Description \\
\hline VAL & Value & $\begin{array}{l}\text { An arbitrary ASCII string of } 40 \text { characters. This is the } \\
\text { field to be sent to OUT. It is either obtained from DOL or } \\
\text { else given a value via dbPuts. }\end{array}$ \\
\hline OVAL & Old Value & $\begin{array}{l}\text { Used to decide when to invoke monitors. If VAL differs } \\
\text { from OVAL, then monitors will be invoked. }\end{array}$ \\
\hline DOL & $\begin{array}{l}\text { Desired Output } \\
\text { Location (Input } \\
\text { Link) }\end{array}$ & $\begin{array}{l}\text { If DOL is a database or channel access link and OMSL is } \\
\text { CLOSED_LOOP, then VAL is read from DOL. }\end{array}$ \\
\hline OMSL & Output Mode Select & $\begin{array}{l}\text { This field has either the value SUPERVISORY or } \\
\text { CLOSED_LOOR. DOL is used to determine VAL only if } \\
\text { OMSL has the value CLOSED_LOOR. By setting this field, } \\
\text { the record can be switched between supervisory and } \\
\text { closed loop mode of operation. While in closed loop } \\
\text { mode, the VAL field cannot be set via dbPuts. }\end{array}$ \\
\hline OUT & Output Link & $\begin{array}{l}\text { This field is used by the device support routines to decide } \\
\text { where to send output. For soft records, it can be a } \\
\text { constant, a database link, or a channel access link. If the } \\
\text { link is a constant, the result is no output. }\end{array}$ \\
\hline SIMM & Simulation Mode & \multirow{4}{*}{$\begin{array}{l}\text { Simulation mode process variables. Refer to Chapter } 3 \text {, } \\
\text { Section "Simulation Mode" on page } 13 \text { for more } \\
\text { information. }\end{array}$} \\
\hline SIML & $\begin{array}{l}\text { Simulation Mode } \\
\text { Location }\end{array}$ & \\
\hline SIOL & $\begin{array}{l}\text { Simulation Value } \\
\text { Location }\end{array}$ & \\
\hline SIMS & $\begin{array}{l}\text { Simulation Mode } \\
\text { Alarm Severity }\end{array}$ & \\
\hline IVOA & $\begin{array}{l}\text { Invalid Alarm } \\
\text { Output Action }\end{array}$ & \multirow{2}{*}{$\begin{array}{l}\text { Whenever the record is put into INVALID alarm severity } \\
\text { IVOA specifies an action. See Chapter } 3 \text {, Section "Invalid } \\
\text { Alarm Output Action" on page } 14 \text { for more information }\end{array}$} \\
\hline IVOV & $\begin{array}{l}\text { Invalid Alarm } \\
\text { Output Value }\end{array}$ & \\
\hline
\end{tabular}

\section{Record Support Routines}

Three record support routines are provided: init_record, process, and get_value.

init_record
This routine initializes SIMM if SIME is a constant or creates a channel access link if SIMU is PV_LINK. If SIOL is PV_LINK a channel access link is created.

This routine next checks to see that device support is available. The routine next checks to see if the device support write routine is defined. If either device support or the device support write routine does not exist, an error message is issued and processing is terminated. 
If DOL is a constant, then the type double constant, if non-zero, is converted to a string and stored into VAL and UDF is set to FALSE. If DOL type is a PV_LINK then dbCaAddInlink is called to create a channel access link.

If device support includes init_record, it is called.

process

get_value
See next section.

Fills in the values of struct valueDes so that they refer to VAL.

\section{Record Processing}

Routine process implements the following algorithm:

1. Check to see that the appropriate device support module exists. If it doesn't, an error message is issued and processing is terminated with the PACT field still set to TRUE. This ensures that processes will no longer be called for this record. Thus error storms will not occur.

2. If PACT is FALSE and OMSL is CLOSED_LOOP, recGblGetLinkValue is called to read the current value of VAL. See Chapter 3, Section "Soft Input" on page 10 for details. If the return status of recGblGetLinkValue is zero then UDF is set to FALSE.

3. Check severity and write the new value. See Chapter 3, Section "Simulation Mode" on page 13 and Chapter 3, Section "Invalid Alarm Output Action" on page 14 for details.

4. If PACT has been changed to TRUE, the device support write output routine has started but has not completed writing the new value. In this case, the processing routine merely returns, leaving PACT TRUE.

5. Check to see if monitors should be invoked.

- Alarm monitors are invoked if the alarm status or severity has changed.

- Archive and value change monitors are invoked if OVAr is not equal to VAL.

- NSEV and NSTA are reset to 0 .

6. Scan forward link if necessary, set PACT FALSE, and return. 


\section{Device Support}

Fields Of Interest

To Device

Support

\section{Device Support}

\section{Routines}

report

init

init_record

get_ioint_info

write_stringout
Each stringout output record must have an associated set of device support routines. The primary responsibility of the device support routines is to write a new value whenever write_stringout is called. The device support routines are primarily interested in the following fields:

\begin{tabular}{|l|l|l|}
\hline \multicolumn{1}{|c|}{ Name } & \multicolumn{1}{|c|}{ Summary } & \multicolumn{1}{c|}{ Description } \\
\hline \hline PACT & Processing Active & $\begin{array}{l}\text { See Chapter 2, Section "Database Common: Field } \\
\text { Descriptions" on page 5 for descriptions. }\end{array}$ \\
\cline { 1 - 2 } DPVT & Device Private & \multicolumn{1}{|c|}{} \\
\cline { 1 - 2 } NSEV & New Alarm Severity & \\
\cline { 1 - 2 } NSTA & New Alarm Status & This is the field written by the device support routines. \\
\hline VAL & Value & $\begin{array}{l}\text { This field is used by the device support routines to locate } \\
\text { its output. }\end{array}$ \\
\hline OUT & Output Link & \\
\hline
\end{tabular}

Device support consists of the following routines:

report (FILE fp, paddr)

Not currently used.

init()

This routine is called once during IOC initialization.

init_record(precord)

This routine is optional. If provided, it is called by the record support init_record routine.

get_ioint_info(int cmd, struct dbCommon *precord, IOSCANPVT *ppvt)

This routine is called by the ioEventscan system each time the record is added or deleted from an I/O event scan list. cma has the value $(0,1)$ if the record is being (added to, deleted from) an I/O event list. It must be provided for any device type that can use the ioEvent scanner.

write_stringout (precord)

This routine must output a new value. It returns the following values:

- 0: Success.

- Other: Error. 


\section{Device Support For Soft Records}

This module writes the current value of VAL.

If the OUT link type is PV_LINK, then dbCaAddInlink is called by init_record.

write_so calls recGblputLinkValue to write the current value of VAL. See Chapter 3, Section "Soft Output" on page 13 for details. 
Chapter 35: stringout - String Output Device Support For Soft Records 


\title{
Chapter 36: subArray
}

\author{
Who is this from?
}

\section{Introduction}

The normal use for the subarray record type is to obtain sub-arrays from waveform records. Setting either the NELM or INDX fields causes the record to be processed with the new value, so that applications in which the length and position of a subarray of a waveform record are dynamically varied can be implemented using standard EPICS operator interface tools. The first element of the sub-array, that at location INDX in the referenced waveform record, can be displayed as a scalar, or the entire subarray (of length NELM) can be displayed in the same way as a waveform record. If there are fewer than NELM elements in the referenced waveform after the INDX, only that number of elements actually available are returned, and NORD is set to reflect this. This record type does not support writing new values into waveform records.

\section{Field Summary}

\begin{tabular}{|l|l|l|l|l|l|l|l|}
\hline \multicolumn{1}{|c|}{ Field } & \multicolumn{1}{|c|}{ Type } & \multicolumn{1}{c|}{ DCT } & \multicolumn{1}{c|}{ Initial } & Access & Modify & $\begin{array}{l}\text { Rec Proc } \\
\text { Monitor }\end{array}$ & \multicolumn{1}{c|}{ PP } \\
\hline \hline VAL & (See FTVL) & No & 0 & Yes & Yes & Yes & No \\
\hline PREC & SHORT & Yes & 0 & Yes & Yes & No & No \\
\hline FTVL & GBLCHOICE & Yes & 0 & Yes & No & No & \\
\hline INP & INLINK & Yes & 0 & No & & N/A & \\
\hline EGU & STRING & Yes & Null & Yes & Yes & No & No \\
\hline HOPR & FLOAT & Yes & 0 & Yes & Yes & No & No \\
\hline LOPR & FLOAT & Yes & 0 & Yes & Yes & No & No \\
\hline
\end{tabular}




\begin{tabular}{|l|l|l|l|l|l|l|l|}
\hline \multicolumn{1}{|c|}{ Field } & \multicolumn{1}{|c|}{ Type } & \multicolumn{1}{c|}{ DCT } & \multicolumn{1}{c|}{ Initial } & Access & Modify & $\begin{array}{l}\text { Rec Proc } \\
\text { Monitor }\end{array}$ & \multicolumn{1}{c|}{ PP } \\
\hline \hline MALM & ULONG & Yes & 1 & Yes & No & No & \\
\hline NELM & ULONG & Yes & 1 & Yes & Yes & No & Yes \\
\hline INDX & ULONG & Yes & 0 & Yes & Yes & No & Yes \\
\hline NORD & LONG & No & 0 & Yes & No & No & \\
\hline BPTR & NOACCESS & No & & & & & \\
\hline
\end{tabular}

3. Field Descriptions

\begin{tabular}{|c|c|c|}
\hline Name & Summary & Description \\
\hline VAL & Value Field & This is used to reference the sub-array. \\
\hline PREC & Display Precision & $\begin{array}{l}\text { Precision with which to display VAL. This field is not } \\
\text { used by record support other than to supply a value when } \\
\text { get_precision is called. }\end{array}$ \\
\hline FTVL & Field Type of Value & This is DBF_STRING, ...,DBF_ENUM. \\
\hline INP & Input Link & $\begin{array}{l}\text { This field is used by the device support routines to obtain } \\
\text { input. It can be a database link, or a channel access link. }\end{array}$ \\
\hline EGU & Engineering Units & $\begin{array}{l}\text { ASCII string describing Engineering units. This field is } \\
\text { used by record support to supply a units description string } \\
\text { when get_units is called. }\end{array}$ \\
\hline HOPR & High Operating Range & \multirow{2}{*}{$\begin{array}{l}\text { These fields determine the upper and lower display limits } \\
\text { for graphics displays and the upper and lower control } \\
\text { limits for control displays. The fields are used by record } \\
\text { support to honor calls to get_graphic_double or } \\
\text { get_control_double. }\end{array}$} \\
\hline LOPR & Low Operating Range & \\
\hline MALM & $\begin{array}{l}\text { Maximum Number Of } \\
\text { Elements In Sub-array }\end{array}$ & $\begin{array}{l}\text { Generally this should be set to the NELM of the waveform } \\
\text { record being pointed to. }\end{array}$ \\
\hline NELM & $\begin{array}{l}\text { Number Of Elements } \\
\text { In Sub-array }\end{array}$ & \\
\hline INDX & $\begin{array}{l}\text { Index Into Referenced } \\
\text { Array }\end{array}$ & $\begin{array}{l}\text { Index of (offset into) waveform record being referenced; } \\
\text { used as first element of sub-array. }\end{array}$ \\
\hline NORD & $\begin{array}{l}\text { Number of Elements } \\
\text { Read }\end{array}$ & $\begin{array}{l}\text { Number of elements that were read of the desired } \\
\text { subarray. This could be less than NELM depending on } \\
\text { INDX and the NELM of the referenced waveform record. }\end{array}$ \\
\hline BPTR & Buffer Pointer & Holds address of sub-array. \\
\hline
\end{tabular}




\section{Record Support Routines}

init_record

process

get_value

cvt_dbaddr

get_array_info

put_array_info

get_units

get_prec
Using MALM and FTVL, space for the array is allocated. The array address is stored in BPTR. This routine checks to see that device support is available and a device support read routine is defined. If either does not exist, an error message is issued and processing is terminated. If device support includes init_record, it is called.

See next section.

Fills in the values of struct valueDes so that they refer to the sub-array.

This is called by dbNameToAddr. It makes the dbAddr structure refer to the actual buffer holding the result.

Retrieves NELM.

Sets NORD.

Retrieves EGU.

Retrieves PREC.

\section{Record Processing}

Routine process implements the following algorithm:

1. Check to see that the appropriate device support module exists. If it doesn't, an error message is issued and processing is terminated with the PACT field still set to TRUE. This ensures that processes will no longer be called for this record. Thus error storms will not occur.

2. Sanity check NELM and INDX. If NELM is greater than MALM it is set to MALM. If INDX is greater than MALM it is set to MALM-1.

3. Call device support read routine. This routine is expected to place the desired sub-array at the beginning of the buffer and set NORD to the number of elements of the sub-array that were read.

4. If PACT has been changed to TRUE, the device support read routine has started but has not completed writing the new value. In this case, the processing routine merely returns, 
leaving PACT TRUE. Otherwise, process sets PACT TRUE at this time. This asynchronous processing logic is not currently used but has been left in place.

5. Check to see if monitors should be invoked.

- Alarm monitors are invoked if the alarm status or severity has changed.

- Archive and value change monitors are always invoked.

- NSEV and NSTA are reset to 0 .

6. Scan forward link if necessary, set PACT FALSE, and return.

\section{Device Support}

Fields Of Interest To Device Support

\section{Device Support}

\section{Routines}

report
The device support routines are primarily interested in the following fields:

\begin{tabular}{|c|c|c|}
\hline Name & Summary & Description \\
\hline PACT & Processing Active & \multirow{5}{*}{$\begin{array}{l}\text { See Chapter } 2 \text { Section "Database Common: Field } \\
\text { Descriptions" on page } 5 \text { for descriptions. }\end{array}$} \\
\hline DPVT & Device Private & \\
\hline UDF & VAL Undefined & \\
\hline NSEV & New Alarm Severity & \\
\hline NSTA & New Alarm Status & \\
\hline INP & Input Link & $\begin{array}{l}\text { This field is used by the device support routines to locate } \\
\text { its input. }\end{array}$ \\
\hline FTVL & Field Type of Value & $\begin{array}{l}\text { This is DBF_STRING, ...,DBF_ENUM. The device support } \\
\text { routine should check that this is correctly defined. }\end{array}$ \\
\hline MALM & $\begin{array}{l}\text { Maximum Number } \\
\text { Of Elements In } \\
\text { Sub-array }\end{array}$ & $\begin{array}{l}\text { Number of elements that will fit in the array the record } \\
\text { allocates. Device support must never return more } \\
\text { elements than this }\end{array}$ \\
\hline NELM & $\begin{array}{l}\text { Number Sub-array } \\
\text { Elements }\end{array}$ & Number of elements in desired sub-array. \\
\hline INDX & $\begin{array}{l}\text { Index Into } \\
\text { Referenced Array }\end{array}$ & Index of beginning of desired sub-array in source array. \\
\hline BPTR & Buffer Pointer & $\begin{array}{l}\text { Address of array device support must copy the source } \\
\text { array into. }\end{array}$ \\
\hline NORD & $\begin{array}{l}\text { Number Of } \\
\text { Elements Read }\end{array}$ & Device support must set this value when it completes. \\
\hline
\end{tabular}

Device support consists of the following routines:

report (FILE fp, paddr) 
Not currently used.

init

init()

Not currently used.

init_record

init_record (precord)

This routine is called by the record support init_record routine.

read_sa

read_sa (precord)

Enough of the source waveform is read into BPTR, from the beginning of the source, to include the requested sub-array. The sub-array is then copied to the beginning of the buffer. NORD is set to indicate how many elements of the sub-array were acquired.

\section{Device Support For Soft Records}

Only the device support module Soft Channel is provided. The INP link type must be either DB_LINK or CA_LINK.

Soft Channel INP is expected to point to a waveform record. 


\section{Chapter 37: sub-Subroutine}

\section{Introduction}

The sub record provides a subroutine escape mechanism.

\section{Field Summary}

\begin{tabular}{|l|l|l|l|l|l|l|l|}
\hline \multicolumn{1}{|c|}{ Field } & \multicolumn{1}{c|}{ Type } & DCT & Initial & Access & Modify & $\begin{array}{l}\text { Rec Proc } \\
\text { Monitor }\end{array}$ & \multicolumn{1}{c|}{ PP } \\
\hline \hline VAL & DOUBLE & No & 0 & Yes & Yes & Yes & Yes \\
\hline INAM & STRING & Yes & Null & Yes & No & & No \\
\hline SNAM & STRING & Yes & Null & Yes & No & & No \\
\hline SADR & NOACCESS & No & 0 & No & No & & No \\
\hline STYP & SHORT & No & 0 & Yes & No & No & No \\
\hline INPA & INLINK & Yes & 0 & No & No & N/A & No \\
\hline INPB & INLINK & Yes & 0 & No & No & N/A & No \\
\hline INPC & INLINK & Yes & 0 & No & No & N/A & No \\
\hline INPD & INLINK & Yes & 0 & No & No & N/A & No \\
\hline INPE & INLINK & Yes & 0 & No & No & N/A & No \\
\hline INPF & INLINK & Yes & 0 & No & No & N/A & No \\
\hline INPG & INLINK & Yes & 0 & No & No & N/A & No \\
\hline
\end{tabular}




\begin{tabular}{|c|c|c|c|c|c|c|c|}
\hline Field & Type & DCT & Initial & Access & Modify & $\begin{array}{l}\text { Rec Proc } \\
\text { Monitor }\end{array}$ & $\mathbf{P P}$ \\
\hline INPH & INLINK & Yes & 0 & No & No & N/A & No \\
\hline INPI & INLINK & Yes & 0 & No & No & N/A & No \\
\hline INPJ & INLINK & Yes & 0 & No & No & N/A & No \\
\hline INPK & INLINK & Yes & 0 & No & No & N/A & No \\
\hline INPL & INLINK & Yes & 0 & No & No & N/A & No \\
\hline A & DOUBLE & No & 0 & Yes & Yes/No & Yes & Yes \\
\hline B & DOUBLE & No & 0 & Yes & Yes/No & Yes & Yes \\
\hline $\mathrm{C}$ & DOUBLE & No & 0 & Yes & Yes/No & Yes & Yes \\
\hline D & DOUBLE & No & 0 & Yes & Yes/No & Yes & Yes \\
\hline $\mathbf{E}$ & DOUBLE & No & 0 & Yes & Yes/No & Yes & Yes \\
\hline $\mathbf{F}$ & DOUBLE & No & 0 & Yes & Yes/No & Yes & Yes \\
\hline G & DOUBLE & No & 0 & Yes & Yes/No & Yes & Yes \\
\hline $\mathrm{H}$ & DOUBLE & No & 0 & Yes & Yes/No & Yes & Yes \\
\hline I & DOUBLE & No & 0 & Yes & Yes/No & Yes & Yes \\
\hline $\mathbf{J}$ & DOUBLE & No & 0 & Yes & Yes/No & Yes & Yes \\
\hline $\mathrm{K}$ & DOUBLE & No & 0 & Yes & Yes/No & Yes & Yes \\
\hline L & DOUBLE & No & 0 & Yes & Yes/No & Yes & Yes \\
\hline LA & DOUBLE & No & 0 & Yes & No & No & No \\
\hline LB & DOUBLE & No & 0 & Yes & No & No & No \\
\hline LC & DOUBLE & No & 0 & Yes & No & No & No \\
\hline LD & DOUBLE & No & 0 & Yes & No & No & No \\
\hline LE & DOUBLE & No & 0 & Yes & No & No & No \\
\hline LF & DOUBLE & No & 0 & Yes & No & No & No \\
\hline LG & DOUBLE & No & 0 & Yes & No & No & No \\
\hline LH & DOUBLE & No & 0 & Yes & No & No & No \\
\hline $\mathbf{L I}$ & DOUBLE & No & 0 & Yes & No & No & No \\
\hline $\mathrm{LJ}$ & DOUBLE & No & 0 & Yes & No & No & No \\
\hline LK & DOUBLE & No & 0 & Yes & No & No & No \\
\hline LL & DOUBLE & No & 0 & Yes & No & No & No \\
\hline PREC & SHORT & Yes & 0 & Yes & Yes & No & No \\
\hline EGU & STRING & Yes & Null & Yes & Yes & No & No \\
\hline HOPR & FLOAT & Yes & 0 & Yes & Yes & No & No \\
\hline
\end{tabular}




\begin{tabular}{|l|l|l|l|l|l|l|l|}
\hline \multicolumn{1}{|c|}{ Field } & \multicolumn{1}{|c|}{ Type } & DCT & Initial & Access & Modify & $\begin{array}{l}\text { Rec Proc } \\
\text { Monitor }\end{array}$ & \multicolumn{1}{c|}{ PP } \\
\hline \hline LOPR & FLOAT & Yes & 0 & Yes & Yes & No & No \\
\hline HIHI & FLOAT & Yes & 0 & Yes & Yes & No & Yes \\
\hline LOLO & FLOAT & Yes & 0 & Yes & Yes & No & Yes \\
\hline HIGH & FLOAT & Yes & 0 & Yes & Yes & No & Yes \\
\hline LOW & FLOAT & Yes & 0 & Yes & Yes & No & Yes \\
\hline BRSV & GBLCHOICE & Yes & 0 & Yes & Yes & No & Yes \\
\hline HHSV & GBLCHOICE & Yes & 0 & Yes & Yes & No & Yes \\
\hline LLSV & GBLCHOICE & Yes & 0 & Yes & Yes & No & Yes \\
\hline HSV & GBLCHOICE & Yes & 0 & Yes & Yes & No & Yes \\
\hline LSV & GBLCHOICE & Yes & 0 & Yes & Yes & No & Yes \\
\hline HYST & DOUBLE & Yes & 0 & Yes & Yes & No & No \\
\hline ADEL & DOUBLE & Yes & 0 & Yes & Yes & No & No \\
\hline MDEL & DOUBLE & Yes & 0 & Yes & Yes & No & No \\
\hline LALM & DOUBLE & No & 0 & Yes & No & No & No \\
\hline ALST & DOUBLE & No & 0 & Yes & No & No & No \\
\hline MLST & DOUBLE & No & 0 & Yes & No & No & No \\
\hline
\end{tabular}

\section{Field Descriptions}

\begin{tabular}{|c|c|c|}
\hline Name & Summary & Description \\
\hline VAL & Value Field & $\begin{array}{l}\text { This field is determined by the subroutine as a result of } \\
\text { record processing. }\end{array}$ \\
\hline INAM & Initialization Name & $\begin{array}{l}\text { This is the name of the initialization entry. It is called once } \\
\text { at record initialization time. }\end{array}$ \\
\hline SNAM & Subroutine Name & $\begin{array}{l}\text { This the the name of the processing routine. It is called by } \\
\text { the the record processing routine. }\end{array}$ \\
\hline SADR & Subroutine Address & Filled in by record processing. \\
\hline STYP & $\begin{array}{l}\text { Subroutine Symbol } \\
\text { Type }\end{array}$ & Filled in by record processing. \\
\hline INPA,...,INPL & $\begin{array}{l}\text { Input Link A, Input } \\
\text { Link } B, \ldots\end{array}$ & $\begin{array}{l}\text { The input links. Each may be a constant, a database link, } \\
\text { or a channel access link. Any link not defined is ignored. }\end{array}$ \\
\hline$A, \ldots, L$ & $A, B, \ldots$ & $\begin{array}{l}\text { The input values If the corresponding INP field is a } \\
\text { constant, this field is initialized with the constant value } \\
\text { but can be changed via dbPuts. }\end{array}$ \\
\hline
\end{tabular}




\begin{tabular}{|c|c|c|}
\hline Name & Summary & Description \\
\hline $\mathrm{LA}, \ldots, \mathrm{LL}$ & Last A, Last B, ... & $\begin{array}{l}\text { Previous input values These fields are used to decide } \\
\text { when to trigger monitors on } \mathrm{A}, \ldots, \mathrm{L} \text {. }\end{array}$ \\
\hline PREC & Display Precision & $\begin{array}{l}\text { Precision with which to display VAL. This field is used by } \\
\text { record support to supply a value when get_precision } \\
\text { is called. }\end{array}$ \\
\hline EGU & Engineering Units & $\begin{array}{l}\text { ASCII string describing Engineering units. This field is } \\
\text { used by record support to supply a units description string } \\
\text { when get_units is called. }\end{array}$ \\
\hline HOPR & $\begin{array}{l}\text { High Operating } \\
\text { Range }\end{array}$ & \multirow{2}{*}{$\begin{array}{l}\text { These fields determine the upper and lower display limits } \\
\text { for graphics displays and the upper and lower control } \\
\text { limits for control displays. The fields are used by record } \\
\text { support to honor calls to get_graphic_double or } \\
\text { get_control_double. }\end{array}$} \\
\hline LOPR & $\begin{array}{l}\text { Low Operating } \\
\text { Range }\end{array}$ & \\
\hline HIHI & Hihi Alarm Limit & \multirow[t]{9}{*}{ These fields specify the alarm limits and severities. } \\
\hline $\mathrm{HIGH}$ & High Alarm Limit & \\
\hline LOW & Low Alarm Limit & \\
\hline LOLO & Lolo Alarm Limit & \\
\hline BRSV & $\begin{array}{l}\text { Severity for a } \\
\text { subroutine return } \\
\text { value less than } 0 .\end{array}$ & \\
\hline HHSV & $\begin{array}{l}\text { Severity for a Hihi } \\
\text { Alarm }\end{array}$ & \\
\hline HSV & $\begin{array}{l}\text { Severity for a High } \\
\text { Alarm }\end{array}$ & \\
\hline LSV & $\begin{array}{l}\text { Severity for a Low } \\
\text { Alarm }\end{array}$ & \\
\hline LLSV & $\begin{array}{l}\text { Severity for a Lolo } \\
\text { Alarm }\end{array}$ & \\
\hline HYST & Alarm Deadband & \multirow{3}{*}{$\begin{array}{l}\text { These parameters specify hysteresis factors for triggering } \\
\text { monitor callbacks, i.e. monitors specified by calls to } \\
\text { caAddEvent or dbAddEvent. A monitor will not be } \\
\text { triggered until VAL changes by more than the specified } \\
\text { amount. }\end{array}$} \\
\hline ADEL & Archive Deadband & \\
\hline MDEL & $\begin{array}{l}\text { Monitor, i.e. value } \\
\text { change, Deadband }\end{array}$ & \\
\hline LALM & $\begin{array}{l}\text { Last Alarm Monitor } \\
\text { Trigger Value }\end{array}$ & \multirow[t]{3}{*}{$\begin{array}{l}\text { These fields are used to implement the hysteresis factors } \\
\text { for monitors. }\end{array}$} \\
\hline ALST & $\begin{array}{l}\text { Last Archiver } \\
\text { Monitor Trigger } \\
\text { Value }\end{array}$ & \\
\hline MLST & $\begin{array}{l}\text { Last Value Change } \\
\text { Monitor Trigger } \\
\text { Value }\end{array}$ & \\
\hline
\end{tabular}




\section{Record Support Routines}

init_record

process

get_value

get_units

get_precision

get_graphic_double

get_control_double

get_alarm_double
For each constant input link, the corresponding value field is initialized with the constant value. For each input link that is of type PV_LINK, a channel access link is created.

If an initialization subroutine is defined, it is located and called.

The processing subroutine is located and its address and type stored in SADR and STYP.

See next section.

Fills in the values of struct valueDes so that they refer to VAL.

Retrieves EGU.

Retrieves PREC.

Sets the upper display and lower display limits for a field. If the field is VAL, HIHI, HIGH, LOW, or LOLO, the limits are set to HOPR and LOPR, else if the field has upper and lower limits defined they will be used, else the upper and lower maximum values for the field type will be used.

Sets the upper control and the lower control limits for a field. If the field is VAL, HIHI, HIGH, LOW, or LOLO, the limits are set to HOPR and LOPR, else if the field has upper and lower limits defined they will be used, else the upper and lower maximum values for the field type will be used.

Sets the following values:

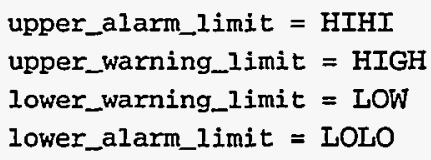

\section{Record Processing}

Routine process implements the following algorithm:

1. If PACT is FALSE then fetch all arguments.

2. Call the subroutine and check return value.

- Call subroutine

- Set PACT TRUE 
- If return value is 1 , return

3. Check alarms. This routine checks to see if the new VAL causes the alarm status and severity to change. If So, NSEV, NSTA and LALM are set. It also honors the alarm hysteresis factor (HYST). Thus the value must change by more than HYST before the alarm status and severity is lowered.

4. Check to see if monitors should be invoked.

- Alarm monitors are invoked if the alarm status or severity has changed.

- Archive and value change monitors are invoked if ADEL and MDEL conditions are met.

- Monitors for A-L are are invoked if value has changed.

- NSEV and NSTA are reset to 0 .

5. Scan forward link if necessary, set PACT FALSE, and return.

\section{Example Synchronous Subroutine}

This is an example that merely increments vaL each time process is called.

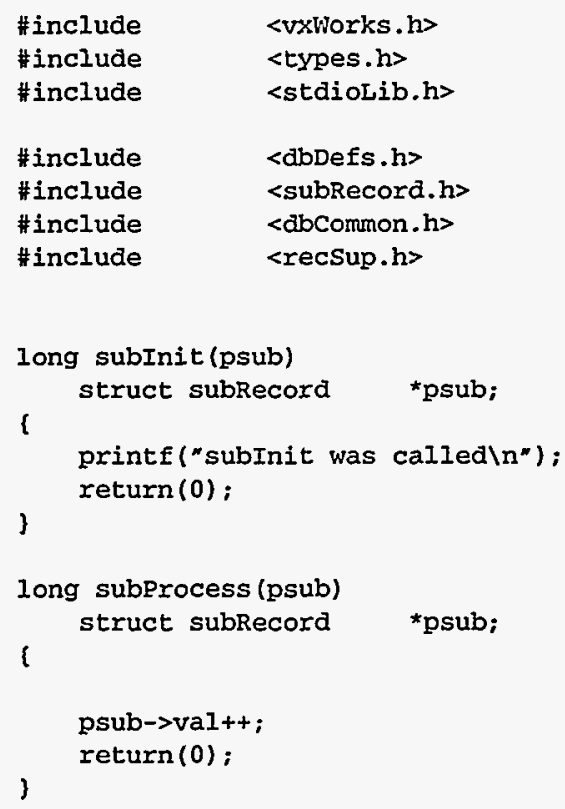

\section{Example Asynchronous Subroutine}

This example shows an asynchronous subroutine. It uses (actually misuses) fields $A$ and $B$. Field $A$ is taken as the number of seconds until asynchronous completion. Field $B$ is a flag to decide if messages should be printed. Lets assume $A>0$ and $B=1$. The following sequence of actions will occur:

1. subProcess is called with pact FALSE. It performs the following steps.

a. Computes, from A, the number of ticks until asynchronous completion should occur.

b. Prints a message stating that it is requesting an asynchronous callback. 
c. Calls the vxWorks watchdog start routine.

d. Sets pact TRUE and returns a value of 0 . This tells record support to complete without checking alarms, monitors, or the forward link.

2. When the time expires, the system wide callback task calls mycallback. myCallback locks the record, calls process, and unlocks the record.

3. Process again calls subProcess, but now pact is TRUE. Thus the following is done:

a. VAL is incremented.

b. A completion message is printed.

c. subProcess returns 0 . The record processing routine will complete record processing.

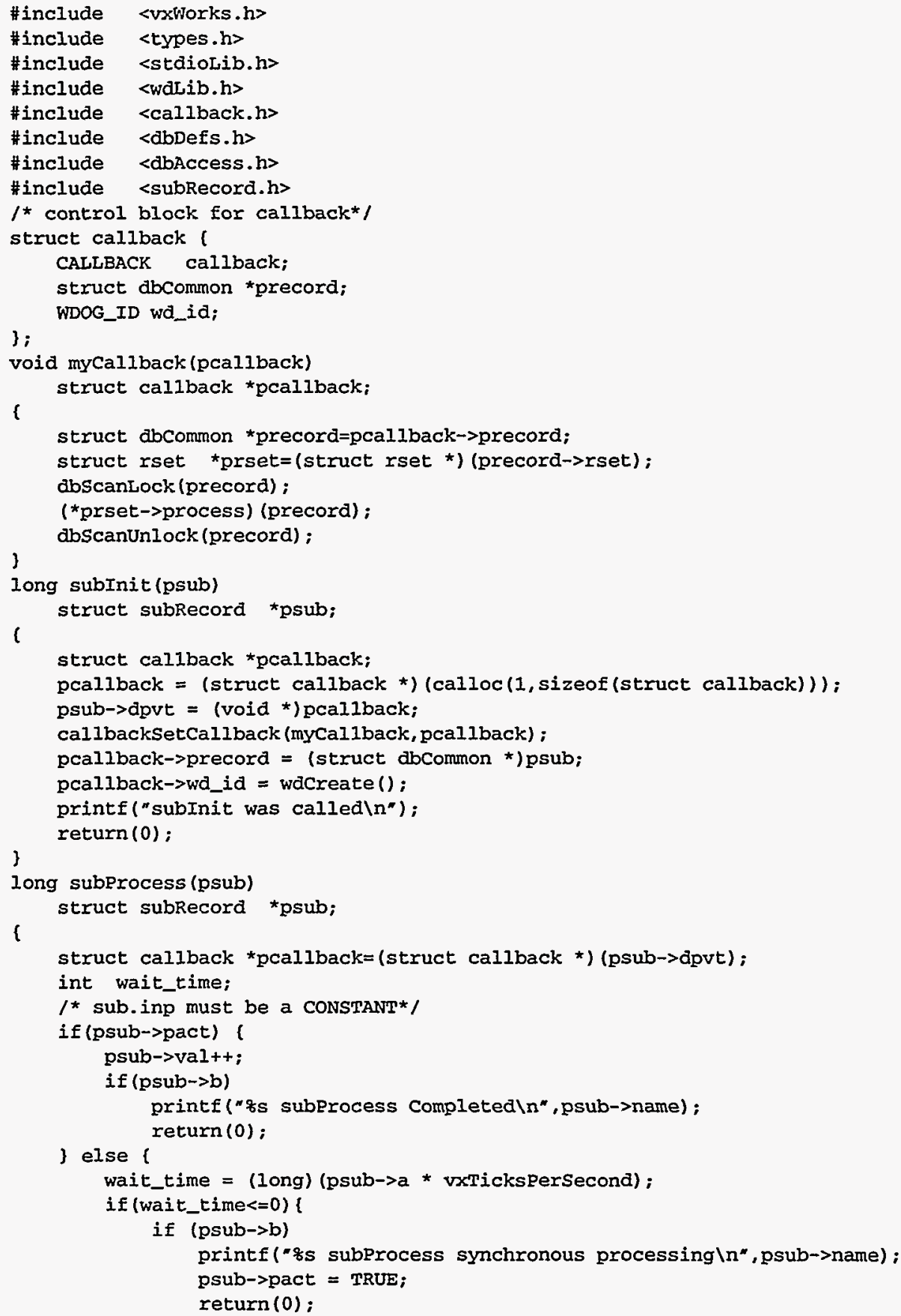




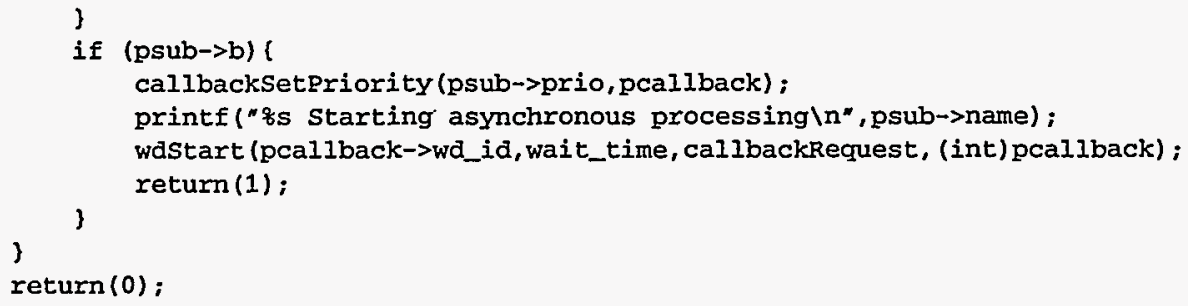




\section{Chapter 38: Timer}

\section{Introduction}

The function of the timer record has been replaced by the pulsecounter, pulseDelay, pulseTrain, and Event records. The Timer record type is included for backward compatibility.

This record type interacts with timer modules.

\section{Field Summary}

\begin{tabular}{|l|l|l|l|l|l|l|l|}
\hline \multicolumn{1}{|c|}{ Field } & \multicolumn{1}{|c|}{ Type } & \multicolumn{1}{c|}{ DCT } & \multicolumn{1}{c|}{ Initial } & Access & Modify & $\begin{array}{l}\text { Rec Proc } \\
\text { Monitor }\end{array}$ & \multicolumn{1}{c|}{ PP } \\
\hline \hline TORG & INLINK & Yes & 0 & No & No & N/A & No \\
\hline OUT & OUTLINK & Yes & $\mathbf{0}$ & No & No & N/A & No \\
\hline VAL & SHORT & No & $\mathbf{0}$ & Yes & Yes & Yes & Yes \\
\hline TSRC & RECCHOICE & Yes & $\mathbf{0}$ & Yes & Yes & No & No \\
\hline PTST & RECCHOICE & Yes & $\mathbf{0}$ & Yes & Yes & No & Yes \\
\hline TEVT & SHORT & Yes & $\mathbf{0}$ & Yes & Yes & No & Yes \\
\hline PREC & SHORT & Yes & $\mathbf{0}$ & Yes & Yes & No & No \\
\hline TIMU & RECCHOICE & Yes & $\mathbf{0}$ & Yes & Yes & No & No \\
\hline MAIN & GBLCHOICE & Yes & $\mathbf{1}$ & Yes & Yes & No & Yes \\
\hline
\end{tabular}




\begin{tabular}{|c|c|c|c|c|c|c|c|}
\hline Field & Type & DCT & Initial & Access & Modify & \begin{tabular}{|l|} 
Rec Proc \\
Monitor \\
\end{tabular} & $\mathbf{P P}$ \\
\hline RDT1 & FLOAT & No & 0 & Yes & Yes & No & No \\
\hline RDW1 & FLOAT & No & 0 & Yes & Yes & No & No \\
\hline PDLY & FLOAT & Yes & 0 & Yes & Yes & No & No \\
\hline DUT1 & FLOAT & Yes & 0 & Yes & Yes & No & Yes \\
\hline OPW1 & FLOAT & Yes & 0 & Yes & Yes & No & Yes \\
\hline DUT2 & FLOAT & Yes & 0 & Yes & Yes & No & Yes \\
\hline OPW2 & FLOAT. & Yes & 0 & Yes & Yes & No & Yes \\
\hline DUT3 & FLOAT & Yes & 0 & Yes & Yes & No & Yes \\
\hline OPW3 & FLOAT & Yes & 0 & Yes & Yes & No & Yes \\
\hline DUT4 & FLOAT & Yes & 0 & Yes & Yes & No & Yes \\
\hline OPW4 & FLOAT & Yes & 0 & Yes & Yes & No & Yes \\
\hline DUT5 & FLOAT & Yes & 0 & Yes & Yes & No & Yes \\
\hline OPW5 & FLOAT & Yes & 0 & Yes & Yes & No & Yes \\
\hline TIDL & DOUBLE & No & 0 & Yes & Yes & No & No \\
\hline T1WD & DOUBLE & No & 0 & Yes & Yes & Yes & No \\
\hline T2DL & DOUBLE & No & 0 & Yes & Yes & No & No \\
\hline T2WD & DOUBLE & No & 0 & Yes & Yes & No & No \\
\hline T3DL & DOUBLE & No & 0 & Yes & Yes & No & No \\
\hline T3WD & DOUBLE & No & 0 & Yes & Yes & No & No \\
\hline T4DL & DOUBLE & No & 0 & Yes & Yes & No & No \\
\hline T4WD & DOUBLE & No & 0 & Yes & Yes & No & No \\
\hline T5DL & DOUBLE & No & 0 & Yes & Yes & No & No \\
\hline T5WD & DOUBLE & No & 0 & Yes & Yes & No & No \\
\hline TITD & FLOAT & No & 0 & Yes & Yes & Yes & No \\
\hline TILD & FLOAT & No & 0 & Yes & Yes & Yes & No \\
\hline T2TD & FLOAT & No & 0 & Yes & Yes & No & No \\
\hline T2LD & FLOAT & No & 0 & Yes & Yes & No & No \\
\hline T3TD & FLOAT & No & 0 & Yes & Yes & No & No \\
\hline T3LD & FLOAT & No & 0 & Yes & Yes & No & No \\
\hline T4TD & FLOAT & No & 0 & Yes & Yes & No & No \\
\hline T4LD & FLOAT & No & 0 & Yes & Yes & No & No \\
\hline T5TD & FLOAT & No & 0 & Yes & Yes & No & No \\
\hline
\end{tabular}




\begin{tabular}{|l|l|l|l|l|l|l|l|}
\hline \multicolumn{1}{|c|}{ Field } & \multicolumn{1}{|c|}{ Type } & DCT & \multicolumn{1}{c|}{ Initial } & Access & Modify & $\begin{array}{l}\text { Rec Proc } \\
\text { Monitor }\end{array}$ & \multicolumn{1}{c|}{ PP } \\
\hline \hline T5LD & FLOAT & No & 0 & Yes & Yes & No & No \\
\hline TRDL & FLOAT & No & 0 & Yes & Yes & No & No \\
\hline TDIS & SHORT & No & 0 & Yes & Yes & No & Yes \\
\hline
\end{tabular}

\section{Field Descriptions}

\begin{tabular}{|c|c|c|}
\hline Name & Summary & Description \\
\hline TORG & $\begin{array}{l}\text { Trigger Delay } \\
\text { Origin (input link) }\end{array}$ & $\begin{array}{l}\text { This is a link specifying the location of the trigger delay } \\
\text { value. This must be a constant, a database link, or a } \\
\text { channel access link. If TORG is a database link, then } \\
\text { TRDL is read from TORG. }\end{array}$ \\
\hline OUT & Output Link & $\begin{array}{l}\text { This field is used by the device support routines to decide } \\
\text { where to send output. }\end{array}$ \\
\hline VAL & Value Field & This field is used to force record processing. \\
\hline TSRC & Clock Source & External or internal \\
\hline PTST & Pre-Trigger State & Low or high \\
\hline TEVT & & Event Number To Be Posted On Trigger \\
\hline PREC & Display Precision & \\
\hline TIMU & Timer Units & Milli, micro, nano. pico seconds \\
\hline MAIN & Maintain on Reboot & \\
\hline RDT1 & Reboot Delay of 1 & \\
\hline RPW1 & Reboot Width of 1 & \\
\hline PDLY & $\begin{array}{l}\text { Delay Source to } \\
\text { Input }\end{array}$ & \\
\hline DUTn & $\begin{array}{l}\text { Delay Width For } \\
\text { Trigger } \mathrm{n}\end{array}$ & $(\mathrm{n}=1-5)$ : In timer units. \\
\hline OPWn & $\begin{array}{l}\text { Output Pulse Width } \\
\text { For Trigger } \mathbf{n}\end{array}$ & $(\mathrm{n}=1-5)$ : In timer units. \\
\hline TnDL & $\begin{array}{l}\text { Delay Width For } \\
\text { Trigger } n\end{array}$ & $(\mathrm{n}=1-5)$ : In seconds. \\
\hline TnWD & $\begin{array}{l}\text { Pulse Width Of } \\
\text { Trigger } n\end{array}$ & $(n=1-5)$ : In seconds. \\
\hline $\operatorname{TnTD}$ & $\begin{array}{l}\text { Trailing Delay Of } \\
\text { Trigger } \mathrm{n}\end{array}$ & $(n=1-5):($ TiLD $+O P W i)$ \\
\hline TnLD & $\begin{array}{l}\text { Leading Delay Of } \\
\text { Trigger } \mathbf{n}\end{array}$ & $(n=1-5):($ DUTi + TRDL $)$ \\
\hline
\end{tabular}




\begin{tabular}{|l|l|l|}
\hline \multicolumn{1}{|c|}{ Name } & \multicolumn{1}{|c|}{ Summary } & \multicolumn{1}{c|}{ Description } \\
\hline \hline TRDL & Trigger Delay & Obtained from trigger delay origin TORG. \\
\hline TDIS & $\begin{array}{l}\text { Timing Pulse } \\
\text { Disable }\end{array}$ & \\
\hline
\end{tabular}

4. Record Support Routines

init_record

process

See next section.

get_value

Fills in the values of struct valueDes so that they refer to the array.

5. Record Processing

This section not yet written.

6. Device Support

Currently device support is intimately combined with record support. 


\title{
Chapter 39: Wait
}

\author{
Ned D. Arnold
}

Advanced Photon Source

Argonne National Laboratory

\section{Introduction}

\section{"Reassignable" PV Links}

This chapterdescribes the capabilities and use of the wait record. The wait record is derived fom the standard calc record with the following additional features: "Reassignable" PV links, an Output Link, a Desired Output input link, an output event number to post, and several options as to when it will execute the output link and event posting. The wait record also has the capability to "process" as a result of an input changing (via CA monitors).

The wait record is a powerful record type that can be used to do "conditional" processing within the database. Its name is derived from the original requirement that initiated its development, i.e. "I want to wait until all the motors have stopped and then trigger the detector". The sections below describe the capabilities of the record.

Like the calc record, the wait record has 12 input links for fetching variables used in the calculation. Unlike the calc record, these input links can be modified during run time. The record contains ASCII fields in which a new Process_Variable.Field name may be written. The record will use the new link the next time the record is processed.

A consequence of reassignable links is that one cannot force the processing of an input record prior to retrieving the data (i.e. there is no .PP flag). This should be considered when designing a database using the wait record.

In this initial version, the "reassignable" PV links do not support channel access connections external to the IOC. Until this feature is added, the specified Process Variables must reside on the same IOC. 


\section{Output Links and Output Events}

The wait record has two kinds of "outputs". The first is an output link to which data will be written when appropriate (see next section). The data to be written can be the result of the calculation (use VAL), fetched from another link (use DOL and specify a "Desired Output Location Name" - DOLN) or a user entered constant ( use DOL, leave DOLN blank, enter constant in DOLD).

As a result of the "reassignable links", there is no application specific control over whether the record specified as the output link will be processed when the data is "put" (i.e. there is no .PP flag associated with the link.) The processing of the destination record will depend on its scan mechanism and ASCII record definition file Process Passive values.

The other "output" of a wait record is an event. If a non-zero value is entered into the OEVT (Output Event) field, the record will "post an event" (using the entered number as the event number) whenever the output link is executed. This is a way of initiating several other records to process as a result of a calculation.

The outputs of the wait record are not necessarily executed every time the record processes. This allows "downstream" processing of records to be done conditionally. The "output execution" options are decsribed below.

- Every Time: Outputs are executed every time the record processes.

- On Change: Outputs are executed if the result of the calculation (VAL) is different than the previous time the record was processed.

- When Zero: Outputs are executed if the result of the calculation is zero.

- When Non-zero: Outputs are executed if the result of the calculation is not zero.

- Transition To Zero: Outputs are executed if the result of the calculation is zero and the previous value was not zero.

- Transition To Non-zero: Outputs are executed if the result of the calculation is not zero and the previous value was zero.

\section{Process Record on Input Change}

In addition to the standard scan mechanisms avaliable to all records (periodic, passive, event, etc), the wait record can be specified to process as a result of one of i's input values changing (using channel access monitors). This offers immediate response to an input change (rather than waiting for the next periodic scan) while minimizing record processing that is not required. The scan mechanism choice of $1 / O$ Intr will enable this feature.

For this release, an additional module, caMonitor.o, must be compiled and loaded with the wait record support to provide this feature.

A word of caution is in order. Because of the event driven nature of this feature, it is quite easy to configure a database that results in an infinite loop that uses all available CPU time. If the wait record is set to process as a result of a channel changing and the processing of the wait record causes the channel to change again, an infinite loop will result. The symptom will be a loss of all channel access connections (lower priority tasks) even though the shell responds normally. Using the vxWorks utility "spy" will confirm the predicament by showing $0 \%$ free CPU time. 


\section{Field Summary}

\begin{tabular}{|c|c|c|c|c|c|c|c|}
\hline Field & Type & DCT & Initial & Access & Modify & $\begin{array}{l}\text { Rec Proc } \\
\text { Monitor }\end{array}$ & PP \\
\hline HOPR & FLOAT & Yes & 0 & Yes & Yes & No & No \\
\hline LOPR & FLOAT & Yes & 0 & Yes & Yes & No & No \\
\hline INIT & SHORT & No & 0 & Yes & No & No & No \\
\hline CBST & NOACCESS & No & Null & No & No & No & No \\
\hline INAN & STRING & Yes & Null & Yes & Yes & No & No \\
\hline INBN & STRING & Yes & Null & Yes & Yes & No & No \\
\hline INCN & STRING & Yes & Null & Yes & Yes & No & No \\
\hline INDN & STRING & Yes & Null & Yes & Yes & No & No \\
\hline INEN & STRING & Yes & Null & Yes & Yes & No & No \\
\hline INFN & STRING & Yes & Null & Yes & Yes & No & No \\
\hline INGN & STRING & Yes & Null & Yes & Yes & No & No \\
\hline INHN & STRING & Yes & Null & Yes & Yes & No & No \\
\hline ININ & STRING & Yes & Null & Yes & Yes & No & No \\
\hline INJN & STRING & Yes & Null & Yes & Yes & No & No \\
\hline INKN & STRING & Yes & Null & Yes & Yes & No & No \\
\hline INLN & STRING & Yes & Null & Yes & Yes & No & No \\
\hline INAA & NOACCESS & No & Null & No & No & No & No \\
\hline INBA & NOACCESS & No & Null & No & No & No & No \\
\hline INCA & NOACCESS & No & Null & No & No & No & No \\
\hline INDA & NOACCESS & No & Null & No & No & No & No \\
\hline INEA & NOACCESS & No & Null & No & No & No & No \\
\hline INFA & NOACCESS & No & Null & No & No & No & No \\
\hline INGA & NOACCESS & No & Null & No & No & No & No \\
\hline INHA & NOACCESS & No & Null & No & No & No & No \\
\hline INIA & NOACCESS & No & Null & No & No & No & No \\
\hline INJA & NOACCESS & No & Null & No & No & No & No \\
\hline INKA & NOACCESS & No & Null & No & No & No & No \\
\hline INLA & NOACCESS & No & Null & No & No & No & No \\
\hline INAV & LONG & No & 0 & Yes & Yes & Yes & No \\
\hline INBV & LONG & No & 0 & Yes & Yes & Yes & No \\
\hline
\end{tabular}




\begin{tabular}{|c|c|c|c|c|c|c|c|}
\hline Field & Type & DCT & Initial & Access & Modify & $\begin{array}{l}\text { Rec Proc } \\
\text { Monitor }\end{array}$ & PP \\
\hline INCV & LONG & No & 0 & Yes & Yes & Yes & No \\
\hline INDV & LONG & No & 0 & Yes & Yes & Yes & No \\
\hline INEV & LONG & No & 0 & Yes & Yes & Yes & No \\
\hline INFV & LONG & No & 0 & Yes & Yes & Yes & No \\
\hline INGV & LONG & No & 0 & Yes & Yes & Yes & No \\
\hline INHV & LONG & No & 0 & Yes & Yes & Yes & No \\
\hline INIV & LONG & No & 0 & Yes & Yes & Yes & No \\
\hline INJV & LONG & No & 0 & Yes & Yes & Yes & No \\
\hline INKV & LONG & No & 0 & Yes & Yes & Yes & No \\
\hline INLV & LONG & No & 0 & Yes & Yes & Yes & No \\
\hline A & DOUBLE & No & 0 & Yes & Yes & Yes & Yes \\
\hline B & DOUBLE & No & 0 & Yes & Yes & Yes & Yes \\
\hline $\mathrm{C}$ & DOUBLE & No & 0 & Yes & Yes & Yes & Yes \\
\hline D & DOUBLE & No & 0 & Yes & Yes & Yes & Yes \\
\hline $\mathrm{E}$ & DOUBLE & No & 0 & Yes & Yes & Yes & Yes \\
\hline F & DOUBLE & No & 0 & Yes & Yes & Yes & Yes \\
\hline G & DOUBLE & No & 0 & Yes & Yes & Yes & Yes \\
\hline $\mathrm{H}$ & DOUBLE & No & 0 & Yes & Yes & Yes & Yes \\
\hline I & DOUBLE & No & 0 & Yes & Yes & Yes & Yes \\
\hline J & DOUBLE & No & 0 & Yes & Yes & Yes & Yes \\
\hline K & DOUBLE & No & 0 & Yes & Yes & Yes & Yes \\
\hline L & DOUBLE & No & 0 & Yes & Yes & Yes & Yes \\
\hline LA & DOUBLE & No & 0 & Yes & Yes & No & No \\
\hline LB & DOUBLE & No & 0 & Yes & Yes & No & No \\
\hline LC & DOUBLE & No & 0 & Yes & Yes & No & No \\
\hline LD & DOUBLE & No & 0 & Yes & Yes & No & No \\
\hline LE & DOUBLE & No & 0 & Yes & Yes & No & No \\
\hline LF & DOUBLE & No & 0 & Yes & Yes & No & No \\
\hline LG & DOUBLE & No & 0 & Yes & Yes & No & No \\
\hline LH & DOUBLE & No & 0 & Yes & Yes & No & No \\
\hline LI & DOUBLE & No & 0 & Yes & Yes & No & No \\
\hline LJ & DOUBLE & No & 0 & Yes & Yes & No & No \\
\hline
\end{tabular}




\begin{tabular}{|l|l|l|l|l|l|l|l|}
\hline \multicolumn{1}{|c|}{ Field } & \multicolumn{1}{|c|}{ Type } & DCT & Initial & Access & Modify & $\begin{array}{l}\text { Rec Proc } \\
\text { Monitor }\end{array}$ & \multicolumn{1}{|c|}{ PP } \\
\hline \hline LK & DOUBLE & No & 0 & Yes & Yes & No & No \\
\hline LL & DOUBLE & No & 0 & Yes & Yes & No & No \\
\hline CALC & STRING & Yes & 36 & Yes & Yes & No & No \\
\hline RPCL & NOACCESS & No & 184 & No & No & No & No \\
\hline CLCV & LONG & No & 0 & Yes & Yes & Yes & No \\
\hline VAL & DOUBLE & No & 0 & Yes & Yes & Yes & No \\
\hline OVAL & DOUBLE & No & 0 & Yes & Yes & No & No \\
\hline PREC & SHORT & Yes & 0 & Yes & Yes & No & No \\
\hline OOPT & RECCHOICE & Yes & 0 & Yes & Yes & No & No \\
\hline OUTN & STRING & Yes & Null & Yes & Yes & No & No \\
\hline OUTA & NOACCESS & No & Null & No & No & No & No \\
\hline OUTV & LONG & No & 0 & Yes & Yes & Yes & No \\
\hline DOPT & RECCHOICE & Yes & 0 & Yes & Yes & No & No \\
\hline DOLN & STRING & Yes & Null & Yes & Yes & No & No \\
\hline DOLA & NOACCESS & No & Null & No & No & No & No \\
\hline DOLV & LONG & No & 0 & Yes & Yes & Yes & No \\
\hline DOLD & DOUBLE & Yes & 0 & Yes & Yes & Yes & No \\
\hline OEVT & USHORT & Yes & 0 & Yes & Yes & No & No \\
\hline ADEL & DOUBLE & Yes & 0 & Yes & Yes & No & No \\
\hline MDEL & DOUBLE & Yes & 0 & Yes & Yes & No & No \\
\hline ALST & DOUBLE & No & 0 & Yes & No & No & No \\
\hline MLST & DOUBLE & No & 0 & Yes & No & No & No \\
\hline SIOL & INLINK & No & Null & Yes & No & No & No \\
\hline SVAL & DOUBLE & No & 0 & Yes & Yes & No & No \\
\hline SIML & INLINK & No & Null & Yes & No & No & No \\
\hline SIMM & GBLCHOICE & No & 0 & Yes & Yes & No \\
\hline
\end{tabular}




\section{Field Descriptions}

This section describes the fields that will be of interest to a typical application developer.

\begin{tabular}{|c|c|c|}
\hline Name & Summary & Description \\
\hline HOPR & $\begin{array}{l}\text { High Operating } \\
\text { Range }\end{array}$ & \multirow{2}{*}{$\begin{array}{l}\text { These fields determine the upper and lower display limits } \\
\text { for graphics displays and the upper and lower control } \\
\text { limits for control displays. The fields are used by record } \\
\text { support to honor calls to get_graphic_double or } \\
\text { get_control_double. }\end{array}$} \\
\hline LOPR & $\begin{array}{l}\text { Low Operating } \\
\text { Range }\end{array}$ & \\
\hline CBST & Callback Structure & Pointer to a record private structure. \\
\hline INnN & $\begin{array}{l}\text { Input } n \text { Process } \\
\text { Variable Name }\end{array}$ & $\begin{array}{l}\text { ( } n=A \text { thru } L \text { ): These fields contain the Process Variable } \\
\text { names of the inputs that will be used for the calculation. }\end{array}$ \\
\hline INnV & Input $\mathrm{n}$ Valid & $\begin{array}{l}\text { ( } \mathrm{n}=\mathrm{A} \text { thru } \mathrm{L} \text { ): These flags indicate if the ASCII string } \\
\text { entered in INnN was found to be a valid (existing) Process } \\
\text { Variable. }\end{array}$ \\
\hline$A, \ldots, L$ & Input Values & $\begin{array}{l}\text { If the corresponding INP field is a constant, this field is } \\
\text { initialized with the constant value but can be changed via } \\
\text { dbPuts. }\end{array}$ \\
\hline LA,...,LL & $\begin{array}{l}\text { Previous Input } \\
\text { Values }\end{array}$ & $\begin{array}{l}\text { These fields are used to decide when to trigger monitors } \\
\text { on } A, \ldots, L \text {. }\end{array}$ \\
\hline CALC & Calculation String & $\begin{array}{l}\text { Expression to be calculated when the record is processed. } \\
\text { Identical to the CALC field in the calc record. }\end{array}$ \\
\hline RPCL & $\begin{array}{l}\text { Reverse Polish Calc } \\
\text { String }\end{array}$ & String used for interpreting CALC string. \\
\hline CLCV & $\begin{array}{l}\text { Calculation String } \\
\text { Valid }\end{array}$ & This flag is set when the CALC string is valid. \\
\hline VAL & Value Field & $\begin{array}{l}\text { This field is calculated, via the CALC expression, each } \\
\text { time the record is processed. }\end{array}$ \\
\hline OVAL & Old Value & \\
\hline PREC & Display Precision & $\begin{array}{l}\text { Precision with which to display VAL. This field is used by } \\
\text { record support to supply a value when get_precision } \\
\text { is called. }\end{array}$ \\
\hline OOPT & Output Option & $\begin{array}{l}\text { This menu specifies when to execute the output link and } \\
\text { post the output event. Choices are "Every Time", "On } \\
\text { Change", "When Zero", "When Non-zero", "Transition } \\
\text { To Zero", "Transition To Non-zero" }\end{array}$ \\
\hline OUTN & $\begin{array}{l}\text { Output Link } \\
\text { Process Variable } \\
\text { Name }\end{array}$ & $\begin{array}{l}\text { This field contains the Process Variable name of the } \\
\text { output link. }\end{array}$ \\
\hline OUTA & Output Address & Pointer to the dbAddr structure of the PV in OUTN. \\
\hline OUTV & Output Link Valid & $\begin{array}{l}\text { This flag indicates if the ASCII string entered in OUTN } \\
\text { was found to be a valid (existing) Process Variable. }\end{array}$ \\
\hline
\end{tabular}




\begin{tabular}{|c|c|c|}
\hline Name & Summary & Description \\
\hline DOLN & $\begin{array}{l}\text { Desired Output } \\
\text { Location Process } \\
\text { Variable Name }\end{array}$ & $\begin{array}{l}\text { This field contains the name of the Process Variable from } \\
\text { which the desired output data will be retrieved (if DOPT so } \\
\text { indicates). }\end{array}$ \\
\hline DOLA & $\begin{array}{l}\text { Desired Output } \\
\text { Location Address }\end{array}$ & Pointer to the dbAddr Structure of the PV in DOLN. \\
\hline DOLV & $\begin{array}{l}\text { Desired Output } \\
\text { Location Valid }\end{array}$ & $\begin{array}{l}\text { This flag indicates if the ASCII string entered in DOLN } \\
\text { was found to be a valid (existing) Process Variable. }\end{array}$ \\
\hline DOLD & $\begin{array}{l}\text { Desired Output } \\
\text { Location Data }\end{array}$ & $\begin{array}{l}\text { This field contains the data fetched from the PV specified } \\
\text { in DOLN (if valid) or a user entered value (if DOLN is not } \\
\text { valid). }\end{array}$ \\
\hline DOPT & Data Option & $\begin{array}{l}\text { This menu specifies whether to use the DOLD field or the } \\
\text { VAL field as output data. }\end{array}$ \\
\hline OEVT & Output Event & $\begin{array}{l}\text { If non-zero, the specified event number will be "posted" } \\
\text { when the output link is executed. }\end{array}$ \\
\hline ADEL & Archive Deadband & \multirow{2}{*}{$\begin{array}{l}\text { These parameters specify hysteresis factors for triggering } \\
\text { monitor callbacks, i.e. monitors specified by calls to } \\
\text { caAddEvent or dbAddEvent. A monitor will not be } \\
\text { triggered until VAL changes by more than the specified } \\
\text { amount. }\end{array}$} \\
\hline MDEL & $\begin{array}{l}\text { Monitor, i.e. value } \\
\text { change, Deadband }\end{array}$ & \\
\hline ALST & Archive Last Value & \multirow{2}{*}{$\begin{array}{l}\text { These fields are used to implement the hysteresis factors } \\
\text { for monitors. }\end{array}$} \\
\hline MLST & Monitor Last Value & \\
\hline SIMM & Simulation Mode & \multirow{5}{*}{$\begin{array}{l}\text { Simulation mode process variables. Refer to Chapter } 3 \text {, } \\
\text { Section "Simulation Mode" on page } 11 \text { for more } \\
\text { information. }\end{array}$} \\
\hline SIML & $\begin{array}{l}\text { Simulation Mode } \\
\text { Location }\end{array}$ & \\
\hline SVAL & Simulation Value & \\
\hline SIOL & $\begin{array}{l}\text { Simulation Value } \\
\text { Location }\end{array}$ & \\
\hline SIMS & $\begin{array}{l}\text { Simulation Mode } \\
\text { Alarm Severity }\end{array}$ & \\
\hline
\end{tabular}

\section{Record Support Routines}

\section{Record Processing}


6. Device Support

7. Device Support For Soft Records 


\section{Chapter 40: Waveform}

\section{Introduction}

The waveform record type stores arrays as data. The array can contain any of the supported data types.

\section{Field Summary}

\begin{tabular}{|l|l|l|l|l|l|l|l|}
\hline \multicolumn{1}{|c|}{ Field } & \multicolumn{1}{|c|}{ Type } & DCT & \multicolumn{1}{c|}{ Initial } & Access & Modify & $\begin{array}{l}\text { Rec Proc } \\
\text { Monitor }\end{array}$ & \multicolumn{1}{c|}{ PP } \\
\hline \hline VAL & See FTVL & No & 0 & Yes & Yes & Yes & Yes \\
\hline RARM & SHORT & Yes & 0 & Yes & Yes & No & Yes \\
\hline PREC & SHORT & Yes & 0 & Yes & Yes & No & No \\
\hline INP & INLINK & Yes & 0 & No & No & N/A & No \\
\hline EGU & STRING & Yes & Null & Yes & Yes & No & No \\
\hline HOPR & FLOAT & Yes & 0 & Yes & Yes & No & No \\
\hline LOPR & FLOAT & Yes & 0 & Yes & Yes & No & No \\
\hline NELM & ULONG & Yes & 1 & Yes & No & No & No \\
\hline FTVL & GBLCHOICE & Yes & 0 & Yes & No & No & No \\
\hline BPTR & NOACCESS & No & 0 & No & No & & No \\
\hline NORD & ULONG & No & 0 & Yes & No & No & No \\
\hline
\end{tabular}




\begin{tabular}{|l|l|l|l|l|l|l|l|}
\hline \multicolumn{1}{|c|}{ Field } & \multicolumn{1}{|c|}{ Type } & DCT & Initial & Access & Modify & $\begin{array}{l}\text { RecProc } \\
\text { Monitor }\end{array}$ & \multicolumn{1}{c|}{ PP } \\
\hline \hline BUSY & SHORT & No & 0 & Yes & No & No & No \\
\hline SIOL & INLINK & Yes & 0 & No & No & N/A & No \\
\hline SIML & INLINK & Yes & 0 & No & No & N/A & No \\
\hline SIMM & GBLCHOICE & No & 0 & Yes & Yes & No & No \\
\hline SIMS & GBLCHOICE & Yes & 0 & Yes & Yes & No & No \\
\hline
\end{tabular}

3. Field Descriptions

\begin{tabular}{|c|c|c|}
\hline Name & Summary & Description \\
\hline VAL & Value Field & This is used to reference the array. \\
\hline RARM & Rearm & When set to 1 , the device will be rearmed. \\
\hline PREC & Display Precision & $\begin{array}{l}\text { Precision with which to display VAL. This field is used by } \\
\text { record support to supply a value when get_precision } \\
\text { is called. }\end{array}$ \\
\hline INP & Input Link & $\begin{array}{l}\text { This field is used by the device support routines to obtain } \\
\text { input. }\end{array}$ \\
\hline EGU & Engineering Units & $\begin{array}{l}\text { ASCII string describing Engineering units. This field is } \\
\text { used by record support to supply a units description string } \\
\text { when get_units is called. }\end{array}$ \\
\hline HOPR & $\begin{array}{l}\text { High Operating } \\
\text { Range }\end{array}$ & \multirow{2}{*}{$\begin{array}{l}\text { These fields determine the upper and lower display limits } \\
\text { for graphics displays and the upper and lower control } \\
\text { limits for control displays. The fields are used by record } \\
\text { support to honor calls to get_graphic_double or } \\
\text { get_control_double. }\end{array}$} \\
\hline LOPR & $\begin{array}{l}\text { Low Operating } \\
\text { Range }\end{array}$ & \\
\hline NELM & $\begin{array}{l}\text { Number of } \\
\text { Elements, in array }\end{array}$ & \\
\hline FTVL & Field Type of Value & This is DBF_STRING, ..., DBF_ENUM. \\
\hline BPTR & Buffer Pointer & Holds address of array. \\
\hline NORD & $\begin{array}{l}\text { Number of } \\
\text { Elements Read }\end{array}$ & \\
\hline BUSY & Busy & Is device busy? \\
\hline
\end{tabular}




\begin{tabular}{|l|l|l|}
\hline \multicolumn{1}{|c|}{ Name } & \multicolumn{1}{|c|}{ Summary } & \multicolumn{1}{c|}{ Description } \\
\hline \hline SIMM & Simulation Mode & $\begin{array}{l}\text { Simulation mode process variables. Refer to Chapter 3, } \\
\text { Section "Simulation Mode" on page 13 for more } \\
\text { information. }\end{array}$ \\
\hline SIML & $\begin{array}{l}\text { Simulation Mode } \\
\text { Location }\end{array}$ & \\
\hline SIOL & $\begin{array}{l}\text { Simulation Value } \\
\text { Location }\end{array}$ & \\
\hline SIMS & $\begin{array}{l}\text { Simulation Mode } \\
\text { Alarm Severity }\end{array}$ & \\
\hline
\end{tabular}

\section{Record Support Routines}

init_record

process

get_value

cvt_dbaddr

get_array_info

put_array_info

get_units

get_prec
Using NELM and FTVL space for the array is allocated. The array address is stored in the record.

This routine initializes SIMM with the value of SIML if SIML type is CONSTANT link or creates a channel access link if SIML type is PV_LINK. VAL is likewise initialized if SIOL is CONSTANT or PV_LINK.

This routine next checks to see that device support is available and a device support read routine is defined. If either does not exist, an error message is issued and processing is terminated.

If device support includes init_record, it is called.

See next section.

Fills in the values of struct valueDes so that they refer to the array.

This is called by dbNameToAddr. It makes the dbAddr structure refer to the actual buffer holding the result.

Obtains values from the array referenced by VAL.

Writes values into the array referenced by VAL.

Retrieves EGU.

Retrieves PREC. 
get_graphic_double

get_control_double

get_graphic_double

get_control_double
Sets the upper display and lower display limits for a field. If the field is VAL the limits are set to HOPR and LOPR, else if the field has upper and lower limits defined they will be used, else the upper and lower maximum values for the field type will be used.

Sets the upper control and the lower control limits for a field. If the field is VAI the limits are set to HOPR and LOPR, else if the field has upper and lower limits defined they will be used, else the upper and lower maximum values for the field type will be used.

Sets the following values:

upper_disp_limit $=$ HOPR

lower_disp_limit $=$ LOPR

Sets the following values

upper_ctrl_limit $=$ HOPR

lower_ctrl_limit $=$ LOPR

\section{Record Processing}

Routine process implements the following algorithm:

1. Check to see that the appropriate device support module exists. If it doesn't, an error message is issued and processing is terminated with the PACT field still set to TRUE. This ensures that processes will no longer be called for this record. Thus error storms will not occur.

2. Call device support read routine.

3. If PACT has been changed to TRUE, the device support read routine has started but has not completed writing the new value. In this case, the processing routine merely returns, leaving PACT TRUE.

4. Check to see if monitors should be invoked.

- Alarm monitors are invoked if the alarm status or severity has changed.

- Archive and value change monitors are always invoked.

- NSEV and NSTA are reset to 0.

5. Scan forward link if necessary, set PACT FALSE, and return. 


\section{Device Support}

Fields Of

\section{Interest To}

Device Support
Each waveform record must have an associated set of device support routines. The primary responsibility of the device support routines is to obtain a new array value whenever read_wf is called. The device support routines are primarily interested in the following fields:

\begin{tabular}{|c|c|c|}
\hline Name & Summary & Description \\
\hline PACT & Processing Active & \multirow{4}{*}{$\begin{array}{l}\text { See Chapter 2, Section "Database Common: Field } \\
\text { Descriptions" on page } 5 \text { for descriptions. }\end{array}$} \\
\hline DPVT & Device Private & \\
\hline NSEV & New Alarm Severity & \\
\hline NSTA & New Alarm Status & \\
\hline INP & Input Link & $\begin{array}{l}\text { This field is used by the device support routines to locate } \\
\text { its input. }\end{array}$ \\
\hline RATE & Sampling Rate & Some device support modules may find this useful. \\
\hline PTSS & Pretrigger Samples & Some device support modules may find this useful. \\
\hline NELM & $\begin{array}{l}\text { Number Of } \\
\text { Elements In Array }\end{array}$ & \\
\hline FTVL & Field Type Of Value & $\begin{array}{l}\text { This is DBF_STRING, ..., DBF_ENUM. The device } \\
\text { support routine should check that this is correctly defined. }\end{array}$ \\
\hline RARM & Rearm & $\begin{array}{l}\text { When set to } 1 \text {, the device will be rearmed. The device } \\
\text { support routine should reset it to } 0 \text { when done. }\end{array}$ \\
\hline BPTR & $\begin{array}{l}\text { Holds Address Of } \\
\text { Array }\end{array}$ & \\
\hline NORD & $\begin{array}{l}\text { Number Of } \\
\text { Elements Read }\end{array}$ & Device support must set this value when it completes. \\
\hline BUSY & Is device busy? & \\
\hline
\end{tabular}

Device support consists of the following routines:

\section{Routines}

Device Support

report

report (FILE fp, paddr)

Not currently used.

init

$$
\text { init () }
$$

This routine is called once during IOC initialization.

init_record

$$
\text { init_record (precord) }
$$

This routine is optional. If provided, it is called by the record support init_record routine. 
get_ioint_info

read_wf get_ioint_info(int cmd, struct abcommon *precord, IOSCANPVT *ppvt)

This routine is called by the ioEventScan system each time the record is added or deleted from an V/O event scan list. cmd has the value $(0,1)$ if the record is being (added to, deleted from) an I/O event list. It must be provided for any device type that can use the ioEvent scanner.

read_wf (precord)

This routine must provide a new input value. It returns the following values:

- 0: Success.

- Other: Error.

\section{Device Support For Soft Records}

If INP is a constant link, then read_wf does nothing. In this case, the record can be used to hold arrays written via dbPuts. If INP is a database or channel access link, the new array value is read from the link. NORD is set.

This module places a value directly in VAL.

If the INP link type is constant, then NORD is set to zero. If the INP link type is PV_IINK, then dbcaAddnlink is called by init_record.

read_wf calls recGb1GetLinkValue which performs the following steps:

- If the INP link type is CONSTANT recGb1GetLinkValue does nothing.

- If the INP link type is DB_LINK, then dbGetLink is called to obtain a new input value. If dbGetLink returns an error, a IINK_AL_ARM with a severity of INVALID_ALARM is raised.

- If the INP link type is CA_LINK, then dbCaGetLink is called to obtain a new input value. If abcaGetLink returns an error, a LINK_AL_ARM with a severity of INVALID_ALARM is raised.

NORD is set to the number of values returned and read_wf returns. 